Faculty of Veterinary Science

\title{
Lecture Notes on
}

\section{ANIMAL NUTRITION}

Kabul University

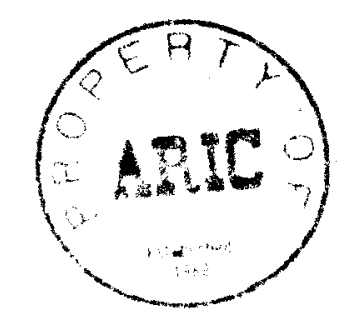




\section{Project AFG/74/022}

Field Document 8

Lecture Notes

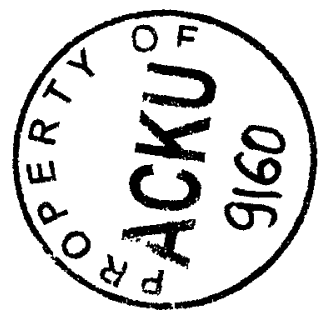

UNITED NATIONS DEVELOPMENT PROGRAMME 
The presentation of material in this publication does not necessarily imply the expression of any views or opinions whatsoever on the part of the Food and Acriculture Organization of the United Nations.

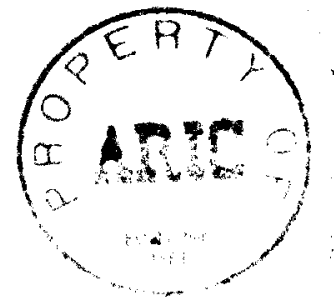




\section{PREFACE}

This Project Document is in continuation of a series of Lecture Hotes, Lab Manuals and Consultancy Reports being produced by the FAO/UNDP Project AFG/74/022 as part of its assistance to the deucopment of the Faculty of Veterinary Science of Kabul University. It has been compiled by Dr. M.L. Mathur, Emeritus Scientist of the Indian Council of Agricultural Research, who was assigned to the Project as Consultant in Animal Nutrition and Buffalo Breeding from December 1981 through April 1982.

This Document has been specially designed for use as a text by the undergraduates of the Faculty following the course on Animal Wutrition and Dietetics during the 3rd year of the D.V.M. program. As such, the basic principles are stressed. It will undoubtedly be a valuable guide to the students and an important addition to the "Book Bank" which the Project is in the process of establishing. 


\section{TABLE OF CONTENTS}

1. The Principles of Animal Nutrition/1

2. Animal Feeds/68

3. Food Evaluation/113

4. The Feeding of Farm Animals/154

Bibliography/262 
CHAPTER 1. The Principles of Animal Nutrition

1.1 The History of Nutrition $/ 2$

1.2 The Animal and its Food/3

1.3 Food Nutrients/3

1.4 The Composition of Plants and Animals/6

1.5 The Role of Animal Husbandry in Human Welfare and the Economic Background of Feeding Livestock/7

1.6 Soil-Plant-Animal- and Human Relationships/9

1.7 The Role and Requirement of Water in the Animal Body/10

1.8 Carbohydrates, Lipids and Proteins in the Animal Body/L2

1.9 Minerals and Vitamins in the Animal Body/18

1.10 Digestion, Absorption and Metabolism of Nutrients/,51 


\subsection{History of Nutrition}

The great French chemist Lavoisier $(1743-1794)$ is kncwn as the founder of the science of Nutrition. He estabished the chemical basis of nutrition by his famous respiration experiments carried out before the French revolution. He concluded that respiration is a combustion process similar to that occurring when substances are burnt outside the body. On the basis of these experiments, Lavoisier stated that ife is a chemical process. Thereafter chemistry and physiology. became important tools in nutrition studies. After Lavoisier, almost 100 years later, the old conception, that the nutritive value of food resided in a single aliment (food) was discarded and proteins, fats and carbohydrates were identified as essential sources of energy. The importance of afew mineral elements like calcium, iron, magnesium, potassium, sodium, sulphur, chlorine (as chloride) and fluorine (as fluoride) in the body was also recognised, but conclusive proof by research regarding their assentiality was maagre or lacking.

C.M.Mc Cay ( $189 \varepsilon-1967)$ devoted over 30 years to studies. of the influence of diet and growth rate upon life span and physiology and pathology of aging, which won him national and international fame.

During this period of 50-60 years, there was great expansion in the field of nutrition. The discovery of vitamins, amino acids and several more essential mineral elements made significant contributions in the science of nutrition. It was now well known that the body needed over forty different nutrients in contrast to three (protein, fat and carbohydrates) known and recognized a century aro. The aim now was to provide all essential nutrients in adequate amounts and optimum proportions to meet the nutritional requirements.

The knowledge of nutrition further expanded on account of direct evidence of nutritional and health problems of animals and humans, basic studics of the functioning of animal organism, of the physiological and biochemical changes involved, and of the effects of various dietary variables. 3. M. Babcock (1943-1931) of isconsin University made mafor contributions in the field of Dairy Chemistry and Animal Nutrition.

E.B. Hart and co-workers continued nutrition studies on cattle at Wisconsin. In 1911, they found that the performance, growth and reproduction of calves, who where fed grain and forage of maize was better than those fed wheat grain and wheat straw. This showed that there was some thing lacking in wheat and present in maize. The knowledge of 
vitamins, amino acids and minerals increased enormously by studies on laboratory rats. The discovery of Insulin and the role of nicotinic acid in the prevention and cure of Pellagra was known by studies on dogs. In addition to cattle, rats and dogs, other animals like guinea pigs, chicks, monkeys, mice and hamsters were used in nutritional studies. Tven the lower form of bacteria have contributed in the discovery of growth factors. The present knowledge of nutrition owes a great deal to the contributions made by research techniques developed in different sciences as Physics, Genetics, Microbiology, Food technology along with that of Chemistry and Physiology. The search for more knowledge on nutrition continues.

\subsection{The Animal and its Food}

Food is the material which after ingestion by animals is capable of being digested, absorbed and utilized. In a general sense, food is used to describe all edible material. Grass and hay are also described as food, but all their components are not digestible. The components capable of being utilized are known as "nutrients".

The food of farm animals consists of plants and plant products and some food of animal origin like milk, fish meal and bone meal. They obtain all the nutrients required for their physiological functions like growth, milk, egg, meat and wool production from the digestion of food consisting of grasses, forages, hay, cereals and its by-products. Since animals depend upon plants for their existence, the study. of animal nutrition begins with the study of plants.

The plants get their food nutrients such as carbon dioxide from air and water and organic and inorganic elements from the soil. By means of photosynthesis, energy from the sunlight is trapped by plants and used in synthesis of complex material from simple substances as carbondioxide, water and inorganic elements. The greater part of the solar energy is stored as chemical energy within the plant itself and it is this energy which is used by the animal for maintenance of life and synthesis of its body tissues.

\subsection{Food Nutrients}

Plants and animals contain similar types of chemical substances, which can be grouped according to constitution, properties and function. The main chemical components of foods, plants and animals are classified as below: 
Fig. I

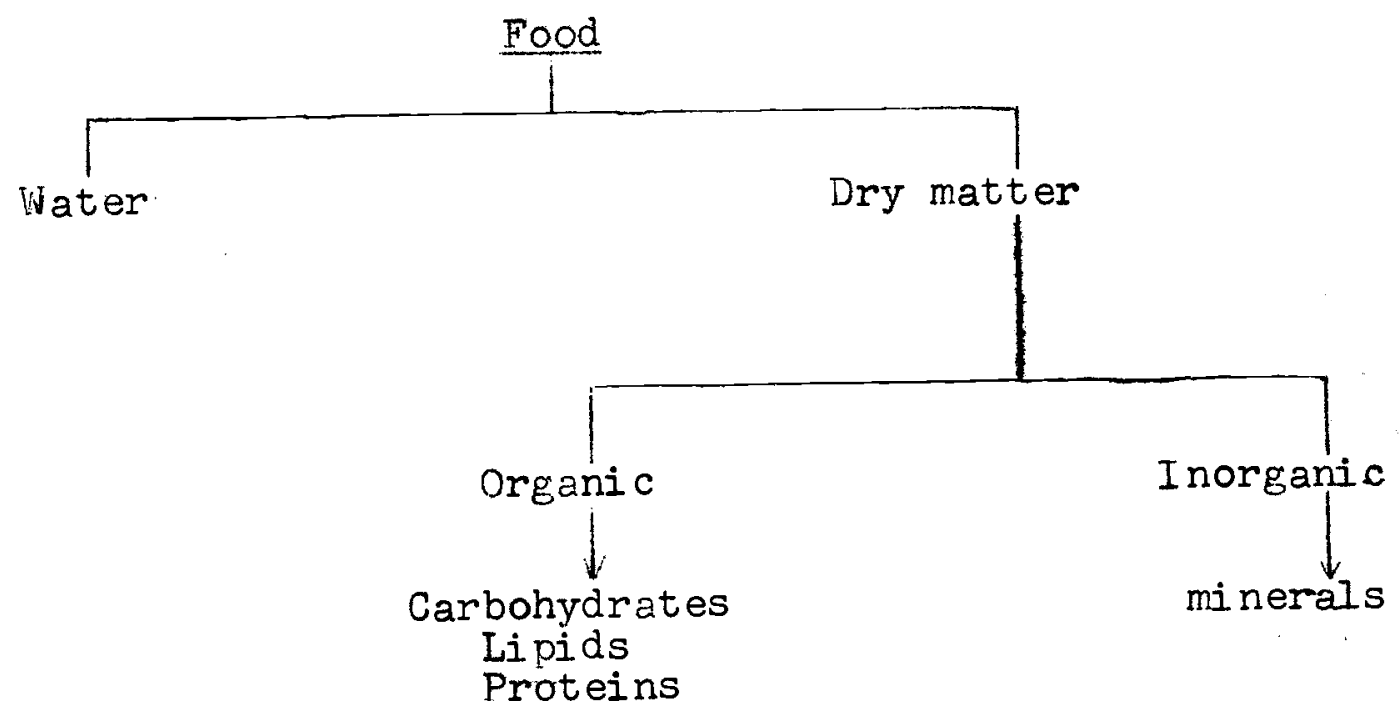

Nucleic acids

Organic acids

Vitamins

The proximate analysis of food was devised by German scientists Henneberg and Stohmann. According to this system of analysis, the feedstuff is analysed into six fractions viz., water, crude protein, ether extract, crude fibre, nitrogen free extract and ash.

The components of the different fractions in the proximate analysis food are as under:

Table: 1

\begin{tabular}{|c|c|}
\hline Fraction & Components \\
\hline 1. Moisture & Water \\
\hline 2. Ash & $\begin{array}{l}\text { Issential Major: } \mathrm{Ca}, \mathrm{K}, \mathrm{Mg}, \mathrm{Na}, \mathrm{S}, \mathrm{P}, \mathrm{Cl} \text {, } \\
\text { elements Trace: } \mathrm{Fe}, \mathrm{Mn}, \mathrm{Cu}, \mathrm{Co}, \mathrm{I}, \mathrm{Zn}, \\
\begin{array}{l}\text { Non-essential Ji, } \mathrm{Ni}, \mathrm{Al}, \mathrm{Cr}, \mathrm{B}, \mathrm{Pb}, \mathrm{Sn} \\
\text { elements }\end{array}\end{array}$ \\
\hline 3. Crude 'rotein & $\begin{array}{l}\text { Proteins, amino acids, amines, nitrates, } \\
\text { nitrogenous glycosides, glyco lipids, } \\
\text { B-vitamins, nucleic acids }\end{array}$ \\
\hline 4. Ether extract & $\begin{array}{l}\text { Fats, oils, waxes, organic acids, pigments, } \\
\text { sterols, Vitamins } 4, \mathrm{D}, \mathrm{E}, \mathrm{K} .\end{array}$ \\
\hline $\begin{array}{l}\text { Total carbohydrates } \\
\text { 5. Crude Fibre }\end{array}$ & Cellulose, hemi cellu: \\
\hline $\begin{array}{l}\text { 6. Nitrogen-free } \\
\text { Extractives }\end{array}$ & $\begin{array}{l}\text { Cellulose, hemi celluloses, Lignin, sugers, } \\
\text { fructans, starch, pectins, organic acids, } \\
\text { resins, tannins, ngments, water soluble } \\
\text { vitamins. }\end{array}$ \\
\hline
\end{tabular}


The above six fractions/nutrients are analysed by chemical methods and the proximate analysis of feed or the chemical comoosition of feed stuffs can be expressed in two ways, viz., "on an as such basis" and on a "Drymatter basis".

The detailed classification of nutrients is also given below.

\section{Fig. 2}

CL 13SIFICATI UN OF NUTRI MUTS BY ANILYSIS

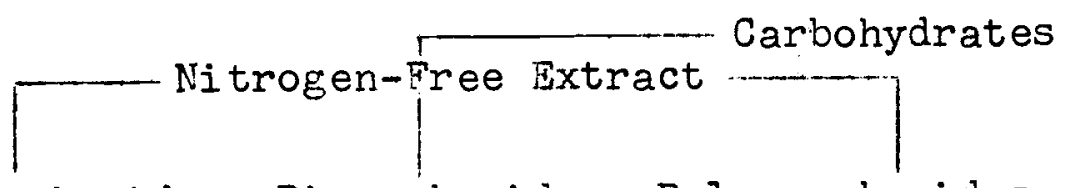

Monosaccharides Disaccharides Polysaccharides glucose fructose sucrose lactose galactose mannose

Crude Fiber
$\begin{aligned} & \text { Polysaccharides } \\ & \text { insoluble) } \\ & \text { cellulose } \\ & \text { hemicellulose }\end{aligned}$

Lipids starch

\section{Compound}

Triglycerides esters of glycerol and fatty acids, such as butterfat, lard, beeftallow, and soybean oil.

lecithin

cephalin
Phospholipids Waxes

sphingomyelin

esters of

a fatty

acid and

long-chain

alcohol,

Thus, pal-

mitic acid+

myri cyl

al cohol =

$\mathrm{C}_{3} \mathrm{H}_{33} \mathrm{OH}$

\begin{tabular}{|c|c|c|c|}
\hline & Protein & & Nonprotein \\
\hline $\begin{array}{l}\text { Essential } \\
\text { Amino Acids } \\
\text { arginine } \\
\text { histidine } \\
\text { isoleucine } \\
\text { leucine } \\
\text { lysine } \\
\text { methionine } \\
\text { phenylalanine } \\
\text { threonine } \\
\text { tryptophan } \\
\text { valine }\end{array}$ & $\begin{array}{l}\text { Semiessential } \\
\text { Amino Acids } \\
\text { cysteine } \\
\text { cystine (synthesized } \\
\text { from methionine) } \\
\text { tyrosine (synthesized } \\
\text { from phenylalanine) }\end{array}$ & $\begin{array}{l}\text { Nonessential } \\
\text { Amino Acids } \\
\text { alanine } \\
\text { asparagine } \\
\text { aspartic acid } \\
\text { glutamic acid } \\
\text { glutamine } \\
\text { glycine } \\
\text { hydroxyproline } \\
\text { proline } \\
\text { serine }\end{array}$ & $\begin{array}{l}\text { amines } \\
\text { free amino acids } \\
\text { urea }\end{array}$ \\
\hline
\end{tabular}




\begin{tabular}{|c|c|c|c|c|c|c|c|}
\hline & Water & $\begin{array}{l}\text { Crude } \\
\text { protein }\end{array}$ & Fat & $\begin{array}{l}\text { Total } \\
\text { carbo- } \\
\text { hydrates }\end{array}$ & Ash & Calcium & $\begin{array}{l}\text { Phosh- } \\
\text { phorus }\end{array}$ \\
\hline$\frac{\text { Typical Green Plants }}{\text { Berseem }}$ & 90 & 2.0 & 0.3 & 6.3 & 1.4 & 0.16 & 0.03 \\
\hline Lucerne & 80 & 4.5 & 1.0 & 12.5 & 2.0 & 0.40 & 0.06 \\
\hline Maize & 75 & 2.0 & 0.6 & 21.0 & 1.4 & 0.07 & 0.05 \\
\hline Cowpea & 80 & 2.5 & 0.5 & 15.0 & 2.0 & 0.25 & 0.05 \\
\hline Jowar & 75 & 1.5 & 1.0 & 21.0 & 1.5 & 0.09 & 0.03 \\
\hline Timothy & 72.4 & 3.5 & 1.2 & 20.7 & 2.2 & 0.16 & 0.10 \\
\hline $\begin{array}{c}\text { Dry plant products } \\
\text { Wheat straw }\end{array}$ & 10 & 3.5 & 1.5 & 76.5 & 8.5 & 0.15 & 0.07 \\
\hline Paddy straw & 10 & 3.5 & 1.5 & 70.5 & 14.5 & 0.19 & 0.07 \\
\hline Timothy hay & 11.4 & 6.3 & 2.3 & 75.6 & 4.5 & 0.36 & 0.15 \\
\hline$\frac{\text { Animal Body }}{\text { New born calf }}$ & 74 & 19.0 & 3.0 & - & 4.1 & - & - \\
\hline Dairy cow & 57 & 17.2 & 20.6 & 0.2 & 5.0 & - & - \\
\hline Sheep & 74 & 16.0 & 5.0 & - & $4 \cdot 4$ & - & - \\
\hline Pig (70kg) & 52 & 15.4 & 30.0 & - & 2.6 & - & - \\
\hline Hen & 56 & 21.0 & 19.0 & $=$ & 3.2 & - & - \\
\hline Man & 59 & 18.0 & 18.0 & - & 4.3 & - & - \\
\hline
\end{tabular}

- Data not available.

1.5 The role of Animal Husbandry in human welfare and the Economic back ground of feeding Livestock Animal husbandry and crop husbandry are dependent on each other. Cattle, buffaloes, sheep, goat, oigs and poultry are the main farm animals. Fishes could also be reared in ponds in the farm. Bullocks and buffaloes are used for draught; cows and female buffaloes supply milk; Sheep is a source of 
wool and meat; goats are kept for milk and meat; Poultry supplies eggs and meat. The faeces and urine of these animals are converted into valuable manure and put back in the soil. The farm yard manure is a good source of nitrogen and fair source of phosphorus and potassium.

The farm animals thus play an important role in the development of agriculture and human welfare in the following way:

1. As a source of draught/traction.

2. As a source of manure.

3. As a converter of agricultural by-products into valuable products of animal orgin like milk, meat, egg, etc. for human consumption.

4. As a source of food for humans and livestock.

5. As a source of wool for humans.

In feeding the farm animals, the livestock owner selects economic rations. He grows the rrotein rich crops which have the highest feeding value. He plans his crop rotation so that he has high quality greens, hay and other roughage at all times of the year specially in winter. He supplements the roughage with the most economic concentrate available, changing it to meet the changed prices of the feeds. For milchcows, fattening cattle and sheep liberal amounts of concentrates are required and fed for optimum production.

It would thus appear that livestock and other farm animals can be maintained and fed economically on farm produce and agricultural by-products and some concentrates purchased from the market. In return they supply valuable food for humans like milk, meat, fishes and eggs which are protective foods of high biological value and rich source of essential amino acids. This is in addition to the use of farm animals for draught and traction.

For feeding of non-herbivorous monogastric animals like pigs and noultry for optimum production, some amount of animal protein as meat meal, bone meal, fish meal and slaughter house waste has to be supplied.

Lately processed noultry droppings, cow dung, and other farm yard waste, at low levels, have been used in the diets of bovines, pies and poultry. Fresh noultry droppings, beddings, dung and urine of cattle and buffalo is being. ensiled with g,reen foolder and cereal straws to make them more palatable and nutritious and fed to farm animals as roughage. 
1.6 Soil-Plant-Animal and Human inter-relationships

It is well known that man is the highest developed living being in this universe. He has developed crop husbandry and animal husbandry and exploited the soil, plant and animal for his existence and welfare. The diet or food of human beings consists of items of plant or animal orgin. These have been produced and developed by him to give him maximum benefit. The plants, producing cereals for human consumption, grow on the soil and get their nutrients like carbon di oxide from the atmosphere and water, organi $c$ and inorgani ce elements from the soil. The food of herbivorous animals like the livestock is mostly of plants and plant by-products. The droppings like faeces and urine by the animals is converted into manure and used to replenish the losses from the soil. It would thus appear that there is a regular inter-relationship between the suil-plant-animal system and the human. 
1.7 The Role and Requirement of Water in the Animal Body

Water makes up over 50 percent of the composition of the animal body and many tissues contain 70 to 90 percent water. It is not simply an inert material or merely a solvent but an active and structural constituent. This nutrient is required in the largest amount and plays a vital role in nutritional physiology.

Properties and Functions of water: Water is the ideal dispersing medium because of its solvent and ionizing powers
which facilitates cell reactions and because of its high specific heat which enables it to absorb the heat of these reactions with a minimum rise in temprature. The latent heat of evaporisation of water also plays on important role in regulating body temperature. Other properties of large significance in physiology are the high surface tension, the tendency to form hydrates and high dielectric constant of water. It plays important role as a solvent and substrate in digestion, in the transport of metabolic products and in the excretion of waste products. It takes part in body reactions as illustrated by the hydrolysis of proteins, fats and carbohydrates whi ch take place in digestion.

As synovial fluid, water lubricates the joints and as cerebro-soinal fluid, it acts as a water cushion for the nervous system. In the ear, it transports sounds, and in the eye, it is concerned with sight.

Metabolic or Oxidation Nater: Most of water utilized by the animal body is ingested as a component of food. A further source is provided by metabolic nrocesses, which is twus called metabolic or oxidation water. When the carbohydrate glucose is oxidised to furnish energy for body processes, carbon dioxide and water results.

$$
\mathrm{C}_{6} \mathrm{H}_{12} \mathrm{O}_{6}+6 \mathrm{O}_{2}-\cdots-6 \mathrm{CO}_{2}+6 \mathrm{H}_{2} \mathrm{O}+686 \mathrm{kcal} \text {. }
$$

Thus glucose yields 60 percent of its weight of water. Similarly,proteins produce about 42 percent of their weight of water and fat over 100 percent. Metabolic water is also produced by the dehydration synthesis of body proteins, fats and carbohydrates. 
Effects of water deprivation: Animals differ markedly in their ability to conserve water and to withstand water deprivation. Some desert animals such as gerbil and camel can tolerate more severe dehydration than a man or a dog, without suffering an explosive heat riae.

Factors governing water excretion and raquirement: The body's need for water is governed by many factors. Approximately $75 \%$ of the tissue formed during growth is water, and in the mature animal such special processes as milk and egg production require water in accordance with the amount of product being formed. In addition to the needs for the formation of tissue and products large quantities of water are also required to balance the losses by excretion through gut, kidney, lungs and skin.

Cattle ingest large amounts of water by itself and through feeds and foder. They also excrete large quantities of water through urine and feces. Other losses of water are through perspiration and expiration.

Water requirements: It is evident that the body must receive sufficient water to balance its losses in addition to the amount recuired for the formation of new tissues or products. This water requirement varies with various class of livestock and the special processes and production. There is no deleterious effect from an excessive consumption of water by animals. 


\subsection{Carbohydrates, Lipids and Proteins in the Animal Body}

Carbohydrates: Carbohydrates are an important source of energy for animals and are the means by which chemical energy is stored. They perform many vital functions in living organisms as structural components of plants and insects. In the storage organs of plants and in the liver and muscles of animals, they are important food reserves. Fost of the energy for metabolic activities of cells; in all organisms is derived from the oxidation of carbohydrates.

Carbohydrates are classified into three main groups: monosaccharides, oligosaccharides and polysaccharides.

Nonosaccharides are the simplest sugars which cannot be hydrolysed into smaller units. They are subdivided according to the number of carbon atoms they possess. eg. Trioses $\left(\mathrm{C}_{3} \mathrm{H}_{6} \mathrm{O}_{3}\right)$, Tetrodes $\left(\mathrm{C}_{4} \mathrm{H}_{8} \mathrm{O}_{4}\right)$, Pentoses $\left(\mathrm{C}_{5} \mathrm{H}_{10} \mathrm{O}_{5}\right)$ and Hexoses $\left(\mathrm{C}_{6} \mathrm{H}_{12} \mathrm{O}_{6}\right)$. The important sugers of these groups are:

Pentoses: D-xylose, D-ribose, L-Arabinose.

Hexoses: Glucose, Tructose, Mannose, Galactose.

Oligosaccharides are compound sugars that yield two to six molecules of simple sugars. Disaccharides yield two simple sugar molecules on hydrolysis; tri saccharides yield three molecules of simple sugars.

The most frequently occurring oligosaccharides in nature are sucrose, maltose and lactose. The fourth dissaccharide, cellobiose is released by the action of microbial cellulase.

Polysaccharides are compounds that yield large number of monosaccharides on hydrolysis. They are classified according to the type of sugar which they produce on hydrolysis. For example,polymers of glucose, fructose and xylose are called glucosans, fructosans and xylans. Polysaccharides are frequently tasteless, insoluble, amorphous compounds of high molecular weight. They are found in nature and serve either as structural or nutrient functions. The plant starches and animal glycogens are reserve nutrients in plant and animals respectively.

Examples: Cellulose, Hemicellulose, Pectin, Chetin, Starch, insulin, Glycogen, Lignin.

Lipids

Lipids are a group of organic substances which are insoluble in water but soluble in organic solvents like 

Saturated fatty acids: Butyric acid, caproic acid, caprylic stearic acid, arachidic acid.

Unsaturated fatty acids: Palmitoleic acid, oleic acid, Iinoleic acid, linolenic acid, eleostearic acid, arachidonic acid, erucic acid.

Other fatty acids: Tuberculostearic acid, ricinoleic acid, chaulmoogric acid.

\section{Compound lipids}

Phospholipids: From the biological view point, phospholipids are the most important of lipids since they are present in all living cells and are essential for their proper functioning. The phospholipids contain nitrogen and phosphorous in addition to carbon, hydrogen and oxygen. Among the many vital functions, regulation of plant and animal cell permeability, participation in the transport and metabolism of synthesized and dietary fats and their role in blood coagulation are important.

Dhospholipids are classified as follows:

(1) Phosphoglycerides (i) Lecithin (ii) Cephalin and (iii) Plasmogens.

(2) Phosphoinositides and

(3) Phosphophingosides.

Glycolipids: These linids are also called cerebrosides and cerebro-glactosides brcause of their presence in brain tissues.

\section{Derived Lipids}

Derived lipids, on hydrolysis, give the products of simple and compound lipids and, in addition, other compounds such as sterids, fatty aldehydes, ketones, alcohols, essential oils and hydrocarbons.

Sterids include both sterols and steroids. Sterids are widely distributed in animals, plants and mi cro organisms.

Sterols: Are wax-like solid alcohols and occur free and estrified with fatty acids ir. most living cells. They are 
present in the unsaponifiable fraction of the etherextract. Examples are ergosterol (from yeast and fungi) and cholesterol (from animals). The two sterols serves as precursors of vitamin $\mathrm{D}_{2}$ and $\mathrm{D}_{3}$.

\section{Proteins}

Proteins are comolex organic compounds of a high molecular weight ranging from a few thousands to a million or more. They contain carbon, hydrogen, oxygen, nitrogen and aften sulphur. The elementary composition of most proteins is very similar. The approximate percentage of carbon is 50-55 percent, hydrogen 6-2, oxygen 20-23, nitrogen 15-18 and sulphur 0-40. Basic composition provides little information concerning the protein molecule. Nitrogen content in protein is about 16 percent.

Nitrogen compounds are found in cell protoplasm; cell nucleus contains proteins (nucleoproteins) which are ultimately associated with cell division and heredity. Another part of the cell cytoplasm, contain thousands of separate proteins, called enzymes, which catalyse the many chemical changes required for the maintenance of cell life. In addition, plants, animals and mi cro-organisms produce extra cellular enzymes which split complex dietary proteins, lipids, and carbohydrates to simple diffusable nutrients which are absorbed by the cell and utilized within them. Proteins are major components of blood, muscles and connective tissues in animals and when fed in excess serve as a source of energy and fat.

\section{Classification of Proteins}

(1) Simple proteins: mhis group includes those proteins which on hydrolysis give only amino acids or their derivatives.

Some simple proteins are soluble in distilled water like albumin, pseudoglobins, protamines and histone. Some simple proteins are insoluble in distilled water as euglobins, prolamines and gluteins.

(2) Conjugated proteins: In this grous simple proteins are combined with nonproteins such as:

(i) Chromoproteins - proteins combined with pigments eg haemoglobin.

(ii) Nucleoproteins - proteins combined with nucleic acid. (iii) Lipoproteins - proteins combined with lioids. (iv) Glyccoproteins - proteins combined with carbohydrates. 
(v) Phosphoproteins - proteins combined with phosphoric acid other than nucleic acid or lecithin eg casein.

(vi) Metalloproteins - proteins combined with metals

(3) Derived proteins: In this group are included all those compounds which are produced from the degradation of naturally occurring proteins by the action of heat, enzymes or chemical agents like proteoses, peptones and peptides.

\section{Aminoacids}

The fundamental structural unit of protein is the amino acid so that proteins are polymers of monomers called aminoacids. The general formula for naturally occuring amino acids is shown below:<smiles>[R]C(N)C(=O)O</smiles>

Amino acids are required by the animal body for performing various physiological functions. Essential amino acids are those which the body cannot synthesize and they are required to be supplied in the diets so that they are dietaryessential. On the other hand, there are amino acids which the body can synthesize through transamination.

Essential amino acids: Arginine, valine, Histidine, isoleucine, leucine, lysine, methionine, phenyl alanine, throonin, tryptophan.

Non essential amino acids: Glycine, Alanine, Serine, Cysteine, Tryosine, Asnartic acid, Glutamic acid, proline, Hydroxyproline, Citrulline, Asparagine.

Ruminants do not require the essential amino acids to be supplied in their diet as the mi cro-organisms present in the rumen van synthesise all the essential amino acids, and when they are digested in the lower gastro intestinal tract, these amino acids are available to the host animals. 
Nucleic acid:

Nucleic acids occur in every living cell. Like proteins they are polymers of high molecular weight.

Nucleosides and Nucleotides

They are carbohydrate derivatives in which purines and pyrimidines found in nucleic acid are linked to a suger in a $B-N-g l y \cos y l$ bond.

Non protein-Nitrogenous compounds

There are a number of nitrogenous compounds which are non-protenous and occur in plants and arimals. These include ami no acids, amides, nitrogenous glucosides, alkaloids, ammonium salts, nitrates etc. 
1.9 Minerals and Vitamins in Animal Nutrition

For proper functioning of the animal body minerals and vitamins are also required in small amounts to prevent deficiency diseases, in addition to proteins, fats and carbohydrates. Minerals and vitamins play an important role in intermediary metabolism of fats, proteins and carbohydrates.

\section{Minerals}

Some mineral elements are essential part of the diet of the animals, plants and mi cro-organism. Those required in relatively large amounts are used in some cases in the synthesis of structural tissues; whereas those required in trace amounts usually function as activators or as component parts of enzyme system. There are about forty mineral elements which occur in nature in the tissues, plants and animals.

Essential mineral elements are those minerals which have been proved to have a metabolic role in the animal's body by conducting feeding experiments. They are calcium, phosphorus, manganese, copper, cobalt and zinc. On the basis of latest research work, fluorine and chromium are also coming in the category of essential elements.

Minerals are generally classified into two categories, viz., macro and micro elements on the basis. of concentration present in the animal body. The concentration of microelements (trace-minerals) is exnressed in terms of parts per million (?.P.M). The concentration of macro-elements (major minerals) is expressed in terms of percentage.

General Functions of Minerals: Some of the minerals are constituents of skeletal structure, like calcium and phosphorus etc. They are also constituents of organic compounds such as proteins and lipids which make body tissues. They are components of various enzyme systems. They play an important role in the maintenance of osmotic pressure and acid base equilibrium. Some of the minerals are resnonsible for irritability of muscles and nerves.

There is lot of interaction in mineral elements. Therefore a nutritional mineral disorder in the animals may be due to imbalance of mineral elements rather than a deficiency of one narticular mineral element. For example deficiency of copper in animals is not to be considered in isolation since molybdenum and sulphur would play an important role in determining the extent of severity. Therefore supplementation of mineral mixtures should be carried out carefully. elements. Detailed functions are discussed below under individual 
Areas of deficiency and excess:

Since there is a soil, plant and animal relationship, it is always desirable to determine the mineral contents in soils and plants and correlate them with that in animals. Intensive crop production in a partiçular area is bound to lower the reserve of trace mineraly in that soil. The feeds and fodders grown on that soil would be deficient in mi cro elements/trace minerals. This deficiency in turn is bound to affect the animals in some way or the other.

\section{Macro-elements (Major minerals)}

The major minerals are required in relatively large quantities by animals: : such as sodium and chlorine (salt), calcium, phosphorus, magnesium, potassium and sulphur.

Calcium: Generally calcium and phosphoms are discussed together since they are closely associated with each other in metabolism. Calcium is most abundant in animal body. About 90 percent of calcium of the body is distributed in bones and teeth. In bones the ratio of calcium to phosphorus is $2: 1$. Bone ash consists entirely of calcium and phosphorus salts. Calcium is an essential constituent of most living cells and tissue fluids. Calcium helps in the coagulation of blood and is also resnonsible for the irritation of nervous tissues. In blood calcium is present in the plasma where its concentration is 8-12 mg per $100 \mathrm{ml}$ in most species. In laying hens, olasma concentration is higher during egg production. Calcium is found in two forms in blood, viz., diffusible and nondiffusible. Non-diffusible calcium is bound to protein. Dietary calcium is equally distributed in diffusible and non-diffusible forms.

The primary source of blood calcium is food, but various physiological conditions tend to maintain constant level even if animals are getting either low or high levels of calcium intake. The nara thyroid glands secrete a hormone (para-thormone) whi ch regulates the calcium levi: in blood. Whenever there is low intake, it helos to mobilize the calcium from the bones.

Absorption and Excretion of Calcium: The absorption of calcium in the digestive tract in the animal body is closely associated with the nhosphorus. The factors which keen 
calcium and phosphorus in solution help in the absorption of these elements. An acidic pH helps in the absorption of calcium. In the simply-stomached animals, oxalates and phytic acid interfere with the absorption of calcium. Though small amounts of fats help in the absorption of calcium, large concentrations of fats in the diet interfere with calcium absorption by forming insoluble soaps. For better absorption of calcium and phosphorus, their ratio should be $1: 2$ or $2: 1$. This ratio is of little importance if plenty of vitamin $D$ is available to the animals.

Faeces, urine and milk are the path of excretion, though a major portion is excreted in the faeces. The term net absorptin is given to the absolute amount of calcium which has been retained by the animal on a certain intake.

Deficiency and Toxicity Symptoms: There are many factors which may be responsible for the failure of normal calcium nutrition besides being the deficiency of calcium in the diet. In growing animals proper growth of bones will not take place, resulting in a condition known as rickets. In this case there will be misshaping of the bones, enlargement of the joints, stiffness and lameness. In severe and orolon ed failure, beading of the ribs also takes place. Calcification of bones does not take place. The blood calcium level goes down. Ri ckets is very common in calves and pigs. In adult animals disturbed calcium metabolism results in a condition known as "osteomalacia", when the bones become weak, porous and soft.

In poultry, the deficiency of calcium causes soft bones and beak, curved legs, low egg production with thin shells. After parturition, high yi elding cows suffer from milk fever (parturient paresis). The serum calcium level goes down resulting in muscular spasms and in extreme cases, paralysis. Intravenous injections of calcium gluconate can restore the normal levels of calcium in the blood and animals can be cured. Excessive intake of calcium is also detrimental. It causes deposition in bones, and the develonment of urinary calculi. Txcessive dietary calcium may interfere with the absorption of phosphorus, magnesium and zinc and to some extent copper, manganese, iron and iodine.

Calcium contents of feeds: Concentrates are generally deficient in calcium excert sesamum cake. Leguminous fodders/hays are rich in calcium while straws are poor. 
Animal by-products like fish meal, mrat meal, bone meal are rich source of calcium. Dicalcium phosphate, calcium carbonate and calcium phosphate are good sources of calcium.

\section{Phosphorus}

Phosphorus is mostly present in the bones of the animal body. This is also oresent in organic compounds like phosphoproteins, nucleo-proteins, phospholipids, hexose phosphate, etc. Phophorus is a component of various enzyme systems and nlays an important role in carbohydrate metabolism. The content of inorganic phosphorus in the blood is 4 to $9 \mathrm{mg}$ per $100 \mathrm{ml}$ depending upon the species and age. Whole blood contains about $35-40 \mathrm{mg}$ phosphorus per $100 \mathrm{ml}$. The same factors which govern calcium also govern phosphorus.

Absorption and Excretion of Phosphorus: The absorption and excretion of phosphorus is governed by the same factors as calcium. Large intakes of aluminium, iron and magnesium interfere with the absorption of phosphorus by forming insoluble phosphates.

Like calcium, the main path of excretion from the body is faeces. In herbivores, phosphorus is excreted in small quantities in urine. In carnivores, the excretion of phosphorus is equally distributed in urine and faeces.

Deficiency and Toxicity Symptoms: Calcium and nhosnhorus are required for bone formation. Deficiency of phosphorus also causes rickets in growing animals and osteomalacia in adult animals. In phosphorus rickets, the blood phosphorus level goes down. Phosphorus deficiency also causes depraved appetite or "PICA" in cattle. Low phosphorus intakes in the diet have been associated with reproductive disorders in cattle and buffaloes. Phosphorus deficency decreases milk production and affects the growth. Sheep are less prone to phosphorus deficiency than cattle because of selective grazing. Phosphorus deficiency can be prevented by using phosphorus sumplements like sterlized bone meal, dicalcium phosphate or wheat bran. Excessive intake of phosphorus may decrease the absorption of other intake of calcium and magnesium decreases phosphorus absorption. 
Phosphorus Supplements: Animal products like fish meal, bone meal are good sources of phosphorus. Cereal grains, wheat bran, rice bran, rice polishing, oil cakes etc, are fairly good sources of phosphorus though poor sources of calcium. Leguminous fodders like berseem and lucerne. are poor sources of phosphorus.

Most of the ohosphorus present in cereals and their by-products is in the form of phytates $i . e$. , salts of phytic acid, $a$ phosphoric acid derivative. Calcium and magnesium phytates occur in cereal grains and by-products which are insoluble. Ruminants can utilize the phytate phosohorus due to mi crobial activity in the rumen, which can break down the phytates. Pigs and poultry cannot effectively utilize the phytate phosphorus.

\section{Magnesium}

Magnesium is closely associated with calcium and phosphorus, specially in the formation of bones. More than 50 percent of the magnesium is found in bones and the rest in soft tissues and body fluids. Vagnesium is an activator of phosphates and takes an active part in the carbohydrate metabolism. It is an activator of various enzyme systems. The blood serum contains $2.5 \mathrm{mg}$ of magnesium depending upon species.

Absorption and Excretion: Magnesium is absorbed primarily as a soluble salt in the small intestine. It is excreted both in faeces and urine.

Function: Nagnesium is involved in many metabolic functions. It is involved in bone formation and in cellular metabolism as an activator of enzymes. It is also involved in activating certain peptidases in protein digestion.

Deficiency and Toxicity Symptoms: The deficiency of magnesium causes (I) vasidilation (flushing of skin as capillaries expand) with a reduction in blood pressure (2) Hyper irritability (nervousness and exitability) and (3) tetany. In rats with normal calcium and phosphorus, lowering of marnesium to 1.8 p.p.m resulted in hyperirritabilitys convultion and death. Calves reared on milk diet wi thout any other supplement for a prolonged eriod also suffer from magnesium deficiency. In these cases the serum magnesium goes down to a level of 0.1 to $0.2 \mathrm{mg}$ per $100 \mathrm{ml}$. 
In adult muminants, magnesium deficiency takes place and is known as "grass staggers" "grass tetany" or "magnesium tetany". This condition occurs in western countries during the sinring season when the animals are turned on to young succulent pastures deficient in magnesium. Hormonal disturbances and the faulty inter-relationships of calcium, phosphorus and magnesium are also responsible for grass staggers.

In poultry, magnesium deficiency causes neurological symptoms like in rats.

Treatment of magnesium deficiencies by intravenous injection of magnesium induces the excretion of excessive amounts of calcium in the urine. When magnesium is fed in large quantities, the calcium excretion is not observed, probably due to the regulation of absorption of magnesium through highly selective mechanisms.

Snontaneous toxi cities have not been reported.

Sources: Most feeds contain sufficient magnesium to meet the requirement of the animal; but to ensure margin of safety, most mineral mixtures contain some magnesium as magnesium sulphate or magnesium oxide.

Farm animals require about 0.06 percent magnesium of the dry ration. ost of the commonily fed roughages and concentrates contain 0.1 percent or more of magnesium.

Inter-relationship between Calcium, Thosphorus and Magnesium There is a close relationship between calcium, phosphorus and magnesium. Increasing calcium or phosphorus or both brings magnesium deficiency in the animal though it is fed with adequate magnesium.

Sodium

Sodium plays an important role along with potassium and chloride in maintaining the acid-base equlibrium and osmotic nressure. Nost of the sodium is present in the body fluids and soft tissues. Sodium is also present in the extra cellular fluids.

Deficiency and Toxicity Symptoms: Sodium deficiency affects the growth of the animals and also reduces the utilization of the digested protein anc energy. In laying birds, this

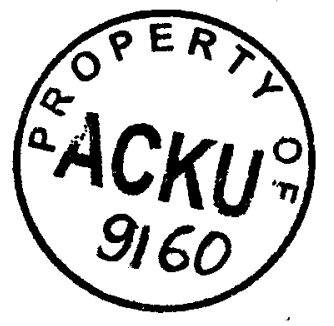


deficiency results in lowered egg production. In rats, eye lesions, reproductive disturbances and death have been reported because of sodium deficient rations.

Sources of Sodium: The chief source of sodium is sodium chloride or common salt. Niost feeds and forages are poor sources of sodium except herbage which is grown on alkaline soils for reclamation.

Potassium

Most of the potassium is found in the cells unlike sodium which is mostly found extra-cellularly. Potassium plays an important role in nerve irritation and carbohydrate metabolism.

Absorption and Excretopm: Potassium is primarily absorbed in the small intestine. Absorbed potassium is excreted primarily via the kidneys through urine.

Functions: Potassium and sodium are closely interrelated in the maintenance of proper osmotic pressure within cells. Both minerals are involved in the maintenence of proper acid-base balance and the transfer of nutrients in and out of individual cells. Potassium is also required in the enzyme reactions involving the phosphorylation of creatine, carbohydrate metabolism and protein synthesis.

Deficiency and Toxicity Symptoms: Potassium deficiency normally does not occur in the farm animals under natural conditions since green fodders are rich sources of this element. In chicks, deficiency symptoms have been produced on experimental diets low in potassium. The deficiency symptoms in chicks are decreased growth rate, weakness and tetany followed by death. Sever paralysis has also been recorded in calves fed on synthetic milk diets and fed on low milk intake.

Potassium deficiencies occasionally occur in the arylot finishing of cattle or sheep when high concentrate rations are used. Defici ency symptoms as growth retardation, unsteady gait, general muscle weakness, pica (Depraved Appetite) diarrhea, distension of abdomen, emaciation (Ioss of flesh), hypertrophy (enlargement) of the heart and kidneys and eventually death.

Excessive levels of votassium interfere with magnesium absorption and utilization. 
Sources: Feeds of plant origin, specially forages, are extremely good sources of potassium.

\section{Chlorine}

Sodium chloride is the princioal source of sodium and chlorine to the animals. It is a usual practice to give salt to animals in the form of salt licks. Deficiency of salt in the diet leads to decreased appetite which results in lowered growth rate and milk production.

Deficiency of salt in noultry leads to feather picking and cannibalism.

Excessive salt intake is detrimental to animal health as it causes excessive thirst, muscular weakness and oedema. Salt poisoning has been reported in pigs and noultry fed on diets containing 4 percent salt on limited water intake.

Sulphur

The body contains about 0.15 percent of sulphur. The requirements of suphur varies in different animals. Nonruminants utilize most of the dietary sulphur from amino acids, having little or no ability to incorporate elemental suphur for aminoacid synthesis. Ruminants, however, use elemental sulphur and sulphates to synthesize amino acids through the action of ruminal micro organisms.

Absorption and Ixretion: Sulphur is mostly absorbed in the small intestine. In some species organic sulphur is absorbed more readily than in the inorganic form.

Both the faeces and urine are paths of sulphur excretion. Small amounts are lost in wool or hair.

Functions: Sulphur is required by animals for use in certain amino acids. post ingested sulnhur is obtained from proteins having sulphur containing amino acidsmethionine, cystine and cysteine. The vitamins biotin and thiamine contain sulphur. Sulphur is also found in all tissues of the body, being high in hair, wool and feathers.

During fermentation in the rumen, methionine is metabolised and converted into ami no acids required by the mi cro-organisms. 
Deficiency and Toxicity Symptoms: Since sulphur is associated with protein synthesis, symptoms of sulphur deficiency is manifested in retarded growth. Sheep fed on non-protein nitrogen without sufficient sulphur, show reduced wool growth as wool contains 4 percent sulphur.

Generally toxicity from excessive suphor does not take place. But when excessive amounts of sulnhur are fed, production of hydrogen sulphide-a highly taxic gas-in the rumen may pose problems.

Sources: In non-ruminants sulphur is best utilized as part of the proteins or as supplemental amino acids.

The ruminants, horses and rabbits can utilize sulphur in the sulphate form or elemental sulphur through microbial action in the rumen or cecum.

Nii cro elements (Trace minerals)

Trace minerals are those which are needed in small amounts. The physiological roles of many of these minerals have only recently been elucidated and further research work is in progress. Many of the trace minerals have small margins of safety. Therefore every care should be taken before incorporating them in the ration of animals.

Iron

Iron is mostly found in the combined form with proteins in the body. It is a component of haemoglobin which helps

in the transportation of oxygen. It is a component of various enzyme systems like cytochrome, peroxidase and catalase. Ferritin is an iron-bound protein present in liver, spleen, kidney and bone marrow. It is probably in this form that iron is stored in the animal body. Blood serum contains an iron-containing protein called siderophillin.

Absorption and Excretion: The iron absortion is related to and controlled by the body requirements. Tormally 5-15 percent of the dietary iron is absorbed. While some iron is absorbed in the stomach, major portion is absorbed in the duodenum. In most animals iron is absorbed primarily in Ferrous state and is stored in the liver in the form of metalloprotein-ferritin.

Iron is excreted through the bile. Much of the iron is reabsorbed. Through this reabsorption mechanism, the 
losses of iron are minimised and the animal can compensate for its poor absorntive capacities. Acidic condition in the gastro-intistinal system helps iron absorption.

Functions: Iron transports oxygen to all cells and tissues of the body as part of the haemoglobin molecule. Myoglobin-a pigmented compound similar to haemoglobin but in smaller size is found in the muscle. It contains iron which has the ability to accept oxygen in much the same manner as haemoglobin. In addition to its major role in the blood transport of oxygen, iron is also an essential part of a variety of enzymes as oxidase, catalase and peroxidase. It also functions as an enzyme activator for arginase.

Deficiency and Toxicity symptoms: Since more than half of the iron present in the body occurs in haemoglobin, its deficiency affects the formation of haemoglobin, which results in anemia. In ruminants, iron deficiency is not very comion since herbage is a rich source of this element. Pigs are the only farm animals in which piglet anemia is very common when they donot have access to soil or pasture and are housed on a concrete floor. Piglets are generally born with low resources of iron and due to rapid growth, fall an easy prey to anemia if adequate iron supplements/injections are not given. In piglet anemi a (Thumps), there is laboured breathing and the haemoglobin level falls to $3-4 \mathrm{~g}$ ner $100 \mathrm{ml}$ blood.

The growth rate is affected. Swine require about $15 \mathrm{mg}$ of iron per day. In poultry, anemia does not occur 15 mg of iron pert
as iron is present in abundant quantities in grains and
byproducts. Poultry requires about 9 mg iron per day. Iron toxicity is not likely to occur because of the selective absorption and storage systems. An excess of iron in the diet can tie up phosphorus in an insoluble iron-phosphate complex creating phosphorus deficiency.

Sources: Most grains and forages are rich source of iron, while milk is a poor source of iron.

Copper

Copper is present in more than dozen enzymes whose roles range from utilization of iron to the pigmentation of skin. Jome of the enzymes are ceruloplasmin, cytochrome oxidase, lysine oxidase, tyrosinase etc. In the utilization of iron for the formation of haemoglobin, copper plays an important role. The element is necessary for the normal pigmentation of hair, fur and wool. The amount of copper that is needed varies with different animals and is extremely 
interdependent on the level of other minerals in the feed. 5 to $\delta$ ppm of cooper in the diet is adequate for most animals, if there is no interfering elements in the ration. Copper is stored primarily in the liver or in the spleen.

Absorption or Excretion: The primary site for copper absorption for various animals is as follows: The jejunum in dogs, the colon in pigs, the duodenum in chicks and man and the stomach and the small intestine in rats. A number of factors influence copper absorption conditions like gastric acidity, the base content of the diet and intestinal secretions have a influence on copper absorption. High levels of molybdenum, sulphur and zinc reduces the availability of copper. Addition of large amounts of calcium carbonate and ferrous sulphide to the diet markedly reduce the assimilation of copper by reducing the solubility of copper and formation of insoluble copper sulphite.

liore than 90 percent of the dietary intake is excreted in faeces through bile, but much of it is reaksorbed. In urine, excretion is low. In ordinary dietary condition, the chief channel of excretion is the intestinal tract.

Functions: Copper plays an important role in the formation of haemoglobin by focilating the obsorption of iron from the inteshaemoglobin as such, conper is found in red blood cells. Copper is required for normal pigmentation of hair, fur and woll. Copper also plays an important role in reproduction functions.

Deficiency and Toxicity Symptoms: Though the animal body contains relatively minute amounts of copper, a deficiency of this element in the food of the animals can lead to serious consequences. Deficiency symptoms include anemia, depressed growth, bone disorders, depigmentation of hair, wool, abnormal wool growth, demyelenation of soinal cord and lesions in the brain.

A condition called "Sway back" in new born lambs has been associated with copner deficiency. "Falling disease" in animals in various parts of A dstralia is characterised by staggering, falling and sudden death. "peat scours" in New-Zealand and "Teartness" in England are due to copper deficiencies created by high molybdenum intake. St eep consuming too little conper not only have a change in the colour of black fleeces, but the wool becomes coarse and straight similar to hair and is referred to as "stringy wool" or "steely wool". 
Clinical cases of copper deficiency have been reported from India. In cattle, the heifers do not $\varepsilon$ et in heat, $i$ the level of copper in blood is below $90 \mathrm{mgm}$ ner $100 \mathrm{ml}$. Toxicities are renorted when the level reaches $250 \mathrm{ppm}$ or above in the feed.

Sources: Copper is widely distributed in feeds. Some of the soils in India, Tlorida and coastal lains in U.S.A. are deficient in copner. Concentrates are rich source of copper, while straws are poor.

Ás copper absorption and utlization are affected by calcium, molybdenum, mercury zinc, cadmium and ferrous sulphate, trace mineralised salt containg copper sulphate or copper carbonate is recommended in deficiency condition. The requirement of copper has been worked out as $50 \mathrm{mg}$ per day in cattle and, $5 \mathrm{mg}$ per day in sheep.

Cobalt is a component of vitamin Bl2 and appears in enzymes involved in the synthesis of DNA and the metabolism of amino acids.

Absorption and Excretion: In the ruminants, cobalt is required by rumen microorganisms for the synthesis of vitamin $B$ i2. the intestine can synthesize vitamin Bl2 but this synthesis is not enough to meet the requirements of poultry and pigs. Hence supplementary feeding in diet is required. Since cobalt from the body is excreted through the bile, it can readily be reabsorbed to minimize loosses in the faeces.

Functions: Cobalt is a component of vitamin Bl2. In ruminants dietary cobalt is utilized for synthesis of vitamin $B 12$, while in non-ruminents dietary $B 12$ is required. to be sufflied in the diwt.

Deficiency and Toxicity Symotions: Cobalt deficiencies have been renorted in soils and feeds in Australia, U.S.A. and other parts of the world. About $0.1 \mathrm{ppm}$ cobalt in the feed is adequate: But deficiency symptoms appear, when the level dros to 0.04 to $0.07 \mathrm{ppm}$ or lower. The symptoms of deficiencies are the same as those for vitamin $B 12$ viz a rough hair coat, scaliness of the skin, absence of oestrus, abortion, low milk nroduction, loss of appetite, rapid loss of weight, emaciation and anemia. 
Continued deficiency may eventually result in death.

Cobalt can be toxic when the intake is excessively high viz 20-25 mgm cobalt per $100 \mathrm{~kg}$ body weight. But the margin of safety is wide and absorption from the intestinal tract is low.

Sources: Generally cobalt is present in adequate amounts in most feeds and fodders ranging from 0.1 to $0.25 \mathrm{ppm}$. Deficient pastures contain less than $0.08 \mathrm{ppm}$. Copper sulphate and chloride are good sources of cobalt.

Iodine The animal body contains very minute quantities of iodine. Nore than half is found in the thy roid gland, where it is incorporated in thyroxine, a hormone secreted by the thyroid gland. Small amounts can be found in the kidneys, salivary glands, hair, stomach, skin, mammary glands and ovaries.

Absorption and Excretion: Iodine is absorbed throughout the entire gastro-intestinal tract. Once iodine is absorbed, it is distributed throughout the extra cellular fluids of the specific areas of storage. Iodine that has been absorbed and metabolised is excreted in the urine.

Functions: Iodine is used in the production of several hormones-derivatives of amino acid tyrosine-known as thyroxine. The thyroid hormones play a major roile in the regulation of the metabolic rate of the body.

Deficiency and Texicity Symotoms: In the deficiency of iodine, the thyroxine production is very much reduced. To produce more thyroxine for physiological functions, the thyroid gland enlarges; this is known as Goiter. It may be found in adult animals, but is also found in new born animals from mothers which have been fed iodine-deficient diets. In addition to enlarged thyroid glands (called big. neck in the calves), other symptoms of iodine deficiency are reduced growth rate, dry skin and brittle hair, resorntion of fetuses, abortions, still births, abnormal estrus in females and reduced libido and poor semen quality in males. Iodine deficient new born jigs are hairless and in sheen, the wool is sparse and of poor quality. 
Treatment of iodine deficiencies may not be successful and hence prevention is far better. Iodine is readily available both in inorganic and organic forms.

An intake of 0.002 to 0.004 milligram per $\mathrm{kg}$. body weight is adequate to prevent Goiter.

Excessive intake of iodine over a prolonged period

of time can cause toxicities. The symptoms of such toxicities include increased prenatal mortality in rabbits and reduced egg production, poor hatchability in noultry and abortion in mammals.

Sources: Plants contain 0.2 to $0.5 \mathrm{ppm}$ sometimes as high as 5 ppm. Seaweeds show a range of 400-500 ppm of iodine. Fish meal is a good source of iodine.

\section{Manganese}

Manganese is needed by the body in small amounts, but it performs several vital roles viz proper formation of bones, for the development and function of reproductive system, and for the normal growth of the whole animal. Manganese is an activator of many enzyme systems like bone phosphatase, muscle adenosine trinhosphatase, peptidases and the liver. It can also be found in the skin, muscle and bones.

Absorption and Excretion: Manganese is absorbed primarily in the small intestine. Absorption can be depressed when excessive amounts of calcium, phosphorus or iron are fed. Manganese is eliminated through the biliary system.

Functions: Manganese has been shown to be involved with a number of enzyme systems in carbohydrate, fat, and protein metabolism. It is also closely involved with calcium and phosphorus in bone metabolism.

Deficiency and Toxicity: Cattle show poor growth, leg disorders, poor fertility and frequent abortions on mancanese defici ent pastures. In swine, the deficiency of manganese results in poor growth of bones with a shortening of the leg bones, enlarged hocks, muscular weakness, increase in back fat and an irregular oestrus cycle. The requirement of manganese depends on the age of the pigs, and on the level of calcium and phosphorus in the diet. In poultry, manganese deficiency causes "slipped tendon" or "perosis" a malformation of leg bones. It is not the 
only factor which causes this syndrom, but other factors are also responsible. In breeding hens, hatchability and shell thickness are reduced. In mammals, manganese def$i c i e n c y$ is characterised by delayed oestrus, poor conception, and decreased litter size in females and decreased libido and abnormal spermatogenisis in malos.

Excessive manganese intakes are tolerated well by most animals. However these excesses can interfere with the absorption of calcium and phosphorus. Conversely an excess of calcium and nhosphorus can interfere with manganese absorption. Iron deficiency anemia can be oroduced when large amounts of manganese are included in the ration. Calcium and phosphorus utilization in bone and teeth formation is adversely affected by high levels of manganese.

Sources: Grains, seeds and their by-products are fairly good sources of manganese. Forages and pastures are generally $h_{i g h}$ in manganese. Ri ce and wheat bran are g,ood sources of manganese. Animal tissues, marine products, dairy products and poultry products are notably low in manganese. Nanganese sulphate is the most commonly used supplement; but the chloride, dioxide and carbonate forms can also be effectively used.

Zinc

Zinc is a constituent of several enzyme systems in the body like carbonic anhydrase, carboxyl peptidase and alcohol dehydrogenase. It is found throughout the body but in higher concentration in the epidermal tissues as skin, hair and wool than the other tissues of the body. It tends to accumulate in bones.

Absorption and Excretion: About 10 percent of the dietary zinc is absorbed. Large amounts of phytic acid or calcium can depress zinc absorption. It appears that metallic zinc and zinc as carbonate, sulphate and oxide are all absorbed equally well.

Zinc that has been absorbed is excreted via the pancreatic duct and the bile.

Functions: Zinc is involved in the enzyme systems of protein and carbohydrate metabolism and in the action of follicle stimulating sex hormones. It is also part of an enzyme system which is responsible for the secretion of hydrochloric acid in the stomach or abomasum. 
Deficiency and Toxicity symptoms: On a zinc deficient diet, the animal tends to be stunted. It is also extremely unhealthy and may die. The other symptoms associated with zinc deficiency are skin diseases, disorders of the feathers, hair coats, lower feed effeciency, delayed sexual maturity, loss of appetite and vomiting.

In cows, zinc deficiency reduces milk production; there is lower fertility, loss of hair, rough scaly skin, and fewer calves are produced. Increasing the zinc contents in ration calves are produce. sub-normal growth, poor feed effeciency, and characteristic skin lesions on the leg and belly. The condition can be prevented by feeding 50-100 ppm zinc in the form of carbonate or sulphate. Sheep fed rations deficient in zinc exhibit abnormal changes in wool and horns. In chicks, zinc defeciency causes poor feathering. The addition of zinc to a diet results in the rapid disappearace of most deficiency symptoms.

Toxicities of zinc are unusual, but, are expressed as anemia, depressed growth, stiffness, hemorriges in bone joints, bone resorotion, a depraved appetite and in severe cases, death.

Sources: Animal product and shellfish are extremely high in zinc. Theat and rice brans are rich in zinc. Feeds and fodders contain adequate amounts of zinc. Zinc can be fed as zinc carbonate or zinc sulphate.

Molybdenum

Molybdenum has been shown to be important in the diet in small amounts (about $2 \mathrm{ppm}$ ), but is detrimental in excessive quantities (about $20 \mathrm{ppm}$ ).

Absorption and Excretion: Molybdenum is absorbed through the gastro-intestinal tract. The rate of absorption can be depressed by the presence of sulphates in the feed. Most of the absorbed molybedenum is excreted rapidly in the urine, but a limited amount is ex reted via the bile.

Functions: Volybdenum is a constituent of xanthine oxidase and nitrate reductase which have biological functions in the purine and nitrate utilization. Excess of nitrogen in birds is excreted in the form of uric acid which is analogous to urea in mammals. Hence birds require considerably larger amounts of molybdenum than mammals. 
The growth promoting effect of molybdenum has been observed in growing lambs. Although molybdenum has, been classed as an essential trace element, it gained importance in animal nutrition because of the condition known as molybdenosis, where its toxic role is more important.

Deficiency and Toxicity symptions: Deficiency symptoms under natural conditions have not been reported specially in mammals. In lambs and poultry, a little addition has been reported to stimulate growth. In lambs, it has an indirect effect, since it helps in the better utilization of cellulose.

In molybdenum toxicity, animals (ruminants) suffer from extreme diarrhoea, loss of weight and reduced milk yields, fading of hair colour and other symptoms of copper deficiency. The condition is known as: "Teartness". Forage in the affected areas contain 30-80 ppm of molybdenum whereas those in healthy areas contain $5 \mathrm{ppm}$. Molybdenum is rerely added to livestock feeds.

Sources: Addition of copper sulphate to the diet can relieve the toxic conditions, because it appears that the problem is one of, molybdenum tying up copper, preventing it from fulfilling its essential roles.

\section{Selenium}

Selenium has long been recognised as a potentially toxic element in feeds, and clinical toricities are well documented. More recently, however, this mineral has been found to be essential. Traces of selenium are required by the animal for normal metabolism. Vitamin $E$ and selenium are interrelated in the metabolic functions in as, much as vitamin E. can partially replace the selenium needs of animals. Absorption and Excretion: Most dietary selenium is absorbed
in the duodenum. Selenium as a metabolic product is excreted primarily in the urine, but it can also be excreted in the feces: or expired air.

Functions: In plants, selenium is associated with proteins, primarily as analogs of sulphur amino acids. Recent research indicates that selenium is a component of gluta-thione peroxidase, an enzyme that destroys peroxidases in animal tissues. Selenium has also been associated in the absorption of lipids 
and tocopherols.

Deficiency and Toxicity Symptoms: Selenium deficiencies are numerous and are manifested in different ways depending on the species of animal involved. In selenium deficient calves and lambs the muscles degenerate. In calves this condition is called white muscle disease and in lambs it is called stiff lamb disease. White muscle disease and chronic diarrhoea in sheep has been cured by 0.05 and $0.1 \mathrm{ppm}$ selenium. Chicks fed a selenium deficient diet develop exudative diathesis-a condition where the walls of capillaries become highly permeable. Liver necrosis is observed in selenium deficient pigs.

Toxicities, of selenium produce alkali disease or blind staggers, characterised by loss of hair, sloughing of hoofs, lameness, anemia, excessive salivation, grinding of teeth, blindness, paralysis and death. In poultry, egg production and hatchability are reduced. Acute cases of selenium poisoning may occur on consumption of certain weeds by cattle and sheep that accumulate higher contents of selenium, such as: "Astragalus bisulcatus" which conteins upto $4000 \mathrm{ppm}$.

\section{Fluorine}

Like molybdenum and selenium, traces of fluorine are essential but it is also known to have toxic effects when taken in excess. In traces, it helps in the development of a normal skeleton; defeciency of fluorine causes dental caries. The element is toxic if taken in excess. Drinking water containing about $3 \mathrm{ppm}$ can produce toxicity. Similary, rations containing more than $100 \mathrm{ppm}$ on a dry matter basis are toxic. An excess in water or dryration causes a condition describes as "Fluorosis".

Fluorine is a cumulative poison. It leads: to the formation of cavities: in the teeth. Bone and joint abnormalities: may also take place.

Fluorine is one of the atmospheric contaminants of industries that use coal, ore or earthy phosphates. Phosphatic fertilizers usually contain fluorides, which may become contaminants in the vegetation fed to animals. 
Chromium

Chromium deficiency is characterised by impaired growth, reduced life span, corneal lesions and defects in sugar metabolism. There is no evidence that supplemental

chromium is beneficial except in certain experimental diets.

Tin

Tin has been found to be essential for normal growth in rats. Without one or two ppm in the diet of rats, growth was about two thirds the normal rate.

\section{Vanadium}

Vanadium has been found to be essential for normal growth in rats. One tenth of a part per million ( $1 / 10 \mathrm{ppm}$ ) of vanadium restored normal growth in rats showing vanadium defici ency. 


\section{Vitamins}

Vitamins are usually defined as complex órganic compounds required in small amounts for maintenance and normal growth, production, reproduction and the general good health of the animal.

The omission of a single vitamin from the diet of any species, that requiresit, will produce specific deficiency symptoms.

Vitamins have been divided into two groups, fat soluble and water soluble, as: follows:

The fat soluble vitamins are $A, D 2, D 3, E$, and $K$. The water soluble vitamins are Bl (thi amin), B2 (riboflavin), panthothenic acid, B6 (pyridoxin), para amino-benzoic acid niacin (nicotinic acid), inositol, biotin, folic acid, cholin, Bl2 (cynocobalamin) and $C$ (ascorbic acid). Many of the vitamins are not very stable and are destroyed by oxidation, which is speeded up by the action of certain metals, heat and light. Though there are about 15 vitamins known to be essential, not all of them are dietary essential for farm animals. For instance, ruminants get their needs of $B$-complex and $K$ through the synthesis of these by ruminal mi cro-organisms.

\section{Fat Soluble Vitamins}

\section{Vitamin A}

All farm animals require vitamin $A$ as a dietary source. Vitamin $A$ is an unsaturated monohydric al cohol known as retinol. The international standard for vitamin $A$ is pure crystaline vitamin A acetate. One international unit of vitamin $A$ is 0.344 mi crograms of pure vitamin $A$ acetate or $0.550 \mathrm{mg}$ of vitamin $A$ palmitate, which is equi valent to 0.3 mg of vitamin $A$ al cohol.

Absorption: Vitamin $A$ is strictly a product of animal metabolism. Vitamin $A$, as such, is not found in plants, but is present as its precursor, carotene, which is known as: provitamin A. Vitamin A is colourless.

There are four types of carotenes which have vitamin $A$ activity. They are $\alpha, \beta$ and $\gamma$-carotene and cryptoxanthene. Carotene is mostly in the $B$ form. Vitamin A contains one $\beta$-ionone ring, and $\beta$ arotene $2 B$-ionone rings. One $i$.u. of vitamin $A$ is equal in activity to $0.6 \mathrm{mcg}$ of $\beta$-carotene. 
Almost no absorption of vitamin $A$ occurs in the stomach. In the small intestine, vitamin $A$ and $B$ carotene are emulsified with bile salts and products of fat digestion and absorbed in the intestinal mucosa. Much of the conversion of $\beta$ carotene to vitamin $A$ takes place in the epethelial cells of the intestine. From the intestine, vitamin $A$ is carried through the lymph system to the liver where it is stored. Part of the carotene is converted to vitamin A in the liver also. From the liver, vitamin A enters the blood stream as free alcohol, where upon it travels to the tissues for use. While the liver is the main storage site for vitamin $A$, adipose tissue and the kidneys can also serve as reservoirs for an excess of it. In swine and sheep, carotene is not absorbed in the blood stream. Cows have the ability to absorb and store this precursor. Grassfed cattle have large stores of carotene in their body fat, which is evidenced by its deep yellow colour.

Vitamin $A$ is extremely heat labile. With the increase in storage temperature, the rate of destruction of vitamin $A$ is accelerated. Vitamin $A$ is also sensitive to certain acids and rancid fats. Minerals such as iron oxide, charcoal, sulphur, ground limestone, bone meal, manganese and iodine, all contribute to the destruction of vitamin $A$ in feed.

Functions: Vitamin $A$ is essential for a number of physioIogical processes. It is used for (1) maintenance of mucous membrane and epethelial development (2) reproduction (3) bone development and (4) vision.

Deficiency and Toxicity Symptoms: Animals suffering from deficiency of vitamin A may show any or all of the following symptoms-stunted growth, loss of appetite, xerophthalmia, night blindness, nervous, disorders and reproductive dysfunctions.

Toxicities can result when excessive amounts of vitamin $A$ are ingested. Examples are over growth of skull bones which punch auditory and optic nerves affecting hearing and sight, and marked changes in skin.

Sources: Vitamin $A$ is found in lipids of animal orgin. The richest sources are fish liver oils. Among the common foods of animal origin, milk fat, egg yolk and liver also contain the highest amounts of vitamin $A$.

Except for yellow corn, practically all cereal grains and by-products have little carotene or vitamin A. Green plants do not contain vitamin $A$, but are rich in provitamin $A$, 
carotene, and therefore have high vitamin A value, straws are poor sources; of vitamin $A$ or carotene. Hays conserved properly and retaining theim green colour contain good amounts of vitamin $A$.

\section{Vitamin D}

Vitamin D is a fat soluble anti-rachitic factor. There are about a dozen different compounds which have vitamin D activity. The two most important forms: are D2 (ergocalciferol) and D3 (cholecalciferol). Some compounds act as provitamin D which when activated give vitamin D activity.

Functions: The primary function of vitamin $D$ is to facilitate absorption of calcium in the intestinal tract as a vitamin component in the production of calcium binding protein. Vitamin D is also involved in the metabolism of other minerals. Intestinal permeability to such minerals as zinc, iron, cobalt and magnesium is altered by vitamin $D$, thus permitting faster and more efficient absorption. Vitamin $D$ helps in the deposition of calcium and phosphorus in the bones.

Deficiency and Toxicity Symptoms: Deficiencies of vitamin D will produce rickets in young animals and osteomalacia and osteoporosis in mature animals. Deficient hens produce eggs with poor egg shell quality and decreased hatchability. Massive dozes of vitamin $D$ may develop hypervitaminotic condition.

Sources: Ultra violet light from the sun is by far the most accessible and cheapest means of supplying vitamin $D$. In countries: where cattle, sheep, goats, pigs and poultry are reared outside their sheds, there is probably no need for vitamin $D$ supplementation. The animals can synthesize vitamin D3 by exposure to sunshine. In places where intensive animal production is being done in covered sheds, vitamin $D$ may be supplemented in the diet. The precursor of vitamin D2, ergesterol, is present in many forages. Grains and their by-products are generally extremely low in vitamin D. Eggs and fish liver oil are good sources of vitamin D. Milk is a variable source. In poultry and pigs, vitamin $D$ should be incorporated in the diet when these animals are reared within sheds. 


\section{Vitamin E}

Vitamin $E$ is known as the antisterility vitamin because of its role in reproduction. There are a number of closely related compounds known as tocopherols which have vitamin $E$ activity. Of these, $\alpha$-tocopherol is the most active compound and is commonly found in nature. Vitamin $E$ is a yellow compound which is soluble in alcohol and fat solvents, but insoluble in water. It is susceptible to destruction by heat, light and alkalies.

Absorption: Bile salts are required for the proper absorption of vitamin $E$ also, as, wi th most lipids. Once absorbed, the vitamin is transported in the $\beta$ lipoprotein fraction of the blood.

Function: Vitamin $E$ acts as an antioxidant at the cellular level. Its: presence in the lipid membrances prevents the formation of peroxides and free radicals whi ch attack polyunsaturaled fatty acids. Vitamin $\mathrm{E}$ plays an important role in many enzyme systems in the animal body. It is an antioxidant and can protect oxidisable vitamin $A$ and carotene. There is an inter-relationship of vitamin $E$ and selenium in the body. Vitamin $E$ deficiency can be partly alleviated by selenium supplementation.

Deficiency symptoms: Numerous deficiency symptoms of vitamin $E$ have been reported in almost all types of livestock. In cattle and sheep vitamin $\mathrm{E}$ deficiency brings about a condition known as muscular dystrophy, which is more common in young calves. If the heart muscle is affected the animal will die. Where skeletal muscles are involved, there may be stiffness of the legs.

In poultry, encephalomalacia or crazy chick disease has been reported due to vitamin E deficiency.

In young goats and sheep, the skeletal muscle degenerates, giving rise to a condition called stifflamb disease. The counterpart in calves is called white muscle disease. In rats, a deficiency of vitamin $E$ leads to reproductive failure, degeneration of the kidney and necrosis of the liver. Steatitis has been observed in vitamin $E$ deficient mink, pigs, and chicks. 
Sources: Vegetable oils, colostrum and cereal germ meals are rich sources of vitamin $E$. It is also very widely distributed in green feeds and cereal grains.

\section{Vitamin $K$}

A large number of naturally occurring compounds have vitamin $K$ activity. Vitamin $K$ is known as the antihemorrhagic vitamin and the prothrombin factor. Vitamin $\mathrm{Kl}$ is the most important naturally occurring compound. Chemically it is 2 , methyl-3 phytyl-1, 4-napthaquinone. \& number of compounds that possess vitamin $K$ activity have been ei ther isolated or synthesized. Vitamin Kl, phylloquinone, has been isolated from alfalfa. Vitamin $\mathrm{K} 2$, menaquinone, is present in fish meal. Menadione (vitamin K3) is produced synthetically and is more potent than either vitamin $K 1$ or $K 2$.

Absorption: Vitamin $K$ is absorbed in the same manner as fats. Thus, any malfunction of the fat absorption mechanism, for example, bilary obstruction, will reduce the availability of vitamin $K$. Vitamin $K$ can be produced by intestinal mi cro-organisms as well as ruminal mi crobes.

The naturally occurring compounds are insoluble in water but soluble in fat solvents and alcohol. Some of the synthetic forms are also soluble in water. Vitamin $\mathrm{K}$ is heat stable, but it is rapidly destroyed when exposed to light. Vitamin $K$ is required in the synthesis of a number of proteins involved in the clotting mechanism; the most important of these being prothrombin, the precursor of thrombin.

Deficiency symptoms: Symptoms of vitamin $\mathrm{K}$ deficiency are low prothrombin levels, increased clotting time, and hemorrhaging. A defici ency of vitamin $K$ is not likely to occur in animals under normal conditions. However a deficiency can result under the following conditions:

(1) Ingestion of an antimetabolite.

(2) Use of a synthetic diet.

(3) Use of antibiotics and sulpha drugs.

In ruminants, vitamin $K$ is synthesized by the microorganisms present in the rumen. During the subsequent passage of these mi crobes into the small intestine, they are digested and the vitamin is made available to the host animal. 
In non-ruminants, the site of synthesis of vitamin $K$ by the mi crobes is in the caecum from where there is poor absorption.

In cattle there is a condition called "sweet clover diseasei which is due to the presence of the compound dicumarol that lowers the prothrombin level in the blood. In the case of poultry, a deficiency of vitamin $K$ increases the clotting time of blood and the animal may somtimes bleed to death.

Sources: Green fodders are rich in vitamin $K$. Liver, milk, eggs and fish meal are excellent sources.

\section{Water Soluble Vitamins}

All water soluble vitamins can be grouped together into $\mathrm{B}$-complex vitamins except vitamin $\mathrm{C}$.

All the vitamins of the $B$ group are essentially required by animal cells, which cannot synthesize any of them except niacin (from tryptophan) and choline (from serine).

Ruminants can synthesise all the vitamins of the $B$ group through the agency of the microbes present in the rumen. After their breakdown in the lower gastro-intestinal tract, B-vitamins are available to asimals which can satisfy their requirements. In the prerumi nant calf, B-complex should be supplied in the ration.

In the non-ruminants also there is considerable

intestinal synthesis of B-vitamins, but their availability to the animal is less.

\section{Thi amine (BI)}

Thiamine is referred to as aneurine, the antineuritic factor. It consists of a molecule of pyrimidine joined to a thiazol ring. It is highly soluble in water and has a meaty flavour. It is destroyed by heat, especially in the presence of alkalis. It is generally marketed in the hydrochloride form to ensure stability in storage.

Absorption: Since thi amine is extremely soluble in water, absorption is rapid and efficient in the small and large intestines. Excesses of thiamine are excreted in the urine. 
Functions: After absorption, thiamine is carried to the liver where it is phosphorylated in conjunction with adenosine triphosphate (ATP) to form thiamine hyrophosphate. In this form, the molecule acts as a coenzyme (cocarboxylase) for the decarboxylation of $-\alpha$-ketoacids which are essential in carbohydrate metabolism.

Deficiency symptoms: The deficiency of thiamine causes accumulation of pyruvic acid and its reduction product, lactic acid, in the tissues. It is because of this that there is more effect on the nervous tissues of the animal. In the case of pigs, there is loss of appetite, reduction in the growth rate, diarrhoea, and vomiting. Birds develop polyneuritis on thiamine deficient diets. The condition is characterised by nerve degeneration and paralysis. In horses, deficiency symptoms sometimes develop if they eat bracken (a fern plant) which contains a thiamine antagonist, thiaminase. Raw fish also contain thiaminase.

Sources: Cereal grains, their by-products, peas, nuts, yeast, pork, liver and egg yolk are fairly good sources of thiamine.

\section{Riboflavin (B2)}

Riboflavin is made up of ribose and isoalloxazine and has the formula $\mathrm{Cl} 7 \mathrm{H} 20 \mathrm{N4} 06$. It is relatively more stable to heat than thiamine but more sensitive to light. It is slightly soluble in water and is a yellowish crystalline compound. Riboflavin is insoluble in acetone, alcohol, chloroform and ether.

Functions: Riboflavin is closely associated with energy metabolism. It is a component of flavoproteins (yellow enzymes). These flavoprotein enzymes contain flavin mononucleotide (FMN) or flavin adenine dinucleotide (FAD) as coenzyme. There are a number of flavoproteins that function in the animal body in the transport of hydrogen.

Deficiency symptoms: Symptoms of riboflavin deficiency are non-specific, like decreased growth rate and poor feed conversion. In chicks, deficiency of vitamin B2 causes "curled toe paralysis" and chicks walk on their hocks. This is due to the degeneration of peripheral nerves. The growth in chicks is also reduced. In breeding hens, 
hatchability is reduced due to riboflavin deficiency. In pigs, deficiency of riboflavin causes poor appetite, reduced growth rate, skin lesions and diarrhoea.

Sources: Brewers yeast, milk, eggs, liver and growing leafy vegetables are rich sources of vitamin B2.

Pyrodoxine (Vitamin B6)

Pyridoxine is also known as vitamin B6, pyridoxal, adermine, vitamin $Y$, the eluate factor, and the rat acrodyna factor. Three biologically active forms of this vitamin exist in the body tissues, namely pyridoxine, the primary alcohol form, pyridoxal, the aldehyde form and pyridoxamine, the amine form. It contains a pyridine structure.

It is stable in heat, but unstable on exposure to light.

Functions: All three forms of this vitamin are converted into pyridoxal phosphate, which is an active co-enzyme of various enzyme systems, including the decarboxylation and transamination of aminoacids. Pyridoxine is also involved in other physiological functions: (1) biosynthesis of co-enzyme A, (2) catabolism of glycogen to glucose-1-phosphate, (3) porphyrin synthesis which is necessary for the formation of hemoglobin.

Deficiency Symptoms: The deficiency of this vitamin causes reduction in growth rate. In adult birds egg production and hatchability are reduced. In pigs, this, deficiency may cause reduced appetite, lowered growth rate and may result in anemia and convulsions. Pyridoxine-defi cient rats develop a specific dermatitis known as; acrodynia.

Sources: Pyridoxine is widely distributed in leafy vegetables, muscle, liver, wheat germs, nuts, molasses and yeas.t. 
Para amino benzoic acid (PABA)

Para amino benzoic acid was first identified as an essential

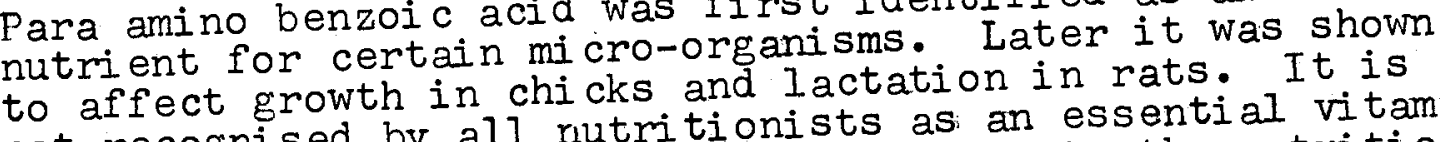
not recognised by all rutritionists as an essential vitamin, as it does not have a direct significance in the nutrition of animals. The chemical structure of PABA is very similar to some of the sulphonamides. There is evidence in animals that PABA may increase the potency of insulin and pen.

\section{Pantothenic Acid (Vitamin B3)}

Pantothenic acid is a dipeptide derivative having the general formula C9 HI 7 O5 N. It contains $\beta-$ al anine and dihydroxy-dimethyl-butyric acid. In nature, it is rarely found in its free form as it is highly susceptible to destruction by acids, bases and heat. Pantothenic acid is available commercially as a calcium or sodium salt. It is insoluble in benzene and chloroform, but soluble in alcohol, acetone and water.

Functions: It is a constituent of co-enzyme $A$ which helps in the transfer of the acyl radical.

Deficiency symptoms: The deficiency of pantothenic acid causes: a characteristic gait called "goose stepping" in pigs. The growth rate is retarded. There is diarrboea, loss of hair and dermatites in pigs. In chicks, growth is reduced with skin lesions. In mature birds, egg production and hatchability are reduced.

Sources: It is widely distributed and present in all living cells. Liver, egg yolk, brewers yeast and molasses are rich sources. Cereal grains, their by-products and leafy green plants are also good sources.

Niacin (Nicotinic acid)

It is also known as the antipellagra factor. Chemically, It is also known as the antipellagra
it is a derivative of pyridine and has the formula C6 H5 $02 \mathrm{~N}$.
It is soluble in water. Ni cotinamide is the amide derivative of nicotinic acid and has the formula $\mathrm{C} 6 \mathrm{H} 6 \mathrm{O} 02 \mathrm{~N}$. In the body, nicotinamide is the physiologically active form of the vitamin. 
Functions: Ni cotinamide is found in co-enzymes I or II. They function in the oxidation reduction system by accepting the hydrogen atom from substrates and trasforring this to other hydrogen acceptors. Nicotinic acid can be synthesized from tryptophan.

Deficiency symptoms: In human beings, the deficiency of niacin causes pellagra. In pigs, it causes poor growth, enteritis, skin lesions and diarrhoea. In poultry the deficiency causes black tongue. Chicks show signs of poor growth and feathering, diarrhoea and dermatitis.

Sources: It is well distributed in nature. Brewers

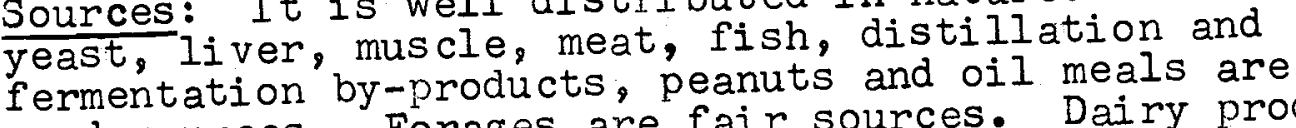
good sources. Forages are fair sources. Dairy producta and eggs are extremely low in niacin. In cereals, the niacin present is not in a form available to animals.

\section{Inositol}

Inositol is not considered essential in diets. Its classification as a vitamin is still disputed by some nutritionists.

Inositol exists in nine forms. It is a cyclo-hexane Inositol exists in nine forms. It is a cyclo biological
compound, with only myo-inositol demonstrating any biologity.

Function: The function of inositol is not completely understood. It is known to be a lipotropic agent similar to that of choline. Inositol also stimulates peristalsis in dogs.

Deficiency symptoms: Most deficiencies of inositol in animals have resulted from the feeding of purified diets. Deficiency symptoms closely resemble those of vitamin $B 6$ and pantothenic acid.

Sources: Inositol is present in adequate amounts in most animal feeds. It is also produced to a limited extent by intestinal mi croflora. High concentrations of inositol skeletal muscle. 
Biotin

Biotin, like the vitamin thiamine, contains the element sulphur, the general formula being $\mathrm{ClO} \mathrm{H} 16$ o $3 \mathrm{~N} 2 \mathrm{~S}$. It is soluble in water and alcohol, but insoluble in ether, chloroform and acetone. Exposure to light and heat does not, reduce biotin activity, but strong acids and acidic and basic solutions can destroy it.

Functions: Its physiological functions are not fully known. Biotin acts as a component in the mechanism of transferring CO2 from one compound to another.

Numerous carboxylation and decarboxylation reactions are involved in carbohydrate, lipid, and protein metabolism.

Deficiency symptoms: In all animals, a deficiency of biotin will depress growth and cause loss of hair and a dermatitis diseases in poultry and pigs. Deficiency diseases can be induced in these animals by feeding sulphadrugs or the raw white of eggs; the latter contains an antimetabolite, avidin, which inactivates biotin. By cooking the eggs, avidin is denatured and the biotin from egg is made available.

Sources: It is widely distributed in feeds and fodders. Animal organs like the liver and eggs, peanuts, yeast, whole grain and molasses are good sources of biotin.

\section{Folic Acid}

Folic acid is also known as vitamins $B 10$ and Bll. Folic acid contains three basic components, namely Elutamic acid, para-amino benzoic acid and a pteridine nucleus. This vitamin has a number of biologically active derivatives besides folic acid. This compound is rather insoluble in water and totally insoluble in fat solvents. It is soluble in absolute alcohol.

Function: The primary role of folic acid is to facilitate single carbon transfer and metabolism. Through this process, folic acid aids in (1) the interconversion of serine and glycine, (2) the synthesis of purines, (3) histidine degradation and (4) the synthesis of methyl groups for compounds such as choline. 
Deficiency symptoms: The deficiency of folic acid causes nutritional anemia and poor growth. In farm animals, folic acid is synthesized by either the rumen or intestinal bacteria. Therefore deficiency does not occur. In chicks, poor feathering and a lass of pigmentation of feathers occur.

Sources: It is present in fairly good amounts in leafy vegetables, yeast, cereal grains and liver.

\section{Choline}

The classification of choline as a vitamin is questionable since it can be replaced in the diet by other compounds. It is a simple compound with three labile methyl groups which can be transferred to other organic compounds.

Functions: Choline is an essential part of the structural phospholípids leeithin and sphingomyelin. Choline is closely associated with fat metabolism and fat transport.

Deficiency symptoms: A deficiency of choline causes growth retardation, fatty livers, reproductive failure, kidney hemorrhage, abnormal gait in pigs, perosis (slipped tendon) in chicks, lowered egg production in poultry and high mortality in the event of severe deficiency.

Sources: Choline is present in all common foods. It is produced by the tissues and is also produced by mi crobial synthesis in the mumen and intestines.

\section{Vitamin B12}

It is also known as cobalamin, cynocobalamin and animal protein factor. The emperical formula is $663 \mathrm{HBd} 014 \mathrm{~N}_{4} 4 \mathrm{PCO}$. The various forms of cobalamin are cynocobalamin, nitrocobalamin and hydroxycobalamin. It is soluble in al cohol and water but insoluble in fat solvents. It is unstable in heat and light and susceptible to destruction by acids and bases. 
Functions: The role of vitamin $\mathrm{Bl} 2$ is closely inter-related with that of other vitamins like choline, folic acid and pantothenic acid, acting primarily in the synthesis of labile methyl goups. Vitamin Bl2 is also a component of various enzyme systems and is also involved in propionic acid metabolism.

Deficiency symptoms: Vitamin BI2 is normally synthesized by the mi cro-organisms in paunch of ruminants and the cecum of non-ruminants. For this synthesis cobalt is essential in feed; without cobalt, Bl2 will not be synthesised. Hence there is no need to supply BI2 to ruminants if small amounts of cobalt are supplied or are present in the feed. Deficiency of $\mathrm{Bl} 2$ in animals causes depressed growth and neurological disorders like an abnormal gait.

Sources: Most animal products and yeast are rich in Bl2.

\section{Vitamin C (Ascorbic Acid)}

Vitamin $C$ occurs as such in nature or in the oxidised form of dehydro-ascorbic acid.

It is water soluble and heat stable in acidic solutions, but is quickly broken down in alkaline solution. Oxidation is hastened by exposure to light.

Functions: Vitamin $C$ is involved primarily in the formation capillary walls, connective tissue and the mechanism of wound repair. Vitamin $C$ is involved in the metabolism of the amino acids tryptophan, tyrosine and phenylalanine. Vitamin C is concerned with various oxidation reduction reactions in living cells. Ascorbic acid is dietary essential for primates and guinea pigs. In otheer animals ascorbic acid is synthesized by rumen mi cro-organisms. In man, its deficiency causes scurvy and bleeding of the gums.

Deficiency symptoms: The deficiency of vitamin $C$ causes scurvy. The bones become weak, teeth become loosened and fall out, the capillaries become fragile and break and anemi a may occur in infants. 
Sources: Citrus fruits are the best source of vitamin $C$. Green leafy vegetables, potatoes and tomatoes are also excellent sources. 


\subsection{Digestion, Absorption and Metabolism of Nutrients}

The chemical composition of feeds and fodders tell us about the characteristics of feedstuffs. But it does not indicate their nutritive value, since the digestibility and utilization of the various nutrients present in the feed are different for the different species of animals. Feedstuffs are a mixture of nutrients such as protains, fats, carbohydrates, minerals, vitamins and water. The organic components are in the form of large insoluble molecules which have to be broken down into simpler compounds before they can pass through the mucous membrane of the alimentary canal into the blood and lymph. This breaking down process is termed Digestion. It includes all the activities of the alimentary canal and its associated glands. The passage of digested nutrients through the mucous membrane is termed Absorption. The utilization of these nutrients by the animal body and the excretion of the end products;

from the body is termed Metabolism.

The important processes in digestion may be grouped into mechanical, chemical enzymatic and mi crobial. The mechanical activities are mastication and muscular contractions in the alimentary canal. Chemi cal/enzymatic digestion is carried out by enzymes secreted into the lumen of the gastro-intestinal tract by the various glands. The microbial digestion of food, also enzymatic, is brought about by the enzymes secreted by bacteria and protozoa present in the gastro-intestinal tract. Microbial digestion is more important in ruminants, where cellulose, hemi cellulose, etc., are digested in the rumen. In ruminants mi crobial digestion precedes the enzymatic digestion in the alimentary tract wherea in other herbivores (horses), microbial fermentation takes place in the posterior part of the digestive tract.

\section{Alimentary canal}

The organs of digestion are the parts of the digestive tract or alimentary canal, extending from mouth to anus. This varies for different farm animals, which are classified as (a) monogastric and avian animals and (b) ruminants.

\section{a. MONOGASTRIC AND AVIAN ANIMALS}

Digestion: The various organs of digestion are the mouth, pharynx, esophagus, slomach, small intestine and large intestine. However, there are major differences in the anatomy and physiology of the organs of the digestire tract of various animal speeies. In the horse, guinea pig and rabbit, the cecum and colon are extremely large and contain a large population of microorganisms. Birds 
and poultry have no teeth and so thete is no chewing. In poultry, the esophagus leads to the crop, from there to the proventriculus (glandular stomach) and then to the gizzard(a very muscular organ). The alimentary canal further continues as the small intestine, cecae and the large intestine. The digestive systems of the horse and fowl are shown in Figures 4 and 5 . 
Fig. 4

DIGESTIVE TRACT OF HORSE

(9)

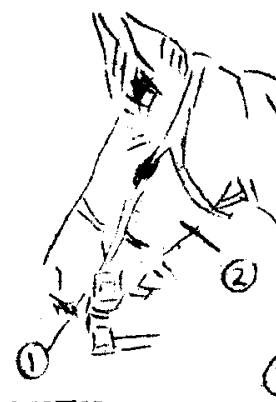

1. MOUTH

2. PHARYNX

3. ESOPHAGUS

4. STOMACH

5. SMALL INTESTINE

6. CECOM -

7. DORSAL COLON

8. VENTRAL COLON

9. RECTUM

10. ANOS

11. SPLEEN

12. LIVER

(1)

(4)

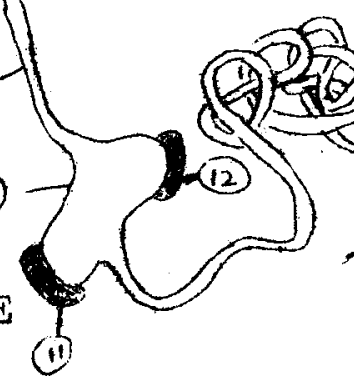

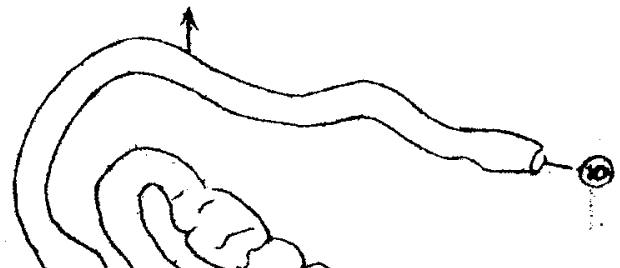

(1)
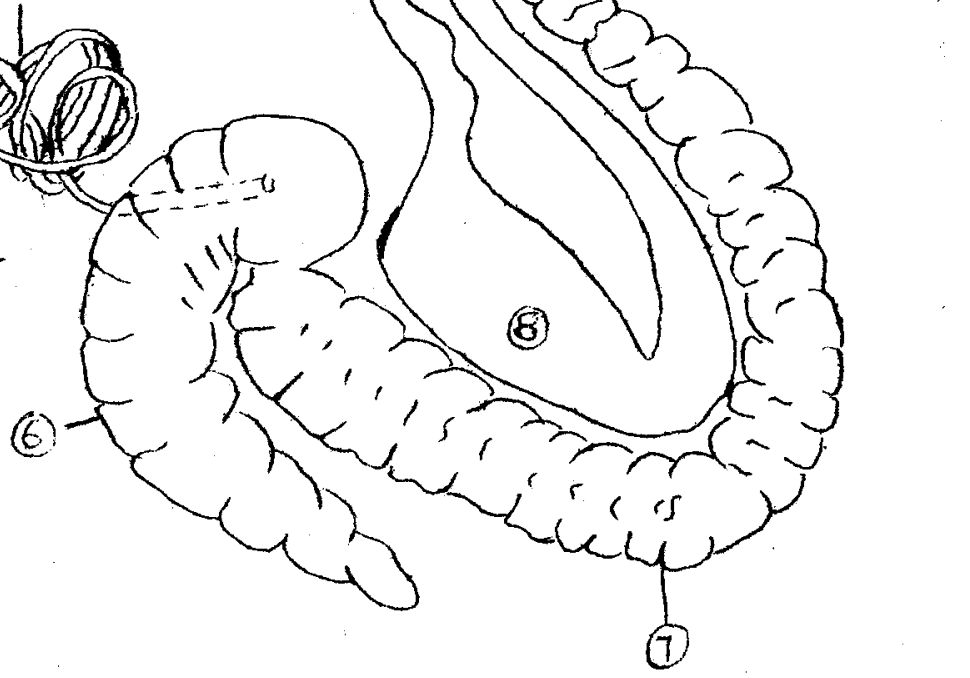

Fig. 5 DIGESTIVE TRACT OF FOWL

(1)

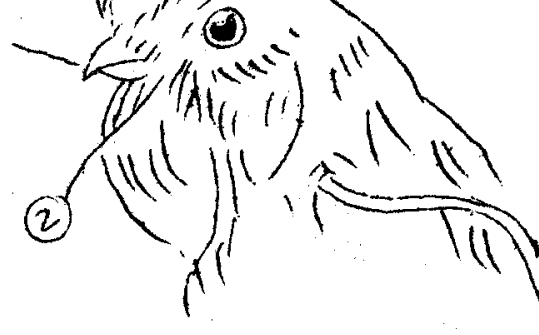

1. BDAK

2. TONGUE

3. ESOPHAGUS

4. CROP

5. PROVENTRI CULUS

6. GIZZARD

7. DUODENUM

8.. SMALL INTESTINE

9. LARGE INTESTINE

10. CLOACA

11. CECA

12. LIVER

13. GALL BLADDER

14. PANCREAS

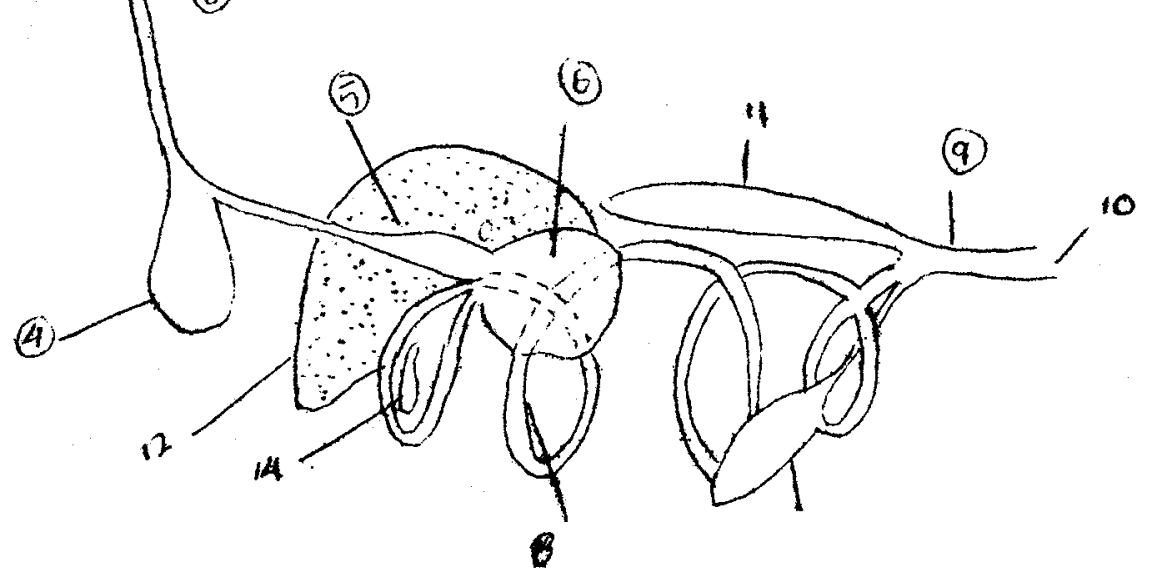


The Mouth: In the mouth the digestion is normally mechanical, that is, food is broken down into smaller particles and mixed with saliva, which acts as a lubricant. Horses use their lips for prehension. Dogs and cats hold food down with their fore limbs, and bring it to their mouths by movements of head and jaws.

Mastication of food varies in different species depending upon the physical structures of the mouth and teeth, and the kind of food being eaten: Horses can chew the large kernels of oats and corn, but not the small kernels of wheat and milo. Carnivorous animals often swallow large chunks of meat with little mastication. Poultry have no teeth and they swallow their food whole. Any grinding is done by the action of the grit in the bird's gi zzard.

The secretion of saliva by the salivary glands varies: from animal to animal. In the horse the stimulus of mastication is necessary for the secretion of saliva. In humans: and dogs, the reflex is active at the sight of food. Sheep secrete 2 to 3 litres, while ponies and horses secrete 10 litres a day.

In addition to its function as. Iubricant, saliva contains the enzyme ptyalin (d-amylase) which splits the glucosidic linkages in carbohdrates. The saliva of most monogastric animals, except the horse, cat and dog, contains d-amylase.

The esophagus is the tube through which food passes from the mouth to the stomach.

The Stomach: The horse has a relatively small stomach, about half the size of that of an adult cow Non-ruminants such as the kangaroo, hamster, hippopotamus and certain primates like the langoor and monkeys have voluminous compartmentalised or sacculated stomachs that serve as the primary site of mi crobial activity. The inner surface of the stomach is increased in area by an infolding of the epithelium and contains a variety of secretory cells which collectively secrete the gastric juices. The presence of food in the stomach stimulates secretion of gastric juice. In the chicken and turkeys, the esophagus empties directly into the crop, where the food is stored and soaked. The food passes from the crop through the proventriculous, an enlarged glandular portion, where digestive juices are copiously secreted and mixed with the food as it passes through to the gizzard, a very muscular organ which normally contains stones or grit that aid in grinding hard seed and grains before they move on into the small intestine. Gastric juice consists mainly of water, with inorganic salts, mucus, hydrochloric acid, the "intrinsic factor" 
important for the efficient absorption of vitamin $\mathrm{Bl} 2$ and the enzyme precursor pepsinogin. The acid concentration of gastric juice is about $0.1 \mathrm{~N}$, which brings the $\mathrm{PH}$ to about 2.0, which activates the pepsinogin to pepsin. Pepsin also has a strong clotting action on milk, as rennin in calves.

Very small quantities of lipase are also secreted in the stomach, but due to the acidity, are unable to hydrolyse fats.

The small intestine: From the stomach the food enters the small intestine, where secretions from duodenal juice, pancreatic juice, sucus entericus and bile are mixed with it. The duodenal secretions do not contain any enzymes, but they lubricate the food material and protect the mucosa from the strong acids entering from the stomach.

The pancreatic juice, secreted by the pancreas enters the intestine through the pancreatic duct. It contains - amylase, lipase, trypsinogen.

Chymotrypsinogen, procarboxypeptidase and inorganic salts like sodium carbonate. The pancreas is stimulated by many factors, especially secretin hormone, to secrete juice. Trypsinogen is converted into trypsin by an enzyme, enterokinase, present in sucus entericus. Trypsin activates chymotrypsinogen and procarboxypeptidase into chymotrypsin and carboxypeptidase respectively. All these enzymes hydrolyse proteins.

Lipase secreted by the pancreatic juice hydrolyses fats into monoglycerides and fatty acids. $\alpha$-amylase hydrolyses starch and glycogen to glucose, maltose and short chain dextrins.

Succus entericus juice contains lipases, enterokinase, aminopeptidases, dipeptidases, maltase, sucrase, lactase, trehalase and oligo-1, 6-glucosidase. The hormone enterocrinin stimulates this secretion.

Bile is secreted by the liver and it does not contain any enzyme. Bile contains sodium anci potassium salts of bile acids, mainly glyco-cholic acid and taurocholic acid. Bile enters the small intestine through the bile duct. Bile helps in the emulsification of fats, whereby fats are broken down to smaller particles. Bile also helps in the absorption of fatty acids and fat-soluble vitamins. Bile is stored in the gall bladder in sheep and pigs until it is required.

The smali intestine is the principal site of absorption of most of the nutrients like ami no acids, vitamins, minerals, lipids and soluble carbohydrates. By the time the food reaches the large intestine, the hydrolysed nutrients have already been absorbed. Some of the feedstuff like cellulose, hemi cellulose and ligin cannot be hydrolysed 
efflciently by monogastric animals and passes through the large intestine which secretes only mucus and no enzyme.

The Large Intestine: The large intestine consists of the cecum and the colon. In pigs and other omnivores, there is an enlargement of the cecum and the colon. Some herbivorous animals, show great extension of the size of the cecum and colon compared with other parts of the tract. In the horse and rabbit about 60 percent of the capacity of the digestive tract is in the cecum and colon. Some birds have no ceca, while others have one or two. Extensive microbial activity occurs in the large intestine, especially in the cecum. The microbial digestion of fibre, although not as efficient as in the rumen, is extenxive in horses, guinea pigs, elephants, sea cows, grouse and many other non-ruminant herbivores. There is relatively little fibre digestion in the large intestine of many non-ruminants like the dog, chicken, cat and humans. But even in these animals some valatile fatty acids are produced, absorbed, and utilized. Large amounts of bacterial protein and vitamins are synthesized in the large intestine, is the major site of sodium absorption and an important site of chloride absorption. Potassium, phosphorus, and magnesium can also be absorbed from the large intestine. In the case of poultry (Fig. 5) there is some modification of the alimentary canal. After the mash is taken in by the bird, it is stored in the crop or diverticulam. Here the food is moistened and some microvial activity takes place, $x$-amylase secreted by the salivary glands, acts on the food. Leaving the crop the food passes, through the esophagus and comes to the proventriculus, which is a glandular stomach and has the same function as the mammalian stomach. From the proventriculus it passes to the gizzard whose a function is to grind food. From there the food passes to the small intestine and then the large intestine. The functions of pancreatic juice, small intestine and large intestine are the same as described earlier.

The digestive processes, in farm animais and poultry is summarised in Table 3 . 
DIGESTI VE PROCESSES IN FARM ANTMALS AND POULTRY

\begin{tabular}{|c|c|c|c|c|c|}
\hline Region & $\begin{array}{l}\text { Secretion } \\
\text { (Secreted by) }\end{array}$ & Enzyme & $\begin{array}{l}\text { Enzyme Acts on, } \\
\text { or Function }\end{array}$ & $\begin{array}{l}\text { End Product } \\
\text { of Digestion }\end{array}$ & Comments \\
\hline Mouth & $\begin{array}{l}\text { Saliva } \\
\text { (salivary } \\
\text { glands) }\end{array}$ & $\begin{array}{l}\text { Amylase } \\
\text { (ptyalin) } \\
\text { Maltase. }\end{array}$ & $\begin{array}{l}\text { Starch, dextrins } \\
\text { Maltose. }\end{array}$ & $\begin{array}{l}\text { Maltose and } \\
\text { dextrins. } \\
\text { Glucose. }\end{array}$ & $\begin{array}{l}\text { None in } \\
\text { ruminants } \\
\text { of minor } \\
\text { importance } \\
\text { in other } \\
\text { species } \\
\text { Saliva } \\
\text { lubricates } \\
\text { food. }\end{array}$ \\
\hline$c_{2}$ op (birds) & Mucus. & & $\begin{array}{l}\text { Lubricates and } \\
\text { softens food. }\end{array}$ & & \\
\hline$\overline{\text { men }}$ & & $\begin{array}{l}\text { Enzymes from } \\
\text { mi croorgani } \\
\text { sms. }\end{array}$ & $\begin{array}{l}\text { Cellulose, poly } \\
\text { saccharides, } \\
\text { starches, sugars, } \\
\text { fats proteins } \\
\text { (urea) }\end{array}$ & $\begin{array}{l}\text { Volatile fatty } \\
\text { acids. } \\
\text { Mi crobial } \\
\text { protein. } \\
\text { B vitamins. } \\
\text { Vitamin K. }\end{array}$ & \\
\hline $\begin{array}{l}\text { jomach } \\
\text { (abomasum) } \\
\text { in animals; } \\
\text { l oventricul- } \\
\text { us in birds } \\
\text { I rrsing } \\
\text { inimals } \\
-\end{array}$ & $\begin{array}{l}\text { Gastric juice } \\
\text { and aci ds } \\
\text { (chi efly HCI) } \\
\text { (walls of sto- } \\
\text { mach). } \\
\text { Mucus } \\
\text { Gastric juice } \\
\text { (walls of } \\
\text { stomach). }\end{array}$ & $\begin{array}{l}\text { Pepsin } \\
\text { lipase (in } \\
\text { carni vores) } \\
\text { Amylase. } \\
\text { Rennin. }\end{array}$ & $\begin{array}{l}\text { Protein. } \\
\text { Fat. } \\
\text { Milk protein } \\
(\text { casein). }\end{array}$ & $\begin{array}{l}\text { Proteoses, } \\
\text { polypeptides, } \\
\text { peptides. } \\
\text { Higher fatty } \\
\text { acids and } \\
\text { glycerol. } \\
\text { Coating of } \\
\text { stomach lining } \\
\text { and lubrica- } \\
\text { tior of food. } \\
\text { Coagulates } \\
\text { milk protein. }\end{array}$ & \\
\hline $\begin{array}{l}\text { (zzard } \\
\text { ( virds) }\end{array}$ & i & & Grinding. & $\begin{array}{l}\text { Ground foods, } \\
\text { Reduced } \\
\text { particle size }\end{array}$ & \\
\hline $\begin{array}{l}\text { I codenum } \\
\text { (small } \\
\text { Ittestine) }\end{array}$ & $\begin{array}{l}\text { Pancreatic } \\
\text { jui ce } \\
\text { pancreas) }\end{array}$ & $\begin{array}{l}\text { Trypsin } \\
\text { Chymotrysin } \\
\text { Amylopsin } \\
\text { (amylase). } \\
\text { Steapsin } \\
\text { (lipase). } \\
\text { Carboxype- } \\
\text { ptidase. } \\
\text { Collagenase. } \\
\text { Cholesterol } \\
\text { esterase. }\end{array}$ & $\begin{array}{l}\text { Proteins, } \\
\text { proteoses, } \\
\text { peptones, and } \\
\text { peptides, } \\
\text { Starch, dext- } \\
\text { rins. } \\
\text { Fats. } \\
\text { Peptides. } \\
\text { Collagen } \\
\text { Cholesterol } \\
\text { Fats }\end{array}$ & $\begin{array}{l}\text { Peptones, } \\
\text { peptides. } \\
\text { Amino acids. } \\
\text { Maltose dext- } \\
\text { rins. } \\
\text { Higher fatty } \\
\text { acids and } \\
\text { glycerol. } \\
\text { Amino acids } \\
\text { and peptides. } \\
\text { Peptides. } \\
\text { Cholesterol } \\
\text { esterified } \\
\text { with fatty } \\
\text { acids. } \\
\text { Emulsion of } \\
\text { fats(soap. } \\
\text { glycerol). }\end{array}$ & Low in \\
\hline $\begin{array}{l}\text { Sinall intes- } \\
\text { tine }\end{array}$ & $\begin{array}{l}\text { Intestinal } \\
\text { juice } \\
\text { (secreted by } \\
\text { intestinal } \\
\text { wall) }\end{array}$ & $\begin{array}{l}\text { Peptidase } \\
\text { (erepsin). } \\
\text { Sucrase } \\
\text { (invertase) } \\
\text { Maltase }\end{array}$ & $\begin{array}{l}\text { Peptides. } \\
\text { Sucrose. } \\
\text { Mal tose. }\end{array}$ & $\begin{array}{l}\text { Amino acids } \\
\text { and dipep- } \\
\text { tides. } \\
\text { Glucose and } \\
\text { fructose } \\
\text { Grucose. }\end{array}$ & $\begin{array}{l}\text { Very low } \\
\text { in mumin- } \\
\text { lants. }\end{array}$ \\
\hline
\end{tabular}




\begin{tabular}{|l|l|l|l|l|l|}
\hline & $\begin{array}{l}\text { Polynuc- } \\
\text { leotidase. }\end{array}$ & Nuclcic acid & $\begin{array}{l}\text { Mononu- } \\
\text { cleotides. }\end{array}$ & $\begin{array}{l}\text { High in } \\
\text { young } \\
\text { mammals. }\end{array}$ \\
\hline $\begin{array}{l}\text { Large } \\
\text { (ntestine } \\
\text { colon and }\end{array}$ & $\begin{array}{l}\text { Cellulase } \\
\text { from mi cr- } \\
\text { oorganisms }\end{array}$ & $\begin{array}{l}\text { Cellulose, } \\
\text { polysaccharides } \\
\text { starches, } \\
\text { sugars. }\end{array}$ & $\begin{array}{l}\text { Volatile } \\
\text { fatty acids, } \\
\text { Microbial } \\
\text { protein. } \\
\text { Bitamins } \\
\text { Vitamin K }\end{array}$ & \\
\hline
\end{tabular}




\section{Absorption:}

(i) Carbohydrates: Carbohydrates are broken down to simple sugars by the enzymes secreted in the small intestine in poultry and other monogastric animals. The simple sugars are absorbed from the small intestine into the portal blood system and then to the liver.

(ii) Fats: A part of the injested fat is hydrolysed in the intestine into mono-and diglycerides. Some of the fats are hydrolysed upto fatty acids and glycerol. The digestion mixture consists of free fatty acids, di-and monoglycerides and unsplit (or resynthesized) triglycerides, with a diameter of 0.5 microns or less. This mixture passes through the epithelium of the villus. As these hydrolysed and unhydrolysed fragments pass through the outer border, the body and the basal membrane of the mucosal columnar epethelial cells of the villus, the free fatty acids are conveyted to triglycerides. In this resynthesis the free fatty acids combine with either simultaneously absorbed mono-or diglycerides or with the endogenous glycerol precursor. Dietary glycerol does not participate in resynthesis. Phospholipids are also synthesi zed here from a phosphorylated base, triglycerides and endogenous glycerol precursor.

The chylomicrons, preformed or synthesized in the wall of the villus, are transferred mainly to the lacteal, where they enter the lymph and are transported to the thoracic duct and then to the main blood stream. (iii) Proteins: The main products of protein digestion are amino acids, which are absorbed from the small intestine to the portal blood and thence to the liver. (iv) Minerals: The absorption of mineral elements from the digestive tract is governed by many factors, but principally by the solubility of the element in contact with the absorbing mernbrane. The absorption of individual minerals has been dealt with earlier. However it is briefly summarised again here. The absorption of calcium and phosphorus is promoted by vitamin $D$. An excess of calcium interferes with the absorption of phosphorus and vice versa. Phosphorus containing phytic acid forms insoluble calcium and magnesium salts which are unavailable to the animal. The presence of oxalic acid in plants forms insoluble calcium oxalate. The deficiency of iron causes anemia. Iodine in organic combination is less well absorbed than in the inorganic form.

Vitamins: Vitamin A is more readily absorbed from the digestive tract than its precursor carotene. The main site of carotene absorption is the small intestine. The absorption of vitamins $D, E$ and $K$ is governed by the 
presence of bile. The absorption of vitamin Bl2 is dependent on the presence of an "intrinsic" factor secreted by the stomach.

\section{Metabolism}

The hydrolysis products of digestion are absorbed through the alimentary tract into the blood stream and distributed to the cells of the body where they undergo chemical changes. The utilization of nutrients and the excretion of end-products in the body are the processes of metabolism. Metabolism includes the energy requiring syrithesis of new complex organic compounds similar to those digested in the alimentary tract, and energy releasing degradation of absorbed nutrients to such simple end-products as carbon dioxide and water. The first aspect of metabolism is known as anabolism, while the second is called catabolism.

Metabolism of carbohydrates: The most important function of carbohydrates is to provide energy to the animal body. This is provided when they are burnt to carbon dioxide and water. One gram molecular weight $(180 \mathrm{~g})$ of hexose yields $686 \mathrm{kcal}$ of heat when burnt to $\mathrm{CO}_{2}$ and water:

$$
\mathrm{C}_{6} \mathrm{H}_{12} \mathrm{O}_{6}+6 \mathrm{O}_{2}-6 \mathrm{CO}_{2}+686 \mathrm{kcal}
$$

Most of the energy released by oxidation in the cell is stored in the form of high energy bonds, particularly those found in adenosine triphosphate (ATP).

The degradation/synthesis of carbohydrates in cells is done by a number of enzymes which are mostly specific. There are a number of pathways in motabolism, but the three prominent sequences are (i) glycolysis, (ii) the citric acid cycle and (iii) the pentose phosphate pathway.

Metabolism of Fat: Most of the dietary lipids enter the lacteals as chylomi crons, and fatty acids and glycerols resulting from the complete hydrolysis of triglycerides. The liver is the key organ in both tranport and utilization of triglycerides. The lipids in the blood may arise either from the intestinal absorption of dietary lipids or from the mobilization of stored fats in the body, or they may come from synthetic processes in the liver. Fats may also be synthesized from non-lipid sources, as both fatty acids and glycerol can be produced in the body from carbohydrate sources also. 
Metabolism of protein: Dietary proteins are digested through the action of proteolytic enzymes to amino acids. These amino acids are aborbed through the small intestine into the portal blood. They are transported to the liver and then to the systemic blood system.

In the blood there is an amino acid pool which is in dynamic equlibrium with the tissue amino acids, which are in turn constantly incorporated into, and released from, the fixed proteins of animal tissues. The amino acids of the blood pool serve as a major source for tissue protein synthesis. Excesses of amino acids not raquired for synthesis of tissues, proteins, hormones, enzymes, etc., are catabolised by the liver. The catabolism of amino acids involves deamination whereby ammonia and $x$-keto acids are formed. The released ammonia is converted into urea, or may be utilized by $x-k$ eto acid to form amino acid.

Most of the amino acids absorbed from the intestine are used for the synthesis of proteins. All essentiall amino acids must be present in adequate amounts, and right proportions in the blood pool for synthesis. There is no storage of protein similar to the storage of fat and carbhydrates in the form of glycogen. Nevertheless, small amounts of protein are deposited in the body tissues. An increase of blood plasma level and an increase in size of the liver, kidney and other tissues after high proteln feeding presumably arises from the accumulation of newly synthesized proteins.

Essential amino acids: There are eight amino acids which are completely indispensable for growth in all animals. Since animal tissues cannot synthesize these amino acids, they must be supplied in the diet to meet metabolic requirements. These are arginine, histidine, isoleucine, lysine, leucine, methionine, phenyi alanine, threonine, tryptophan and valine.

\section{Ruminants}

Digestion: The various organs of digestion are the mouth, esophagus, stomach (rumen, reticulun omasum and abomasum), small intestine and large intestine-cecum, colon and rectum.

The digestive system of the cow is shown in Fig. 6. 
Fig. 6

DIGESTI VE TRACT OF COW

1. MOUTH

2. OESOPHAGUS

3. RUMEN

4. RETI CULUM

5. OMASIUN

6. ABOMASUM

7. DUODENUM

8. SMALL INTESTINE

9. CAECUM

10. COLON

11. RECTUM

12. ANUS

13. IIVER

14. BILE DUCT

15. GALI BLADDER

16. FAN CREAS
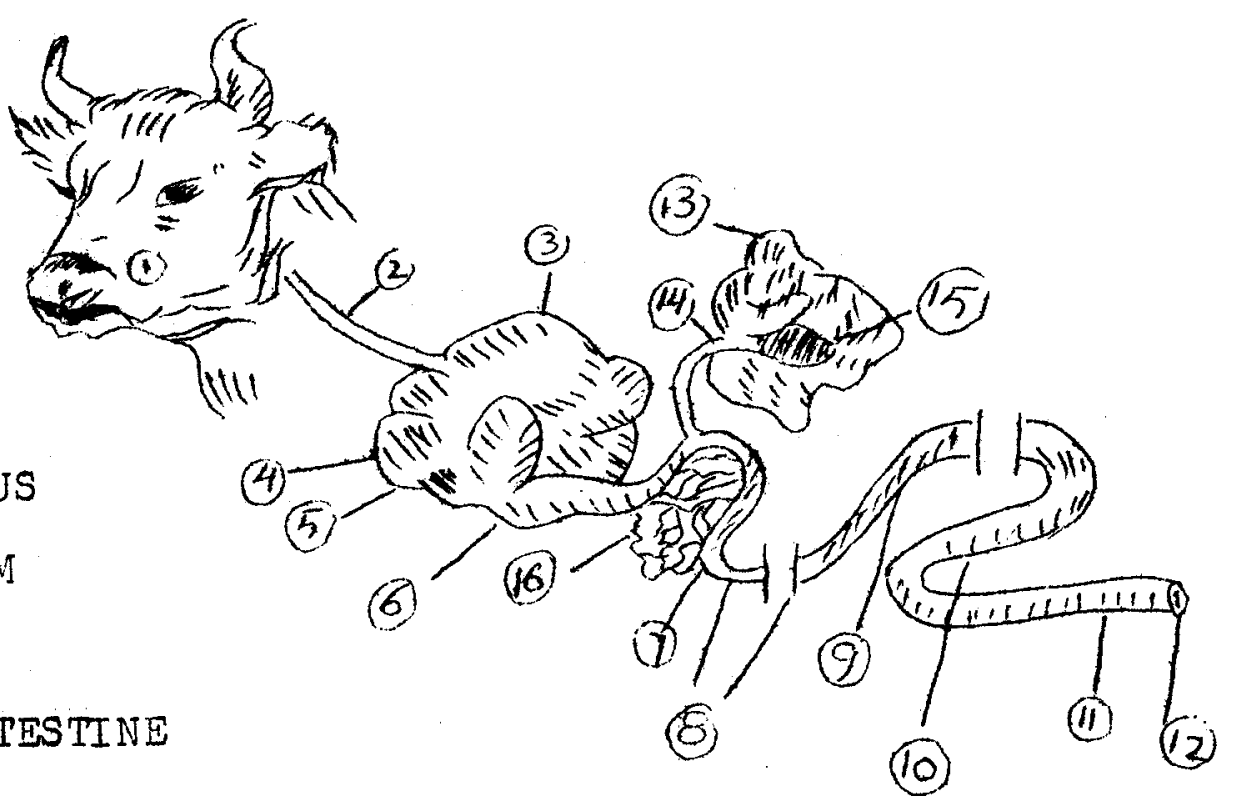
The mouth: The relative importance of the mouth and its components (teeth, tongue, cheeks and salivary glands) varies with species. In most species, the functions. of the mouth are to bring in feed mechanically, to break it up and mix it with saliva, which acts as lubricant to facilate swallowing. Ruminants use mainly the tongue for prehension. The mastication of food is done in the mouth. Riuminants thoroughly grind the grass or the forage consumed by them. The major part of grinding is done during rumination when the boluses are regurgitated and remasticated. Some ruminants, like cattle, swallow small grains with very little chewing; hence the grains should always be crushed/ground, when fed to cattle.

In ruminants, the saliva is secreted continuously. Cattle secrete about 130 to 180 litres saliva per day. The esophagus is the tube through which the food passes from the mouth to the rumen.

The stomach: In ruminants, there are four parts of the stomach, namely the rumen, reticulum, omasum and abomasum. The rumen and reticulam have more than 50 percent of the total capacity of the digestive tract of the alimentary canal. The four compartments hold 60-65 percent of the total volume of food, compared to 25 percent by the small intestine and 10 percent in the large intestine and less: than 5 percent in the cecum. The food is diluted with copious amount of saliva, both when it is eaten and during rumination. The breakdown of food is accomplished partly by physical and partly by chemi cal means. The contents of the rumen are continually being mixed by rhythmi c contractions of its walls and, during rumination, material at the anterior end is drawn back into the esophagus and returned by a wave of contracttion to the mouth. Any li quid is rapidly swallowed again, but coarser material is: thoroughly chewed before being returned to the rumen. Grazing cattle ruminate about $\&$ hours a day. The actual time depends upon the fibrous content of the feed. If the feed contains little or no coarse roughage, it may fail to provide sufficient stimulation for rumination.

The rumen and reticulum form a fermentation vat into which the food enters. The chemi cal breakdown of the food is brought about by the enzymes secreted by the bacteria and the protozoa. The products of chemical breakdown or fermentation are absorbed by the rumen of the host animal for its own needs and the food leaving the rumen is a mixture of food residues, some fermentation products, bacteria and protozoa. There is a continuous flow of secretion through the salivary glands in the rumen and a continuous outflow of digesta through the reticulu-rumen to the omasum. Since food remains for a considerably long 
time in the rumen, any freshly eaten food also mixes with the previous meal.

Rumen micro-organisms play three important functions. They degrade complex polysaccaharides like cellulose and hemi cellulose to volatile fatty acids, whi ch supply 55-60 percent of the energy needs of the host animal. They synthesize all the essential amino acids required by the host animal for metabolism. The mi crobes also synthesize the vitamin $B$ complex required by the host animal.

The combined contractions of rumen and reticulam are instrumental in washing finer particles of food through to the omasum. Hers, water is absorbed from the digesta before it enters the abomasum, which is the true stomach. Gastric juice containing pepsin is secreted in the abomasum. From the abomasum onwards the process of digestion and absorption are similar in ruminants: to those in monogastric/simple stomached animals.

Digestion of carbohydrates in the rumen: The major portion of the ruminant diet consists of polysaccharides or structural carbohydrates like cellulose, hemicellulose, pentosans and other carbohydrates which cannot be hydrolysed by the enzymes secreted by these animals in the digestive tract. Other carbohydrates like starch, fructosans etc., are also taken in by the animals. About 70-75 percent of the digestible organic matter of normal diets is digested by the rumen mi cro-organisms with the production of volatile fatty acids, carbondioxide and methane.

Soluble carbohydrates are rapidly fermented, starches. are less rapidly fermented, while structural carbohydrates like cellulose and hemicellulose are slowly fermented. The presence of lignin, which forms a ligno-cellulose complex, reduces the quantity of cellulose digestion, as the enzymes, secreted by the mi cro-organisms are unable to break down the lignin. As the plant matures its lignin content increases; tree leaves, straws etc. are rich in lignin. In spite of the composition of the carbohydrates ingested, they are broken down to volatile fatty acids like acetic, propionic and butyric acid. Higher fatty acids like valeric and isovaleric acid are also formed in smaller amounts. The acetic acid is predominant and represents 60 to 70 percent, proponic acid, 15 to 20 percent, butyric acid 10 to 15 percent, of the fatty acid mixture. On an excluslvely roughage diet, the production of acetic acid is the highest. As the concentrates in the diet are increased, the proportion of acetic acid reduces and that of proponic acid increases. Lactic acid is also formed as an intermediary product, but is fermented to acetic and propionic acids. 
Digestion of Fats in the Rumen: Fats are hydrolysed to fatty acids and glycerol. The glycerol is fermented to propionic acid. The unsaturated fatty acids are hydrogenated by rumen mi cro-organisms.

Digestion of protein in the rumen: Rumen mi cro-organisms produce proteolytic enzymes which hydrolyse dietary proteins to peptides and amino acids which are further fermented by deamination to carbon dioxide, ammonia and short chain fatty acids. Some of the amino acids are directly utilized by the bacteria for their own body synthesis. However, ammonia is the major soluble nitrogenous constituent in the rumen liquer, part of it being utilized by rumen bacteria along with carbon moiety to synthesize microbial proteins.

The proportion of dietary protein hydrolysed in the rumen depends on a number of fctors like the solubility and quantity of the protein. On a normal diet, about 50-60 percent of the protein is attacked by the mi cro-organisms. In some cases the protion degraded by the mi cro -organisms may be higher or lower. Therefore, the quality and quantity of amino acid mixture eventualy absorbed from the gastro-intestinal tract will depend on the balance of rumen activities.

\section{Digestion of non-protein nitrogenous compounds:}

Ruminants can utilize non-protein nitrogenous compounds such as urea, biuret etc., as a source of protein through the micro-organisms. Urea and biuret is broken down in the rumen into ammonia and carbon dioxide by the enzyme urease secreted by the micro-organisms. This ammonia is used as a nitrogen source by rumen mi cro-organisms for synthesis of microbial proteins, along with a carbon skeleton coming from the carbohydrate/proteins. Supplementation of urea diets with rapidiy available carbohydrates like starch and molasses enhances the utilization of urea nitrogen.

\section{Absorption}

Carbohydrates: Most of the volatile fatty acids are absorbed directly from the rumen, reticulum and omasum. Small amounts may pass to the abomasum and small intestine, from where they are absorbed. A portion of these volatile fatty acids 
is used by the bacteria and protozoa to synthesize their own polysaccharides or used as a carbon skeleton for the synthesis of their body proteins.

Due to the fermentation of carbohydrates by the bacteria, gases like carbondioxide and methane are produced. Traces of nitrogen, oxygen and hydrogen are also present in the gas mixture. Most of the gases produced in the rumen are lost by eructation. Under metabolic disorders, the gas is trapped and bloat occurs. In acute cases the animal dies.

Fat: Lipids, emulsified by bile salts, are broken down by lipase to monoglycerides and fatty acids in small intestine. The monoglycerides and fatty acids are absorbed directly into the mucosa after the small intestine and are transported to the portal circulation.

Protein: The major portion of the ammonia produced in the rumen is absorbed through the ruminal wall into the portal blood and is carried to the liver, where it is converted into urea. The greater part of the urea is excreted in the urine although a part of it is returned to the rumen via saliva or the ruminal wall.

The ami no acid mixture produced by micro-organisms is absorbed through the intestinal villi into portal circulation, and carried to the liver, where they enter its amino acid pool.

Minerals: Mineral absorption occurs throughout the small and large intestine.

Vitamins: Most of the vitamins are absorbed in the upper portion of the intestine with the exception of vitamin $\mathrm{B}_{12}$, which is absorbed in the ileum.

\section{Metabolism}

Carbohydrates: The larger proportion of di etary carbohydrates is fermented in the rumen to acetic, propionic, butyric and a small amount of higher volatile fatty acids (valeric and isovaleric acid etc.). Acetic and propionic acid are 
absorbed almost as such through the rumen wall into the portal circulation; butyric acid is converted to beta-hydroxybutyric acid. (BHBA) across the rumen wall and diffuses into the portal blood, from where all these acids are carried to the liver. Propionic acid is converted into glucose in the liver. Part of the glucose is further converted into glycogen, stored and partly converted to L-glycerophosphate which is used for synthesis of triglycerides. The residual glucose enters the blood pool and is transported to different body tissues, where it may be utilized as a source of energy, as a source of reduced co-enzymes in the synthesis of fatty acids and for the synthesis of muscle glycogen.

Lipids: Dietary lipids as such, or altered in the rumen, enter the lacteals as chylomicrons ( $500 \mathrm{~m} \mu$ in diameter) and then diffuse to the venous blood via the thoraxic duct. A small amount of dietary triglycerides may be hydrolysed to low fatty acids and glycerol in the digestive tract and directly absorbed into the portal blood system. The liver is the key organ in both transport and utilization of triglycerides.

Proteins: Amino acids, from their pool in the liver, are either used for synthesis of protein or may enter the systemmatic circulation and join the amino acids produced from the disintegration of tissue cells during catabolic processes. These amino acids are mainly utilized for synthesis of protein of different tissue systems in various organs, and a small fraction is utilized for the production of other biologi cally important compounds like hormones and enzymes. Exoesses of amino acids are carried to the liver, where they are broken down to keto acids and ammonia. 


\section{CHAPTER 2. Animal Feeds}

2.1 Feeds and Fodders- the classification of Feedstuffs/ 69

2.1.1 Forages/ 71

2.1 .2 Concentrates/ 92

2.1.3 Protein Supplements/96

2.1.4 By-product Feeds and Crop Residues/ 100

2.1.5 Supplements, Additives and Implants/ 104

2.2 Feed Processing Methods/ 109

2.3 The Effects of Storage on Feedstuffs/ 112 
2.1 FEEDS AND FODDERS

Feeds are naturally occurring ingredients or materials fed to animals for the purpose of sustaining them. A feedstuff is any product, of natural or artificial origin, that has nutritional value in the diet when properly prepared. There are various types of feedstuffs available for the feeding of livestock. These feedstuffs can be grouped into different classes on the basis of bulkiness and chemical composition.

Roughages and concentrates: The first broad grouping of feedstuffs is based on bulkiness, which is dependent on the content of crude fibre present. Roughages are feedstuffs which are bulky and contain more than 18 percent of crude fibre. They are relatively low in the concentration of energy yielding nutrients. These roughages are straws, green fodders, hays, silages, hulls, shells etc. Roughages may be dry or green. They can be further grouped into maintenance quality, containing about 3 to 5 percent digestible crude protein (DCP), non-maintenance quality, containing below 3 percent DCP, and productive type, containing more than 5 percent DCP on dry matter basis. The maintenance type of roughages are green maize, green sorghum and green oats. The non-maintenance type of roughages are wheat straw, rice straw, maize straw, jowar (sorghum) straw and millet straw, The productive type of roughages are berseem, lucerne, oow peas and alfalfa. The terms forage, fooder and roughage are used interchangeably by many people and in many countries.

Concentrates: The concertrates are broadly divided into three categories. The first category includes those concentrates which are rich in energy and low in DCP (carbonaceous). eg., cereal grains like wheat, barley, maize, sorghum etc. In the second category are concentrates that are very rich in digestible crude protein, eg.s ground nut cake, sesame cake and cotton seed cake. These are also called proteinous concentrates. The third category is in between, with medium range protein and energy concentrations, like brans and chunis (chuni is a mixture of husk, germ and small pices of endos perm). Fish meal, meat meal and frog meal are also called concentrates. 


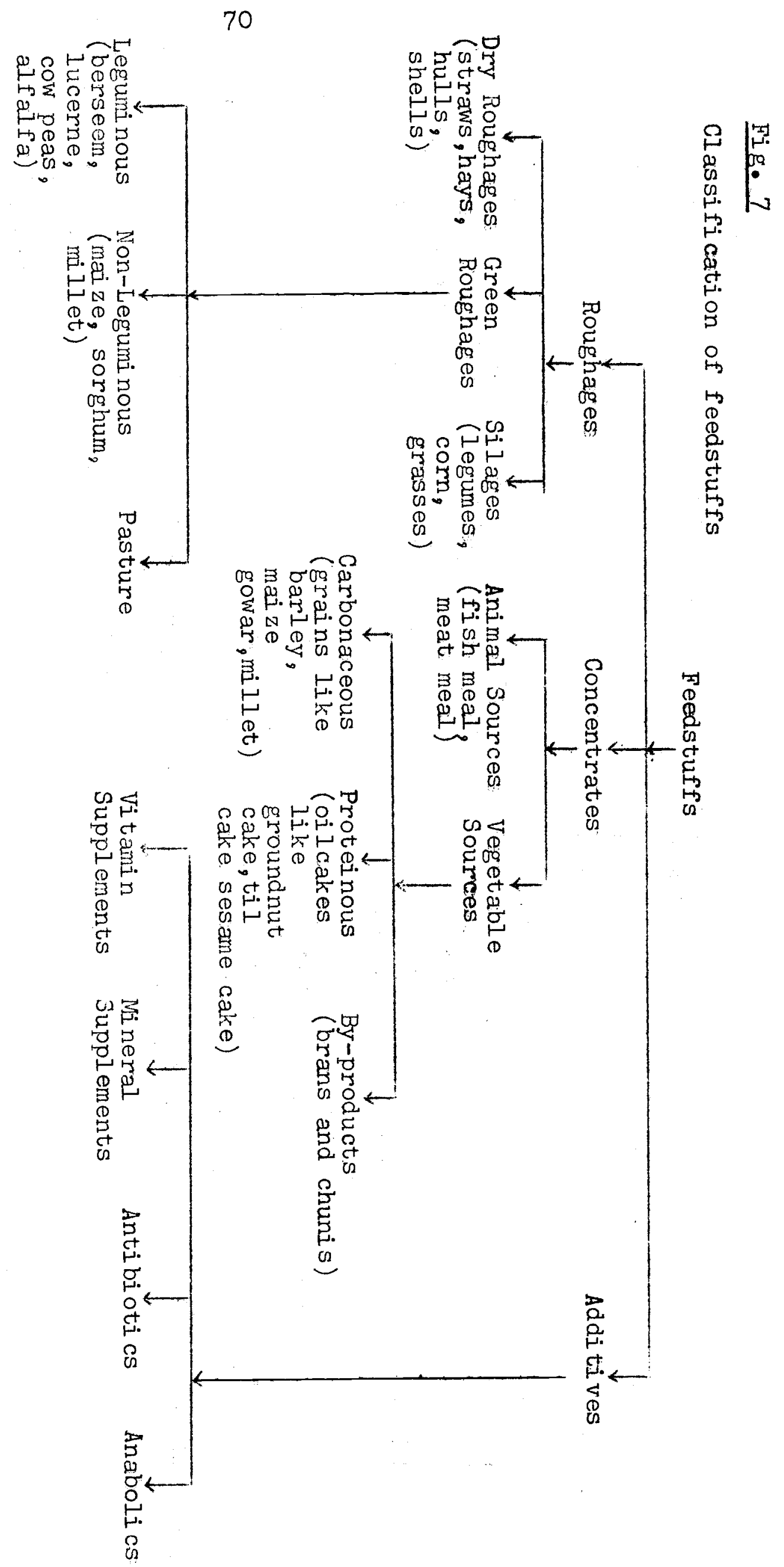


2.1.1 Forages. Forage is defined as vegetable material in a fresh, dried; or ensiled state (pasture, hay or silage) fed to livestock. In the dry state forages average more than $18 \%$ fibre. The term roughage is often used interchangeably with forage, although roughage usually implies a coarser, bulkier feed than forage. Roughages, may be dry or green. The dry roughages are either available as by-products from the main cereal crops like wheat straw, paddystraw, jowarstraw, maize straw and millet straw, or may be specially prepared from green fodders, as in the preparation of hay. The green roughages include cultivated fodders or grasses.

Cultivated Fodders: A brief account of some of the green fodders is given below under the following heads: (i) time and method of sowing, (ii) manuring and irrigation, (iii) yield and (iv) chemical composition and nutritive value.

\section{Cowpea, Lobia (Vigna Catiang, Vigna Sinesis).}

Cowpea is an important quick-growing legume which fits well in crop rotation. It is adapted to warm summer climates. and can be grown on all types of soils, ranging from sandy loams to heavy loams, if they are well drained. It is susceptable to water logging condition. It can be sown alone or with non-legumes like jowar or maize.

(i) Time and method of sowing: If irrigation is available, this crop can be sown in February/March. The green fodder will then be availabe during May/June. As a rain-fed crop it is sown in July. The crop is generally ready in three months. The seeds are sown either by broad casting or behind the plough at $22-45 \mathrm{~cm}$ intervals. The seed rate varies from 20 to $25 \mathrm{~kg}$ per hectare, depending on the system adopted for sowing: for broad casting, the seed rate is $25-30 \mathrm{~kg}$.

(ii) Manuring and irrigation: About 50-60 quintals per hectare of farm yard manure will be sufficient for this crop. Application of 4 to 6 quintals of superphosphate per hectare before sowing greatly increases the yield.

(iii) Yield: When sown alone, the yield is 200 to 300 quintals per hectare. When mixed with jowar or maize, the yield is a little more but the nutritive value is lowered.

(iv) Chemical composition and nutritive value: The approximate chemical composition is, crude protein 18.2, ether extract 2.6 , 
crude fibre 25.3, nitrogen free extract 39.6 , ash 14.2 percent on dry basis.

The approximate nutritive value is DCP 3.5, SE 9.0, TDN $10.3 \mathrm{~kg}$ per $100 \mathrm{~kg}$ raw material respectively. Digestible energy is 0.5 and matabolisable energy $0.4 \mathrm{Mcal} / \mathrm{kg}$.

\section{Jowar (Andropogan Sorghum, Sorghum Vulgare)}

This is a kharif (Monsoon rain-fed) crop, grown both under irrigated and rain-fed conditions. It does well in hot and dry climates. It requires a well drained soil and appears susceptible to water logging conditions. It can be grown in any type of soil, but loan soils have been shown to give more yield.

(i) Time and method of sowing: The sowing is done between April and August for fodder and June and July for grains. The land is generally ploughed once with a mould board plough, followed by two ploughings with a desi plough or harrowings. When sown for fodder, the seed rate varies from 55 to $60 \mathrm{~kg}$ per hectare, and for grains, 15 to $20 \mathrm{~kg}$. It can be sown mixed with legumes like cowpeas.

(ii) Manuring and irrigation: Jowar is generally grown as a rain-fed crop. If the rainfall is between 25 and 30 $\mathrm{cm}$ during the season, no irrication is required. About $100 \mathrm{~kg}$ of nitrogen per hectare will increase the forage yield.

(iii) Yield: The fodder is ready for harvest within 70-90 days. The average yield of the fodder varies between 250 and 450 quintals per hectare.

(iv) Ghemical coposition and nutritive value: The approximate.. chemi cal composition of jowar at the prime stage of growth is, crude protein 7.8, ether extract 1.7 , crude fibre 32.3 , NFE 49.6 and ash 2.6 percent on dry basis respectively. The approximate nutritive value is DCP 1.1, SE 12.0, TDN $16.2 \mathrm{~kg}$ per $100 \mathrm{~kg}$ raw material respectively. Digestible energy is 0.71 and metabolisable energy $0.58 \mathrm{Mcal} / \mathrm{kg}$ respectively.

\section{Maize (Zea Mays)}

Maize is an important kharif crop. It requires warm and temperate climates and grows well on alluvial loam and fertile and well drained soils. The crop grows well in slightly acidic to neutral soils ( $\mathrm{pH} 5.5$ to 7.5 ). 
(i) Time and method of sowing: Sowing is done from the middle of March to the middle of September for fodder, and in July for grains in the plains and from May to June in the hills. To grow this fodder, the soil should be well prepared.

It may either be sown by broad casting the seeds or sown in rows behind the plough, the latter system is more common. When sown in lines the kernels should be dropped at a distance of $22 \mathrm{~cm}$ from row to row and the same distance should be maintaned between plants. When sown for grains, the distance between plants should be $22 \mathrm{~cm}$ and between rows $45 \mathrm{~cm}$. The seed rate is 15 to $20 \mathrm{~kg}$ per hectare for grains and about 35 to $40 \mathrm{~kg}$ for fodder.

(ii) Manuring and irrigation: Under rain-fed conditions there is no need for irrigation, but when sown in the dry season, the crop requires irrigation after every fortnight, depending upon climate and soil condition.

The application of 300 to $350 \mathrm{~kg}$ of ammonium sulphate per hectare increases the forage yield.

(iii) Yield: The fodder is ready in 60 to 70 days for fodder, but it takes about 90 to 110 days for grain production. The yield of fodcer is between 350 and 450 quintals ner hectare.

(iv) Chemical composition and nutritive value: The approximate chemical composition is, crude proti en 7.2 , ether extract 1.8 , crude fibre 30.8 , nitrogen free extract 51.6 and ash 8.6 percent on dry basis respectiveley. The approximate nutritive value is DCP 1.17 , starch equivalent 14.5 , TDN $16.9 \mathrm{~kg}$ per $100 \mathrm{~kg}$ raw material. The digestible energy is 0.74 and metabolisable energy $0.61 \mathrm{Mcal} / \mathrm{kg}$.

\section{Berseem or Egyptian clover (Trifolium al exandrium):}

Egyptian clover has migrated to many countries from Egypt. It is a proteinrich fodder and has many desirable qualities. Ten to fifteen kilograms of fodder, along with straw or other dry fodder, constitute a maintenance ration.

(i) Time and method of sowing: The crop is sown from the middle of September to the end of October in the plains and from the middle of August to the first week of September in the hills. This crop requires a thorough preparation of the land. After harvesting, of the kharif crop, the field must be ploughed once with mould board or disc plough followed by two or three harrowings and finally completed by planking. When the crop is cultivated for the first time, inoculation of the seeds with bacterial culture, just before sowing, is necessary. The seed rate of ordinary 
diploid berseem is 20 to $25 \mathrm{~kg}$ and that of giant berseem 30 to $35 \mathrm{~kg}$ per hectare. It is sown by broad cast which is then immediately followed by irrigation.

(ii) Manuring and irrigation: Like all legumes, it requires phosphatic manures. An application of $150 \mathrm{~kg}$ of ammonium sulphate, along with $500 \mathrm{~kg}$ of superphosphate per hectare at the time of sowing is nessasary for good yield. It requires irrigation after every 10 to 12 days: in early winter and every 15 days during deep winter. The crop is normally irrigated after every cutting.

(iii) Yield: The crop is ready 55 to 60 days after sowing, for the first cutting. Subsequent cuttings are made at 30 day intervals. In all, five to six cuttings can be made. The total yield of fodder may vary between 500 and 600 quintals per hectare.

(iv) Chemical composition and nutritive value: The approximate chemi cal composition (12 weeks old first cut) is, cruce protein 21.5 , ether extract 2.6 , crude fibre 20.6, nitrogen free extract 41.0 and ash 14.3 percent on dry basis respectively. The approximate nutritive value is, DCP 2.51 , starch equivalent 10.0 , TDN $11.9 \mathrm{~kg}$ per $100 \mathrm{~kg}$ of raw material.

The digestible energy is 0.52 and metabolisable energy $0.43 \mathrm{Mcal}$ per $\mathrm{kg}$ respectively.

\section{Lucerne (medi cago sativa) Alfalfa.}

This is a perennial leguminous crop. Once grown it continues to supply nutritious fodder for $3-4$ years. It is sown both as an annual and a perennial crop. The crop is generally grown in irrigated areas of dry tract and gives yi.elds in well-drained, sandy loam soils.

(i) Time and method of sowing: The best time of sowing is between early October and the end of November. The land should be prepared thoroughly like for berseem. The seed rate is between 15 and $18 \mathrm{~kg}$ per hectare. It can also be sown, like berseem, by broad casting. Unlike berseem it does not require culturing. Once the seeds are sown, the field must be irrigated immediately. Another method of sowing, esnecially when the field is not properly prepared, is to fill the land first with water and then to sow by broad casting. This operation is followed by planking.

(ii) Manuring and irrigation: An application of about $100 \mathrm{~kg}$ of nitrogen (500 kr ammonium sulphate) and $100 \mathrm{~kg}$ of $\mathrm{P}_{2} \mathrm{O}_{5}$ (700 kg of superphoshate) gives the best yields 
per hectare. It is better if half the nitrogen requirement is met with compost or farm yard manure and the other half with ammonium sulphate. Irrigation depends upon climatic and soil conditions; in the summer it is required after every 10 days, and in the winter (when taken as a perennial) after every 15 to 20 days. The crop should be irrigated after each cutting.

(iii) Yield: The first cutting is ready after 2 to 2.5 months of sowing. During the rainy season its growth is affected by other monsoon grasses.

As a perennial crop it may yield upto 1000 to 1200 quintals per hectare. When taken as an annual crop (upto June), the yield is: 700 to 900 quintals per hectare.

(iv) Chemical composition and nutritive value: The approximate chemi cal composition is, crude protein 20.2, ether extract 2.3, crude fibre 30.1 , nitrogen free extract 36.6 and ash I0.7 percent on dry basis respectively.

The approximate nutritive value is DCP 3.24 , starch equivalent

9.7 and TDN $120 \mathrm{~kg}$ per $100 \mathrm{~kg}$ raw material.

The digestible en ergy is 0.53 and metabolisable energy $0.43 \mathrm{Mcal}$ per $\mathrm{kg}$ respectively.

\section{Doob grass (cynodon dactylon)}

This is one of the best fodder grasses and is a good soil binder. It is a perennial with creeping habits. It contains about 10 to 12 percent protein and is propogated by stem and root cutting. The best sowing time is during the monsoons, but it can also be planted in the spring and Summer, when water is available.

In some strains of doob grass, the protein content may

be as high as 20 percent which, with progressive maturity, is lowered to half.

The average yield of the grass is about 300 to 350 quintals of fodder per hectare. It is an excellent pasture grass and is always found in natural pastures mixed with legumes.

\section{Clover (Melilotus parviflora)}

Clover is generally drought resistant and hence preferred as a fodder. Though a number of varieties are available, only the white and yellow varieties are used for fodder purposes. It grows well in dry and cold climates on loamy to heavy soils. 
(i) Time and method of sowing: It is generally sown from September to the end of October. This fodder can be grown in unirrigated areas, so it is better to sow the crop immediately after the harvest of the Kharif crop, so that the residual moisture present in the soil can be utilized for the germination of seeds. One ploughing, followed by two harrowings of the land are sufficient for soil preparation. The seed rate is about 20 to $25 \mathrm{~kg}$ per hectare. The seeds. are sown by broadcasting and mixed with the soil by harrowing.

(ii) Manuring and irrigation: When taken as an irrigated crop, the first irrigation may be done after 10 to 15 days of sowing and thereafter every month. Since it is a legume, it responds to phosphatic fertilizers, which are required at the rate of $250 \mathrm{~kg}$ of super phosphate per hectare before sowing for satisfactory results.

(iii) Yield: Under irrigated conditions, it gives about 300 to $\frac{150}{350}$ quntals of fodder per hectare. Under unirrigated conditions the yield is about 200 to 250 quintals.

(iv) Chemical composition and nutritive value: The approximate chemi cal composition of aerial parts is crude protein 27.8 , ether extract 3.2 , crude fibre 15.6 , nitrogen free extract 41.3 and ash 12.1 percent on dry basis respectively. The approximate nutritive value is, DCP 3.5 and TDN $12.0 \mathrm{~kg}$ per $100 \mathrm{~kg}$ raw material.

The digestible energy is 0.54 and metabolisable energy 0.44 Mcal per $\mathrm{kg}$ respectively.

\section{Pastures}

A pasture is an area of grassland on which there is growth of forage that animals may graze on. Grasslands may be divided into two main groups: natural grassland which includes rough and hill grazing and cultivated grassland which may be further subdivided into permanent and temporary pastures. The latter form part of a crop rotation, while permanent pastures are intended to remain as grass indefinitely. Natural grasslands normally include a large number of species of grasses, lagumes and herbs, whereas culti vated grasslands may consist of pure species or mixtures of a relatively small number of species. Pasture plants are classed into grass, legumes, browse and forbs. 
Chemi cal composition

The composition of pasture is very variable. Moisture content is as high as $85 \%$ in early stages of growth and as low as $65 \%$ as the plant matures. Crude protein varies from as little as $3 \%$ in very mature herbage to about $30 \%$ in young, heavily fertilized grass. The crude fibre content ranges: from $20 \%$ to as much as $40 \%$ in very mature samples. The soluble carbohydrates of grasses include fructans and the sugars glucose, fructose, sucrose, raffinose and stachyose. The total percentage varies from $4 \%$ in some varieties to $30 \%$ in some Italian rye-grasses. The cellulose content ranges from 20 to $30 \%$ while hemi celluloses vary from 10 to $30 \%$ on a dry basis.

Proteins are the main nitrogenous compounds in herbage. Grass proteins are particularly rich in the amino acid arginine, with appreciable amounts of glutamic acid and lysine. The non-protein nitrogen (NPN) fraction comprises of amino-acids and amides such as glutamine and asparagine. Nitrates may also be presient. Nitrate itself is relatively non-toxic to animals. The toxic effect on ruminants is causedi by the reduction of nitrate to nitrite in the mumen. Nitrite, but not nitrate, oxidises the ferrous iron of hemoglobin to its ferric state, producing a brown pigment, methemoglobin, which is incapable of transporting oxygen to body tissues. The toxi c symptoms include trembling, staggering, rapid respiration and death.

Toxi c symptoms may occur in animals grazing on herbage containing more than $0.07 \%$ nitrate- $N$ in the dry matter. Some authorities consider $0.22 \%$ nitrate-N a lethal dose. while others have suggested a value far in excess of this. A sudden intake of nitrate may be particularly dangerous. The mineral content of pasture is variable depending upon the species, soil type, stage of growth and fertilizer. application. The lipid content as determined in ether extract rarely exceeds $4 \%$. Green herbage is an exceptionally rich source of carotene, the precursor of vitamin $A$. Most green forage crops are good sources of vitamins $E$ and the B-vitamins, especially riboflavin. The composition and nutritive value of pasture herbage is greatly influenced by its stage of growth.

\section{Factors affecting natural grassland}

The factors affecting the local ecosystem are (i) environments like the soil and climate and (ii) biotic influences such as the natural fauna of the area, grazing by animals, firing and other changes brought about by man-clearing and cutting of jungles, etc. 
Soil: The effect of soil type on natural grassland is mostly the result of the moisture availabe to the different grass species growing in that area. The mineral content of pasture may very in different soils. The grasses sehima, dicanthium, cenchmus-di.canthium and sinidicus are associated with black suila, sardy loams and sandy soils. Saccharum grasslands, ar esent in swampy lands.

Climate: Climeto is one of the most important factors determining the ype of grassland and its botanical composition. Gconally, the wetter the climate, the more dense the cover, as in the humid tropi cs; where treeless grasslands aro corely found, except in the alpine pastures of the Himalayas. In the tropical countries, grasses like hetropogon, di conthium, imperata, andropogon, both-riochloa, cymbopogen, sacciarum, sehima, sorghum and eulalia are widely distributed. In cold and temperate countries, holcus lanatus, danthoria pilos a and lolium spp or rye grasses are found in aburdace.

Biotic influe ac Grassland fires, which have become frequent features in the popics, affect the dominance of some species. The clearing of rests by the removal of its tree cover also affectis cinposition of grassland. The botanioal compositio ot is affected by grazing.

Pasture Le um. compriag some of the more commonly grazed clovers. huceno wd alfalfa are included in this category, as are peas and $\mathrm{n}$ when grown as green fodder crops. A problem lie culy encountered in cattle and sheep grazing on legume domi... pasure is bloat, characterised by an accumulatio: of un the rumen. The primary cause of bloat is the ne.,ion of the fermentation gases in a stable foam, renting their elimination by eructation.

Browses are the cilble parts of woody vegetation, such as the leaves, steme Ex UWigs, of bushes. The quantity of forage intake throug wing depends upon the species of the animal and the cuantity of vegetation. For example goats and camels wil. lowse more than cattie, buffalos and sheep. It is therefor preferable to keep a balance of both browsers and grazers togetior in free range grazing to maintain proper ecosystem.

In arid and seidid regions of the tropics, browse shrubs and trees cowit.me a large portion of the cut and fed 
fodder for camels, goats and other herbivores. The browse shrubs and trees are various species of acacia, brachystegia, cajanus, cassia, eriosema, gleditsia, gliricida, indigofera, leucena, lonchocarpus, milletia, parkinsonia, piliostigma, prosposis, sesbania and tamar-indicus. Some common browse shrubs are ipil ipil, koo babul (leucena lucocephala), gli ricidia (gli ri cidia maculata), dadap (erythrina spp.), jharberi (zi zi phus species) and some desmodiun species.

Forbs are range herbs other than grass which animals may eat and are also called weeds.

\section{Range Forages}

Ranges are large, naturally vegetated, mostly unfeneed areas where animals may harvest a rather sparse growth of grasses, legumes, and other edible parts of forbs and browses. Nutrient deficiencies are rather common on the range. The forages are generally inadequate and result in energy, protein, mineral and vitamin deficiencies.

The following are among the advantages and disadvantages of pasture and range forages.

Advantages:

They lessen feed costs. The amount of expensive grain and protein supplements reeded can be greatly reduced. Pasture forages lessen the hazards of nutritional deficiencies. The threat of communicable disease is reduced because the animals are not in such close contact. Pastures require less capital for buildings and equipment. There is no need for highly developed skills in management as in stall feeding.

Pastures make for improved soil conservation on rolling 1 and.

Pastures and ranges provide a fairly uniform supply of feed throughout the season.

Animals get valuable exercise by grazing on pasture. A good pasture program permits the maximum use of land not suited for crop production. 
Disadvantages:

Land used for pasture may bring higher returns if used otherwise.

Some range areas require large amounts of land to support each animal.

The nutritive value of forage may be poor due to poor soil in many places.

The major vegetation types of Afghanistan are shown in Fig. 8

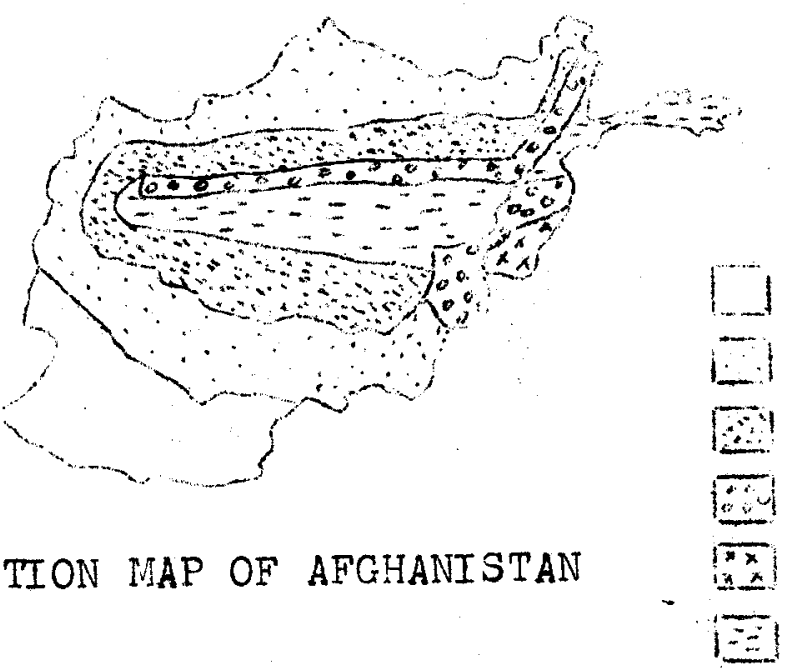

DESERT

STEPPE

DECIDUOUS FOREST CONI FEROUS

FOREST

Fig. \& VEGETATION MAP OF AFGHANISTAN

SCLEROPLYLLOUS

FOREST

ALPINE TUNDRA

Desert vegetation

The average annual rainfall precipitation in the desert areas ranges from 100 to $200 \mathrm{~mm}$ with great variation within the season and from year to year. The evaporation rate in the desert area is naturally high. The soils are

mostly saline or sodic. area.

1. Calligonum-Aristida community. This community covers the large areas of mobile sand-dunes with average annual precipitation less than $150 \mathrm{~mm}$. The vegetation covers $1 \%$ to $25 \%$ of the area, with ralatively low salt content. The dominant plant species are colligonum molle, C.turkestani com, C.intertextum, C.amoenum, Aristida pennata, A.karelenii and Euphorbia cheirolepis. 
2. Chenopodiaceous community. This community covers an area of non-sandy soil where the mean annual precipitation is less than $150 \mathrm{~mm}$. The amount of soluble salts (sulphates, chlorides etc.) is rather high. The dominant species; are Haloxylon salicornicum and $\mathrm{H}$. Persi cum.

3. Tamarix Community of extreme south-west. This community covers large areas along the Iranian border, where the average annual precipitation is 1 ess than $100 \mathrm{~mm}$. The soils are saline or sodic. The dominant species are tamarix articulata (along the Helmand River), T. lepto stachys, T. dioica, T. macrocarpa, T. manifera, T. meyeri, T. passerinoides;, T. pentandra and

T. serotina.

\section{Steppe Vegetation}

The steppe vegetation comprises two distinct communities.

1. Artemisian steppe. The shrub-steppe community forms a broad transitional belt between desert and deciduous forest from West (Herat) to South East (Ghazni). Afghanistan on the south side of the Hindukush. Mean annual rainfall ranges from $200-300 \mathrm{~mm}$. The soils are well developed and contain considerable amounts. of gypsum. The dominant plant species are Artemisia herba-alba, stocksia brahuica, Zygophyllum, Fabago var. oxanum, Hertia intermedia, Atriplex repens, and Atriplex hastanum var. salinum. Artemisia maritima is widely distributed from steppe zone to alpine zone, forming a large pure community. on mountain slopes it grows on saline soils.

2. Grass Steppe. This community occupies the fertile loess plains below the deciduous forest (Pistacia vera community) on the north side of the Hindukush mountain range. The annual precipitation varies from 150 to $300 \mathrm{~mm}$. In spring, the vegetation cover reaches about $90 \%$ but dries up quickly after the middle of May. The soils vary from a deep praitrie soil with high organic content in the Kunduz-Tali qan areas, to a shallower soil that is relatively low in organic matter in the Balkh-Jowzjan areas. The dominant plants are Bromus spp., Poa bulbosa, Agropyron cristatum, Agropyron trichophorum, stipa sibirica, Festuca spp., Lolium loliaceum, Echinochloa crus-galli, pinnesetum dichotomum, Aeluropus littoralis, and cynodon dactylon. These are all grasses, forbs and cryptogams being little in evidence. 


\section{Deciduous Forests}

With increasing altitude and rainfall, xeromorphic woodlands replace the steppe vegetation. The average annual precipitation ranges from 300-500 mm. Pistacia atlantica forms a broad belt from the Harirud valley along the mountains of the south (above the Artemisian steppe) almost to the eastern frontier. Pistacia vera forms a broad belt from Badghis to Badakhshan (above the grass steppe) in northern Afghanistan. Other important species are Pistacia khinjuk, Amygdalus bucharica, Fraxinus xanthoxyloides, and Cotoneaster"spp.

\section{Coniferous Forests:}

The juniper forests are distributed over two main areas: Juniper excelsa is distributed in the north east, from the Paropamisus to Band-i-turkestan, whille Juniperus semiglobosa occurs, to the South in Eastern Afghanistan. Cedrus deodara and Pinus gerardiana are distributed over large areas in Laghman (Nuristan), Kunar, and Paktia provinces. Picea smithiana and Abies webbi ana occur only in eastern Afghanistan. In the lower part of the conifer zone in Nuristan, Quercus dilatata, Q.Semicarpifolia, Jugulans regia, Acer turkestanicum, Celtis caucasia, Pyrus. pashia, and Viburnum cothinifolium, are mixed in cedar. and pine forests. The average annual precipitation in juniper forests ranges from 400 to $600 \mathrm{~mm}$ and in the cedar. pine forests it ranges from 600 to $1000 \mathrm{~mm}$.

\section{Sclerophyllous Forest}

In eastern Afghanistan, from Chaga-Sarai to Kandai, different types of western Himalayan and Meditermanean evergreen sclerophyllous forests occur. The dominant tree is. Quercus baloot, vicariant of Quercus ilex of the mediterranean region, with spiny coriaceous leaves. The Quercus baloot forest forms an extensive belt at altitudes between 130 and 2000 metres. It covers a very broad ecological range and is extremely drought and cold resistant. Reptomia boxifolia forest forms the lowest forested belt at an altitude of 800 to 1300 metres. Other important species in the lower elevations are Olea cuspidata, Pistacia khinjuk, Pi cus palmata, Zizyphus jujuba and Punica granatum. The mean annual precipitation ranges from 400 to $600 \mathrm{~mm}$ in these areas of sclerophyllous forest. 


\section{Alpine Tundra}

Alpine vegetation occupies a large area in the central and easternmost highlands of Afghanistan. The mean annual precipitation ranges from 400 to $600 \mathrm{~mm}$, nearly $90 \%$ of it being in the form of snow. The temperature ranges $20 \mathrm{CO}$ (winter) to $25 \mathrm{CO}$ (summer). The main plant genera are Kobresia, Carex, Primula, Pedicularis, Cousinia, Acantholimon, Astragalus, Oxytropics, Koenigia, Dralea, Delphinium, Cerestium and Oxyria. 
$\underline{\mathrm{HAY}}$

Hay is the aerial part of forage crops harvested during the growing period and preserved by drying for later use in animal feeding. Green forages, when dried to about 80-85 percent dry matter, preserve most of their nutrients: including carotene. Good hay must keep the characteristic green colour of the crop; it should be prepared in a way that keeps the loss of leaves down and maximum green colour retained by the hay. The hay should be free from fungus or mould and bad odour. The aroma of the finished product should be such that it is relished by the animals. The hay should not have more than $15 \%$ of moisture to ensure safe storage without risk of fermentation and combustion. An average quality hay contains $25-35 \%$ crude fibre and $45-45 \%$ TDN.

Importance of hay. It is an important forage for the feeding of livestock like cattle buffalo, horses and donkeys, Since green forage cannot be made available throughout the year in many countries, the green is cut, converted into hay and stored for feeding through the dry period. However, hay suffers a higher loss of nutrients from the time it is cut to the time it reaches the manger.

Kinds of hay. Crops having soft and pliable stems are more suitable for hay making. A great variety of legumes, grasses and cereal crops can be used. These legumes, grasses and cereal crops are also fed green and can also be made into silage or haylage.

The legumes are berseem, lucerne (alfalfa), cowpeas and clover. The grasses used for making hay are timothy, Bermuda grass, bahia grass and Johnson grass, suden grass and hybrid sorghum. The hay prepared from grasses are generally low in protein and calcium and high in fibre and less palatable compared to legume hays.

Cereal hays: Small grains, like barley, oats, rye, wheat, maize, jowar and bajra (millet) make satisfactory hay crops when the stems and leaves are still soft and green. They make most nutritious hay when cut in the soft dough stage.

Hay quality. The quality of hay is described as follows:

1. It should be free from foreign material, cut at the right stage of maturity and should be properly cured and stored. 
2. It should be leafy, show no sign of weathering or spoilage losses, and have a bright green colour.

3. It must be available to be consumed by the animals in large amounts.

4. It must be high in energy.

5. It should be rich in minerals and vitamins.

High quality hay possesses, the physical and chemical characteristics commonly associated with palatability and an abundance of feed nutrients. Hay quality is determined by stage of maturity at cutting time, weathering in the field, and the method of harvesting and storing.

Making quality hay. The way to make hay is firstly to harvest the crop at the optimum stage of maturity which will provide the maximum yield of nutrients per acre without damage to the next crop and secondly to cure properly, which involves reducing the water content of the green herbage from 65 to 85 percent moisture to 20 percent or less. The factors affecting hay quality can be grouped into growing, equipment, harvesting, curing and the hay making system and storage. Good forage (a mixture of legumes and grasses) should be grown using quality seeds and on good soils with proper application of manures and fertilizer. Good equipment like mowers or mower conditioners, barn hay forks, hay loaders, side delivery rakes, automatic pickup balers and stack machines should be used wherever available. The for age should be harvested at full bloom stage of its growth for maximum yield of digestible nutrients. The forage should be quickly and properly cured or dried in the sun or drier. so that it can be stored safely without excessive heating or becoming mouldy and to enable it to. retain the maximum leafiness, green colour, aroma, nutritive value and patalability.

In order to achieve these objectives, the moisture content should be reduced to $15-20$ percent. Shattering of the leaves should be avoided or mi nimizedi by transporting the leguminous fodder from the field early in the morning, when the leaves. still retain some dew. Losses of carotene due to bleaching and losses in sugar, starch and carbohydrate content due to fermentation must be mi ni mi zed with proper curing or drying methods. Leaching losses from rain should be avoided. 
Hay making includes a series of processes with automatic machines from field to feeding. The most common systems are: Long, loose hay, chopped hay, packaged hay, baled hay and hay stacks.

Storing hay. The system of storage varies from area to area. In arid regions, where there is little rainfall during fall and early winter, a good stock of loose or baled hay may provide entirely satisfactory storage. In high rainfall areas, more expensive water proof storage is required. A modified system can be used when conditions are between these two extremes.

Hay feeding fundamentals. The following fundamentals are recommended:

Monogastric animals including swine and poultry should be fed a large proportion of grains and other concentrates which can be digested by the enzymes of these animals. Ruminants, with their four stomach compartments and the help of mi croorganisms can subsist largely, or entirely, on bulky, high fibre forages, which because of their low energy per unit weight of dry matter, must be consumed in large quantities to supply their rutrient needs. The horse, because of the large size of its cecum and large intestine can utilize quantities of hay intermediate between simply stomached and ruminant animals.

Proportion of hay to concentrate. Cattle, sheep and horses will eat 2 to 3 pounds of hay per 100 lbs. of body weight when hay alone is fed, when the quality of hay is good, its consumption is more and that of costly concentrates will be lessened.

The proportion of hay to concentrate will be determined by comparative costs and the quality of hay by its DCP and TDN contents.

Ruminants need some roughage. Good quality hay will partially meet protein requirements also. In monogastric animals, when forage is included in the ration, high quality dehydrated alfalfa hay should be fed. High quality hay is essential for horses also. 


\section{SILAGE}

Silage is fermented high moisture forage stored under anaerobic oonditions in a silo. Silos are designed so that anaerobic (airless) conditions prevail during the storage of high-moisture green forage. These conditions provide an environment in which mi cro-organisms ferment the soluble carbohydrates of the feed, producing lactic acid, volatile fatty acids and decarboxylic acids. The products of fermentation brings the $\mathrm{pH}$ down in the range of 3.8 to 5.0 , in which region, the mi crobial growth i inhibited. About 8-12 percent lactic acid is formed.

The silage can be stored for several years if it is kept in anaerobic conditions. However, once the silo is opened, the silage should be consumed within 12 months to prevent the yeasts and moulds from becoming active again causing deterioration of the feed. Silages are very palatable and allow the farmer to get maximum yields per acre, because the entire aerial part of the plant is used. Silage in a good silo can remain unchanged for 10-15 years.

Haylage is a low-moisture silage made from green forage

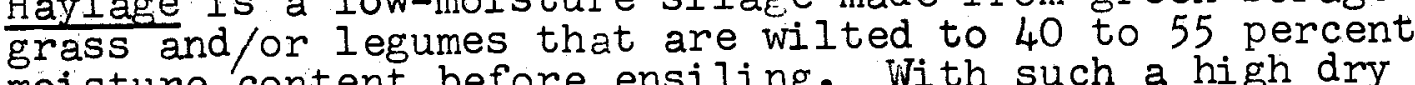
moisture content before ensiling. With such a high dry matter anaerobic conditions are difficult to achieve. Wilted crops preserve higher $\mathrm{pH}$ values then wet crops, and consequently a higher concentration of lactic acid is of less importance than when wet crops are ensiled. Haylage is higher in protein and carotene, but lower in TDN and vitamin D.

For haylage to be properly ensiled, it is very important that as much air as possible be excluded from the silo, although it is more difficult to ensile than conventional silage materials because it is hard to pack. Sometimes molasses are added to improve lactic acid fermentationabout $30-35 \mathrm{~kg}$ molasses are added per tonne of green fodder.

The Ensiling process. This refers to the changes which take place when forage with sufficient moisture to cause fermentation is stored in a silo in the absence of air. In other words it is the process of conserving green fodder as silage. The entire ensiling process requires 2 to 3 weeks, during which time the following aerobic (with air) and anaerobic (airless) activities predominate: 
Aerobic activity. The living plant cells of the forage continue to respire, consuming the oxygen of air trapped within the silage, producing carbon dioxide and water and releasing energy or heat. At the same time aerobic yeast and moulds thrive and multiply and the temperature rises to $3800 \mathrm{C}$ during this short period.

Anaerobic activity. Once the available oxygen has been utilized, anaerobic bacteria-chiefly acid forming and proteolytic-multiply at a prodigious rate. Simultaneously, the moulds and yeasts die, but continue to function as enzyme systems which produce alcohol and other end-products. The combined anaerobic activity produces the following changes:

-The carbohydrates and sugars, are broken down into lactic acid, acetic acid and small amounts of other acids and alcohols.

-Small quantities of proteins are broken down into ammonia, amino acids, amines and amides and the acidity finally reaches a point when the bacteria are killed off and the silage making process is completed.

Optimum $\mathrm{pH}$. The formation of a pH of 3.5 to $l_{4} .5$ is desirable in good silage as it will prevent the growth of bacteria. Excellent low moisture silage (45 to $60 \%$ water) is frequently made in a pH range of from 4,0 to 4.5 and even upto 5.0 .

Sugar content of the forage. When cut at the proper stage of maturity, corn (maize), sorghum (jowar), millet (bajra), oats and napier possess just the right amount of sugar for the production of good silage. On the other hand, if cut when too immature, these crops, being higher in sugar and water may cause excessive acid formation and result in unpalatable silage, To make good quality grass (hay) silages, the forage should be wilted to below 70\% moisture content or preservatives should be added.

Effect of preservatives. The addition of carbohydrate preservatives, such as molasses and grains speed up the formation of $l a c t i c$ and acetic acids and also provides bacteria with a readily available source of energy. On the other hand the addition of preservatives increases the cost of silage and may result in nutrient losses during the ensiling process. 
Kinds; of silage

Silage can be made from crops which are ri.ch in soluble carbohydrates like maize (corn), sorghum (jowar), millet (bajra), napier grass and oats. Cultivated and natural grasses having about $35 \%$ dry matter are also excellent material for ensiling.

Leguminous fodder crops after wilting to 35-40 percent dry matter and sunflowers, turnips and sugar beet tops mixed with dry roughage (at 30 to $35 \%$ dry matter) can also be ensiled.

Characteristics of good silage. Good silage should have the following physical and chemical characteristics:

Physical. It should have an acceptable aroma with no mould growth. Good silage is uniform in moisture and keeps a greenish yellow colour and is palatable by animals. A fermentation loss of about $10-15 \%$ is inevitable in the silage making process. The silage should have no visible mould and should not be musty or slimy.

Chemical. Some salient chemical characteristics of good silage are:

$-a \mathrm{pH}$ value of between 4.0 and 5.0 .

-a lower concentration of volatile substances than that of lactic acid.

-ammonia nitrogen production not less than 10-12

percent of the total nitrogen.

-less than 0.2 percent concentration of butyric acid.

\section{How to make good silage}

There are various methods of making silage, but the principle is the same in all the methods.

A good silo of any kind-tower, oxygen-limiting, trench, bunker, or stack-should be prepared and kept ready well in advance of harvesting.

The green crops are harvested at the appropriate stage of maturity with 30-35\% dry matter. Sorghum is generally cut when the seeds are hard. Cereal crops should be cut when the grain is in the milk to soft dough stage. Legumes are generally cut at early bloom to half bloom stage. Grasses are cut when heading to their bloom stage. For each forage, there is an appropriate stage, just as there is for 
making hay

The crops can be ensiled as such or as chaffed material. Since the length of the plant or cut plant affects the packing, it is theoretically preferable to chaff the forage from $1 / 4$ to $3 / 8$ inch. The chaffed fodder is then filled into the air tight silo within a day or two, the mass being properly packed to minimize its air content, and then trampled with tractors or bullocks as required. After proper packing the material is sealed with mud and straw or polyethylene sheets. The silage is generally ready after 4 to 6 weeks.

If the crop used for ensiling is not rich in soluble carbohydrates or if it is desired to enhance its preservation or feeding value, then additives or preservatives; may be added. Two types of additives are generally used in silage making: feed additives: like grains and feeds like corn, cornmeal and cobmeal, oats, barley, dried whey and molasses; and chemical additives like sodium metabisulphite, mineral acids, lactic acid and formic acid. Molasses are added at the rate of 40 to $80 \mathrm{lbs}$; dried whey at the rate of 30 to 60 lbs; ground grain at the rate of $150 \mathrm{lbs}$; and sodium metabisulphite at the rate of 8 lbs per ton of green forage respectively.

\section{Advantages and disadvantages of silage.}

Some of the advantages of silage are:

-Its retention of a higher proportion of plant nutrients than hay because shattering and bleaching losses are minimised. Silage preserves about $85 \%$ of the feed value, while hay, even when made under the best conditions, will preserve only about \&O\% and, under poorer conditions, only 50 to $60 \%$ of the feed value.

-The possibility of producing the maximum quantity of feed per acre of land and consequently increasing the livestock carrying capacity of the farm or ranch.

-The feasibility of making top quality hay crop silage when, due to inclement weather, it is not possible to make hay.

-Its: being the most economical form in which the whole stock of corn or sorghum can be processed or stored.

- Less storage space requi rements per unit weight of dry matter than dry hay, even when the latter is baled or chopped.

-The elimination of the danger of loss by fire if stored within the recommended moisture range. 
-Being the most satisfactory and economical way in which to preserve a number of by-products feeds.

-The possibility of removing forage crops from the land earlier than would otherwise be possible.

-As one of the best methods of controlling the European corm borer, since the removal of corn stalk is required in making corn silege.

- As an aid in controlling weeds, which are often spread throughout hay or fodder.

-As the cheapest form in which a good, succulent winter feed can be provided on most farms and ranches.

- As a better source of protein and of certain vitamins, especially carotene and other unknown factors, than dried roughage.

-Being a very palatable feed and slightly laxative in nature.

- Making for less waste, the entire plant being consumed, this is an important consideration with coarse, stemmy forages.

-Its ability to hold the feeding value of protein, carbohydrates and carotene better and for a longer time than any other method of preservation.

-The possibility of complete mechanization of the feeding system, thereby eliminating much labour and time.

-Its many advantages over pasture, including (a) no fencing required (b) approximately one third more forage from the same acreage (c) harvesting at optimum maturity (d) more uniform quality (e) little or no bloat ( $f$ ) closer observation of animals that are confined to a lot or corral (g) reduced damage to the growing sward and (h) lessened top soil loss as a result of alleviating the hoof action of grazing animals.

Some of the disadvantages of silage are that:

-It requires a silo or storage structure and other special equipment for best results, compared to the simpler methods of field curing and storing of hay which are less expensive. 
-It possesses considerably less vitamin $D$ than sun-cured hay.

-Two to three times as much tonnage as hay must be handled.

-An added expenditure is incurred when preservatives are necessary.

-It may be an expensive forage preservation system, especially when a dried forage is fed along with it.

-It lessens the amount of organic material returned to the soil.

\subsubsection{Concentrates}

Concentrates are feeds that are high in nitrogen free extract (NFE) and total digestible nutrients (TDN) and low (less than $18 \%$ ), in crude fibre (CF). They may be either high or low in protein. Cereal grains and their by-products and oil meals and oil cakes are classified as concentrates.

Grains and high-energy feeds (carbonaceous feeds) are the feeds used primarily for their energy content. High energy feed's generally contain less than 20 percent protein and 18 percent crude fibre. Many protein supplements can also be classified as high-energy feeds.

Grains are the seeds from cereal plants and they constitute the bulk of the high energy feeds. The digestible crude protein (DCP) ranges between 7 and 10 percent and total digestible nutrients (TDN) ranges from 75 to 80 percent. The cereal grains are mai ze (corn), sorghum (jowar), millet (bajra), oats, barley and rye.

Fats and oils are rich sources of feed energy. They have 2.25 times the energy of carbohydrates. Animals fats are cheaper than vegetable fats.

Grain milling and milling by-products. All grains fed to animals generally undergo processing as grinding. Additionally most grains are milled in some manner for preparation of food for human consumption. A number of by-products are produced in these milling processes. Which are not required for human consumption but used for feeding 
livestock. These are wheat bran, rice bran, rice polish, maize husk, gram husk and gram chuni. They have 4 to $10 \%$ DCP and 55 to $65 \%$ TDN. Oil expressed from oil seeds is used for human consumption and oil cakes for the feeding of livestock. The common oil cakes are made from groundnut, mustard, cottonseed, linseed and coconut oils. These have 20 to $40 \%$ DCP and 65 to $75 \%$ TDN.

Nutrient composition of grains. Grains are fed to livestock primarily for their high energy content. Their carbohydrate content is about 80 percent and crude-protein about $10 \%$. Barley, maize, jowar and millet contain $1-2 \%$ DCP and 15-16\% TDN. The grains contain 1-3\% lipids and more minerals than forages. All grains are extremely low in calcium, but are good sources of phosphoms. All cereal grains except yellow corn are low in vitamin A. Oats contain high amounts of vitamin E. Thiamine, riboflavin, pantothenic acid and pyridoxine are found in the kernels.

Niacin is found in high concentration in wheat, maize and rice.

Effect of stage of maturity on the nutritive value of grains

As thegrains mature, there is a stegdy decrease from about $80 \%$ to $25 \%$ in moisture content and in increase from about $75 \%$ to $85 \%$ in the carbohydrate content. There is a slight drop from about $16 \%$ to $20 \%$ in protein content and an increase from about $3 \%$ to $5 \%$ in fat content.

Grain storage. When grain is properly stored in well designed facilities, losses due to spoilage and contamination can be held to a minimum. However, when adequate attention is not given to storage facilities and the condition of the grain to be stored, the grain may spoiled.

Moisture: When grains are stored at moisture levels below $13 \%$, the growth of most micro-organisms and mites is kept in check. If the moisture level is reduced to $10 \%$, the development of most insects will be arrested although at levels below $12 \%$, the incidence of grain breakage is increased. When the moisture level is increased above $30 \%$, sprouting can occur in the stored grain, generating heat and leading to fire hazards.

Temperature: The problems associated with storage decreases when the temperature of storage is lowered. When the storage temperature is decreased to $50 \mathrm{C}$, mites do not develop. Temperatures of $160^{\circ} \mathrm{C}$ inhibit the growth of insects and at $0^{\circ} \mathrm{C}$ fungi do not grow. 
Biological Factors: In addition to the physical destruction of stored grain by moisture and temperature, biological factors such as mould growth and insect and rodent damage can also cause damage. Damage by biological factors can be minimised by careful control of moisture and temperature.

Grains which are good sources of nutrient for livestock are also relished by insects and rodents. Grain that is broken and in poor condition will encourage the infestation by insects and rodents.

Fumigation and residual contact pesticides are two methods used for the control of insect and rodent pests. Fumigants are particularly effective since they can diffuse throughout the intergranular spaces of the stored grain. Many of the fumigants that are used to kill pests are equally effective against man, so fumigation should be done by trained persons and all precautions taken both before and after.

Rodents. It has been estimated that rats consume $10 \%$ of their body weight in feeds per day. In addition to loss of feed, there is contamination from the feces and urine of the pests.

Mi crobial contamination. Grains in broken condition allow micro-organisms ready access to the interior of the kernel and these can subsequently lower their value. In recent years the problem of mycotoxi cosis, diseases produced in livestock from toxin producing moulds and fungi, has received considerable attention.

Other High Energy Feeds. Feed grains and their milling by-products comprise the vast majority of the energy feeds. In addition, there are numerous other feeds, which are fed to cattle for a supply of energy. Seeds from plants other than Gramineae can be used effectively, e.g., beans. Fat provides an extremely concentrated source of energy. Molasses is a liquid energy feed which is highly digestible and palatable to cattle. Root tubers, when cheap, could also be fed to livestock.

Fats. Animals can tolerate a rather high fat content in their rations. Suckling animals also consume substantial amounts of fat in milk. A small amount of fat in the ration is desirable as it contains fat soluble vitamins. Nost feeds for suckling animals, dogs, livestock and poultry contain fat upto $10 \%$ of the ration. 
When added to livestock rations, fats (1) increase the caloric density mixing equiprient, (4) facilitate palleting of feeds, (5) increase palatability and (6) help to homogenize and stabilize certain feed additives.

Molasses. Molasses (including cane, blackstrap, beet, citrus, wood and starch molasses) is extremely palatable and an excellent source of energy.

In addition to its use as energy feed, molasses is also used ( 1 ) as an appetizer, (2) to reduce the dustiness of the ration, (3) as (5) to supply unidentified factors, (6) in the case of cane molasses, to provide trace minerals and (7) to provide a carrier for non-protein nitrogen and vitamins in liquid supplement. Molasses is fed to cattle at the rate of 10 to $15 \%$ of the ration and to poultry at the rate of $2-5 \%$ of the ration.

Roots and Tubers. A root crop consists of the fleshy subterranean parts of a harvested plant-for example carrots and beets. Tubers are short, thickened, fleshy stems, or terminal portion of stems or rhizomes, that are usually formed underground. Examples are peanuts and potatoes. Roots and tubers are relatively good sources of energy but have limited amounts of proteins, calcium and vitamin D. The roots and tubers generally used are potatoes, sweet potatoes, chufas, cassava, sugar beets, mangels, carrots and turnips. 


\subsubsection{Protein Supplements}

These are feed stuffs containing more than $20 \%$ protein or protein equivalent. Animals of all ages and kinds require adequate amounts of dietary protein for maintenance, growth, finishing, reproduction, work and wool production. Proteins are found in most of the feeds commonly fed to animals. The amount of protein, its digestibility and the balance of essential aminoacids are important factors that must be considered in balancing rations.

Importance of Protein Feeds. The primary function of protein feeds is to supply those aminoacids not provided in adequate amounts by the cereal portion of non-ruminant rations or nitrogen precursors of microbial protein in the case of ruminants. Ingredients that contain more than $20 \%$ percent of their total weight in crude (total) protein are generally classified as protein feeds. Protein supplements may be further categorised according to the source of origin as plant proteins, animal proteins (mammalian, avian and marine), non-protein nitrogen and single-cell proteins. Plants provide more than $80 \%$ of the protein feeds used in livestock rations. Nost protein feeds of plant origin consists of oil seed cakes or meals.

Many protein feeds of animal origin are derived from sources that are considered unsuitable for human consumption as by-products of processing meat, poultry, fish and milk.

Plant proteins. The bulk of the protein of ruminants (cattle, sheep, goats), whose requirements for specific aminoacids are met by microbial fermentation of the material in the fore stomach (rumen). comes from plant sources.

Proteins in plants are primarily associated with tissues that are actively metabolizing, such as leaves, centers of growth, and seeds. By being consumed in large quantities by livestock, plant materials supply the major portion of their protein requirement, although they are not intrinsically very protein-rich compared to other feed stuffs. If not adequately available in the fodders, protein requirements can be made up by feeding oil cakes made from soya bean meal, sunflower meal, mustard or rape seeds, cotton seeds, groundnuts or linseeds. The protein content and nutritive value of oil cakes very according to the seed from which they are produced, the oil being extracted from the oil seeds by expellers, hydraulically, or by solvents, and then used for human consumption, while the oil cakes are fed to livestock.

Additional plant proteins are obtained as by-products from grain milling, brewing and distilling and starch production. Most of 
these industries use starch in grains and seeds, then dispose of the residue, which contains a large portion of the protein of the original plant seed.

Pulse proteins. Pulses are seods of leguminous plants. They are used primarily for human consumption, but can be fed to livestock also if the prices are economic. When pulses are ground, the outer hull and seed coat and the broken seed not required for human consumption can be fed to cattle:

Animal proteins. Protein supplements of animal origin are derived from meat packing and rendering operations, poultry and oultry processing, milk and milk processing and fish and fish processing.

a) Ineat and meat by-products: Meat is defined as the clean, wholesome flesh derived from slaughtered animals and is limited to (skeletal) striated muscles.

Neat by-products are the non-rendered, clean, wholesome parts other than meat. This feed classification includes lungs, kidneys, brain, bone, blood, spleen, stomach and intestines. It does not include hair, hooves or teeth.

Meat prodiacts are senerally unpalatable to ruminants, hence only limited amounts are fed to omnivorous species of lj.vestock.

b) Poultry and poultry waste: The three nost extensively used high protein by-products of the poultry industry are hatchery by-products, poultry by-products and poultry feathers. Culled birds, unsalable eggs, eggshells and slaughter waste are also used in animal feeds.

c) Dairy products: These include skimmed milk, dried whole milk, buttermilk, condensed buttermilk, dried skimmed milk and dried buttermilk and cheese meal. These products are available only in production areas and when in surplus to human requirements.

d) Fish and marine by-products: Fish and marine by-products are rarely fed to ruminants and non-ruminant herbivores al though commonly fed to swine and poultry. Fish meal-a by product of the fisheries industry-consists of dried, ground whole fish or fish cuttings, with or without the extraction of part of the oil. The salt content is generally $3 \%$ but does not exceed $7 \%$.

Non protein nitrogen (NPN) feedstuffs. These are feedstuffs which contain nitrogen in a form other than proteins or peptides. Since micro-organisms in the rumen of ruminant animals degrade dietary proteins to synthesize microbial protein, it follows that if we 
feed carbohydrate and NPN sources, both precursors of aminoacids, microbial protein is successfully synthesized. However, under normal conditions, the amount of NPN must be carefully monitored to avoid toxicity problems resulting from the excessive production of ammonia in the rumen.

NPN products available commercially are urea (pure and feed grade), biuret, ammonium acetate, ammoni um bi carbonate, ammoni um carbonate and ammonium lactate.

Urea. Crude protein is determined by multiplying the nitrogen content of the feed stuff by 6.25 . Thus feed grade urea ( $45 \%$ nitrogen) would have a crude protein equivalent of 281 percent. However urea contains no precursors for the formation of a carbon skeleton for protein. Therefore high energy feeds (carbohydrates and $f a t$ ) must be fed simultaneously to maximize protein production.

When urea is fed to ruminants, it is initially broken down in the rumen into ammoni a and carbon dioxide by the enzyme urease which is produced by certain micro-organisms. Paralleling this catabolism of urea in the rumen, carbohydrates are degraded by other ruminal micro-organisms to form volatile fatty acids and keto acids. The ammonia liberated in the mumen is then combined with the available keto acids to form aminoacids, which are in turn incorporated into microbial protein. Throughout the digestion process, micro-organisms are passed from rumen to the more distal digestive organs. In the abomasum and small intestine, these microbes are hydrolyzed and digested to such a decree that the mi crobial protein is broken down to free amino acids which can then be absorbed by the host animal. These steps are summarized below:

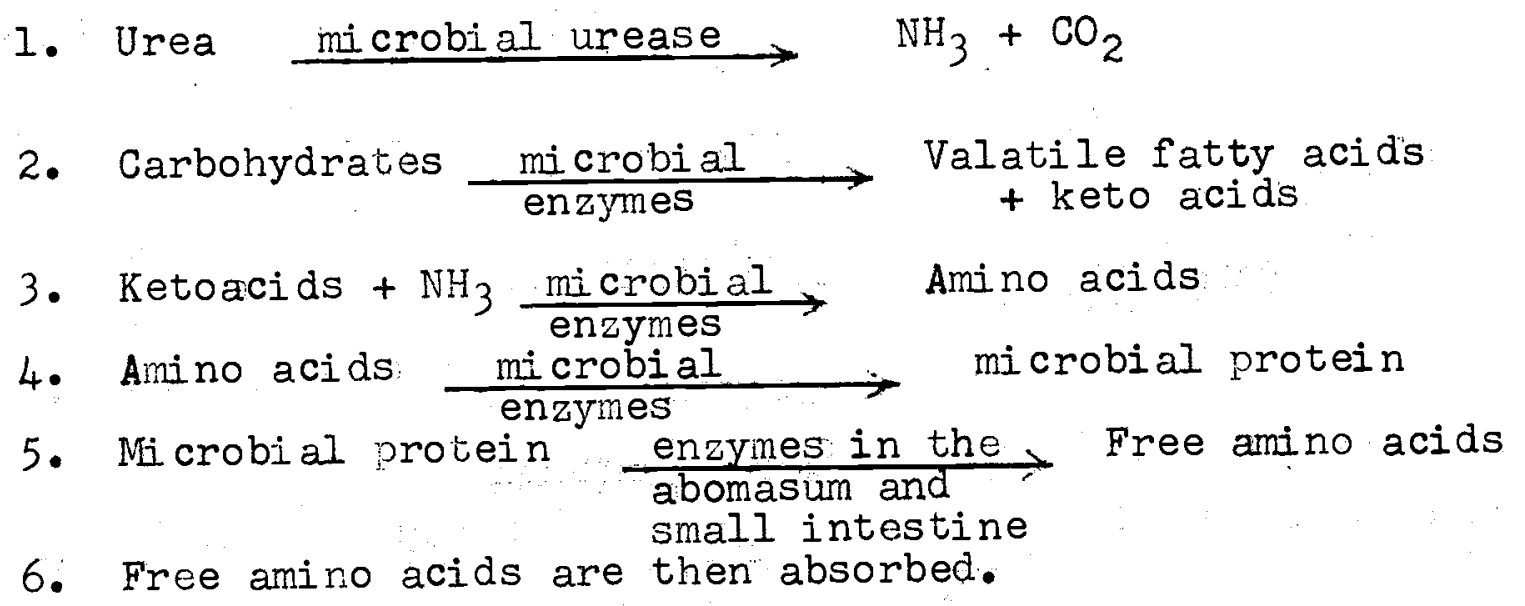

If all the amino acids are to be produced in the rumen, it is necessary to provide an additional precursor-sulphur, so that methionine and cystine, both sulphur containing amino acids, can be synthesized. 
Urea can be fed to animals by different methods:

1. Mixed in with the concentrate mixture. It is also provided in a complete mixed feed.

2. Dissolved in water and mixed with molasses the liquid supplement is then mixed with or sprayed on chaffed straw or forage.

3. Mixed with silage by dissolving the urea in water and mixing with chopped fodder before ensiling.

4. Mixed with molasses and the mixture sprayed over low quality forage pasture.

About 50 to 75 grams of urea per head per day can be safely fed to cattle by the above method if it is properly dispersed in the ration and not ingested by the animal in concentrated form. Cattle can however become susceptible to urea toxicity under the following conditions:

1. Poor mixing of feed.

2. Error in ration formulation.

3. Inadequate period of adaptation.

4. Low intake of water.

5. Feeding urea in conjunction with poor quality roughage.

6: Low feed intake prior to exposure to feed containg urea.

7. Rations that promote a high $\mathrm{pH}$ in ruminal fluid.

In the case of sheep, some receiving as little as $8.5 \mathrm{~g} /$ day have died, while others have consumed upto $100 \mathrm{~g} /$ day wi thout ill effects. Toxic symptoms appear when the ammonia level in the peripheral blood exceeds $1 \mathrm{mg} \%$, while the lethal level is about $3 \mathrm{mg} \%$. Such levels are usually associ ated with rumi nal ammonia concentrations of $80 \mathrm{mg} \%$, the actual level depending upon pH. Ammonia, which is the actual toxic agent in urea poisoning, is most toxic at high ruminal pH. 


\subsubsection{By-products feeds and crop residues}

With the increase in world human population and decrease in reserve stocks of food grains for human consumption, more and more agro-industrial by-products and crop residues are being included in the rations of livestock. These agro-industrial by-products and crop residues can be grouped according to their nutrient content: energy rich suplements like molasses from cane and beet, citrus, reject bananas, pineapple bran and by-products, cassava by-products; protein rich supplements like oil seed cake, fish and meat meal, pulses, chunnies, animal organic waste (cattle, sheep, pig and poultry manure); by-products mostly supplying minerals like bone meals, sea weeds etcis and those from the brewery, fruit and vegetable industries. The by-products are dealt with under the following headings:

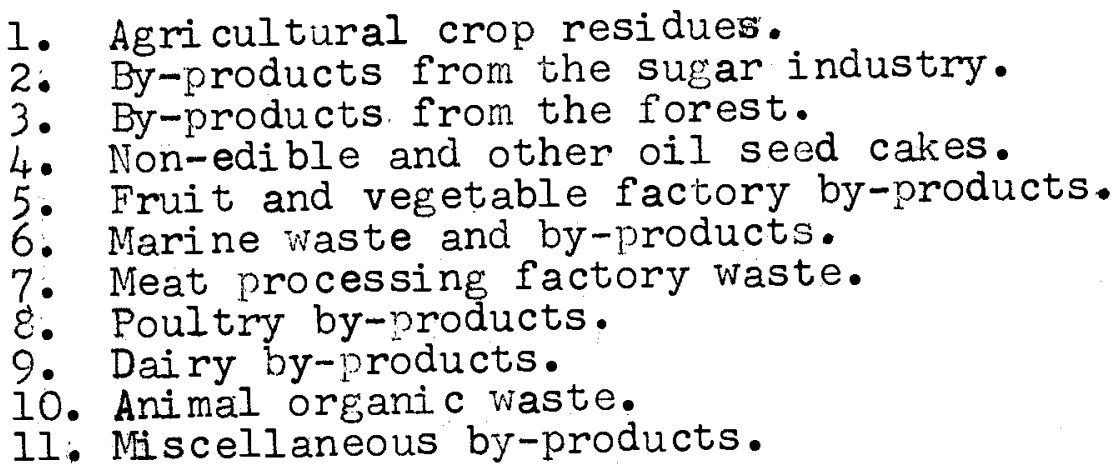

1. Agricultural crop residues: Crop residues, also known as straws, are parts of the plant left over after harvesting and separating cereal grains like wheat, rice, maize, oats, barley, jowar, millet etc. These straws are low in available energy, nitrogen, minerals and vitamins. When fed alone, the straws do not supply sufficient nutrients for maintenance, but their nutritive value can be improved by physical, chemical and mi crobiological treatment. Impregnation of chaffed paddy straw or other straw with $1-2 \%$ urea, $10 \%$ malasses and $0.5 \%$ mineral mixture improves digestibility and voluntary intake in cattle. Biological treatment of poor quality roughages and alkali treatment of poor straws or crop residues improves their nutritive value. The cellulose, hernicellulose and lignin of the plant residues undergoes enzymatic hydrolysis by high activity enzyme cellulase producing soluble sugars.

Examples are paddy straw, wheat straw, maize straw, oat straw, barley straw, jowar straw and bajra (millet) straw. In addition pulse srraw, groundnut husk, rape husk, rice husk, and maize husk are also available. After harvesting, the seeds are threshed out of the pods and split to form "dals" used for human consumption. The husk of the pods with leaves and tenderstems are left behind as by-products which are fairly nutritious. 
2. By-products from the sugar industry: The by-products available from sugarcane industry are sugarcane tops, bagasse (pulp). molasses, press mud and condensed molasses soluble.

Sugarcane tors consist of a portion of stem, tapering into leaves. The cane tops are palatable and cattle can be maintained entirely on tops with a little protein supplement through concentrate mixture or groundnut cake. They can also be converted into good quality silage which is alatable to livestock.

Bagasse is the pul left over after sugar cane juice is extracted or expressed from the plants. The feeding value of bagasse is improved by treatment with $3.3 \%$ sodium hydroxide or by treating it with high temperature and pressure or feeding it with molasses and protein supplements.

Molasses is the thick, dark brown paste left after the suger crystals are separated from the treated cane juice. It contains about $50 \%$ sugar and is a good source of energy for cattle. Molasses as the main source of energy and urea as the main source of nitrogen can be fed as such as a liquid feed, or mixed with chaffed roughage and fed to cattle.

Press Mud is a by-product of the sugar industry obtained during the process of precepitation of impurities from sugar cane juice. Its organic matter content is about $60 \%$ and its calcium content is also high.

Condensed molasses solubles/dried yeast sludge is the by-product of various fermentation processes in which large quantities of molasses is used to produce alcohol, yeast, citric acid, mono sodium glutamate etc. During this fermentation the soluble carbohydrates of molasses are utilized by various mi cro-organisms, leaving behind an organic matter residue. This product is a rich source of mi crobial protein and is a useful ingredient of animal feeds. After condensation to 65 to 75 percent dry matter, it is called condensed molasses solubles. In India, the product available after fermentation of molasses to alcohol is called yeast sludge. Dried yeast sludge has been safely incoriorated as an ingredient to a basal, cereal free ration for poultry at $20 \%$ level with better results. 
3. By-products from the forests: The by-products available from the forest for cattle feeding are dry leaves and seeds. These are available jn substanial quantities in countries where the area under forest cover is 10-20\% or more. Leaves are collected to feed sheep and other animals in the relatively few forested parts of Afghanistan.

4. Non-edible and other oil seed cakes: After the oil is expressed from edible or non-edible oil seeds, either by expeller, hydraulic or solvent extraction processes, the residual oil seed cakes are available for feeding livestock. The oil cakes are rich in protein ( 20 to $50 \%$ C.P) and can be incorporated in the concentrate mixture at the rate of from 10 to 30 percent. Examples are ground nut cake, mustard cake, rape seed cake, cotton seed cake and sesame cake.

5. Fruit and vegetable factory by-products: These are residual by-products from three sources: cuiled, unmarketable or damaged but wholesome fruits and vegetables; crop residues left in the field; and canning, juicing or processing wastes, and can be used for feeding livestak. But their continued availability, storage, and handling are major problems, as these products are highly perishable. For example, apples and pears are processed to extract the juice or fleshy pulp, after which the skin, seeds and cores are discarded as waste. The residual pulp after extracting the juice from citrus fruits like grapes, and raisins. and tomatoes can also be utilized for livestock feeding.

6. Marine waste and by-products: Various by-products are available from the fish, prawn, frog and shrimp industries. By-products. are also available from the sea weeds industry. Fish meal consists of dried ground whole fish or fish cullings, with or without the extraction of oil.

7. Meat processing factory waste: Meat by-products are the non-rendered, clean, wholesome parts, other than meat obtained from slaughtered animals, and include lungs, kidneys, brain, bone, blood, spleen, stomach and intestines. It does not include hair, hooves or teeth. Meat products are generally unpalatable to ruminants, and only limited amounts are fed to omni vorous species of livestock. However, these products make up the bulk of the feeds incorporated in mink rations. 
8. Poultry by-products: Poultry by-products consist of the non-rendered, clean parts of the carcasses of slaughtered poultry, like the heads, feet and viscera-free from fecal content and foreign matter except for such trace amounts as are unavoidable in good factory practice. Dried, rendered and ground poultry by-products make poultry meal. Poultry by-products are lower in nutritive value than the flesh of the animal. However, they may be successfuly used in animal rations in small amounts, but not as the sole source of protein.

9. Dairy by-products: Skimmed milk and buttermilk have long been used on, or in close proximity to the farms where they are produced. Now plants have been built for dehydrating skimmed milk, buttermilk and whey. Dried milk by-products, wherever they are available, are incorporated in commercial poultry feeds. The superior nutritive value of milk by-products is due to their high quality proteins, vitamins, minerals and sugar lactose. Milk by-products are palatable and highly digestible.

10. Animal organic waste (manure and litter ): Manure is a mixture of animal excrements (consisting of undigested feeds plus certain body waste) and beddings. Litter is the product formed when manure is mixed with bedding. The beciding is generally a highly absorbant material consisting of straw, peanut hulls, wood shavings, saw dust, and bark. Dried poultry waste is a product composed of freshly collected feces from conmercial laying or broiler flocks. It is thermally dehydrated to a noisture content of not more than 15 percent. It should not contain any extraneous material like wire, glass or nails. It is fed as an ingredient in sheep, lamb, beef, dairy cattle and broiler and layer chiciken feeds.

11. Miscellaneous by-products: Included in this category are various agro-industrial by-products not covered under the above headings, such as brewery waste (including grain, sludge and yeast), silk worm pupae meal, maize gluten feed, tapioca waste, tea industry waste, aquatic weeds etc. These are included in the concentrate mixture in small proportions depending on availability. 


\subsubsection{Supplements, Additives and Implants}

Supplements are feedstuffs added to improve the value of basal feeds. Additives are substances adcied to a basic feed, usually in small quantities, for the purpose of fortifying it with certain nutrients, stimulants, or medicines.

Implants are substances implanted into the body for the purpose of growth promotion or controlling some physiological function like estrus. Compounds used in imolants are generally materials (e.g., peptide hormones) that would be destroyed during digestion. Hence implants enable the body to absorb the compounds intact. Additionally, implants provide a means of controlled continuous release of chemicals.

The primary nutrient parameters to be taken into consideration while formulatine rations are protein, energy and fibre. After fulfilling protein and energy requirements, other micronutrients like minerals, vi tamins and anino acids are added to correct any deficiencies.

Mineral supplements. The netabolic functions and interrelationships among the minerals are extremely varied and complex. An excessive amount of one mineral can create a deficiency of another. In addition, the difference between requirements and toxicity levels is very narrow for several trace minerals, so mineral supplemention must be done very carefully. The functions, deficiency symptoms, toxicities, interrelationships and sources of individual minerals have been discussed earlier. In some countries, the areas of excess and deficiency have been mapped out and suitable mineral mixtures prescribed to meet nutrional requi rements. Mineral. mixtures are prepared from natural sources, by-products and synthetic chemical compounds.

Macro minerals

1. Sodium (Na) Common salt, sodium sulphate

2. Chlorine ( $\mathrm{Cl})$ Sodium bicarbonate

3. Calcium ( $\mathrm{Ca}$ ) Steamed bone meal, bone ash monocalcium

. phosphate, di calcium phosphate

4. Phosphorus(F) Tricalcium phosphate, calcium carbonate, Ldiammoni um phosphate

5. Magnesium(Mg) Magnesi um carbonate, magnesi um oxide,

5. Magnesium(Mg) magnesium hychoxide, magnesium sulphate

6. Potassium(K) Potassium chloride, potassium carbonate,

7. Sulphur (S) Potassium bi carbonate, potassium sul sulphate, calcium sulphate Potassium sulphate, sodium sulphate, zinc sulphate 
Mi cro minerals
8. Cobalt (Co)
cobalt oxide, cobalt acetate, cobalt carbonate
cobalt chloride
Q. Copper ( $\mathrm{Cu}$ )
copjer carbonate, copper chloride, copper sulphate, copper oxide, copper iodide
10. Iodine (I)
potassium iodide, sodium iodide, cuprous iodide, potassium iodate, calcium iodate
11. $\operatorname{Iron}(\mathrm{Fe})$
ferrous sulphate, iron phosphate, iron oxide, iron carbonate, iron chloride
12. Manganese( $\mathrm{Mn})$ manganese oxide, manganese sulphate, manganese chloride, manganese carbonate, manganese phosphate
13. Zinc $(\mathrm{Zn})$ zinc oxide, zinc sulphate zinc chloride, zinc carbonate, zinc acetate
14. Selenium(Se) sodiun selenate, sodiun selenite

The composition of suitable mineral supplements/mixitures have been given under the section on the feeding of farm animals.

Vitamin supplements. The requirements for vitamins are extremely small compared with those for energy and protein, but the omission of even a single vitamin from the diet of a species that requires it will produce specific deficiency symptoms. The functions, deficiency symptons, interrelationships and sources of individual vitamins have been discussed earlier. Nowadays, premixes containing minute amounts of chemically pure sources of the required vitamins are fed to cattle along with the concentrate mixture.

Feed additives and implants are drugs that fight disease, protect animals fron infection and aid in increasing the production of meat, milk and eggs. They are classed according to their different nodes of action. to retain or enhance the palatability of food. They are antioxidants and flavouring asents. Antioxidants are compounds that prevent oxidative rancidity of polyunsaturated fats such as ethoxyquin or butylated hydroxytoluene. Flavouring agents such as sweeteners increase palatability and feed intake.

Additives that enhance the color or quality of marketed livestock products. Xanthophylls, arsanilic acid, 
sodium arsanilate and rosarsone are used to enhance the yellow pigmentation of broilers and that of egg yolks to imorove market value. Oxytetracycline is said to imorove the texture and quality of egg shells.

Additives that facilitate digestion and absorption. By altering the environment within the gastro intestinal tract either through mechanical or chemical means, production and feed efficiency can often be increased.

The additives that physically aid digestion are grit for poultry and roughage substitutes for ruminants. Since poultry do not have teeth, most grinding takes place in the thickly muscled gizzard. Then hard, coarse, or fibrous feeds are given to poultry, the addition of grit helps in better grinding of the food. When ruminanis are fed high energy concentrate mixtures, hay, cotton seed hulls or ground corn cobs are included as roughage to aid in rumi nation.

The additives that chemically alter digestion and absorption are:

(i) Buffers and neutralizers such as carbonates, bi carbonates, hydroxides, oxides, salts of volatile fatty acids, phosphate salts, amonium chloride and sodium sulphate which prevent sudden changes of the $\mathrm{pH}$ in the rumen, thereby stabilizing the mi crobial population.

(ii) Chelates such as EDTA (Ethylene diamine tetra acetic acid) which are used to increase the availability and absorption of certain ninerals like zinc in chicks. Chelated forms of iron, con, er and cobalt are also available.

(iii)Enzymes. Barley grains are soaked before being fed to poultry, as soaking increases their enzymatic activity.

(iv) Probiotics which help to establish a desirable balance of rstro-intestinal organisms and the substances contributing towards this balance. The addition of molasses and alcohol has some probiotic effect. Rumenculture inoculams are also used to establish the right balance of mi croflora.

(v) Production-promoting drugs. Most of these drugs can be classified as either antibiotics or arsenicals. Antibiotics are substances produced by living organisms (moulds, bacteria, or green plants) such as chlortetraycline, that have bacteriostatic or bactericidal properties.

In addition to their use as growth stimuators, antibiotics are used as nutritional stimulants to promote better feed efficiency in ruminants and to increase egg production, hatchability, and shell cuality in poultry. Their mode of action has not been fully established. Esever the proven or probable modes of action are as follows: 
-Studies have indicated that antibiotics can replace inadequate intakes of certain vitamins and amino acids.

-They may selectively inhibit growth of nutrient destroying organisms while promoting the growth of nutrient producing organisms.

-They increase feed and/or water intake.

-They may inhibit the growih of organisms which produce toxic waste roducts or toxins.

-They may kill or inhibit pathogenic organism within the gastro intestinal tract.

-They may improve the digestion and subsequent absorption of certain nutrients.

Arsenicals. Various comounds containing arsenic have been shown to have production-monoting effects and are currently being used at low levels in poultry fecds. Those currently being fed to livestock are arsanilic acid, sodium arsanilate, carbasone, nitarsone, and rosarsone.

Aciditives that alter metabolism. Recent research studies have shown that metabolic processes in animals can be manipulated through the use of exogenous chemi cals. Synthetic hormones have been used to increase livestock production. Hormones are chemi cals relcased by a specific area of the body that are transplanted to another region within the animal where they elicit a physiological

response. Many of the hormones of the body and their physiological responses have been identified by scientists, who have also successfully synthesized compounds which produce the same responses as those froil naturally produced hormones. Animal Nutritionists have been able to administer hormones exogenously and have obtained specific responses in terins of growth stimulation or milk production. Hormonal products used to jncrease production can be administered as either a subcutaneous implantation or a feed ingredient. When implanted, the active chemical compounds are released slowly but constantly into the blood stream. The blood levels of hormones in animals fed these compounds fluctuates according to the physiological factors associated with the digestion and absorption of the nutrients of the feed, such as the nutritional state of the animal, quantity of feed consumed etc. At present three comounds are available commercially: diethyl stilbesterol (DIS), synover and ralgro. Inplantation of growth stimulants is not difficult but it must be done correctly to maximise benefits. When addid to feed, hormones and hormone like compounds are either growth stimulators, e.g., diethylstilbesterol 
(DES) and melongesterol acetate (MGA), or regulators of metabolic rate, e.g•, iodinated casein which is a thyroxi ne like compound.

Tranquilizing drugs like aspirin and resperpine, are sometimes fed to livestock to iimprove production by keeping the animals in minimal activity, thereby lowering the nutrient requirements for maintenance, However they also appear to supress feed intake, so in spite of some beneficial effects they are not very popular.

Additives that affect the ceneral well being of the animal. Feed additives have been developed strictly for medicinal purposes. Examples are activated carbon, antibloat compounds, antifurigals, and artiparasitic drugs. 


\subsection{Feed Processing Methods}

Feed processing encompasses all the operations necessary to achieve the maximum potential nutritional value of a feed stuff, including changing ingredients in such a manner as to maximise their natural value. Feed processing may be physical and/or chemical. Physical chances resuit for example from moisture addition or removal, heat, pressure, agiloneration (clustering topether), and particle reduction. Chemical changes may include structural changes in the starch content and the disrupting of the protein matrix resulting in changes in digestibility and metabolic end products.

The feed processing methods discussed are described under the headings: grain processing methods, and forage processing methods.

\section{Grain Processing Methods}

1. Mechanical alterations

a) Dehulling is the process of removing the outer coats of grains, nuts, and some frui is.

b) Extruding, where the feed is pressed, pushed, or protruded through constrictions under pressure.

c) Grinding is that rocess by wich a feedstuff is reduced in particle size by impact, shearing, or attrition.

d) Rolling refers to the rocess by which crains are compressed into flat particles by passing them between rollers.

Dry rolling, also called cracking or crushing, involves passing the grains, without steam, between a closely fitted set of steel rollers usualiy grooved on the surface.

Steam rolling, also called crimping or steam crimping, involves exposing the grains to steam for a short poriod of tine, usually between 1 and 8 minutes, followed by rolling.

\section{Heat Treatinents}

a) In Dry Heat Processing the feed is surrounded with dry air and heated.

Vicronising is a coined word to describe a dry heat treatment of grain by mi crowaves emi tted from infrared burners. In micronising, the grain is heated to $150^{\circ} \mathrm{C}$ by eas fired infrared generators as it passes along an oscillating steel plate or skillet, whence it is dropped onto knorling rolls. 
Popring is the exploding, or puffing out of grain resulting from the rapid application of dry heat, and involves the same principle as making popcorn.

Roasting is a simple process of heating feed to the desired temperatue in some form of oven for a period of time.

b) Moist heat processing consists in surrounding the feed by water or steam and either cooking in a conventional vessel or under pressure, or compressing. The common moist heat processing methods are cooking (the application of heat), crumbling (the crushing of rallets of comounded feed), exmloding (in which the grain swells when steamed under pressure and them exposed to the air), flaking (a modification of steam rolling in which the grain is steamed for a longer time or under pressure) and pelleting (the aggiomeration of feed by compaction and forcing through die openings).

\section{Moisture Alterations}

Water is important in feed preparation and processing. Sometimes the water content of a feed must be altered for proper storage and feeding.

Drying is the removal of moisture by artificial or natural means.

Branmash is steamed wheat bran.

$\mathrm{High}$ moisture grains are harvested at a moisture level of 22 to 40 percent and stored without drying.

Reconstituted grain is mature grain that is harvested at the normal moisture level (10 to 14\%) with water being later added to bring the moisture level to 25 to $30 \%$, and the wet product stored in a suitable structure for 15 to 21 days prior to feeding.

Watered Feeds. Water is frequently added to feed, with the amount varying from just enough for dust control to making a slo. Sometimes hard grains are soaked for from 12 to 24 hours.

4. Blocks are compressed ackages, generally weighing from 30 to 50 pounds each.

5. Liquid Supplements are sup lements in liquid form many of them containing water, molasses and urea, and usually with added trace minerals and vi tamins. 
6. Fermenting. Two fermentation processes are of practical importance in livestock feeding: ensiling, and the improvement of the nutritional value of the feed, either by fermenting the feedstuff ifself, or by fermenting other materials that may be used as feed additives to supplement the original feed.

7. Hydroponics (or sprouted grain) is the growing of plants with their roots immersed in an aqueous solution contatning the essential mineral nutrients salts, instead of soils. This means that sorouted grain for feed is produced with water and chemicals, wi thout soil.

Unprocessed (whole) corm is shelled corm, the kernels of which have not been broken. 


\subsection{Effect of Storage on Feedstuffs}

The extent of the effects of storage on feedstuffs is dependent upon a number of factors, including moisture content, temperature, degree of maturity when harvested, the manner of handling before storage, the type of storage bins or containers used, and the length of time stored.

Storage affects the nutritive value of feeds as follows:

-Loss of carotene. Carotene content decreases significantly in storage, with consequent loss of vitamin A activity.

-Trace minerals destroy vitamins in the feeds or vitamin premixes.

-Destruction by light. Riboflavin, pyridoxine, and ascorbic acid are readily destroyed by light.

-Vitamins $A, D$ and $\mathbb{E}$ are unstable with consequent loss of potency over time.

-Thiamin ( $B_{1}$ ) content is little changed even on long storage under favorable conditions.

-Fats deteriorate with the formation of free fatty acids which may affect palatability.

-Proteins may deteriorate, especially if the grains are placed in storage bins immediately following harvesting.

-Insects may destroy feedstuffs unless they are controlled

through sanitation and the use of insecticicies. 


\section{CHAPTER 3. Food Evaluation}

3.1 The Importance of Monitoring Feed Quality/ 114

3.2 How to take Feed Samples/ 114

3.3 Feed Analysis/ 114

3.3.1 Physical Evaluation/ 115

3.3.2 Chemical Analysis/ 116

3.3.3 Weende Analysis/ 130

3.3 .4 van Soest Analysis/130

3.3.5 Bomb Calorimetry/131

3.3.6 Biological Analysis/ 133

3.4 Techniques utilized in Feed Analysis/ 134

3.5 Types of Feed Evaluation Trials/ 135

3.6 Nitrogen Balance Trials/ 140

3.7 Energy Balance Trials/ 142

3.8 Calorimetric Systems $/ 143$

3.9 Systems for expressing the Energy Value of Feedstuffs/ 145

3.10 Predicting Protein and Energy Values by Regression Equations/ 152 


\subsection{The Importance of Monitoring Feed Quality}

The chemical composition and nutritive value of feeds and fodders available in various publications or books pertains to a particular lot in a particular area or zone and in a particular country. It cannot have universal aplication. There may also be variations from year to year in the same lace. It is very necessary therefore, to monitor and recheck feed quality and to analyse feeds and fodders regularly to ensure that livestock production is not affected by decreases in the quality of foeds and the livestock owner not put to any financial loss in production. Agricultural production in quality and quantity depends on the ciuality of the seed, the soil, aplication of manures and fertilizers in adequate amounts and at apropriate thes and dequate rainfall or irrigation at the proper time of grotih. For example, the legume fodder berseen, Grown under favourable condlions, will have legurne fodder, berseen,
nore than $22 \%$ crude protein and yi eld $600 \mathrm{~kg}$ per hectare. But
if the quality of seed is oor, proper mures and fertilizers have not been aplied and irrigation is poor, the fodder may give only $15 \%$ crucie protein and the yield may je only $400 \mathrm{~kg}$ per hectare. The primary loss, in productior, is borne by the producer and the secondary loss, in quality, by the buyer. The buyer purchases the fodder under the impression that it contains $22 \%$ crude protein and will feed $t t$ accordingly. The animals will be under fed and the production suffer.

\subsection{How to take feed samples}

Feeds are highly variable in composition. Feeding value can vary from one bale of hay to another. Several sailes must be taken from various represcntative areas. These sainles are then thoroughly mixed together to form a representative composite sample of the entire feed. An ali quot (part of the whole) is taken from this composite, so that the final cralysis will represenc an overall average.

All feed samples should be put in plastic consiners or insulated bars and sent immediately to the lavoratory for analysis. Feeds with high noisture content, such as greens or silage should be frozen until analyzed.

\subsection{Feed Analysis}

Feeds are analyzed by physical, chemical, or biolo ical procedures. Although physical evaluati on may be the least accu: te, it provides a quick and easy means of obtaining considerable intormation about overall qualj.ty. The chemical rocedure is more ac irate but takes time. The biological method needs the nost ti ie and expense 
and the results are often variable.

\subsubsection{Physical Evaluation}

The physical evaluation of feecistuffs, especially fodders, is based largely on eye and smell appraisal-the feed should lood and smell good.

Characteristics of rood grains and other concentrates: The easily recognisable characteristics are

1. Seeds not sulit or cracked

2. Low moisture content-10 to $12 \%$ moisture

3. Good colour, characteristic of the species

4. Concentrates and seeds free from mould

5. No rodent or insect danage

6. No foreien material, such as iron filings, stone chips and other aciulteranis

7. No rancid odour

Characteristics of cood hay: Good hay is

1. Made from plants cut at an early stage of maturj ty, thus assurine the maximum content of protein, ninerals and vitamins and the highesi dicestibility.

2. Leafy, imlying high protein content.

3. Bright green in colour, indicating proper curing, a high carotene content and palatability.

4. Free fron foreign material, such, as weeds, dirt and stubble.

5. Free from nould and dust.

6. Pine stemned and oliablemot coarse, stiff and roody.

7. Pleasant and fragrant snelling. 
Characteristics of good silage:

1. A "clean", rather pleasing acid odour, in contrast to the objectionable odour of poor silage.

2. A pleasing taste-it is not bitter or sharn.

3. It is not nouldy, misty, or slimry.

4. It is uniform in moisture and colour. Green or brownish silago is generally cood; tobacco brown or dark brown silage indicates excessive heat; and biack silage is rotten and should not be fed.

\subsubsection{Chemical Analysis}

A cherical analysis gives a solid foundation on which to base the evaluation of feeds. The cheirical composition of feeds serves as a basis for nurchase and ration formulation.

Reagents: Unless specified otheruse, pure chemicals (impurity free) and distilled water nust be emplow in tests.

Sanple Preparation: Grind about $100 \mathrm{~s}$ of the sample till it can pass through a lmi IS Si eve. AJternatively, ASTM Si ve 18 or BS Sieve 16 or Tyler Sieve 16 may be used. Transfer this prepared sample to a well-stoppered glass bottle.

\section{Moisture Determination}

Weigh accurately about $5 \mathrm{~g}$ of the prepared sample in a tared aluminium dish vith a cover, having a djameter of at least $50 \mathrm{~mm}$ and a depth of aboit $4.0 \mathrm{~mm}$. Shake the dish until the contents are evenly distributed. Ith cover removed place the dish and cover in an air..oven maincained at $135 \pm 20 \mathrm{C}$ and dry for at least 2 hours. Place cover on dish, cool in a desiccator and weigh. Repeat the rocess of hoating, cooling and weighing until the difference in mass becween two successive weighings is less than one milligran. The noisture content, percent by mass is given by $\frac{100(1-1-12)}{M_{1}-M}$, where

$M_{I}=$ mass of the dish with the material before drying

$\mathrm{M}_{2}=$ nass of the dish with the material after drying and

$M=$ mass of the enpty dishe 
Detcrmination of Crude Protein

Principle- The vercentage of crude protein is ascertained by multiplying the percentase of nitrosen, otiner than ammoniacal nitrogen, by a factor. The quantity of amoniacal nitrogen is separately decermined and deducted from total nitrogen content. For animal feeds and feeding stuffs the factor to be used is 6.25 , excent in case of wheat anc its producte for which it is 5.70 .

\section{Apparatus}

Kjeldahl Flask-500 ml capacity.

Distillation Assombly-The assembly consists of a round bottom flask of 1000 wl capacj. fitted with a rubber stopper through which one end of a connecting bulb tube passes. The other end of the bulb tube is comected to the condenser which is attached by means of a rubier tube to a dip tube which dips into a knom quantity of standard sulphuric acid or boric acid solution contained in a conical flasl: of $500 \mathrm{ml}$ capacity, to which 3 to 4 drops of methyl rod indicator solution have been added.

\section{Reagents}

1. Potassiun Sulphate or Anhydrous Sodium Sulphate

2. Copper Sulphate

3. Concentrate Sulphuxic Acid-r.d. 1.84

4. Sodium Hydroxide Solution - Dissolve about $450 \mathrm{~g}$ of sodium hydroxide in 1000 inl of water.

5. Standard Sulohuric Acid- $0.5 \mathrm{~N}$.

6. Standard Sodiun Hycroxide Solution - $0.25 \mathrm{~N}$.

7. Methyl Red Irdicator Solution-Dissolve $1 \mathrm{~g}$ of methyl red in $200 \mathrm{ml}$ of rectified soirit, 95 percent by volume.

¿. Boric Acid Solution-Saturated. Dissolve $60 \mathrm{~B}$ of boric acid in one litre of hot vater, cool and allow to mature for 3 days before decanting the clear licuid.

9. liagnesium Oxide- carbonate free, freshly irnited.

Procedure

Total ritrocen- Transfer carofully about 28 of the prenared

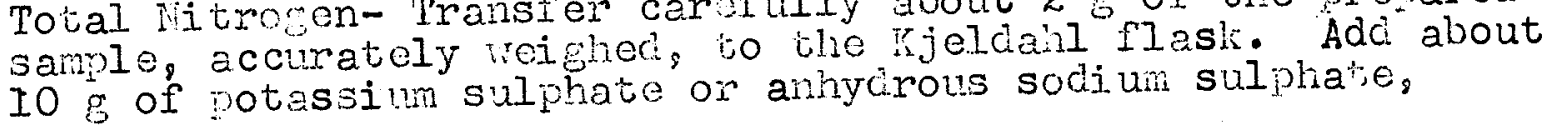


about $0.5 \mathrm{~g}$ of con er sulphate and $25 \mathrm{ml}$ or more, if necessary, of concontrated sulphuric acid. Place the flask in an inclined osjtion, and heat below the boiling point of the acid until frothing ceases. Increase heat until the acid boils vigorously and digest for a time aftor the mixture is clear or until. oridation is complete (about 2 hours). Cool the conients of the rlask. Transfer quantitiatively to the round botton flask with about $200 \mathrm{ml}$ water. Add a few pieces of punice stone to pevent bumping. Carefully add a sufficient guantity of the sodium hydroxide solution along the sides of the flask so it does not nix at once but forms a layer under the acid, until the solution is alkaline. Assemble the apparatus, taking care that the tip of the di -tube extends below the surface of the standara sulphuric acid solution in the receiver.

Mix the contents of the flasli by shaking and distil until all the anmonia has assed over into the standara sulniuric acid solution. Titrate with siendard sodiun hydroxide solution.

Carry out a blank determination using all reacents in the same quantitidies but wi thout the matemal to be tested.

Alterratively, the ammonia evolved by distillation can be absorbed in boric acid. Carry out dicestion as prescribed above. Transfer completely the contents of the digestion flask into the round botton flask through the separating funnel. Rinse the separating funnel. With water. The total volune of liquid in the distiliation flask should not exceed half its capacity othervise frothing may occur. Add an excess of solium hydroxide solution to make the solution alkaline. Immediately connect the round bottom flask to the stean trap and condenser. The condenser should be arranged to di the dip-tube in $50 \mathrm{ml}$ of 2 or 3 drops of the mired indicator. Distil about one-third of the total volume of the solution in the flask. Cool and aismantle the distillation assembly. Rinse the tio of the condenser and the djp-tuoe with water, collecting the washings in the receiver. Titrate the annonia present in the distillate vith sulphuric acid until the grass-green colour changes to steel-grey, an additional drop then giving the purple colour.

Anmoniacal Nitrogen- Neigh caccurately 2 to $4 \mathrm{~g}$ of the prepared sample. Shalie it with water and filter. Wash the residue thoroughly with water. Transfer the filtrate to the distillation flask and dilute to about $200 \mathrm{ml}$ with water. Add about 5 \& of manesium oxide. Connect the flasl to the condenser by means of the connecting bulb tube and distil about 100 mi of liquid into the receiver containing standard sulphuric acid and methyl red indicator solution. Titrate the contents of the receiver with standard sodium hydroxide solution. 
Carry out a blank determination using all reagents in the same quantities but without the material to be tested.

\section{Calculation}

Total nitrogen (on moisture-free basis). percent by mass where

$$
=\frac{140(B-A) N}{m(100-M)}
$$

$$
\begin{aligned}
\mathrm{B}= & \text { volume in ml of the standard sodium hydroxide } \\
& \text { solution used to neutralize the acid in blank } \\
& \text { determination } \\
\mathrm{A}= & \text { volume in nl of the standard sodium hydroxide } \\
& \text { solution used to neutralize the excess acid in the } \\
& \text { test with the naterial } \\
\mathrm{N}= & \text { normality of the standard sodium hydroxide solution } \\
\mathrm{m}= & \text { mass in } \mathrm{B} \text { of the material taken for the test and } \\
\mathrm{M}= & \text { moisture percentage }
\end{aligned}
$$

Then boric acid solution hos been used for absorption, the calculation of total nitrogen is given by

Total nitrogen (on moisture-free basis), percent by mass where

$$
=\frac{140 \mathrm{VN}}{\mathrm{n}(100-\mathrm{M})}
$$

$V=$ volume in ml of the standard sulphuric acid used in titration,

$\mathrm{N}=$ normality of the standard sulphuric acid,

$m=$ mass in $g$ of the material taken for the test and

$M=$ moisture percentage

Ammoniacal nitrogen (on noisture-free basis),

$$
\begin{aligned}
& \text { Ammoniacal nit trogen (on hy mass } \\
& \text { where }
\end{aligned}=\frac{140(b-a) N}{m(100-M)}
$$

$b=$ volume in $m I$ of the standard sodium hydroxide solution used to neutralize the acid in blank determination

$a=$ volume in $m l$ of the standard sodiun hydroxide solution used to neutralize the excess acid in the test with the naterial 


$$
\begin{aligned}
& N=\text { normality of the standard sodium hydroxide solution } \\
& m=\text { mass in } g \text { of the material taken for the test and } \\
& M=\text { moisture percentage. }
\end{aligned}
$$

Crude protein (on noisture-free basis), percent by mass where

$$
=6.25(X-Y)
$$

$$
\begin{aligned}
& X=\text { percent by mass of total nitrogen and } \\
& Y=\text { percent by mass of ammoniacal nitrogen. }
\end{aligned}
$$

\section{Determination of Urea Nitrogen}

Principle - The percentage of urea nitrogen is ascertained by deducting the percentage of ammoniacal nitrogen from percent total ammoniacal nitrosen which includes both amnoniacal and urea nitrogen. However, a suitable qualitative test for detecting the presence of urea nitrogen should precede the quanticative determination as outlined below.

\section{Apparatus - as above}

\section{Reagents}

1. Defoaming Solution - Dissolve $50 \mathrm{~g}$ diglycol stearate in $375 \mathrm{ml}$ of benzene, $75 \mathrm{ml}$ of alcohol, and $250 \mathrm{ml}$ of dibutyl phthalate. Warm, if necessary.

2. Urease Solution - Dissolve standardized urease in water so that each $10 \mathrm{ml}$ neutralized solution will convert the nitrogen of at least $0.1 \mathrm{~g}$ pure urea. Prepare fresh urease solution for every determination.

Standardization of ureqse solution - To determine alkalinity of commercial urease preparation dissolve $0.1 \mathrm{~g}$ in $50 \mathrm{ml}$ of water and titrate with $0.1 \mathrm{~N}$ hydrochloric acid using methyl red as indicator. Add the same quantity of $0.1 \mathrm{~N}$ hydrochloric acid to each $0.1 \mathrm{~g}$ of urease in preparing the urease solution. To determine enzyme activity, prepare about $50 \mathrm{ml}$ of a neutralized one percent solution of urease. Add different quantitities of solution to $0.1 \mathrm{~g}$ samples of pure urea and follow with enzyme digestion and distillation as directed in the determination. Calculate activity of the urease preparation from the quantity of the urease solution that converted the urea, thereby permitting complete recovery of the nitrogen by distillation. 
3. Calcium Chloride Solution - Dissolve $25 \mathrm{~g}$ calcium chloride in $100 \mathrm{ml}$ of water.

4. Standard Sulphuric Acid $-0.5 \mathrm{~N}$ or $0.1 \mathrm{~N}$ when the amount of nitrogen is small.

5. Standard Sodium Hydroxide Solution $-0.25 \mathrm{~N}$ or $0.1 \mathrm{~N}$.

6. Methyl Red Indicator Solution - Dissolve lg of methyl red in $200 \mathrm{ml}$ of rectified spirit, 95 percent by volume.

7. Magnesium Oxide - (carbonate-free), freshly ignited, heavy type.

Procedure

Weigh accurately about $2 \&$ of the prepared sample in the Kjeldahl flask. Shake it with about $250 \mathrm{ml}$ of water. Add $10 \mathrm{ml}$ urease solution, put the stopper on tightly and let it stand for 1 hour at room temperature, or 20 ni nutes at $400 \mathrm{C}$. Cool to room temperature, if necessary. Use more urease solution if the samile contains more than 5 percent urea (approximately equal to 12 percent protein equivalent). Rinse stopper and neck with a few millilitres of water. Add 2 है of magnesium oxide (heavy type), I ml of calcium chloride solution and $5 \mathrm{ml}$ of defoaning solution. Connect the flask to the condenser by means of the connecting bulb tube and distil about $100 \mathrm{ml}$ of liquid into the receiver containing standard sulphuric acid and methyl red indicator solution. Titrate the contents with the standard sodium hydroxide solution.

Carry out a blank determination using all reagents in the same qualities but without the material to be tested.

\section{Calculation}

Total ammoniacal nitrogen (urea and amnoniacal nitrogen) (moisture-free), percent by mas.

where

$$
=\frac{140(B-A) N}{m(100-M)}
$$

$B=$ volume in $m l$ of the standard sodium hydroxide solution used to neutralize the acid in blank determination

$A=$ volume in $\mathrm{mI}$ of the standard sodium hydroxide solution used to neutralize the excess acid in the test with the material

$\mathbb{N}=$ normality of the standard sodium hydroxide solution 
$m=$ mass in $g$ of the material taken for the test, and

$\mathrm{M}=$ moi sture percentage.

Urea nitrogen $=a-b$

where

$a=$ percent by mass of total ammoniacal nitrogen

$b=$ percent by mass of ammoniacal nitrogen

Crude Fat Determination

Reagents

1. Petroleum Ether - boiling range $40^{\circ}-60^{\circ} \mathrm{C}$.

2. Hexane, Food Grade - conforming to IS : 3470 - 1996.

Procedure

Weigh accurately about $2.5 g$ of the prepared sample, dried as

described under moisture determination and extract with

petroleum ether or hexane, in a Soxhlet or other suitable

extractor. The extraction period may vary from 4 hours at

a condensation rate of 5 to 6 drops per second to 16 hours

at 2 to 3 drops per second. Dry the exiract on a steam-bath for 30 minutes, cool in a desjccator and weigh until the difference between two successive weighings is less than one mg. Note the lowest mass. If necessary preserve the fat-free material in a desiccator for the determination of crude-fibre content.

Calculation

Crude fat (on moisture-free basis),

percent by mass

where

$\mathrm{M}_{1}=$ mass in $g$ of the extraction

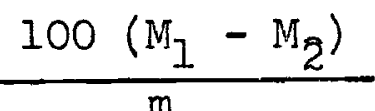

flask with dried extract

$\mathrm{M}_{2}=$ mass in $g$ of extraction flask, and

$m=$ mass in $g$ of the dried sample taken for the test.

Determination of Crude Fibre

Reagents

1. Sulphuric Acid $-0.255 \mathrm{~N}\{1.25$ percent $(\mathrm{m} / \mathrm{v})\}$, accurately prepared.

2. Sodium Hydroxide Solution $-0.313 \mathrm{~N}\{1.25$ percent (m/v)\}, accurately prepared. 


\section{Procedure}

Weigh accurately about $2 \mathrm{~g}$ of the dried material and extract the fat for about $\&$ hours with petroleum ether or hexane, food grade, using a Soxhlet or other suitable extractor or use the residue from the crude fat determination. Transfer the fat-free dry residue to a one-litre conical flask. Boil $200 \mathrm{ml}$ of dilute sulphuric acid in a beaker and transfer the whole of the boiling acid to the flask containing the fat-free material and immediately connect the flask to a reflux water condenser and heat, so that the conten ts of the flask begin to boil within one minute. Rotate the flask frequently, taking care to keep the material from remaining on the sides of the flask out of contact with the acid. Continue boiling for exactly 30 minutes. Remove the flask and filter through fine linen (about 18 threads to the centimetre) held in a funnel, and wash with boiling water until the washings are no longer acid to litmus. Bring to the boil some quantity of sodium hydroxide solution. under a reflux condenser. Wash the residue on the linen into the flask with $200 \mathrm{ml}$ of the boiling sodium hydroxide solution. Immediately connect the flask with the reflux condenser and boil for exactly 30 minutes. Renove the flask and immediately filter through the filtering cloth. Thoroughly wash the residue with boiling water and transfer to a Gooch crucible prepared with a thin but compact layer of ignited asbestos. Wash the residue thoroughly first with hot water and then with about $15 \mathrm{ml}$ of 95 percent (by volume) ethyl alcohol. Dry the Gooch crucible and contents at $105 \pm 10 \mathrm{C}$ in the air-oven to constant mass. Cool and weigh. Incinerate the contents of the Gooch crucible at $600+20^{\circ} \mathrm{C}$ in a muffle furnace until all the carbonaceous natter is burnt. Cool the Gooch crucible containing the ash in a desiccator and weigh.

NOTE- Alternatively, instead of the conical flask and the reflux condenser, use a tall form spoutless beaker of 600 to $800 \mathrm{ml}$ capacity and cover it with a roundbottomed flask filled wi th cold water, which acts as a condenser. If the water in the flask becomes hot, it may be relaced by another flask containing cold water.

\section{Calculation}

Crude fibre (on moisture-free basis), percent by mass where

$$
=\frac{100\left(\mathrm{M}_{1}-\mathrm{M}_{2}\right)}{\text { (III }}
$$

$\mathrm{M}_{1}=$ mass in $\mathrm{g}$ of Gooch crucible and contents before ashing $M_{2}=$ mass in $g$ of Gooch crucible containing asbestos $m=$ mass in $g$ of the dried material taken for the test. 
When the residue from fat determination is used: Crude fibre (on moisture-free basis), percent by mass

$$
=\frac{\left(M_{1}-M_{2}\right)(100-f)}{m_{1}}
$$

where

$$
\begin{aligned}
& M_{1}=\text { mass in } g \text { of Gooch crucible, and contents before ashing, } \\
& M_{2}=\text { mass in } g \text { of Gooch crucible containing asbestos and ash, } \\
& f=\text { crude fat (on moisture-free basis), percent by mass, and } \\
& m_{1}=\text { mass in } g \text { of the fat-free material taken for the test. }
\end{aligned}
$$

\section{Determination of Total Ash}

Procedure

Weigh accurately about $2 g$ of the dried material in a tared porcelain, silica or platinum dish. Ignite with the flame of a Meker burner for about one hour. Complete the ignition by keeping in a muffle furnace at $550 \pm 20^{\circ} \mathrm{C}$ until grey ash results. Cool in a desiccator and weigh. Ignite the dish again in the muffle furnace for 30 minutes, cool and weigh. Repeat this process until the difference in mass between two successive weighings is less than $1 \mathrm{mg}$. Note the lowest mass.

NOTE - Preserve the dish containing this ash for the determination of acid insoluble ash.

Calculation

Total ash (on moisture-free basis), percent by mass

where

$$
=\frac{100\left(M_{2}-M\right)}{M_{1}-M}
$$

$\mathrm{M}_{2}=$ the lowest mass in $g$ of the dish with the ash

$M=$ mass in $g$ of the empty dish, and

$\mathrm{M}_{1}=\underset{\text { mass in }}{\mathrm{g} \text { of }}$ the dish with the dried material taken

\section{Determination of Acid Insoluble Ash}

Reagents

Dilute hydrochloric acid-approximately $5 \mathrm{~N}$, prepared from concentrated hydrochloric acid. 
Procedure

Weigh accurately $2 \mathrm{~g}$ of the dried material in a tared porcelain, silica or platinum dish. Ignite with a Meker burner for about one hour. Complete the ignition by keeping in a muffle furnace at $550^{\circ} \mathrm{C} \pm 20^{\circ} \mathrm{C}$ until grey ash results. Moisten with concentrated hydrochloric acid and evaporate to dryness. Keep in an air oven maintained at $135 \pm 20 \mathrm{C}$ for about 3 hours. Cool and add $25 \mathrm{ml}$ dilute lydrochloric acid, cover with a watch-glass and heat on a water-bath for 10 minutes. Cool and filter through whatman filter paper No. 42 or its equivalent. Wash the residue with hot water until the washings are free from chlorides as tested with silver nitrate solution and return the filter paper and redidue to the dish. Ignite it in a muffle furnace at $550^{\circ} \pm 20^{\circ} \mathrm{C}$ for one hour. Cool in a desiccator and weigh. Ignite the dish again for 30 minutes, cool and weigh. Repeat this process till the difference between two successive weighings is less than one milligram. Note the lowest mass.

Calculation

Acid insoluble ash (on moisture-free basis), percent by mass

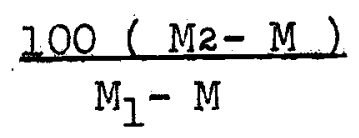

where

$$
\begin{aligned}
& M_{2}=\text { the lowest mass in } g \text { of the dish with the acid } \\
& \text { insoluble ash } \\
& M=\text { mass in } g \text { of the empty dish, and } \\
& M_{1}=\text { mass in } g \text { of the dish with dried material. }
\end{aligned}
$$

Determination of Nitrogen Free Extract

The nitrogen free extract (NFE) fraction of the proximate analysis is determined by the following formula:

$$
\begin{aligned}
\mathrm{NFE}=100-(\% \text { moisture }+\% \text { crude fibre } & +\% \text { ash }+\% \text { ether extract } \\
& +\% \text { crude protein })
\end{aligned}
$$

This fraction represents a catch-all for the organic material for wilich there is no specific analysis. The vast majority of components in this fraction are carbohydrates (starch, fructans, pectins, celilulose, hemicellulose, and lignin), but other substances such as pignents, organic acids, and water soluble vitamins, are also present.

\section{Determination of Salt (Chlorine as Sodium Chloride)}

\section{Reagents}

1. Ferric Sulphate Solution - dissolve $60 \mathrm{~g}$ of ferric sulphate $\left\{\mathrm{Fe}_{2}\left(\mathrm{SO}_{4}\right)_{3}\right\}$ in one litre of water 
2. Ammonium Hydroxide Solution - prepared by mixing one volume of ammonium hydroxicie with 12 volumes of water

3. Concentrated Nitric Acid - r.d. 1.42

4. Ferric SuIphate Indicator Solution - prepare as 25 percent $(\mathrm{m} / \mathrm{v})$ solution. Filter and add equal volume of nitric acid

5. Standard Silver Nitrate Solution - $0.1 \mathrm{~N}$

6. Standard Potassium Thiocyanate Solution - $0.1 \mathrm{~N}$

Procedure

Weight accurately about $1 g$ of the dried materjal and transfer to a $250 \mathrm{ml}$ graduated flask. Add $50 \mathrm{ml}$ of the ferric sulphate solution with a pipette, gently swirling the flask. Add $100 \mathrm{ml}$ of the ammonium hydroxide solution to bring it to the mark. Swirl the flask enough to ensure thorough mixing but avoid vigorous shaking. Allow to settle for 10 minutes. Filter through an $11 \mathrm{~cm}$ Whatman filter paper No. 41 or its equivalent. Transfer from the filtrate, an aliquot of $25 \mathrm{ml}$ to a $250 \mathrm{ml}$ beaker. Add $10 \mathrm{ml}$ of nitric acid and $10 \mathrm{ml}$ of the ferric. sulphate indicator solution. Then add with constant stirring, a known quantity of the standard silver nitrate solution in slight excess. Heat the solution to the boil and cool to room temperature and sti i to coagulate the precipitate. Titrate the excess of silver nitrate with the standard potassium tiliocyanate solution. The end point is indicated by the first appearance of a reddish tint that persists for 15 seconds.

Calculation

Chlorine as sodium chloride (on moisture-free basis),

percent by mass

where

$$
=\frac{5.845\left(\mathrm{AN}_{1}-\mathrm{BN}_{2}\right)}{\mathrm{m}(100-\mathrm{M})}
$$

$A=$ volume in $\mathrm{ml}$ of the standard silver nitrate solution used

$\mathrm{N}_{]}=$normality of the standard silver nitrate solution

$B=$ volume in $\mathrm{ml}$ of the standard potassim thiocyanate solution used up by the excess silver nitrate solution

$\mathrm{N}_{2}=$ normality of the standard potassium thiocyanate solution

$m=$ mass in $g$ of the dried material taken for the test

$M=$ percent moisture content. 


\section{Determination of Calcium}

Reagents

1. Hydrochloric Acid - $25 \mathrm{ml}$ concentrated hydrochloric acid diluted to $100 \mathrm{ml}$.

2. Methyl Red Indicator - dissolve $0.15 \mathrm{~g}$ of methyl red in $500 \mathrm{ml}$ of water.

3. Ammonium Hydroxide solution -50 percent ( $/ \mathrm{v})$.

4. Dilute Ammoni um Iydroxide Solution - 2 percent ( $/ \mathrm{v})$.

5. Ammonium Oxalate Solution - saturated.

6. Concentrated Sulphuric Acid - r.d. 1.84

7. Standard Potassium Permanganate Solution - $0.1 \mathrm{~N}$

\section{Procedure}

Ashing and Extraction - Accurately weigh about $3 \mathrm{~g}$ of the material into a silica dish. Char carefully and continue the ashing in a muffle furnace at a temperature not above $450^{\circ} \mathrm{C}$ until the ash is white or almost so. Cool the ash, moisten with a few millilitres of distilled water and add 3 to $5 \mathrm{ml}$ concentrated hydrochloric acid drop by drop. Evaporate to dryness on a water-bath and continue heating on the water-bath for one hour to render silica insoluble. Moisten the residue with $20 \mathrm{ml}$ distilled water and add about 2 to $3 \mathrm{ml}$ concentrated hydrochloric acid. Heat on a water-bath for a $f e w$ minutes and filter through medium filter paper washing thoroughly with hot water, cool the filtrate and make it up to volume, shake thoroughly.

Transfer a $25 \mathrm{ml}$ aliguot of the solution prepared as above to a $400 \mathrm{ml}$ breaker, dilute to about $100 \mathrm{ml}$ with water and add two drops of methyl red indicator solution. Add ammonium hydroxide solution dropwise until a brownish-orange colour is obtained ( $\mathrm{pH} 5.6)$. Add two drops of hydrochloric acid so that the colour of the solution is pink (pH 2.5 to 3.0). Dilute to about $150 \mathrm{ml}$, bring to the boil and add slowly, with constant scirring, $10 \mathrm{ml}$ of hot ammonium oxalate solution. If the red colour of the solution changes to orange or yellow, add hydrochloric acid dropwise until the colour again changes to pink. Leave overnight to allow the precipitate to settle. Filter the supernatant liquid through ashless filter paper and wash the precipitate thoroughly with dilute aminonium hydroxide solution. Place the paper with the precipitate in the beaker in which precipitation was carried out and add a mixture of $125 \mathrm{ml}$ water and $5 \mathrm{ml}$ 
concentrated sulphuric acid. Heat to 70 to $90^{\circ} \mathrm{C}$ and titrate with the standard potassium permanganate solution until the first slight pink colour is obtained.

Calculation

Calcium (as $\mathrm{Ca}$ ) (on moisture-free basis), percont by mass

$$
=\frac{2000 \mathrm{AN}}{\mathrm{m}(100-\mathrm{M})}
$$

where

$$
\begin{aligned}
A= & \text { volume in } m \text { l of the standard potassiun permanganate } \\
& \text { solution required in the titration, } \\
N= & \text { nomality of the standard potassiun permanganate } \\
& \text { solution, } \\
m= & \text { mass in } g \text { of the material taken for the test } \\
M= & \text { percent moisture content. }
\end{aligned}
$$

\section{Determination of Phosphorus}

Reagents

1. Concentrated Nitric Acid - r.d. 1.42

2. Nitric Acid ( $1: 1)$ - a mixture of equal volumes of concentrated nitric acid and water

3. Ammonium Molybdate Stock Solution - take $200 \mathrm{~g}$ of powdered ammoniun molybdate in a stoppered graduated cylinder of $1000 \mathrm{ml}$ capacity, add $800 \mathrm{ml}$ water and shake well for 25 minutes to dissolve the ammonium molybdate. Add gradually 25 percent $(\mathrm{m} / \mathrm{v})$ ammonium hydroxide solution until the solution is clear. (about 100 to $140 \mathrm{ml}$ ammoniun hydroxide may be required). Avoid adding excess ammonia. Make up the volune to one litre. If necessary, filter the solution through a fluted filter paper and stock this solution.

4. Nitric Acid Solution - 2 percent $(\mathrm{m} / \mathrm{v})$

5. Potassium Nitrate Solution - 3 percent $(\mathrm{m} / \mathrm{v})$

6. Standard Sodium Hyciroxide Solution - $0.1 \mathrm{~N}$

7. Standard Nitric Acid Solution - $0.1 \mathrm{~N}$

8. Phenolphthalein Indicator Solution - dissolve $0.1 \mathrm{~g}$ phenolphthalein in $100 \mathrm{ml}$ of 60 percent $(\mathrm{m} / \mathrm{v})$ rectified spirit. 
Procedure

Precipitation - Take a $10 \mathrm{ml}$ aliquot of the prepared solution in a $150 \mathrm{ml}$ beaker. In a dry breaker, prepare ammonium molybdate solution by pouring into it, quickly and simultaneously $10 \mathrm{ml}$ of the ammonium molybdate stock solution and $10 \mathrm{ml}$ concentrated nitric acid; or take $10 \mathrm{ml}$ concentrated nitric acid first in the beaker and into this pour quickly $10 \mathrm{ml}$ of the ammoniun molybdate stock solution, whirling the beaker during addition. Pour this freshly preparer clear liquid quickly into the beaker containing the aliquot and stir.

NOTE - The temperature devloped in the molybdate solution is sufficient to precipitate all the phosphorus present in the aliquot. Under no circumstances should the phosphomolybdate precipitate be heated either on a water-bath or directly over a burner which will cause precipitation of nyolybdic anhydride.

Filtration and Washing - Allow the precipitate to stand overnight and then filter through a disc of Whatman filter paper No. 42 in a Gooch crucible by suction or through a 9-cm Whatman filter paper No. 42 over an ordinary funnel. Ensure as far as possible that only the supernatant liquid is passed through the filter paper, retaining the precipitate, which is then washed twice with dilute nitric acid and then with potassium nitrate solution until the washings are free from acid. If an ordinary funnel and filter paper are used, freedom from acidity may be tested by collecting sufficient filtrate in a test-tube to which a few drops of phenolphthalein indicator solution and one drop of the standard sodium hydroxide solution are added. If the pink colour appears with one drop of the standard alkali, the precipitate is free from acid.

Titration- Transfer the precipitate with the filter paper back to the beaker in which precipitation was carried out. When a Gooch crucible is used for filtration, transfer the whole crucible along with the filter paper to the beaker in which precipitation was carred out. Add the standara sodium hydroxide solution from a burette, just sufficient to dissolve the precjpitate and then add $5 \mathrm{ml}$ in excess. See that no yellow precipitate sticks to the filter paper. Note the total volume of the standard sodium hydroxide solution added. Add about 10 drops of phenolphthalein indicator solution and titrate the excess of alkali with the standard nitric acid.

Calculation

Phosphorus (on moisture-free basis), percent by mass

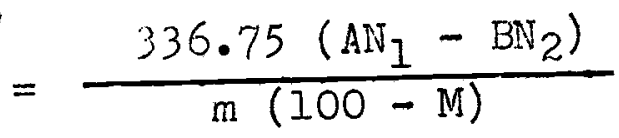

where

$A=$ volume in $\mathrm{ml}$ of the standard sodium hydroxide solution used 


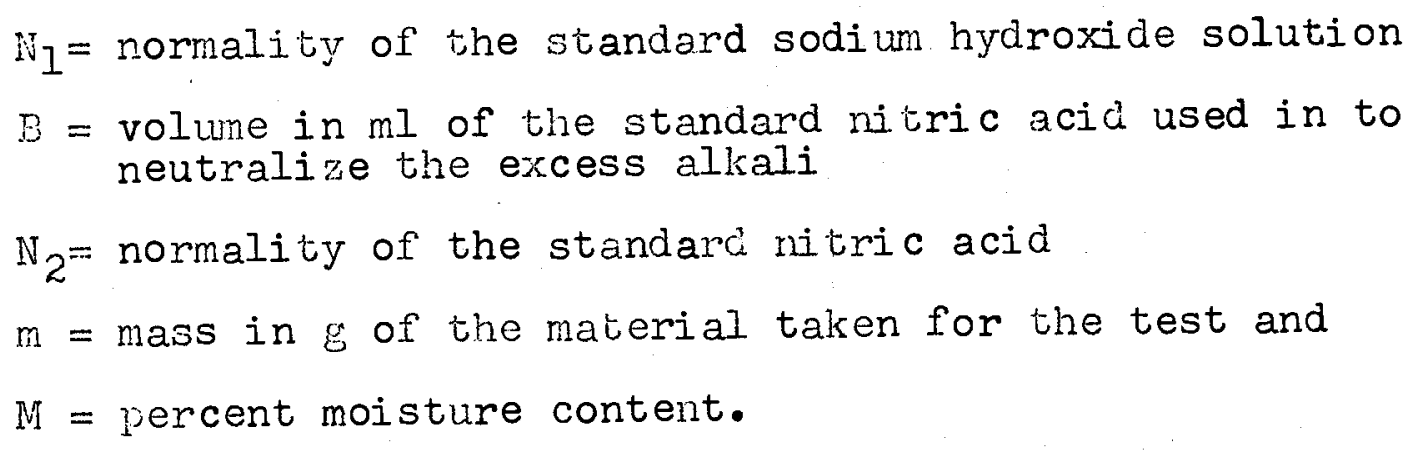

The chemical composition of feedstuffs can be expressed on an "as such basis" or on a "dry matter basis". The advantage of the former is that it helps in the computation of rations. Dxpressing the cheric cal composition on a "dry matter basis" on the other hand enables the comparison of feedstuffs by bringing them all to a stadard unit of measurement.

\subsubsection{Weende Analysis}

In this system of feed analysis, the total carbohydrates of forages are partitioned into crude fibre and nitrogen free extract: This division was based on the assumption that crude fibre is less digestible than nitrogen free extract. However, this method is no longer being followed.

\subsubsection{Van Soest Arralysis}

Here the feed sample is initially boiled in a neutral detergent solution to separate the soluble and insoluble fractions. The neutral detergent solubles consist of cell contents which are highly (about $98 \%$ ) digestible by both ruminants and nonruminants. It includes various sugars, starches, pectins, proteins, lipids, nitrogenous compounds, soluble carbohydrates and water soluble minerals and vitamins. The insoluble fraction contains the cell walls, which can be further fractionated by boiling in acidic detergent solution. Hemi cellulose is solubilized during this procedure, leaving behind the lignocellulose fraction of the feed. Cellulose is then separated from lignin by the addition of sulphuric acid, after which only lignin and acid insoluble ash remain. This resicue is then ashed, and the difference of weights before and after ashing yields the amount of lignin present in the feed. The feed analysis is presented in a flow diagram below. 


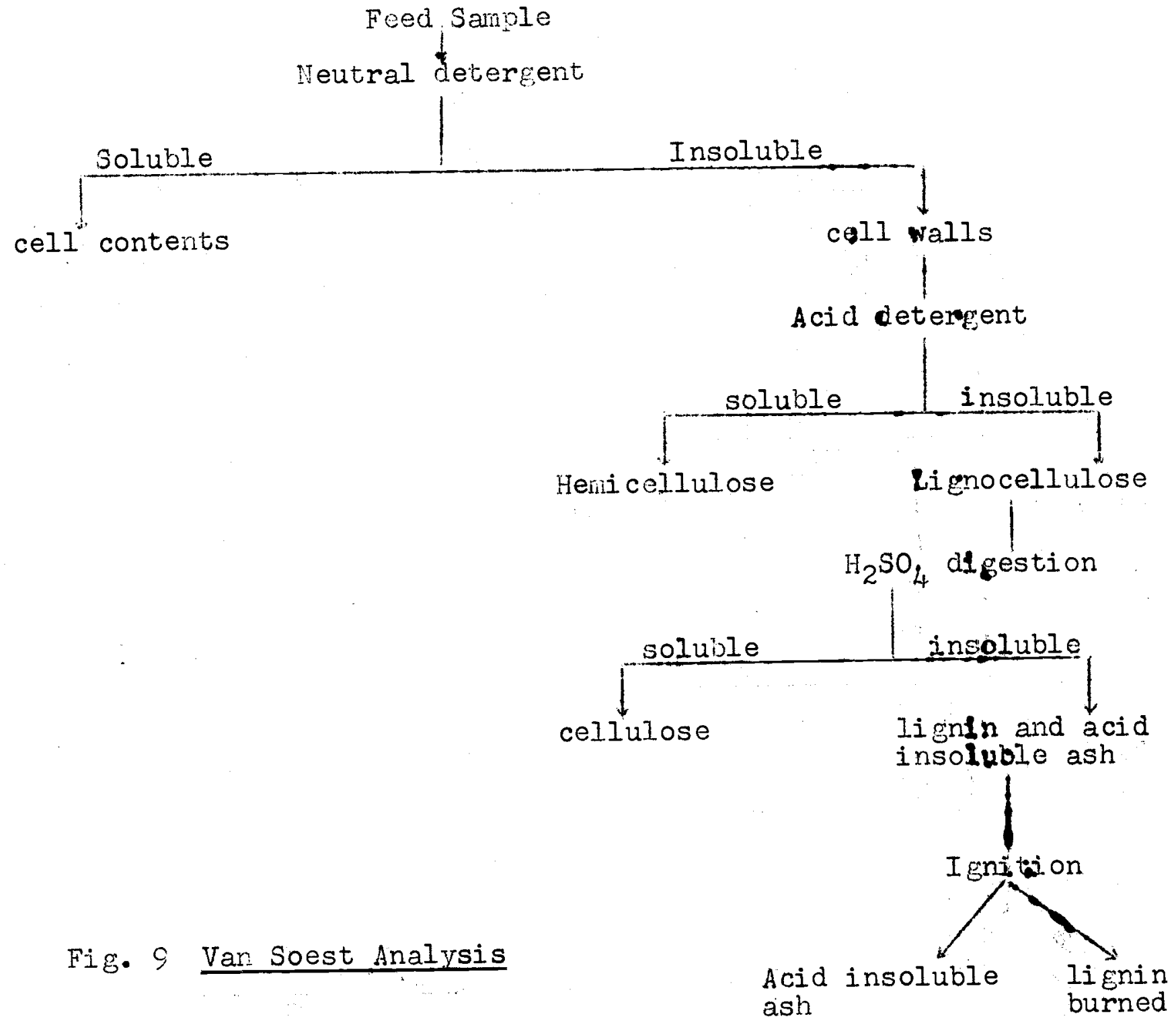

This method is being used by many nutritionists for the eveluation of forage and can be used for other feeds also.

\subsubsection{Bomb Calorimetry}

When compounds are burned completely in the presence of oxyen, the resulting heat is referred to as gross energy or the heat of combustion. The bomb calorimeter is used to determine the gross energy of feed, waste products from feed (feces and urine), and tissues. Gross energy is expressed in calories. A calorie is 
defined as the amount of energy as heat required to raise the temperature of 1 gram of water by $1^{\circ} \mathrm{C}$ (to be precise from $14.5^{\circ}$ to $15.5^{\circ} \mathrm{C}$ ). A kilocalorie (Kcal) is 1000 calories; a megacalorie (Mcal) equals one million calories.

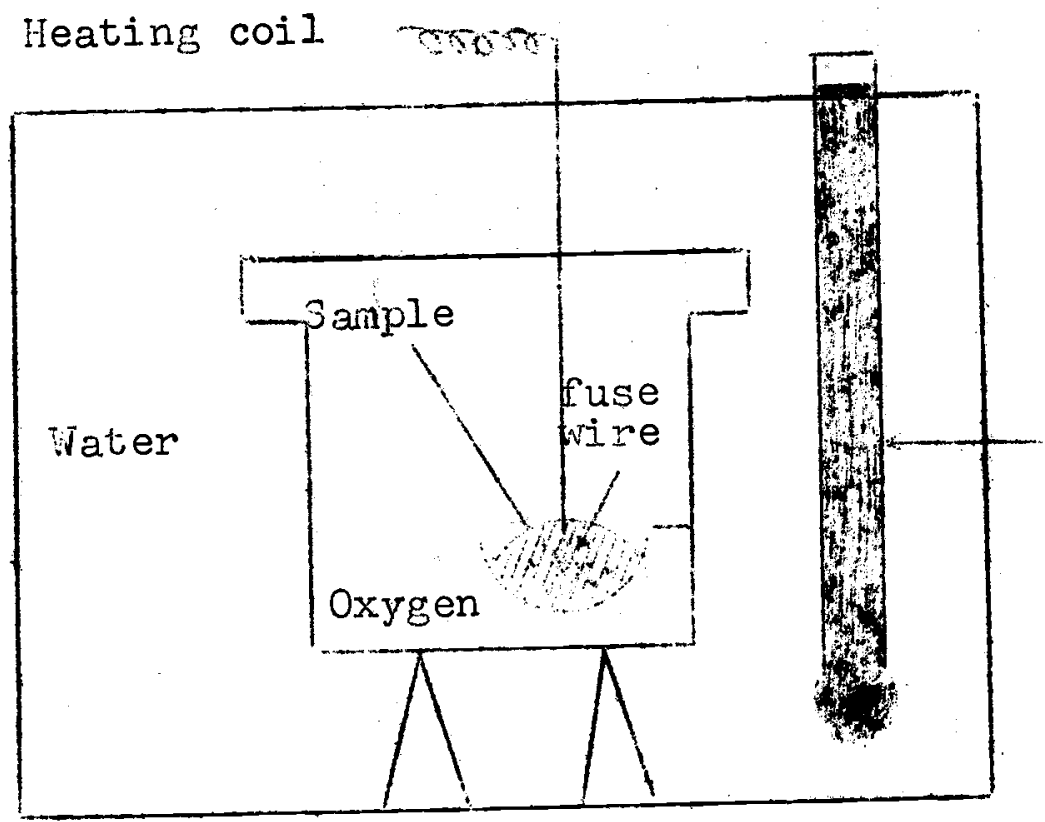

Thermometer

Fig. 10 Bomb Calorimeter - Schematic

In bomb calorimetry, a weighed amount of the feed sample to be tested is burned by electric heating coil in an inner vessel that has been filled with oxygen at 25-35 atm. The calorimeter is immersed in an outer uessel containing a known amount of water, whose tmperature is noted before ignition and after the material has been burned, the heat produced in the combustion of the sample warming the water.

Before the sample, with its unknown heat of combustion can be analyzed, the energy equivalent or heat capacity of the calorimeter must first be determined. This is done by burning a sample with a precisely known heat of combustion in the calorimeter - usually benzoic acid, because it is completely combustible, nonhygroscopic and readily available in a very pure form. The energy equivalent is determined by multiplying the known heat of combustion of the standard ( 6318 calories per gram for benzoic acid) by the weight of the standard sample, the result being divided by the rise in temperature produced by the burning of the standard. This gives the energy equivalent of the calorimeter in calories per degree $C$. Then a known weight of the feed sample is burned in the calorimeter, taking care to maintain the same conditions, oxygen pressure, 
amount of water in the outer vessel, etc., as for the standard. The resulting temperature rise is recorded, which when multiplied by the energy equivalent gives the total energy released by the sample in calories. Dividing this value by the sample weight gives the gross heat of combustion of the feed sample in calories per gran.

\subsubsection{Biological Analysis}

The two types of biological assays practised are microbiological and the use of nutrient-deficient animals.

Biological assays tend to be laborius and time consuming. Large numbers of samples are needed to produce statistically reliable results and quite often, data obtained from these assays is highly variable. The assay utilizing nutrient deficient animals is perticularly cumbersone, firstly because the animals should be of approximately the same age, sex and weght and secondly quite some time is required to induce deficiency conditions in these animals

In microbiological assay, a micro-organism is selected that is known to require the nutrient in question, so that its growth can be inhibited by the denial of the nutrient. The growth medium is prepared so that it is nutritionally complete except for the nutrient to be tested. Graded levels of nutrients are then added to the media and growth response curves obtatned. The sample to be assayed can then be tested and compared to the growth response curve to determine the concentration of the nutrient. $B$ complex vitamins are assayed in this manner.

Nutrient-deficient animals assay uses rats or chicks that are fed diets deficient in a specific nutrient. Growth response curves are developed by the feeding of known arnounts of the nutrient to some of the deficient animals. Other deficient animals are given the growth curves. In addition, the evaluator can observe the changes in specific tissues as various levels of the specific nutrients are supplied. 


\subsection{Techniques utilized in feed evaluation}

Two surgical techniques which have been developed to aid in feed evaluation are cannulation and fistulation and the use of indicators. In the evaluation of feeds and their utilization in the body, it is necessary to obtain or introduce samples into various parts of the digestive tract. Through surgical procedures, permanent openings can be made in the body which give the researcher ready access to the desired segment of the gastrointestinal tract. Fistulation and cannulation techniques enable the research worker to (1) determine flow rates, (2) collect digestive fluids, (3) infuse materials in various parts of the digestive tract and (4) observe movements of the organs.

Cannulation is the procedure in which a cannula (tube) is inserted in the cavity of an organ and subsequently brought to the exterior of the body.

The most common and simple form of cannulation uses veins, especially the jugular vein. A hollow needle is inserted in the vein to be cannulated and a small tube is passed through the needle into the vein. Once the tube j.s in the vein, the needle can be either left in place or removed. An anticoagulant such as heparin is used to flush the tube; blood samples can then be taken periodically without having to puncture the vein each time. When the cannula is not in use, a sinall wire is placed in the lumen of the tube to prevent blood clots from stopping it up.

In Fistulation an opening is made in a hollow organ and the edges of the opening exteriorized by sewing to the body wall. A plug is then attached to the opening to prevent leakase of the contents from within the organ the plug is renoved when samples are needed. A fistula differs from a cannula in that a fistula is a permanent opening in the body wall and the organ while canrula is a tube which leads to the interior of the body.

Indicators or tracers are used to study rates of passage, forage intake and feed digestibility. They can be either internal-inert portions of the plant food itself, like lignin, silica and plant chromogen, or external-inert chemicals added to the feed, e.g., chromic oxide and certain dyes.

The indicators I) should not alter the digestive process 2) should be palatable 3) should move together with the feed through the digestive tract and 4 ) should be highly recoverable. Digestion trials terd to be laborious and awkward, since a total collection of feces is necessary. Indicators provide a qui ck, indirect way of detemining feed digestibility. The following equations are used in the deternination of digestibility through the use of indication:

Digestion coefficient
of dry matter 
Digestion coefficent of

a particular nutrient $=100-100\left(\frac{\%}{\%}\right.$ indicator in feed $x \%$ nutrient in feces $)$

In dicators are used to estimate forage intake and digestibility in grazing animals. A feces collection bag is placed on the grazing animal and feed intake is determined through the use of indicators. The total collection of fecal material is weighed and the dry matter content determined. Samples of forages being grazed are analysed to determine the content of the internal indicator (e.g., lignin). The fecal material is then analysed for lignin content and from this information, the amount of dry matter consumed is calculated as below:

Dry matter consumed

$=$ fecal output (dry basis) $x \%$ internal indicator in feces(dry basis) \% indicator in forage(dry basis)

It is possible to estimate the total amount of fecal dry patter, without making total collections, through the use of external indicators. All that is required is to obtain grab samples-that is small samples of fecal material taken directly from the rectum. From the quantity of external indicator fed and the amount present in the feces, the fecal dry matter output can be calculated:

Fecal dry matter output $=\frac{\text { weight of the external indicator fed }}{\% \text { external indicator in fecal dry matter }}$

\subsection{Types of Feed Evaluation Trials}

After developing suitable techniques for feed analysis, it is necessary to set up trials to evaluate the feed. This can be done in vivo (through the use of animals) or in vitro (in test tubes).

Digestion and Metabolism Trials

The chemical composition of the feed gives only the potential value of the food. Losses of nutrients in the feces, urine, gases etc., fron the animal during digestion, absorption and metabolism must also b taken into consideration to get the actual nutritive value. This is because not all the nutrients present in the feed are completely available to the animal body, lage portions of the nutrients being excreted undigested. It is for this reason that digestibility is defined as the portion of the feed or of any single nutrient in the feed not recovered in the feces, i.e., the portion which has been absorbed by the animal. The digestibility 
expressed as a rercentage is called the digestion coefficient. For example, if a bullock is eating $20 \mathrm{~kg}$ of green maize containing $5 \mathrm{~kg}$ of dry matcer per day and is excreting $2 \mathrm{~kg}$ of dry matter in the feces, then $3 \mathrm{~kg}$ dry matter is being digested ever day. The dry matter digestion coefficiont is then $3 / 5 \% 100=60 \%$. Digestion coefiicients can be calculated for dry natter, crude protein, crucie fibre, ether extract and nitrogen free extract. The digestion coefficient for asi is not calculated since most of the minerals are re-excreted in the gut. Digestion coefficients can also be measured for cellilose and the gross energy of the food. coefficients, since the nut ined are the ap arent ficestibility small proportions of nutrients from previously utilized food in the form of mucosal debris, urispent enzymes etc.

The digestibility of a feedstuff is affected by l) the species of the animal (ruminants, non-ruminants), 2) the pliysical form of the feed (processed or unprocessed), 3) variations between individual and 6 ) adaptability to the ration and changes in the make up of microbial populations.

In a typical digestion trial four to six adult, apparently healthy, animals of the same species, age and sex are taken. Male animals are preferable as it is easier to collect their feces without contamination with urine as in females.

The animals are fed the test feed for a preliminary period of 21 days to remove the effects of previous food. This is followed intake and feces voidec is notcd every 24 hours daily record of feed During the trial period, the animals are kept in metabolism stalls or métabolism cases with separate arrangentructed for the collection of feces and urine. The latter is not required for the determination of dis a do ded the balances of nitroger, caj.cium, piosphorus etc. In poultry, digestibijity dotermination is a little complicated, since undigested feed is excreted from a single opening, the cloaca. In practice the fecal and urinary orifices need to be surgically separated. Alternatively, chemical nethods must be used. The urine mostly contains nitrogenous compound in the form of uric acid, wille the feces are nostly protein. The nitrogen fractions

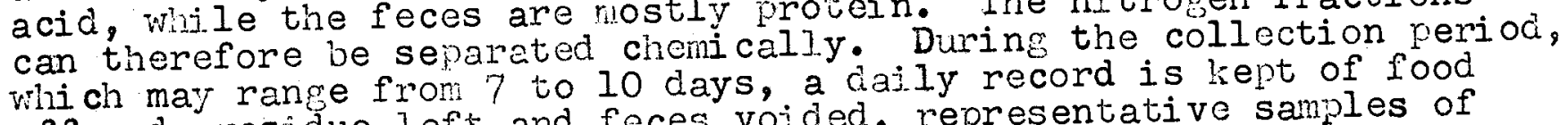
offered, residue left and feces voided, representative samples of which are taken daily and dried in a hot air oven. The dried samples are collected and the composite sample obtained at the end of the collection period analysed for proximate principal and / or other individual nutrients. For the estimation of crude proteín, an aliquot of fresh feces is taken daily and preserved in sulphuric acid, then the composite mixed and analysed. An example of the digestion coefficient determination of crude protein of maize fodder is given below. On an average six male bullocks consumed $20 \mathrm{~kg}$ per head daily of greer majze containing 25 percent dry matter and 1.6 percent crude protein. During the 
same period, they voided, on an average, $20 \mathrm{~kg}$ per head per day of feces containing 10 percent dry matter and 0.6 percent crude protein on wet basis. The digestibility coefficients of dry matter and crude protein may be calculated as follows:

\begin{tabular}{|l|l|l|l|}
\hline Intake & Outgo & Digested & $\begin{array}{l}\text { Digestion } \\
\text { coeffici ent } \\
\text { (percent) }\end{array}$ \\
\hline $\begin{array}{l}\text { Dry matter: } \\
\frac{20 \times 25}{100}=5.0 \mathrm{~kg}\end{array}$ & $\frac{20 \times 10}{100}=2.0 \mathrm{~kg}$ & $5.0-2.0=3.0 \mathrm{~kg}$ & $3 / 5 \times 100=60$ \\
\hline $\begin{array}{l}\text { Crude protein: } \\
\frac{20 \times 1.6}{100}=0.32 \mathrm{~kg}\end{array}$ & $\frac{20 \times 0.6}{100}=0.12 \mathrm{~kg}$ & $0.32-0.12=0.20 \mathrm{~kg}$ & $\frac{0.20}{0.32} \times 100=62.5 \mathrm{~kg}$ \\
\hline
\end{tabular}

The length of the collection period required for reliable results varies with the species. In ruminants, accuracy increases with longer periods of collection.

Indirect methods of determining digestibility by differences

The digestibility of individual feeds can be determined directly only if they provide a satisfactory diet over the test period when fed alone. Exainples are green maize, oats, grasses and legumes. Some feeds, however, cannot be fed alone and therefore their digestion coefficeients cannot be determined directly, e.g., concentrates like maize grain, cakes, and bran as they do not supply the necessary bulk. Similarly, non-maintenance type roughages like straws and poor quality fodders also cannot be tested directly, since they will not supply the required nutrients by themselves. For such feeds an indirect method must be used, which involves two or more digestibility trials.

In the first trial a basal maintenance type fodder is fed in the place of the feed in question. For instance, if the digestibility of the nutrients in groundnut cake needs to be estimated, then the first trial may be conducted by giving green maize only to the animals, yielding the digestibility of the nutrients present in green maize. Groundnut cake is fed together with mai ze in the second trial; it is assumed that the digestion coefficients of the nutrients in the green maize will renain the same as in the first trial. The green maize component in the feces can therefore be be subtracted. The remaining fecal nutrients are considered to 
have come from the groundnut cake. Suppose, for example that it was found in the first trial that maize fodder is $60 \%$ and $65 \%$ digestible in terms of dry matter and crude protiein respectively. In the second trial, $20 \mathrm{~kg}$ of green maize and $1 \mathrm{~kg}$ of groundnut cake were fed to the animals which excreted on an average $22 \mathrm{~kg}$ of feces.

The following composition percentages have been determined:

\section{$\%$ dry matter}

green maize

groundnut cake

feces
25

90

10

\section{$\%$ crude protein}

1.6

45

0.70

These figures yield, for the second trial, the following amounts in kilograms:

\section{$\mathrm{kg}$ dry matter}

green maize

groundnut cake

feces
5

0.9

$2 \cdot 2$

\section{$\mathrm{kg}$ crude protein}

0.32

0.45

0.15

Since green maize dry matter is only $60 \%$ digestible, i.e., $40 \%$ indigestible, the amount of green maize dry matter voided is $5 \times 40 / 100=2 \mathrm{~kg}$. Thus the amount of ground cake dry matter in the feces is $0.2 \mathrm{~kg}$, which implies that $0.7 \mathrm{~kg}$ was digested.

Consequently, the

Digestion coefficient of Eroundnut cake dry matter is

$$
\frac{0.7}{0.9} \times 100=78 \%
$$

Similarly, it can be calculated that the
Digestion coeficient of groundnut cake crude protein $=91 \%$

The above calculation is only correct to the limits of the validity of the assumption that the digestibility of green maize, determined 
alone, is not effected when fed along with the groundnut cake supplement. When the assumption does not hold good, one gets the so-called associative effect of feeds.

For the digestibility determination of wheat and rice straws or other poor quality roughages that cannot be fed alone because of their low nutritive value, three sets of trials are needed. The first trial is with maintenance quality roughages like green maize oats or hay, while the second trial is conducted with this basal roughage along with oil cake. From the second trial the digestion coefficients of the nutrients in the oil cake are determined. In the third trial, the same oil cake is fed along with wheat straw or other poor quality roughage. By subtracting the nutrients lost through oil cake in the feces from the total loss, the disestibility of the nutrients in the wheat straw can be determined.

\section{Total Digestible Nutrients (TDN)}

The chemical composition of feed stuffs does not give their true nutritive value, since losses in the animal body are not taken into consideration. Digestibility data are used to determine the digestible nutrients present in the feed and this forms one of the ways of calculating its energy value. One system of expressing energy value is in terms of TDN.

TDN = percent ( digestible crude protein + digestible crude fibre + digestible NFE + digestible ether extract $\times 2.25$ )

The ether extract is multiplied by 2.25 because the energy value of fats is approximately 2.25 times that of carbohydrates and proteins.

The Nutritive Ratio of a particular feed is the amount of digestible crude protein nutrients expressed as a proportion of the digestible non-nitrogenous nutrient content. $N R=\frac{\text { Digestible crude protein }}{\text { Digestible carbohydrates + Digestible ether extract } x 2 \cdot 25}$

Groundnut cake, which is rich in digestible crude protein (DCP) has an NR of around $1: 2$, called narrow. Wheal straw and grass hay, with low DCP's, have wide nutrition ratios-around $1: 60$ 


\subsection{Nitrogen Balance Trials}

These are used to determine the availability of protein in feeds. The organisation and breakdown of the various components in a nitrogen balance trial is illustrated in Fig. Il.

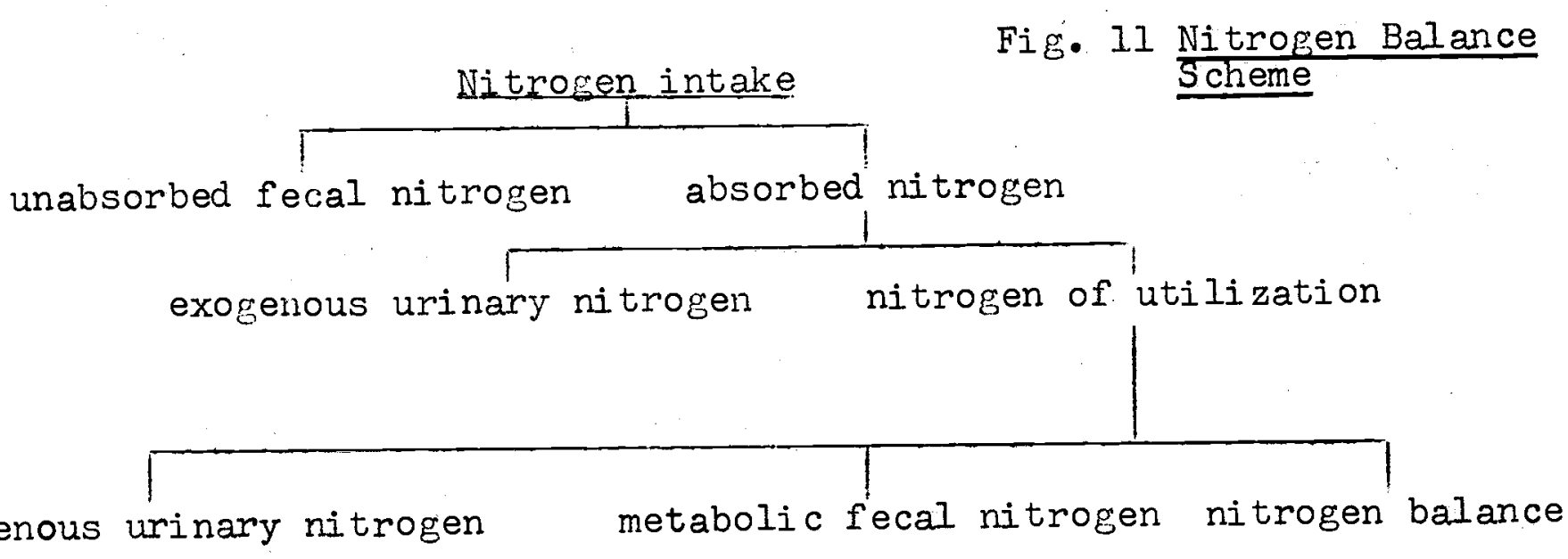

This type of experiment involves the collection of both feces and urine, much of the nitrogen found in which comes from sources other thar ingested feed. It is necessary to withhold feeding until the test animals enter the catabolic state. The nitrogen excreted during this period is called endogenous urinary nitrogen and metabolic fecal nitrogen, measured in the urine and feces respectively. These values are then subtracted from the nitrogen values obtained from the excreta during the feeding stage of the balance trial. Exogenous urinary nitrogen and fecal nitrogen from feed are determined by the following equations:

Exogenous urinary nitrogen = total urinary nitrogen - endogenous $\begin{aligned} & \text { Fecal nitrogen from feed }=\text { total fecal nitrogen } \text { - metabolic fecal } \\ & \text { nitrogen }\end{aligned}$

Through the use of nitrogen balance scheme, the biological value (BV) of a feedstuff can be determined. BV is defined as the percent of absorbed nitrogen retained.

$$
\mathrm{BV}=100 \times\left(1-\frac{\text { Exogenous urinary nitrogen }}{\text { Nitrogen intake-Fecal nitrogen from feed }}\right)
$$

Another method of evaluating protein sources is the use of the protein effeciency ratio (PER). Animals are weighed at the commencement and after completion of the feeding period. The gain in body weight is then computed as a ratio 
with the amount of protein consumed:

$$
\mathrm{PER}=\frac{\text { gain in body weight }}{\text { protein intake }}
$$

The PER depends on the level of protein fed. That is, at a dietary level of $10 \%$ protein PER values will be different from those obtained at $20 \%$ protein. PER values are therefore usually related to a standard; or else the maximum value obtained after trials at several different protein levels is used. $A$ third method of protein evaluation is the determination of net protein utilization (NPU), by the following equation:

$$
N P U=\frac{B-B}{I} \times 100
$$

where

$$
\begin{aligned}
& B= \text { nitrogen content of the bodies of the animals } \\
& \text { given the diet containing the protein source being } \\
& \text { tested. } \\
& B_{1 I}= \text { nitrogen content of the bodies of the animals } \\
& \text { given a diet excluding nitrogen }
\end{aligned}
$$

The relation between NPU, BV and digestibility is given below:

$$
\mathrm{BV}=\frac{\mathrm{NPU}}{\text { digestibility }}
$$




\subsection{Energy Balance Trials}

Here the quantity of interest is the apparent digestible energy. It is obtained by subtracting the energy content of the feces from the gross energy of the feed, as determined by bomb calorimetry. The true digestible energy is obtained by further subtracting the fecal energy of a fasting animal, since some of the energy in the feces represents energy derived from metabolic end products. Most researchers however feel that apparent digestible energy is an adequately accurate and simple measure for the evaluation of the energy content of feeds.

Subtracting the energy values obtained from urine and gases collected from the animal from the apparent digestible energy yields netabolizable energy. The latter can be further partitioned into heat increment, which is the heat produced during nutrient metabolism and fermentation, and net energy, the energy remaining for maintenance, growth and production. A further quantity, the heat production in the body is obtained by adding the values for heat increment and net energy for maintenance.

The organization and breakdown of the various components in an energy balance trial is sketched in Fig. 12 .

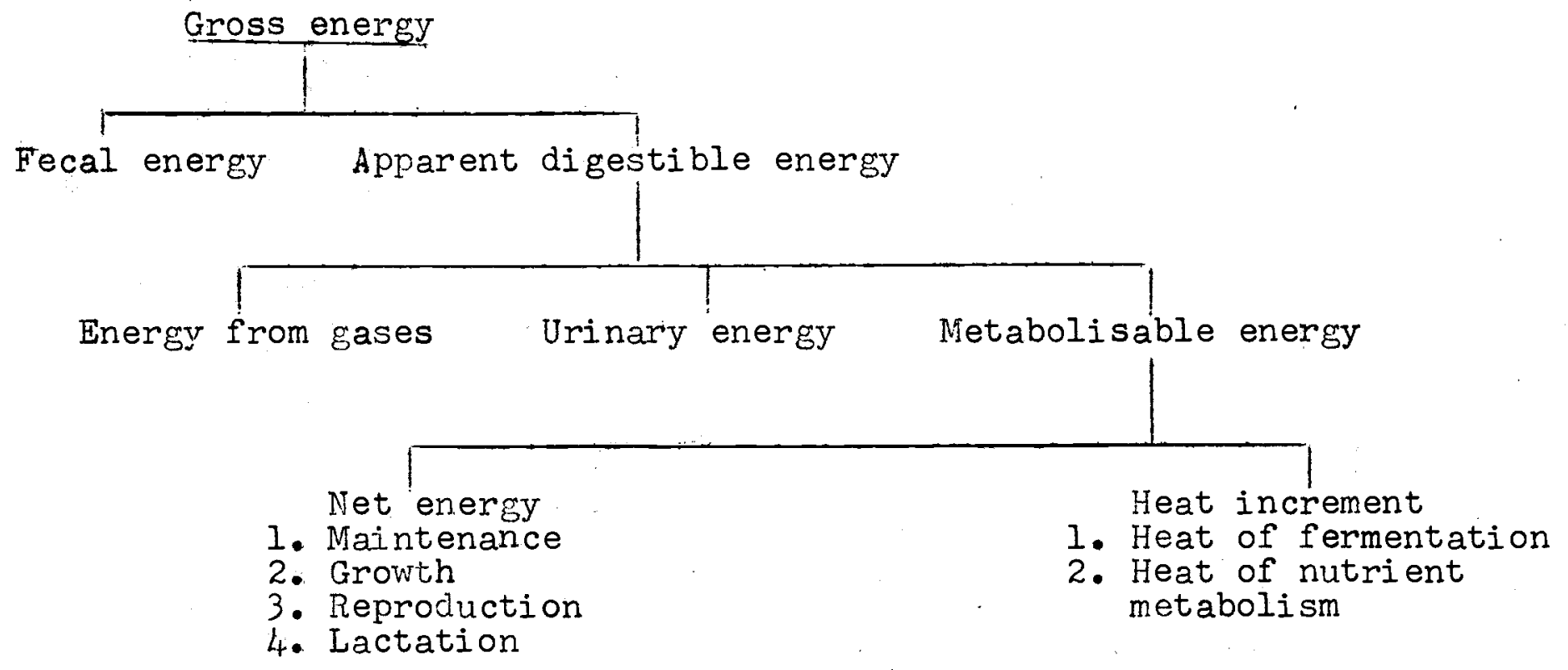

Fig. 12. Energy Balance Scheme 


\subsection{Calorimetric Systems}

Energy losses in the feces and urine are easily measured by the metabolism trials. The measurement of gaseous energy loss and the heat loss or increment, however, needs sophisticated apparatus. In one method, called direct calorimetry, the heat production is measured directly by combining the features of a respiration chamber and a calorimeter. A. direct calorimtric apparatus was first used by Atwater in 1892 for human beings, and then by Armsby at Pennsylvania State University for farm animals. Now many such respiration calorimeters have been built at a number of research centres. These apparatus are however very expensive. In this apparatus there is provision for. recording the intake of feed, water and oxygen and the outgo of feces, urine, gaseous excreta and heat losses from the body. Heat is lost from the body surface by conduction, radiation and convection. It is also lost by evaporation of water from the skin and expired gases through the lungs. Some examples of determining the net energy by direct calorimetry are given below on the basis of experiments conducted by Armsby.

Table 4.

Net Energy Values for Ruminants (Kcal $/ 100 \mathrm{~kg}$ dry matter)

Feed gross losses in energy excreta metabolisable heat increment net energy energy (ME) (Ne)

Wheat straw $444.4 \quad 306.2$ 138.2 116.0 $24 \cdot 4$

Timothy $451.8 \quad 266.4$ 185.4

78.2 107.2

It is evident from the above table tilat in the case of wheat straw about $84 \% \mathrm{ME}$ is lost as heat increment. It is possible to circumvent the high costs of this method through the use of carbon-nitrogen balance, or by gaseous exchange which needs only a respirator. The nutrients oxidised in the animal body are protein, fat and carbohydrates. This method is called indirect calorimetry.

Using carbon-nitrogen balances, it is possible to calculate that 1 gram of protein retained in the body is equivalent to 5.7

kiloralories and 1 gram of fat retained is equivalent 9.5 kilocalories. It is then easy to compute the energy retained by the animal. This procedure has been used by Kellner and by Armsby. The ME, which is calculated by accounting for all energy losses from the feces, urine and gases, is subtracted from the animal's energy gain to give the heat loss or increment. 
The gain of energy from protein and fat can also be directly determined by slaughter and measurement of the gross energy of the carcass. This technique has been used by many workers. The respiratory exchange of gases method measures oxygen consumption, carbon dioxide production and urinary nitrogen to calculate the non-protein respiratory quotient (RQ).

$$
R Q=\frac{\text { volume of carbondioxide produced }}{\text { volume of oxygen used }}
$$

When exclusively carbohydrates are being oxidised in the body for energy purposes the RQ is 1 .

$$
\mathrm{C}_{6} \mathrm{H}_{12} \mathrm{O}_{6}+6 \mathrm{O}_{2}=6 \mathrm{CO}_{2}+6 \mathrm{H}_{2} \mathrm{O}+673 \mathrm{cal}
$$

The RQ from the oxidation of fats alone is 0.7 , while that for proteins alone is intermediate. The quantity of protein catabolised can be estimated from the output of nitrogen in the urine. For each gram of protein $0.16 \mathrm{~g}$ of nitrogen is excreted. The heat of combustion of protein is taken as $4.3 \mathrm{Kcal} / \mathrm{gm}$.

Some caution must be exercised in using RQ to determine heat production in the case of ruminants.

Physiological values of nutrients:

1 gram carbohydrate $=4 \mathrm{Kcal}$

1 gram fat $\quad=9 \mathrm{Kcal}$

1 gram protein $=4 \mathrm{Kcal}$. 
3.9 Systems of Expressing the Inergy Value of Feedstuffs

There are various systems in vogue in different countries for expressing the energy value of feeds and animal requirements. Among them total digestible nutrients (TDN), starch equvalent (SE), digestible energy (DE), metabolizable energy ( $M E$ ), net energy (NE), 'Scandinavi an feed units (SFU), oat unit (OU) and the French feed unit (UF). The best units are those that account for all the losses incurred by the animal in utilizing the energy of the feed.

\section{Total Digestible Nutrients (TDN)}

The use of TDN as a measure of nutritive value of feedstuffs involves digestion experiments in which the digestion coefficients of various organic nutrients, like carbohydrates (crude fibre + nitrogen free extract), fat and protein are determined by digestibility trials as described earlier, in which only the losses of nutrients in the feces is accounted for. Losses through other channels are not considered. It is consequently the easiest energy value to determine in practice. The feed and feces are analysed for crude protein, ether extract, crude fibre and nitrogen free extract. The amount of these nutrients not recovered in the feces are considered to be digested.
TDN = percent (digèstible crude protein + digestible crude fibre + digestible nitrogen Iree extract + digestible ether extract $\times 2.25$ )

However, as energy losises in the urine, gases and heat increment are not considered, the use of TDN for feeding standards is not the most accurate. 'In India and America, where it forms the basis of the famous Morrison standard, it has long been in use, although in India it is gradually being replaced by the ME system.

The Starch Equivalent(SE) expresses the amount of feed required to produce as much animal $f a t$ as is being produced by a unit amount of starch when fed in adaition to maintenance rations. For instance, linseed cake has a starch equivalent of $74 \mathrm{~kg}$, which means that $100 \mathrm{~kg}$ of linseed cake can produce as much animal fat as $74 \mathrm{~kg}$ of pure starch when fed along with a maintenance ration. In other words, $100 \mathrm{~kg}$ of linseed cake contains as much net or productive energy as $74 \mathrm{~kg}$ of starch. The $\mathrm{SE}$ is essentially the same as the net energy of the feedstuff, since both expressions aim at stating the productive value of the feed, the only difference is that while the net energy is expressed in calories, the SE is expressed in terms of starch, which is regarded a source of net energy to the animal. 
Feeding standards based on the starch equivalent method of Kellner are in use in most European countries. This method, like the net energy system of Armsby, takes into account almost all the losses involved in the digestion of food, and is perhaps also open to similar criticisms. The advantage seems to be that without the help of any costly instrument, it is possible to calculate the net energy value of feeds from simple digestibility data. Kellner determined the starch equivalent values of different feedstuffs by keeping the animals in a big animal calorimeter where all forms of heat losses could be determined accurately. Then, by measuring the intake and output of carbon and nitrogen, he found that his animals were exactly on a maintenance ration, $i . e$. , the animals maintained their body weights, he added pure starch, straw pulp cellulose, wheat gluten (protein) and oil to the maintenance diet and determined again the carbon-nitrogen balance. One of Kellner's $C / N$ balance studies is shown in Table 5 below.

Table 5. Carbon-Nitrogen Balance (Kellner)

\begin{tabular}{|c|c|c|c|c|c|c|}
\hline \multirow[t]{2}{*}{ Nutrient } & \multirow{2}{*}{$\begin{array}{l}\text { Intake } \\
\text { (g) }\end{array}$} & \multicolumn{4}{|c|}{ Outgo (g) } & \multirow{2}{*}{$\begin{array}{c}\text { Balance } \\
\text { (g) }\end{array}$} \\
\hline & & Feces & Urine & Gases & Total & \\
\hline Nitrogen & 390.55 & 105.69 & 263.76 & - & 369.45 & $\begin{array}{l}+21.1 \mathrm{~g} \text { nitrogen }\left(\mathrm{N}_{2}\right) \\
\text { taken in as protein }\end{array}$ \\
\hline Carbon & 5668.9 & 1456.9 & 283.3 & 3247.9 & 4988.1 & $\begin{array}{l}+680.8 \mathrm{~g} \text { carbon }(\mathrm{C}) \\
\text { taken in as fat and } \\
\text { protein }\end{array}$ \\
\hline
\end{tabular}

From the above balance data, it is obvious that $21.1 \mathrm{~g}$ of nitrogen should be in the form of proteins in the animal body. Assuming that $1 \mathrm{~g}$ of nitrogen corresponds to roughly $6 \mathrm{~g}$ of protein the protein gained by the animal may be calculated as $21.1 \times 6=126.6 \mathrm{~g}$. Similarly $680.8 \mathrm{~g}$ of carbon has been converted into fat and protein in the animal body. The fat gained by the animal can be calculated as follows:

Ig protein contains $0.5254 \mathrm{~g}$ of carbon

$126.6 \mathrm{~g}$ protein should contain $126.6 \times 0.5254=66.5 \mathrm{~g}$ carbon

Net carbon gain exclusively as fat $=680.8-66.5=614.3 \mathrm{~g}$.

Assuming that $1 \mathrm{~g}$ of carbon corresponds to about $1.307 \mathrm{~g}$ of fat (on the basis of 76.5 percent carbon in fat) the fat gained is $802.9 \mathrm{~g}$. The small quantity of glycogen stored in the body was 
neglected by Kellner in assuming that the whole carbon gain was due to proteins and fat.

To calculate the starch equivalent, he converted the energy stored in the form of fat in the animal body. For this purpose the amount of protein stored was converted to the weight of fat containing the same amount of energy. This was then expressed as fat producing power of starch. The starch equivalent can then be calculated from

$$
\mathrm{SE}=\frac{\text { weight of fat stored per unit weight of food }}{\text { weight of fat stored per unit weight of starch }} \times 100
$$

Using $\mathrm{N} / \mathrm{C}$ balance methods, Kellner got the following data with individual pure nutrients consisting of protein, fat, and carbohydrates (that is, the fat producing power of each of these individual nutrients):

Nutrient

1. One $\mathrm{kg}$ of digestible protein produced

2. One $\mathrm{kg}$ of digestible starch and cellulose produced

3. One $\mathrm{kg}$ of digestible cane sugar produced

4. One $\mathrm{kg}$ of digestible fat produced
Grams of fat

248

188

474 to 598

Taking starch as the unit, the fat producing powers of proteins, fats and carbohydrates was calculated by him as follows:

Starch equivalent

$$
\begin{aligned}
& \text { 1. One part of digestible protein }=\frac{235}{248}= \\
& \text { 2. One part of digestible fat }=\frac{474}{248} \text { to } \frac{598}{248}= \\
& \text { 3. One part of digestible starch }=\frac{248}{248}=1.91 \text { to } 2.41
\end{aligned}
$$

The ether extraction technique normally employed extracts not only fat but also other extraneous matters like chlorophyll and waxes. Because of this defect in the ether extraction method, Kellner concluded that for instance, the ether extract from oil cake (which is mostly a pure $f a t$ ) and the same extract from a green plant could not have equal fat producing capacities or starch equivalent value. He therefore suggested the following factors to be used in calculation of $\mathrm{SE}$ by his method. 
Factor

1. One part of digestible fat from coarse fodders like 1.91 green or dry roughage (straws, hays, silage, green grasses etc)

2. One part of digestible fat from brans and other grains or grain products

3. One part of digestible fat from oil seeds, oil cakes and other animal products

Having determined all these values for pure nutrients like starch, cane suger and wheat gluten Kellner proceeded to test his findings on actual feeds. He found that the observed and calculated values agreed well in the case of oil meals and oil cakes but not with coarse feeds like straws and hays. Kellner inferred that the more fibrous the feed, the greater was the expenditure of energy in chewing, masticating, digestion etc. He also demonstrated that the energy spent on unchopped fodder was more than on chopped fodder. Using a respiration apparatus, Kellner and Zuntz determined the losses of energy from mastication, digestion and assimilation. Armsby not only determined the energy required for mastication, digestion and assimilation of food, but also determined the amount of heat and gases given of $f^{\prime}$ by the body using his respiration calorimeter. By means of his apparatus he was able to calculate the true net energy avalable in various feedstuffs.

Gross energy (GE) is the energy given out in the form of heat when the feed is completely burned down to its ultimate products, namely $\mathrm{CO}_{2}$ and water. It is determined by burning the food in a bomb calorimeter.

Digestible energy (DE). All the heat produced by burning food in the bomb calorimeter is, however, not utilized in the animal body, because food is not digested completely. The amount of energy excreted in the feces when subtracted from gross energy gives the digestible energy content of the feed.

Metabolisable energy (ME). In addition to the loss of energy in the feces, energy is also lost in urine and due to rumen fermentation. When the losses in urine, faeces and combustible gases are subtracted from the gross energy intake, metabolisable energy of the ration is estimated.

$M E=G E$ in feed - (GE in faeces + GE in urine + GE in gases) 
For example, in an experiment with sheep fed $1 \mathrm{~kg}$ of cow peas, the following data was obtained:

$\begin{array}{llllll}\text { gross } & \text { energy } & \text { energy } & \text { energy } & \text { total } & \text { ME } \\ \text { energy } & \text { loss in } & \begin{array}{l}\text { loss in } \\ \text { intake }\end{array} & \text { loss in gases } & \text { loss } & \\ & & \text { locine } & \text { (eg methane) } & & \\ 4.333 & 2.033 & 0.196 & 0.208 & 2.437 & \text { I.896 } \\ \text { Mcal } & \text { Mcal } & \text { Mcal } & \text { Mcal } & \text { Mcal } & \text { Mcal }\end{array}$

Net energy (NE) is defined as the gross energy of the feed minus the losses of energy as feces, urine, combustible gas (methane) and heat increment. Net energy is the portion of the gross energy that is available to the animal for tissue gain, milk production, work and maintenance. The heat increment is the amount of energy spent in chewing, mastication, absorption and utilization of the food. The secretion of digestive juice and the microbial breakdown of crude fibre (heat of fermentation) requires energy. Similarly energy is required during absorption and metabolism of nutrients.

\section{The Scandinavian Food Unit(SFU)}

This system has in common with those discussed so far the fact that it evaluates foods in terms of the production they promote in the animal. It differs from Armsby's and Kellner's systems in that foods are evaluated in simple feeding trials and not by calorimetry. In addition, the value of the food is stated not in absolute terms, but relative to the value of a common feed like barley, and in this respect the Scandinavian Food Unit resembles the starch equivalent system. The food under investigation is substituted for barley or for another food of known value in a control ration, and the original and revised rations are compared with one another in terms of the production they promote in lactating cows or fattening animals. If it were found, for example, that $1 \mathrm{~kg}$ of barley in the ration of a dairy cow could be replaced by $1.2 \mathrm{~kg}$ of oats without affecting milk production or body weight change, the oats would be given a value of $1.0 / 1.2=0.83$ food units per $\mathrm{kg}$. This method of evaluation requires no elaborate apparatus, but is expensive in terms of animals and time. (An experiment to evaluate one food with reasonable accuracy needs 30 to 40 cows and could last 20 weeks). As in other systems, therefore, the need for laborious experimentation has been avoided by predicting food unit values from the di gestible nutrients. The factors used are essentially those of Kellner, except that digestible protein is considered to have a net energy value 1.43 times that of carbohydrate, which is 50 percent higher than Kellner's 
factor of 0.94 . The justification for the higher factor is that when foods are given to milking cows and to pigs their protein is used for milk and tissue protein synthesis and is not deaminated, as in Kellner's fattening steers; the losses of energy in urine and as heat associatied with deamination are therefore reduced. Depending on whether barley or oats is used, the Scandinavian Feed Unit (SFU) or the Oat Unit (OU) represents the equivalent of net energy provided by $I \mathrm{~kg}$ of barley grain, or oat grain, of average quality. The SFU is used in Scandinavia, France and some other countries in Europe. The Oat Unit is used in the USSR and some neighboring countries.

The Modified Feed Unit or French Feed Unit should not be confused with the scandinavian system as the conversion factors are different.

Table 6.

Determination of nutritive values of feeds in different feed and energy units (Kielanowski, 1972)

\begin{tabular}{|c|c|c|c|c|c|c|}
\hline \multirow{3}{*}{ Feed Uníts } & \multirow{3}{*}{$\begin{array}{l}\text { Units of } \\
\text { digestible } \\
\text { nutrient }\end{array}$} & \multicolumn{4}{|c|}{ Digestible } & \multirow{3}{*}{$\begin{array}{l}\text { Further } \\
\text { procedure }\end{array}$} \\
\hline & & $\begin{array}{l}\text { Crude } \\
\text { protein }\end{array}$ & $\begin{array}{l}\text { Dther } \\
\text { extract }\end{array}$ & $\begin{array}{l}\text { Crude } \\
\text { fibre }\end{array}$ & $\begin{array}{l}\text { Nitrogen } \\
\text { free } \\
\text { extract }\end{array}$ & \\
\hline & & \multicolumn{4}{|c|}{ MULTIPLY BY } & \\
\hline $\begin{array}{l}\text { TDN } \\
\text { (wei ght } \\
\text { unit } \\
\text { or } \% \text { ) }\end{array}$ & $\begin{array}{l}\text { weight } \\
\text { unit } \\
\text { or } \%\end{array}$ & 1 & 2.25 & 1 & 1 & sum up. \\
\hline $\begin{array}{l}\text { SE } \\
\text { (weight } \\
\text { unit } \\
\text { or } \% \text { ) }\end{array}$ & $\begin{array}{l}\text { weight } \\
\text { unit } \\
\text { or } \%\end{array}$ & 0.94 & $\begin{array}{l}2.41 * \\
2.12 \\
1.91\end{array}$ & 1 & 1 & $\begin{array}{l}\text { sum up } \\
\text { and mul- } \\
\text { tiply by } \\
\text { the avail- } \\
\text { ability }\end{array}$ \\
\hline $\begin{array}{l}\mathrm{DE} \\
\mathrm{Kcal} / \mathrm{kg}\end{array}$ & $\mathrm{g} / \mathrm{kg}$ & 5.79 & 8.15 & 4.42 & 4.06 & sum up \\
\hline $\begin{array}{l}\mathrm{ME} \\
\mathrm{Kcal} / \mathrm{kg}\end{array}$ & $\mathrm{g} / \mathrm{kg}$ & 4.32 & 7.73 & 3.59 & 3.63 & sum up \\
\hline $\begin{array}{l}\mathrm{NE} \\
\mathrm{Kcal} / \mathrm{kg}\end{array}$ & $\mathrm{g} / \mathrm{kg}$ & 1.71 & 7.52 & 2.01 & 2.01 & sum up \\
\hline
\end{tabular}




\begin{tabular}{|c|c|c|c|c|c|c|}
\hline $\mathrm{SFU} / \mathrm{kg}$ & $\mathrm{g} / \mathrm{kg}$ & 0.94 & $\begin{array}{l}2.41 * \\
2.12 \\
1.91\end{array}$ & 1 & 1 & $\begin{array}{l}\text { sum up, multiply } \\
\text { by the availability } \\
\text { and divide by } 700\end{array}$ \\
\hline $\mathrm{OU} / \mathrm{kg}$ & $\mathrm{g} / \mathrm{kg}$ & 0.94 & $\begin{array}{l}2.41 * \\
2.12 \\
1.91\end{array}$ & 1 & 1 & $\begin{array}{l}\text { sum up, multiply } \\
\text { by the availavility } \\
\text { and divide by } 600\end{array}$ \\
\hline \multicolumn{7}{|c|}{$\begin{array}{l}\text { *igestibility of ether extract of oil seeds, oil cakes and feed } \\
\text { of animal ori gin should be multiplied by } 2.41 \text {, that of leguminous } \\
\text { seeds, cereal grains and their by-products by } 2.12 \text { and that of } \\
\text { hays, straws, chaff, green fodders, silages, roots and tubers } \\
\text { by l, } 1 \text {. }\end{array}$} \\
\hline
\end{tabular}

Table 7

Conversion Factors for TDN, SFU and OU for a Constant Concentration of Digestible Protein (Kielanowski 1972)

( $157 \mathrm{~g}$ per $\mathrm{kg} \mathrm{SE}=155 \mathrm{~g}$ per $\mathrm{kg} \mathrm{TDN}=110 \mathrm{~g}$ per $1 \mathrm{SFU}=94 \mathrm{~g}$ per $\mathrm{kg}$ OU)

\begin{tabular}{|l|l|l|l|l|}
\hline \multirow{2}{*}{ Feed Unit } & \multicolumn{4}{|c|}{ Equi valent to } \\
\cline { 2 - 5 } & SE kg & TDN kg & SFU & OU \\
\hline $1 \mathrm{~kg} \mathrm{SE}$ & 1.0 & 1.01 & 1.43 & 1.67 \\
\hline $1 \mathrm{~kg}$ TDN & 0.99 & 1.00 & 1.41 & 1.65 \\
\hline $1 \mathrm{SFU}$ & 0.70 & 0.71 & 1.0 & 1.17 \\
\hline $10 \mathrm{U}$ & 0.60 & 0.61 & 0.86 & 1.0 \\
\hline
\end{tabular}

$\underline{\text { Table \& }}$

Energy equivalents of $\mathrm{SE}_{2} \mathrm{TDN}, \mathrm{SFU}$ and $\mathrm{OU}$ for a constant consentration of digestible protein (Kielanowshi 1972)

\begin{tabular}{|l|l|l|l|}
\hline \multirow{2}{*}{ Feed unit } & \multicolumn{3}{|c|}{ Equivalent to } \\
\cline { 2 - 4 } & DE (Mcal) & ME (Mcal) & NE (Mcal) \\
\hline $1 \mathrm{~kg} \mathrm{SE}$ & 4.42 & 4.25 & 3.03 \\
\hline $1 \mathrm{~kg} \mathrm{TDN}$ & 4.36 & 4.20 & 3.00 \\
\hline $1 \mathrm{~kg} \mathrm{SFU}$ & 3.09 & 2.98 & 2.12 \\
\hline $1 \mathrm{~kg}$ OU & 2.65 & 2.55 & 1.82 \\
\hline
\end{tabular}


3.10 Predicting protein and energy values by regression equations

The U.S. National Research Council (NRC) has developed the following regression equations to obtain estimates of digestible protein from crude protein, based on the data of different researchers.

Table 7

Equations used to estimate Digestible Protein (y) from Crude Protein ( $x$ )

\begin{tabular}{|c|c|c|}
\hline $\begin{array}{l}\text { Animal } \\
\text { Species }\end{array}$ & Type of Feed & Equation \\
\hline Gattle & $\begin{array}{l}\text { Dry forages or roughages } \\
\text { Pastures and green feeds } \\
\text { Silages } \\
\text { Energy feeds }\end{array}$ & $\begin{array}{l}y=0.886 x-3.06 \\
y=0.850 x-2.11 \\
y=0.908 x-3.77 \\
y=0.918 x-3.98\end{array}$ \\
\hline Sheep & $\begin{array}{l}\text { Dry forages or roughages } \\
\text { Pastures and green feeds } \\
\text { Silages } \\
\text { Energy feeds }\end{array}$ & $\begin{array}{l}y=0.897 x-1.33 \\
y=0.932 x-3.01 \\
y=0.908 x-3.77 \\
y=0.916 x-2.76\end{array}$ \\
\hline Goats & $\begin{array}{l}\text { Dry forages or roughages } \\
\text { Pastures and green feeds } \\
\text { Silages. } \\
\text { Energy feeds }\end{array}$ & $\begin{array}{l}y=0.933 x-3.44 \\
y=0.908 x-3.77 \\
y=0.916 x-2.76\end{array}$ \\
\hline Horses & $\begin{array}{l}\text { Dry forages or roughages } \\
\text { Pastures and green feeds } \\
\text { Silages } \\
\text { Energy feeds }\end{array}$ & $\begin{array}{l}y=0.849 x-2.47 \\
y=0.908 x-3.77 \\
y=0.916 x-2.76\end{array}$ \\
\hline Rabbits & $\begin{array}{l}\text { Dry forages or roughages } \\
\text { Pastures and green feeds }\end{array}$ & $y=0.722 x-1.33$ \\
\hline
\end{tabular}

The livestock industry is gradually changing from the TDN system of feed evaluation to calorimetric measures like digestible energy, metabolisable energy, and net energy. Unfortunately, calorimetric values for only a small number of feeds have been determined experimentally because of the relative newness of these approaches. Hence it has been necessary to develop regression equations that allow one to interconvert TDN and calorimetric values. For finishing cattle, sheep, and horses, metabolisable energy values can be derived from digestible energy and crude protein values using the following equation: 
$\mathrm{ME}(\mathrm{Kcal} / \mathrm{kg})=\mathrm{DE}(\mathrm{K} \mathrm{cal} / \mathrm{kg}) \times \frac{96-(0.202 \times \text { crude protein } \%)}{100}$

Total digestible energy estimates for ruminants can be calculated from either digestible energy or metabolisable energy from the equations below:

$$
\begin{aligned}
& \operatorname{TDN}(\%)=\frac{\mathrm{DE}(\mathrm{Kcal} / \mathrm{kg})}{4,409} \times 100 \\
& \operatorname{TDN}(\%)=\frac{\mathrm{ME}(\mathrm{Kcal} / \mathrm{kg})}{3,616} \times 100
\end{aligned}
$$

Lofgreen and Garrett have established equation whereby net energy for maintenance and for growth can be estimated:

$$
\begin{aligned}
& \text { LogF }=2.2577-0.2213 \text { \{metabolisable energy }(\mathrm{Kcal} / \mathrm{kg})\} \\
& \text { NE maintenance }(\mathrm{Mcal} / \mathrm{kg})=77+\mathrm{F} \\
& \mathrm{NE} \text { growth }(\mathrm{Mcal} / \mathrm{kg})=2.54-0.0314 \mathrm{~F}
\end{aligned}
$$

The net energy system of Mie and Flatt for lactating cattle is based on the following equation:

$\mathrm{NE}$ lactation $=0.77+0.84$ digestible energy $(\mathrm{Mcal} / \mathrm{kg})\}$ 
CHAPTER 4. The Feeding of Farm Animals

4.1 Maintaining Farm Animals; Feeding Standards/ Ration Formulation/ 155

4.2 The Feeding of Cattle and Buffaloes/ 156

4.2.1 Feeding 3tandard Tables/ 156

4.2.2 Dairy Calf Feeding/ 163

4.2.3 Feeding Lactating Cows and Buffaloes/ 170

4.2.4 Feeding Dry Cows and Buffaloes/ 175

4.2.5 Feeding for Reproduction/ 175

4.2.6 Feeding Breeding Bulls/ 176

4.2.7 Feeding Working Bullocks/ 177

4.2.8 Feeding for Meat Production/178

Program of Practicals for the $5^{\text {th }}$ Semester $/ 182$

4.3 Feeding Sheep/ 183

4.3.1 Nutrient Reouirements of Sheep/ 183

4.3.2 Early Weaning/ 185

4.3.3 Feeding Growing and Finishing Lambs/ 191

4.3.4 Feeding Breeding Ewes, Rams and Lactating Sheep/ 193

4.3.5 Feeding Range Sheep/ 194

4.3.6 Effects of feeding on Wool Production/ 197

4.4 Cattle and Sheep feeding in the Scondinavian Feed Unit System/198

4.4.1 Feeding Standards for Cattle/ 198

4.4.2 Feeding 3tandards for Sheep/ 204

4.4.3 Ration Formulation/ 211

4.5 Feeding Goats/ 218

4.6 Feeding Poultry/ 228

4.7 Feeding Horses, Ponies, Mules, Donkeys and Camels/ 250

Program of Practicals for the $6^{\text {th }}$ 3emester/ 261

Bibliography/ 262 
4.1 Maintaining farm animals; Feeding standards; Ration formulation

The practical daily feeding of the individual animals or the commercial herd is related to their nutrient requirements for various physiological functions, a requirement being defined as the amount of the nutrient that must be supplied in the ration to meet the needs of normal healthy animals given an otherwise nutritionally adequate diet in a hygienic environment. Nutrient requirements vary with the size of the animal and the type and level of production. The requirements for maintenance and the various forms of production-groth, fattening, reproduction, milk, work, etc. are derived by conducting a number of experiments with animals exhibiting different physiological functions, and set down in tables.

Feeding standards are tables listing the amounts of one or more nutrients required by different species of animals for specific productive functions. Most feeding standards are expressed in either quantities of nutrients required per day, and/or concentration in the ration. The first type is used where animals are provided a given amount of feed during a 24-hour period and the second is used where animals are provided a ration wi thout

limitation on the time during which it is consumed.

Different countries have evolved their ow standards on the basis of experiments conducted with animals and the agro-climatic conditions prevalent in that country. These standards are modified from time to time.

Data on feeding standards are available in four systems: 1) Morrison's standard based on TDN systerns followed in the United States and India, 2) Kellner's starch equivalent system followed in most European countries, 3) the Scandinavian feed unit system followed in some European countries and 4) the Calorimetric or Energy evaluation system, as digestible energy, metabolisable energy and net enercy.

The energy evaluation system is relatively new, so feeding standards for all purposes and all feeds are not yet available. In the United states and India, the TDN system is gradually giving way to energy measures. Similarly England is now gradually using metabolisable energy with adjustments according to the effeciency of a feed for a particular purpose.

The key concept in ration formualtion is the balanced ration, which is one that provides an animal the right proportions and amounts, over a 24 hour period, of all the required nutrients for maintenance, growth, finishing, reproduction, lactation, egg for maintenance, growt, finishing, reproduction, wormulated, feeds are initially divided into three categories 1) concentrates, 2) roughages and 3) supplements. The feeding of cattle and buffaloes, sheep, goats, poultry, horses, donkeys and canels is discussed in the following sections. 
4.2 The Feeding of Cattle and Buffaloes

\subsubsection{Feeding Standard Tables}

The feeding standards for maintenance and various productive functions are given in the tables below.

Table 10. Nutrient Requirements for Pre-ruminants Calves

\begin{tabular}{|l|c|c|c|c|c|c|c|c|c|}
\hline Age & $\begin{array}{c}\text { Body } \\
\text { Weight } \\
\mathrm{kg}\end{array}$ & $\begin{array}{c}\text { Daily } \\
\text { gain } \\
g\end{array}$ & $\begin{array}{c}\text { DCP } \\
\mathrm{g}\end{array}$ & $\begin{array}{c}\text { TDN } \\
\mathrm{kg}\end{array}$ & $\begin{array}{c}\text { ME } \\
\text { Mcal }\end{array}$ & $\begin{array}{c}\text { Ca } \\
g\end{array}$ & $\begin{array}{l}P \\
g\end{array}$ & $\begin{array}{l}\text { Vitamin A } \\
10001 \mathrm{U}\end{array}$ & $\begin{array}{c}\text { Vitamin D } \\
1 \mathrm{U}\end{array}$ \\
\hline Birth to 15 days & 25 & 200 & 80 & 0.40 & 1.5 & 2.5 & 1.5 & 1.5 & 200 \\
\hline 15 to 30 days & 30 & 300 & 90 & 0.50 & 1.7 & 3.0 & 2.0 & 1.5 & 250 \\
\hline 31 to 60 days & 40 & 300 & 125 & 0.80 & 2.4 & 3.5 & 2.5 & 1.7 & 250 \\
\hline 60 to 90 days & 50 & 350 & 150 & 1.00 & 3.6 & 4.0 & 3.8 & 2.0 & 360 \\
\hline
\end{tabular}


Table 11. Nutrient Requirements for Growing Dairy Cattle, Buffaloes and Large Breeds(Cross-bred and Exotic)per head per day

\begin{tabular}{|c|c|c|c|c|c|c|c|c|c|c|c|c|c|}
\hline $\begin{array}{c}\text { Body } \\
\text { wt. } \\
\vdots \\
\mathrm{kg} \\
\end{array}$ & $\begin{array}{c}\text { Dry } \\
\text { Feed } \\
\mathrm{kg}\end{array}$ & $\begin{array}{l}\text { Crude } \\
\text { Pro- } \\
\text { tein } \\
g\end{array}$ & $D C P$ & $\begin{array}{r}\text { TDN } \\
\mathrm{kg} \\
\end{array}$ & $\begin{array}{c}S \mathrm{~S} \\
\mathrm{~kg}\end{array}$ & $\begin{array}{l}\mathrm{DE} \\
\mathrm{Mcal}\end{array}$ & $\begin{array}{l}M E \\
\text { Mical }\end{array}$ & $\begin{array}{l}\mathrm{NE} \\
\mathrm{Ncal} \\
\end{array}$ & $\begin{array}{l}\mathrm{Ca} \\
\mathrm{g}\end{array}$ & $\mathrm{g}$ & $\begin{array}{l}\text { Caro- } \\
\text { tene } \\
\mathrm{mg}\end{array}$ & $\begin{array}{l}\text { Vita- } \\
\text { min } \mathrm{A} \\
1000 \\
1 \mathrm{U}\end{array}$ & $\begin{array}{c}\text { Vita- } \\
\text { min D } \\
10\end{array}$ \\
\hline 40 & 0.5 & 110 & 100 & 0.5 & 0.49 & 2.2 & 1.8 & 0.9 & 2.2 & 1.7 & 4.2 & 1.7 & 265 \\
\hline 45 & 0.6 & 135 & 120 & 0.6 & 0.59 & 2.6 & 2.1 & 1.1 & 3.2 & 2.5 & 4.8 & 1.4 & 300 \\
\hline 55 & I.2, & 180 & 145 & 0.9 & 0.89 & 4.0 & 3.3 & 1.3 & 4.5 & 3.5 & 5.8 & 2.3 & 360 \\
\hline 75 & 2.1 & 345 & 255 & 1.5 & 1.49 & 6.6 & 5.4 & 1.6 & 9.7 & 7.5 & 7.9 & 3.2 & 495 \\
\hline 100 & 3.2 & 455 & 320 & 2.2 & 2.18 & 9.7 & 8.0 & 2.1 & 13 & 10 & 11 & 4.0 & 660 \\
\hline 150 & 4.5 & 520 & 355 & 3.0 & 2.97 & 13.2 & 10.8 & 3.2 & 18 & 14 & 16 & 6 & 990 \\
\hline 200 & 5.9 & 595 & 390 & 3.8 & 3.76 & 16.7 & 13.7 & 4.5 & 21 & 16 & 21 & $\varepsilon$ & 1320 \\
\hline 250 & 7.3 & 670 & 430 & 4.5 & $4 \cdot 46$ & 19.8 & 16.3 & 6.0 & 24 & 18 & 26 & 10 & - \\
\hline 300 & 8.7 & 745 & 465 & 5.2 & 5.15 & 22.9 & $1 \varepsilon .8$ & 7.2 & 27 & 20 & 32 & 13 & - \\
\hline 350 & 10.2 & 830 & 500 & 5.9 & 5.84 & 26.0 & 21.3 & 8.1 & 29 & 22 & 37 & 15 & - \\
\hline 400 & 11.8 & 930 & 540 & 6.6 & 6.53 & 29.1 & 23.8 & 9.0 & 30 & 23 & 42 & 17 & - \\
\hline 450 & 12.5 & 1055 & 590 & 7.0 & 6.93 & 30.8 & 25.3 & 9.8 & 30 & 23 & 48 & 19 & $=$ \\
\hline 500 & 13.0 & 1110 & 610 & 7.3 & 7.23 & 32.2 & 26.4 & 10.6 & 30 & 23 & 53 & 21 & - \\
\hline 550 & 13.8 & 11.60 & 625 & 7.7 & 62 & 33.9 & 27.2 & 11.4 & 30 & 23 & 58 & 23 & - \\
\hline 600 & 13.8 & 1190 & 630 & 7.7 & 7.62 & 33.9 & 27.8 & 12.1 & 30 & 23 & 64 & 26 & - \\
\hline 550 & 13.6 & 1220 & 635 & 7.6 & 7.54 & 33.5 & 27.5 & 12.9 & 30 & 23 & 69 & 28 & - \\
\hline 700 & 133.4 & 1235 & 630 & 7.5 & 7.53 & 33.1 & 27.1 & 13.6 & 30 & 23 & 74 & 30 & - \\
\hline 750 & 13.2 & 1240 & 620 & 7.4 & 7.52 & 32.6 & 26.4 & $14 \cdot 4$ & 30 & 23 & 79 & 32 & - \\
\hline 1800 & 12.7 & 1165 & 570 & 7.1 & 7.03 & 31.3 & 25.7 & 15.1 & 30 & 23 & 85 & 34 & - \\
\hline 1850 & 12.1 & 1060 & 510 & $6 . \varepsilon$ & 6.73 & 30.0 & 24.5 & 15.7 & 30 & 23 & 90 & 36 & - \\
\hline
\end{tabular}


Table 12. Nutrient Requirements for growing Dairy Cattle, Buffaloes and Zebu (small breeds per head per day)

\begin{tabular}{|c|c|c|c|c|c|c|c|c|c|c|c|c|c|}
\hline $\begin{array}{l}\text { 3ody } \\
\text { reight } \\
\mathrm{kg}\end{array}$ & $\mid \begin{array}{c}\text { Dry } \\
\text { feed } \\
\mathrm{kg}\end{array}$ & $\begin{array}{l}\text { Crude } \\
\text { protein } \\
\mathrm{g}\end{array}$ & $\begin{array}{l}\text { Digesti } \\
\text { ble pro } \\
\text { tein } \mathrm{g}\end{array}$ & $\mid \begin{array}{c}\mathrm{TDN} \\
\mathrm{kg}\end{array}$ & $\begin{array}{l}\mathrm{SE} \\
\mathrm{kg}\end{array}$ & $\begin{array}{l}\mathrm{DE} \\
\mathrm{Mcal}\end{array}$ & $\begin{array}{l}\text { ME } \\
\text { Mcal }\end{array}$ & $\begin{array}{l}\mathrm{NE} \\
\mathrm{Mcal}\end{array} \mid$ & $\begin{array}{l}\mathrm{Ca} \\
\mathrm{g}\end{array}$ & $\begin{array}{l}P \\
g\end{array}$ & $\begin{array}{l}\text { Caro- } \\
\text { tene } \\
\text { mg }\end{array}$ & $\begin{array}{l}\text { Vita- } \\
\text { min A } \\
100010\end{array}$ & $\begin{array}{l}\text { Vita- } \\
\text { min D } \\
I U\end{array}$ \\
\hline 20 & 0.3 & 65 & 60 & 0.3 & 0.29 & 1.3 & 1.1 & 0.6 & 1.1 & 0.8 & 2.1 & 0.8 & $130^{\circ}$ \\
\hline 25 & 0.4 & 90 & 80 & 0.4 & 0.39 & 1.8 & 1.5 & 0.8 & 1.5 & 1.1 & 2.6 & 1.0 & 165 \\
\hline 35 & 0.8 & 135 & 110 & 0.6 & 0.59 & 2.6 & 2.2 & 0.9 & 3.2 & 2.5 & 3.7 & 1.5 & 230 \\
\hline 50 & 1.4 & 265 & 200 & 1.0 & 0.99 & 4.4 & 3.6 & 1.0 & 6.5 & 5.0 & 5.3 & 2.1 & 330 \\
\hline 75 & 2.0 & 345 & 240 & 2.4 & 1.38 & 6.2 & 5.1 & 1.5 & 8.4 & 6.5 & 7.9 & 3.2 & 495 \\
\hline 100 & 2.8 & 390 & 255 & 2.9 & 1.88 & 8.4 & 6.9 & 2.1 & 11 & 8.0 & 11 & 4.0 & 660 \\
\hline 150 & 4.3 & 460 & 295 & 2.7 & 2.67 & 11.9 & 9.8 & 3.1 & 15 & 11 & 16 & 6 & 990 \\
\hline 200 & 5.7 & 530 & 330 & 3.4 & 3.37 & 15.0 & 12.3 & 4.5 & 18 & 14 & 21 & 8 & 1320 \\
\hline 250 & 7.0 & 610 & 365 & 4.0 & 3.96 & 17.6 & 14.5 & 6.0 & 21 & 16 & 26 & 10 & - \\
\hline 300 & 8.2 & 680 & 395 & 4.6 & 4.55 & 20.3 & 16.6 & 7.2 & 23 & 17 & 32 & 13 & - \\
\hline 350 & 9.3 & 760 & 430 & 5.2 & 5.15 & 22.9 & 18.8 & $\therefore .1$ & 24 & 18 & 37 & 15 & $=$ \\
\hline 400 & 10.2 & 820 & 450 & 5.7 & 5.64 & 25.1 & 20.6 & 8.9 & 25 & 19 & 42 & 17 & - \\
\hline 450 & 10.4 & 875 & 465 & 5.8 & 5.74 & 25.6 & 20.9 & 9.8 & 26 & 20 & 48 & 19 & - \\
\hline 500 & 10.0 & 885 & 455 & 5.6 & 5.54 & 24.7 & 20.2 & 10.6 & 26 & 20 & 53 & 21 & - \\
\hline 550 & 10.0 & 84.3 & 420 & 5.6 & 5.54 & 24.7 & 20.2 & 11.4 & 25 & 19 & 58 & 23 & - \\
\hline 600 & 9.8 & 800 & 355 & 5.5 & 5.54 & $24 \cdot 2$ & 19.9 & 12.1 & 24 & 18 & 64 & 26 & - \\
\hline
\end{tabular}


Table 13. Nutrient Requirements for Maintenance of Mature

Cattle and Buffalo Breeding Bulls

\begin{tabular}{|c|c|c|c|c|c|c|c|c|c|c|c|c|}
\hline $\begin{array}{c}\text { Dody } \\
\text { weight } \\
\mathrm{kg}\end{array}$ & $\begin{array}{c}\text { Dry } \\
\mathrm{kg}\end{array}$ & $\begin{array}{c}\text { Crude } \\
\mathrm{kroteir} \\
\mathrm{g}\end{array}$ & $\mathrm{DCP}$ & $\mathrm{TDN}$ & $\mathrm{SE}$ & $\mathrm{kE}$ & $\mathrm{kg}$ & $\mathrm{NE}$ & $\mathrm{Ca}$ & $\mathrm{P}$ & Corotene & Vitamin A \\
\hline 500 & 8.3 & 640 & 300 & 4.6 & 4.55 & 20.3 & 16.6 & 9.5 & 20 & 15 & 53 & 21 \\
\hline 600 & 9.6 & 735 & 345 & 5.4 & 5.35 & 23.8 & 19.5 & 10.8 & 22 & 17 & 64 & 26 \\
\hline 700 & 10.9 & 830 & 390 & 6.1 & 6.04 & 26.9 & 22.1 & 12.3 & 25 & 19 & 74 & 30 \\
\hline 800 & 12.0 & 915 & 430 & 6.7 & 6.63 & 29.5 & 24.2 & 13.9 & 27 & 21 & 85 & 34 \\
\hline 900 & 13.1 & 1000 & 470 & 7.3 & 6.23 & 32.2 & 26.4 & 15.2 & 30 & 23 & 95 & 38 \\
\hline 1000 & 14.1 & 1075 & 505 & 7.9 & 7.82 & 34.8 & 28.6 & 16.9 & 32 & 25 & 106 & 42 \\
\hline 1100 & 15.1 & 1160 & 545 & 8.4 & 8.36 & 37.0 & 30.4 & 18.2 & 35 & 27 & 117 & 47 \\
\hline 1200 & 16.1 & 1235 & 580 & 9.0 & 8.81 & 39.7 & 32.5 & 19.5 & 38 & 29 & 127 & 51 \\
\hline 1300 & 17.1 & 1310 & 615 & 9.6 & 9.54 & 42.3 & 34.7 & 20.7 & 40 & 31 & 138 & 55 \\
\hline 1400 & 18.1 & 1380 & 650 & 10.1 & 10.00 & 44.5 & 39.8 & 21.9 & 43 & 33 & 148 & 59 \\
\hline
\end{tabular}

Table 14. Nutrient Requirements for Lactating Dairy Cattle and

Buffaloes per head per day

\begin{tabular}{|c|c|c|c|c|c|c|c|c|c|c|c|c|}
\hline $\begin{array}{c}\text { Body } \\
\text { wei ght } \\
\mathrm{kg}\end{array}$ & $\begin{array}{c}\text { Dry } \\
\text { feed } \\
\mathrm{kg}\end{array}$ & $\begin{array}{l}\text { Crude } \\
\text { protein } \\
\mathrm{g}\end{array}$ & {$\left[\begin{array}{c}D C P \\
g\end{array}\right.$} & $\begin{array}{r}\mathrm{TDN} \\
\mathrm{kg} \\
\end{array}$ & $\begin{array}{l}\mathrm{SE} \\
\mathrm{kg}\end{array}$ & $\begin{array}{l}\mathrm{DE} \\
\text { Mcal }\end{array}$ & $\begin{array}{l}\text { ME } \\
\text { Mcal }\end{array}$ & $\begin{array}{l}\mathrm{NE} \\
\mathrm{Mcal} \\
\end{array}$ & $\begin{array}{c}\mathrm{Ca} \\
\mathrm{g}\end{array}$ & $\begin{array}{l}P \\
g\end{array}$ & $\begin{array}{c}\text { Carotene } \\
\mathrm{mg}\end{array}$ & $\begin{array}{l}\text { Vitamin A } \\
10001 \mathrm{U}\end{array}$ \\
\hline 350 & 5.0 & $46 \pi$ & 220 & 2.8 & 2.78 & 12.3 & 10.1 & 6.9 & 14 & 11 & 37 & 15 \\
\hline 400 & 5.5 & 521 & 245 & 3.1 & 3.07 & 13.6 & $11 \cdot 2$ & 7.6 & 17 & 14 & 42 & 17 \\
\hline 450 & 6.1 & 585 & 275 & 3.4 & 3.36 & 15.0 & $12: 3$ & 8.3 & 18 & 13 & 48 & 19 \\
\hline 500 & 6.5 & 638 & 300 & 3.7 & $3: 66$ & 16.3 & 13.4 & 9.0 & 20. & 15 & 53 & 21 \\
\hline 550 & 7.0 & 691 & 325 & 4.0 & 3.96 & 17.6 & 14.4 & 9.6 & 21 & 16 & 58 & 23 \\
\hline 600 & 7.5 & 734 & 345 & $4: 2$ & 4.16 & 18.9 & 15.2 & 10.3 & 22 & 17 & 64 & 26 \\
\hline 650 & 8.0 & 776 & 365 & 4.5 & 4.45 & 19.8 & 16.2 & 10.9 & 23 & 18 & 69 & 28 \\
\hline 700 & 8.5 & 830 & 390 & 4.8 & 4.75 & $21: 1$ & 17.3 & 11.6 & 25 & 19 & 74 & 30 \\
\hline 750 & 9.0 & 872 & 410 & 5.0 & 4.95 & $22: 0$ & 18.0 & 12.2 & 26 & 20 & 79 & 32 \\
\hline 800 & 9.5 & 915 & 430 & 5.3 & 5.25 & 23.3 & 19.1 & 12.8 & 27 & 21 & 85 & 34 \\
\hline
\end{tabular}


Table 15. Nutrient Requirements for Maintenance and Pregnancy (Last two months gestation)

\begin{tabular}{|c|c|c|c|c|c|c|c|c|c|c|c|c|}
\hline $\begin{array}{c}\text { Body } \\
\text { weight } \\
\text { kg }\end{array}$ & $\begin{array}{c}\text { Dry } \\
\text { feed } \\
\mathrm{kg}\end{array}$ & $\begin{array}{c}\text { Crude } \\
\text { protein } \\
\mathrm{g}\end{array}$ & $\mathrm{DCP}$ & $\mathrm{TDN}$ & $\mathrm{SE}$ & $\mathrm{DE}$ & $\mathrm{ME}$ & $\mathrm{NE}$ & $\mathrm{Ca}$ & $\mathrm{P}$ & Carotene & Vitamin A \\
\hline 350 & 6.4 & 570 & 315 & 3.6 & 3.56 & 15.8 & 13.0 & 8.7 & 21 & 16 & 67 & 27 \\
\hline 400 & 7.2 & 650 & 355 & 4.0 & 3.96 & 17.2 & 14.1 & 9.7 & 23 & 18 & 76 & 30 \\
\hline 450 & 7.9 & 730 & 400 & 4.4 & 4.36 & 19.2 & 15.9 & 10.7 & 25 & 20 & 86 & 34 \\
\hline 500 & 8.6 & 780 & 430 & 4.8 & 4.75 & 21.1 & 17.3 & 11.6 & 29 & 22 & 95 & 38 \\
\hline 550 & 9.2 & 850 & 465 & 5.2 & 5.15 & 22.9 & 18.8 & 12.6 & 31 & 24 & 105 & 42 \\
\hline 600 & 10.0 & 910 & 500 & 5.6 & 5.54 & 24.6 & 20.2 & 13.5 & 34 & 26 & 114 & 46 \\
\hline 650 & 10.6 & 960 & 530 & 6.0 & 5.94 & 26.4 & 21.6 & 14.4 & 35 & 28 & 124 & 50 \\
\hline 700 & 11.3 & 1000 & 555 & 6.3 & 6.24 & 27.7 & 22.7 & 15.3 & 39 & 30 & 133 & 53 \\
\hline 750 & 12.0 & 1080 & 595 & 6.7 & 6.63 & 29.5 & 24.2 & 16.0 & 42 & 32 & 143 & 57 \\
\hline 800 & 12.6 & 1150 & 630 & 7.1 & 7.03 & 31.2 & 25.6 & 17.0 & 44 & 34 & 152 & 61 \\
\hline
\end{tabular}

Table 16. Nutrient Requirements for Milk Production (Nutrients required per $\mathrm{kg}$ of milk)

\begin{tabular}{|c|c|c|c|c|c|c|c|c|c|}
\hline Percent Fat & $\begin{array}{r}\text { Crude protein } \\
\mathrm{g}\end{array}$ & $\begin{array}{c}\text { DCP } \\
\mathrm{g}\end{array}$ & $\begin{array}{r}\text { TDN! } \\
\mathrm{kg} \\
\end{array}$ & $\begin{array}{l}S E \\
k g\end{array}$ & $\begin{array}{l}\mathrm{DE} \\
\mathrm{Mcal}\end{array}$ & $\begin{array}{l}\mathrm{ME} \\
\mathrm{Mcal} \\
\end{array}$ & $\begin{array}{l}\mathrm{NE} \\
\mathrm{Mcal} \\
\end{array}$ & $\begin{array}{r}\mathrm{Ca} \\
\mathrm{g}\end{array}$ & $\begin{array}{l}P \\
g\end{array}$ \\
\hline 2.5 & 66 & 42 & 0.255 & 0.252 & 1.12 & 0.91 & 0.55 & 2.4 & 1.7 \\
\hline 3.0 & 70 & 45 & 0.280 & 0.277 & 1.03 & 0.99 & 0.64 & 2.5 & 1.8 \\
\hline 3.5 & 74 & 48 & 0.305 & 0.302 & 1.34 & 1.06 & 0.69 & 2.6 & 1.9 \\
\hline 4.0 & 78 & 51 & 0.330 & 0.327 & 1.46 & 1.13 & 0.74 & 2.7 & 2.0 \\
\hline 4.5 & 22 & 54 & 0.355 & 0.351 & 1.57 & 1.21 & 0.78 & 2.8 & 2.1 \\
\hline 5.0 & 86 & 56 & 0.380 & 0.376 & 1.68 & 1.28 & 0.83 & 2.9 & 2.2 \\
\hline 5.5 & 90 & 58 & 0.405 & 0.401 & 1.79 & 1.36 & 0.88 & 3.0 & $2 . \overline{3}$ \\
\hline 6.0 & 94 & 60 & 0.430 & 0.426 & 1.90 & 1.43 & 0.93 & 3.1 & 2.4 \\
\hline 7.0 & 98 & 63 & 0.460 & 0.455 & 2.01 & 1.54 & 1.38 & 3.3 & 2.6 \\
\hline$\varepsilon .0$ & $10 d$ & 69 & 0.510 & 0.500 & 2.22 & 1.80 & 1.53 & 3.5 & 2.8 \\
\hline 9.0 & 118 & 75 & 0.560 & 0.554 & 2.44 & 2.06 & 1.68 & 3.7 & 3.0 \\
\hline 10.0 & 127 & 81 & 0.600 & 0.594 & 2.62 & 2.16 & 1.80 & 3.9 & 3.2 \\
\hline 11.0 & 133 & 85 & 0.650 & 0.643 & 2.83 & 2.34 & 1.95 & 4.1 & 3.4 \\
\hline
\end{tabular}


Table 17. Nutrient Requirement for Working Bullocks per head per day

Normal Work

\begin{tabular}{|c|c|c|c|c|c|c|c|}
\hline $\begin{array}{c}\text { Live weight } \\
\mathrm{kg}\end{array}$ & $\begin{array}{c}\text { Dry matter } \\
\mathrm{kg}\end{array}$ & $\begin{array}{c}\mathrm{DCP} \\
\mathrm{kg}\end{array}$ & $\begin{array}{c}\mathrm{TDN} \\
\mathrm{kg}\end{array}$ & $\begin{array}{l}\mathrm{SE} \\
\mathrm{kg}\end{array}$ & $\begin{array}{l}\mathrm{DE} \\
\mathrm{Mcal}\end{array}$ & $\begin{array}{l}\mathrm{ME} \\
\mathrm{Mcal}\end{array}$ & $\begin{array}{l}\mathrm{NE} \\
\mathrm{Mcal}\end{array}$ \\
\hline 200 & 4.0 & 0.24 & 2.0 & 1.98 & 8.72 & 7.2 & 6.0 \\
\hline 300 & 5.8 & 0.33 & 3.1 & 3.07 & 13.51 & 11.4 & 9.3 \\
\hline 400 & 7.6 & 0.45 & 4.0 & 3.96 & 17.44 & 14.4 & 12.0 \\
\hline 500 & 9.4 & 0.56 & 4.9 & 4.85 & 21.36 & 18.0 & 14.7 \\
\hline 600 & 11.2 & 0.66 & 5.8 & 5.74 & 25.29 & 20.8 & 17.4 \\
\hline
\end{tabular}

Heavy Work

\begin{tabular}{|l|c|c|c|c|c|c|c|}
\hline 200 & 5.0 & 0.25 & 2.7 & 2.67 & 11.77 & 9.5 & 8.1 \\
\hline 300 & 7.0 & 0.42 & 4.0 & 3.96 & 17.44 & 14.4 & 12.0 \\
\hline 400 & 9.8 & 0.57 & 4.8 & 4.75 & 20.93 & 17.3 & 14.4 \\
\hline 500 & 11.2 & 0.71 & 6.4 & 6.34 & 27.90 & 23.0 & 19.2 \\
\hline 600 & 13.4 & 0.82 & 8.0 & 7.92 & 34.88 & 28.8 & 24.0 \\
\hline
\end{tabular}




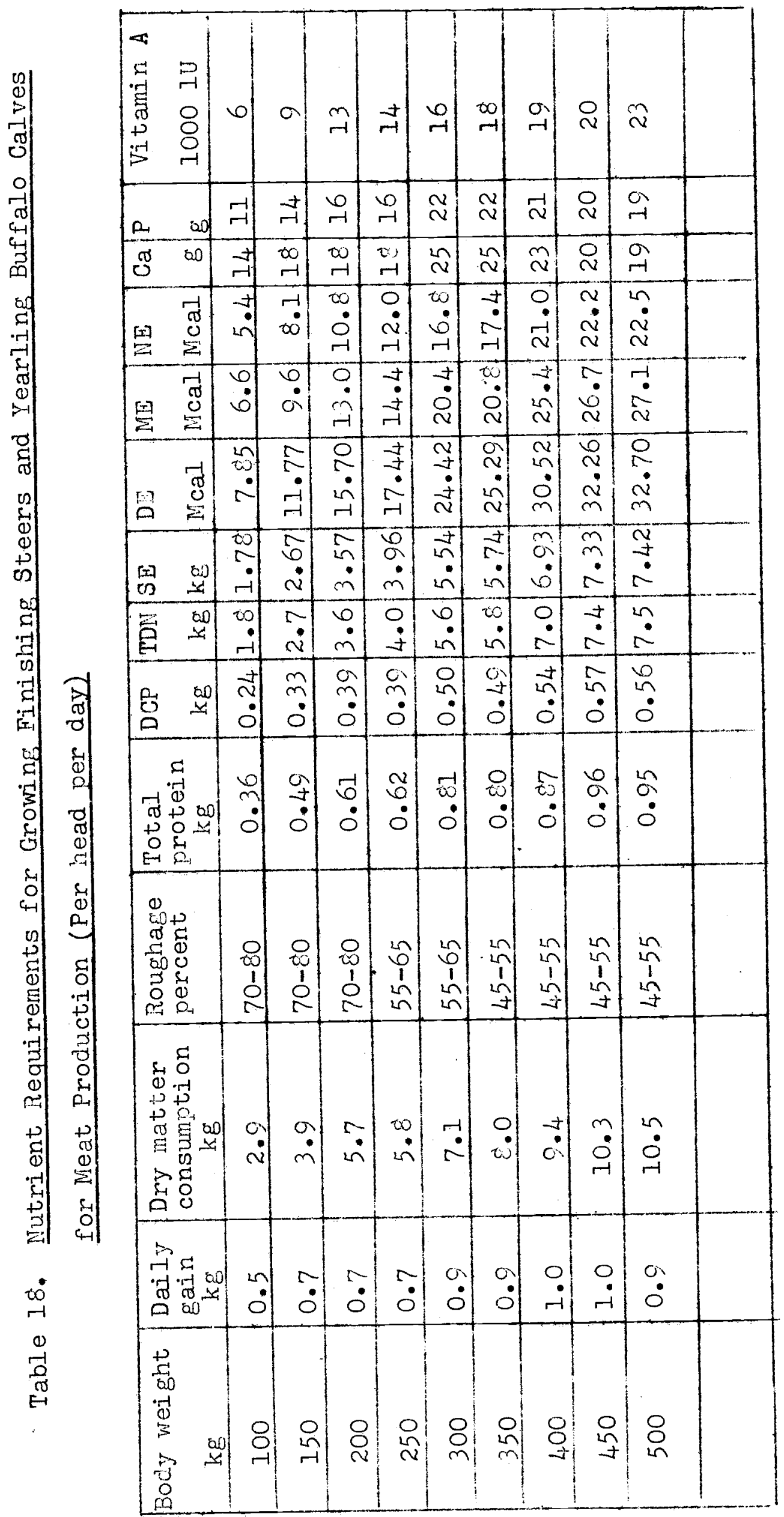




\subsubsection{Dairy Calf Feeding}

The plane of nutrition of the calf plays a very important role in the optimum rate of weight gain. The higher the plane of nutrition, the earlier the onset of puberty and thus a quicker return on capital. The success of catile and buffalo breeding depends on rearing calves successfully to the breedable age as fast as possible with a minimum of mortality. Utmost care should therefore be taken in calf rearing. Well grown, vigourous animals are usually those that have had excellent care from birth.

The reticulo-rumen (fermentation vat), though non-functional, has an inherent capacity of about 2 litres at birth. The larger the period that the calf has access to a plantiful supply of milk, the less will be its urge to supplement its diet with other foods. Introducing roughage and concentrates in the diet of the calves at an early age will help in early establishment of microbial populations and development of the rumen, resulting in the utilization of coarse fodders and starchy food into available forms of energy and the synthesizing of $B$ vitamins and protein from simple nitrogenous compounds. Energy requirement per unit body weight is more for calves than for adult ruminants. Proteins of hich biological value should be fed until the rumen functions at its optimum. The supplementation of $B$ complex and $K$ vitanins is unnecessary after the rumen is fully functional and able to synthesize them. Minerals like calcium, phosphorus, sodium, chlorine, magnesium, potassium, sulphur, iron, copper, cobalt, manganese, iodine and zinc should be supplied in the required amounts.

Colostrum: After parturition, the umbilical cord is sealed with antiseptic. Normal healthy calves stand up about 15 minutes after birth and are able to suckle in about half an hour. Weaker calves take a little longer. The weaning of the calves from the dam should preferably be done at birth and not later than 4 days after it. The colostrum is fed within the first four to six hours afier birth and is continued for four days at the rate of one-tenth the body weight of the calf, twi ce or thrice daily. The colostrum is rich in protein, largely due to its content of lactoglobulins, which also provide antibolies to the calves. When colostrum is not available, either because of the death of the dam or for other reasons, the calves may be given normal herd-milk suplemented with vitamin $A$ (cod liver oil, shark liver oil or synthetic vitamin A), or two eggs added to normal herd-milk. Intramuscular administration has been found very beneficial. T'wo ounces $\left(6 \mathrm{~g}_{\bullet}\right)$ of castor oil may be given to compensate the laxative effect of colostrum if the latter is not available.

Milk: For four to seven days after the initial 4 day period, weaned calves should be fed milk from their own dams, after which milk from the general herd may be given. As a general 
rule, calves may be fed milk at the rate of ten percent of their body weight. For the first few weeks the milk fed should be very fresh to ensure that its temperature is the same as first milk from the cow. Calves may be encouraged to drink milk from an ordinary open pail by mouth feeding with one's fingers.

There are a number of methods of feeding calves for the first six months.

When a calf is reared on whole milk, grain mixtures and hay, it requres about $400 \mathrm{~kg}$ of whole milk. Generally whole milk. is given at the rate of 10 percent of body weight for the first six weeks, 7.5 percent in the seventh and eight weeks, 5 percent in loth, Ilth and 12 th weeks and then gradually reduced to 2.5 percent till the calf is 26 weeks old. Slightly higher amounts may also be given. Grain mixtures, mineral supplements and legume hay or haryali (cynodon dactylon) hay is introduced from the fourth week onward. The antibiotic Aurofac/terramycin may be given with milk or mixed with calf starter.

Calf Starter: An ideal calf starter contains about 20 to 25 percent DCP and 70 to 75 percent TDN. The composition of seven calf starters is given below using feeds according to availability.

Table 19. Calf starter compositions

\begin{tabular}{|l|l|l|l|l|l|l|l|}
\hline Feeds & I & II & III & IV & V & VI & VII \\
\hline crushed maize & 40 & - & 50 & - & 30 & 50 & 20 \\
\hline crushed barley & - & 50 & - & - & 20 & - & - \\
\hline crushed oats & - & - & - & 40 & - & - & 20 \\
\hline crushed gram & 15 & - & - & - & - & - & 10 \\
\hline ground nut cake & 30 & 30 & - & 20 & - & 30 & 20 \\
\hline $\begin{array}{l}\text { secorticated } \\
\text { cotton seed cake }\end{array}$ & - & - & 20 & - & - & - & 10 \\
\hline Iinseed cake & - & - & - & 10 & 30 & - & - \\
\hline fish meal & - & - & 20 & - & - & 10 & - \\
\hline meat meal & - & 10 & - & 20 & - & - & 5 \\
\hline dried skim milk & - & - & - & - & 20 & - & 5 \\
\hline wheat bran & 15 & 8 & 10 & - & - & - & 10 \\
\hline rice polish & - & - & - & 10 & - & 10 & - \\
\hline approximate DCP & $20-25$ & $20-25$ & $20-25$ & $20-25$ & $20-25$ & $20-25$ & $20-25$ \\
\hline approximate TDN & $70-75$ & $70-75$ & $70-75$ & $70-75$ & $70-75$ & $70-75$ & $70-75$ \\
\hline
\end{tabular}


To the above mixture, the following may be added:
a) salt
1 percent
b) mineral mixture
2 percent
c) molasses
5-10 percent according to availability
d) Rovimix
10 grams per quintal
e) Aurofac
20 grams per quintal

The constituents of the calf starter can be altered according to the availability of the feeds. The maize fraction can be replaced completely by barley and partly by rolled oats, sorghum or millet. Instead of ground nut cake, linseed, sesame, decorticatea cotton seed, or soya bean cakes may be used. Rice polish could be used in place of wheat bran. Meat meal and dried skin milk can replace fish meal.

Mineral supplement: The mineral supplement mixture may be prepared by mixing together the proportions by weight of the following ingredients:

Finely powdered sterlized bone meal 45.00 parts

Ground chalk (calcium carbonate) 10.00 parts

Dicalcium phosphate

12.00 parts

Common salt

30.00 parts

Yellow oxide of iron

0.25 parts

Potassium iodide

2.25 parts

Starch

0.75 parts

Sodium carbonate

0.75 parts

Sodium thiosulphate

1.75 parts

To every $100 \mathrm{~kg}$ of the mixture, add finely powdered, $50 \mathrm{gms}$ of cobalt chloride, $0.25 \mathrm{~kg}$ of copper sulphate and $0.3 \mathrm{~kg}$ of manganese sulphate.

Roughage: The feeding of good quality hay or leguminous green fodders to calves at an early age has been found to cause early development of rumen functions. Concentrate diets without roughage have been found to result in increased acid production in the rumen thereby damaging the rumen mucosa. Succulent fodders, 
preferably legumes or their hay should be made available to the calves round the year. Stopping milk after the seventh or eighth weeks has not shown any adverse effect on live weight; this may be due to the development of digestive organs and the functioning of the rumen at an early age. It has been observed that at this stage, calves are able to consume energy as per N.R.C. Standards provided good quality forage, fresh or as hay, is available.

Three methods of calf rearing are practised. In the first system, whole milk in adequate quantities is fed upto 10 weeks of age and then gradually reduced but fed fill the calves are 6 months old. Grain mixtures and hay are introduced in the 3 rd or 4 th week. In the second system, whole milk is reduced from 4 th week and fed only upto the 8th week, but skim milk and concentrate mixtures are introduced from the 3 rd week onwards and roughage from the fourth week. In the third system, known as the "economic rearing of calves", whole milk is fed in adequate amounts upto the third or fourth week and then fed in reduced quantity to the eighth week only, and calf starter and good quality hay are introduced from the fourth week onwards. The feeding schedule for calves from birth to six months of age according to these three systems is presented in Table 20. 
1. Antibiotic may be fed with the concentrates.

2. Green fodders are also fed along with hay to calves after three months or 12th weeks of age.

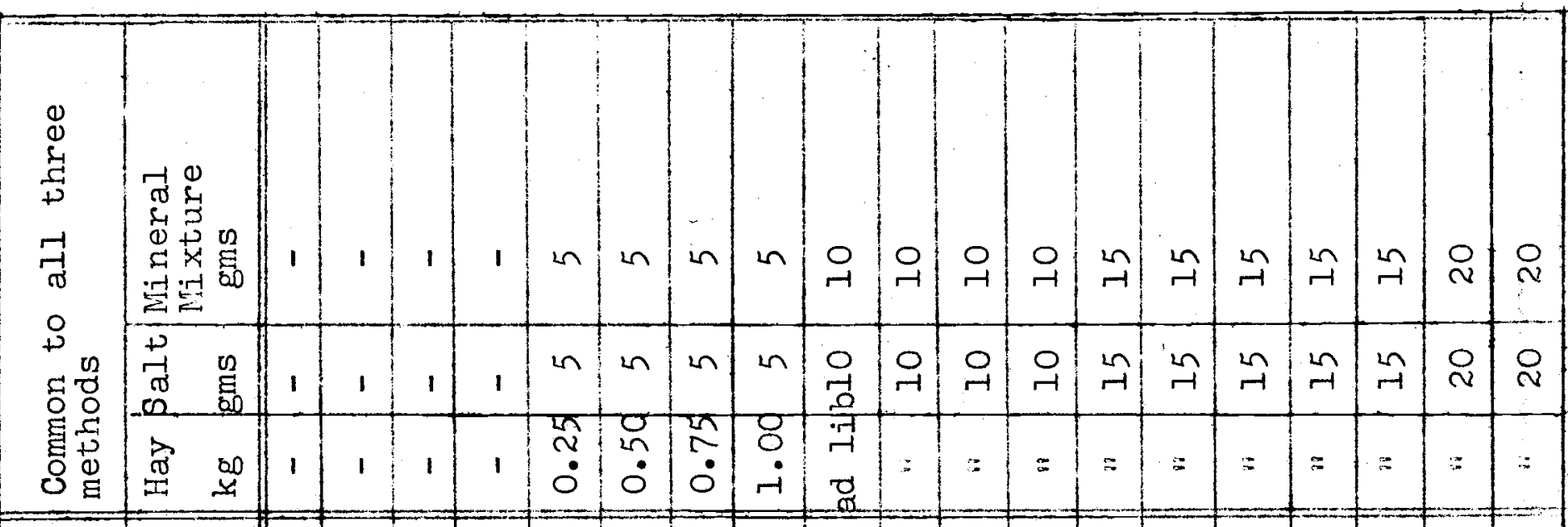

3

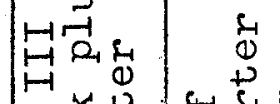

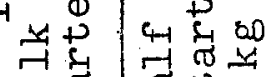

ช

कृ

$+\infty 0^{2} 0$

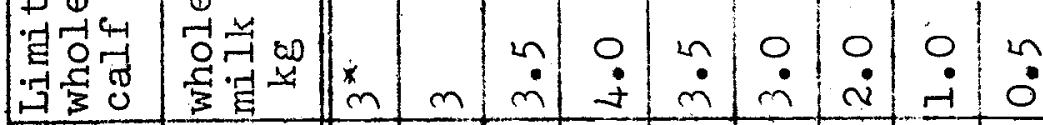

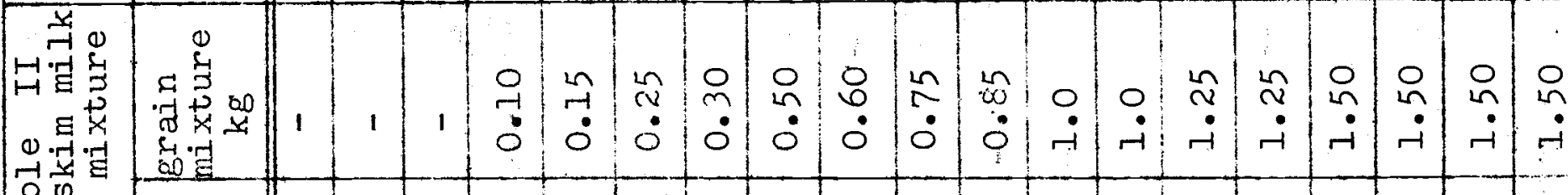

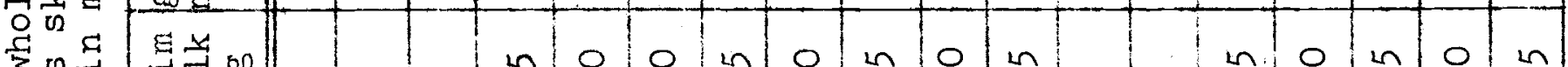

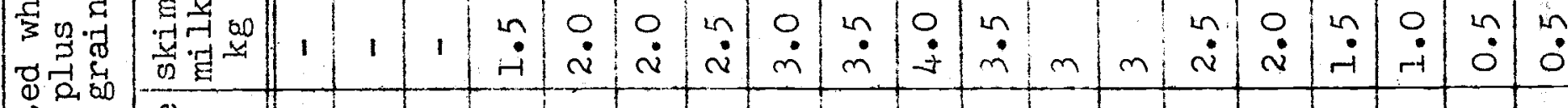

$+3$

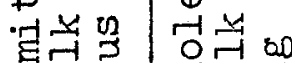

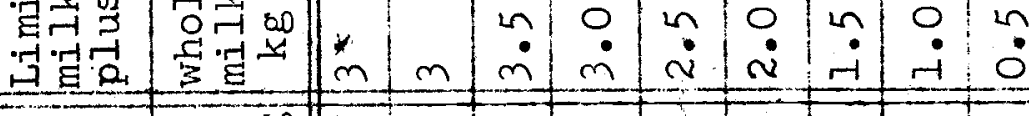

(1) 选

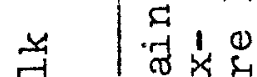

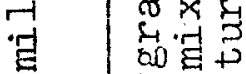
(1) 1

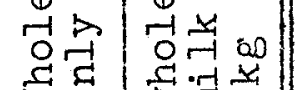

80

t4

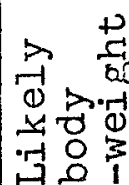

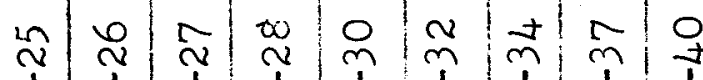

\begin{tabular}{cccc|c|c|c|c|c|c|c|c}
1 & 1 & 1 & 1 & 1 & 1 & 1 & 1 & 1 & 1 & 1 & 1 \\
-1 & $n$ & $n$ & 1 & $b$ & $w$ & 0 & $m$ & 0 & 0 & $m$ & 0
\end{tabular}

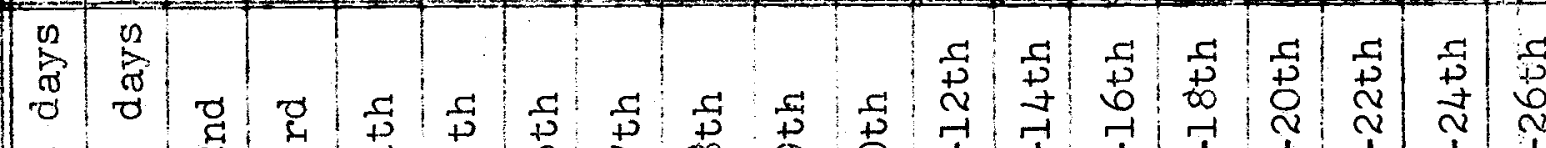

$G$

.

(1) $\frac{1}{1}$

600

$<3$

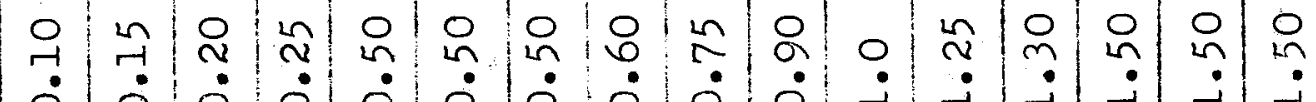

(1)

in 2 in

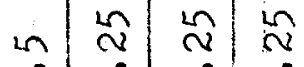

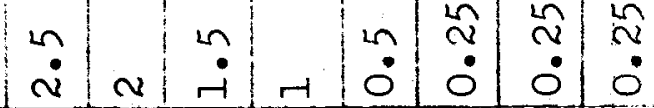

†

Hन 
The nutrient requirements for the growth of calves have been shown in the tables of feeding standards. Keeping in view the requirements and availability of feeds and fodders, it is then possible to work out growth rations. The following ration schedules have been found to be satisfactory.

Table 21. Feeding Dairy Calves (including replacement heifers) from three months of age to maturity

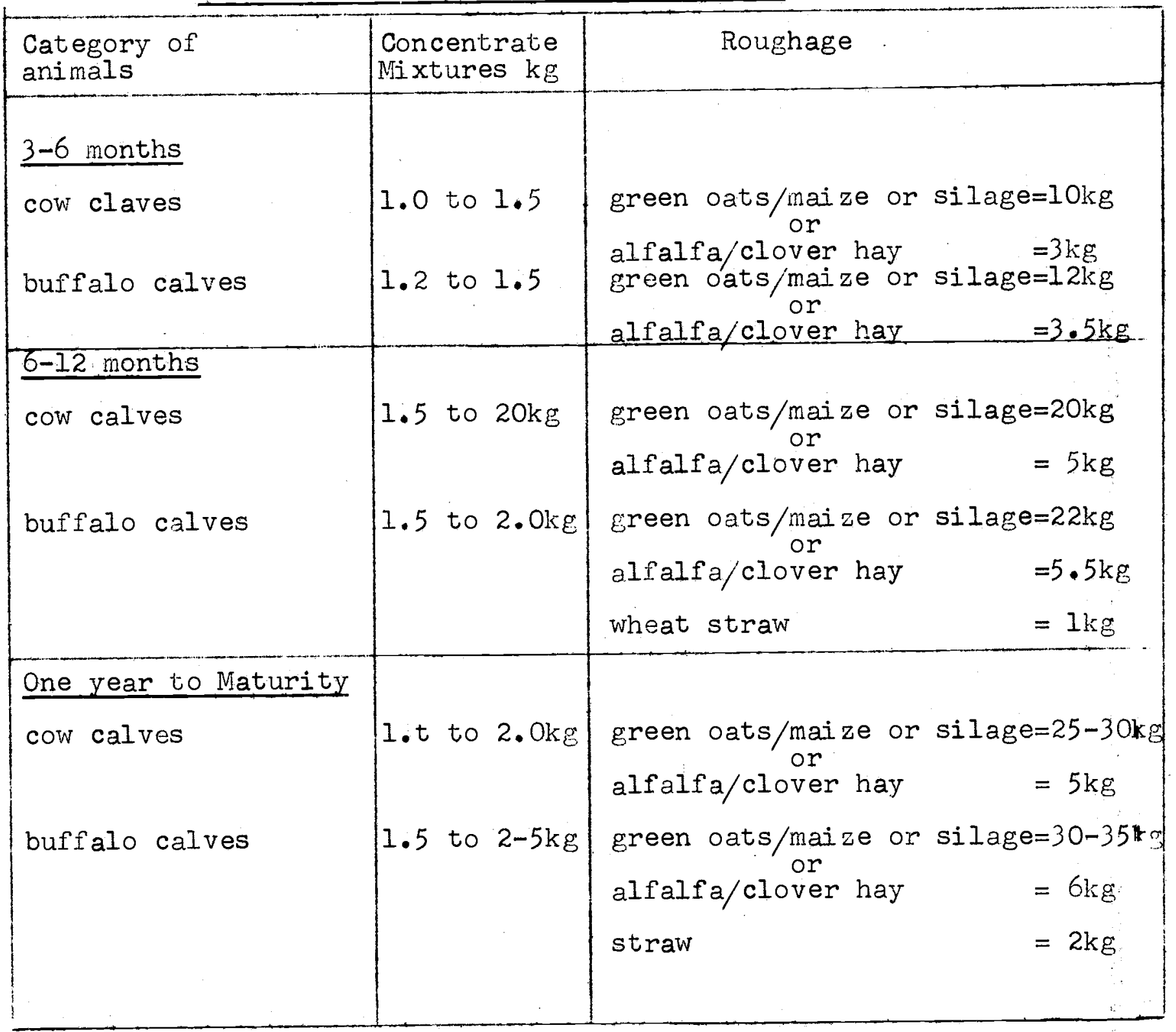


An example of the calculation of growth production rations is given below.

Growth requirement of a $200 \mathrm{~kg}$ bull calf:

$$
\begin{array}{llll}
\text { D.M. } & \text { DCP } & \text { TDN } & \text { ME } \\
5.7 \mathrm{~kg} & 0.33 \mathrm{~kg} & 3.4 \mathrm{~kg} & 12.3 \mathrm{~kg}
\end{array}
$$

1. Ration: Wheat straw and concentrate mixture

\begin{tabular}{llll}
$\underset{(\mathrm{kg})}{\text { Quantity }}$ & DCP & TDN & ME \\
& $(\mathrm{kg})$ & $(\mathrm{kg})$ & $(\mathrm{Mcal})$ \\
\hline
\end{tabular}

wheat straw
(DCP 0\%; TDN 40\%; ME 1.4Mcal $/ \mathrm{kg}$ )
4
$0 \quad 1.6 \quad 5.6$
concentrate mixture
(DCP $16 \% ;$ TDN $70 \%$ ME $22.5 \mathrm{Mcal} / \mathrm{kg}$ ) $2 \quad 0.32 \quad 1.8 \quad 5.0$
Total

$6 \quad 0.32 \quad 3.4 \quad 10.6$

The suply of DCP and TDN in this ration is therefore satisfactory, but ME has fallen short, it can be made up by feeding a little more wheat straw.

2. Ration: Wheat straw, green fodders and concentrate mixture Quantity DCP TDN NE $\begin{array}{llll}(\mathrm{kg}) & (\mathrm{kg}) & (\mathrm{kg}) & (\mathrm{Mcal})\end{array}$

Wheat Straw

4

$0 \quad 1.6$

5.6

Green clover

$\begin{array}{lllll}(\text { DCP } 1.5 \% \text { TDN } 10 \% ; \mathrm{ME} 3.35 \mathrm{Mcal} / \mathrm{kg}) & 3 & 0.045 & 0.3 & 1.05\end{array}$

Concentrate Mixture

(DCP 15\%; TDN 75\% ME 2.9 Mcal $/ \mathrm{kE}) \quad 2 \quad 0.300 \quad 1.5 \quad 5.80$

Total

$0.345 \quad 3.4 \quad 12.45$ 
3. All Roughage Ration

Egyptian clover

(DCP $1.5 \%$ TDN $10 \%$ ME $3.5 \mathrm{Mcal} / \mathrm{kg}$ )

Quantity
$(\mathrm{kg})$

$\begin{array}{lll}\text { DCP } & \text { TDN } & M E \\ (\mathrm{~kg}) & (\mathrm{kg}) & (\mathrm{Mcal}) \\ 0.45 & 3.0 & 10.5\end{array}$

\subsubsection{Feeding lactating cows and buffaloes}

In organised dairy farms, it is always necessary to prepare a sort of concentrate mixture. A balanced concentrate mixture is usually prepared in such a way that 3 to $4 . \mathrm{kg}$ of it may support a yield $10 \mathrm{~kg}$ of milk. Normally this concentrate mixture is fed at the rate of one $\mathrm{kg}$ concentrate for every three $\mathrm{kg}$ of milk for cows and 2 to $2.5 \mathrm{~kg}$ milk for buffaloes when the maintenance part of the ration is provided separately. Concentrate mixtures are prepared not only because they are more palatable than single ingredients, but also to ensure proper balance of protein and energy in the correct ratios. A concentrate mixture having about 15 percent DCP and 70 percent TDN is considered suitable. A mixture of minerals ( $1 \%$ ) and $2 \%$ by weight of salt, and sometimes $1 \%$ calcium carbonate are generally adced to all concentrate mixtures as they are poor in minerals, especially calcium. Roughages and concentrates are usually poor sources of cominon salt. Concentrate mixtures are normally prepared with grains (like maize, barley and oats), oil cakes, gram, cotton seed and wheat or rice bran as shown below:

Table 22. Typical concentrate mixture

\begin{tabular}{|c|c|c|c|c|c|}
\hline Feed ingredient & Parts & $\begin{array}{l}\mathrm{DCP} \\
(\mathrm{kg}) \\
\end{array}$ & $\begin{array}{l}\text { TDN } \\
(\mathrm{kg})\end{array}$ & $\begin{array}{l}\mathrm{SE} \\
(\mathrm{kg})\end{array}$ & (ME \\
\hline $\begin{array}{c}\text { Barley ( } 7 \% \text { DCP, } 78 \% \text { TDN, } 75 \% \text { SE } \\
270 \text { MCal ME) }\end{array}$ & 30 & 2.1 & 23.4 & 22.5 & 84.2 \\
\hline $\begin{array}{r}\text { Gram (11\% DCP, } 80 \% \text { TDN, } 75 \% \text { SE } \\
28 \& \text { MCaI ME) }\end{array}$ & 20 & 2.2 & 16.9 & 15.0 & 57.6 \\
\hline $\begin{array}{c}\text { Ground nut cake ( } 42 \% \mathrm{DCP}, 75 \% \mathrm{TDN} \\
70 \% \mathrm{SE} \text { and } 270 \mathrm{MCaI} \mathrm{ME})\end{array}$ & 20 & 8.4 & 15.0 & 14.0 & 54.0 \\
\hline Wheat bran ( $8 \%$ DCP, $65 \%$ TDN , 60\% & 30 & 2.4 & 19.5 & 18.0 & 70.2 \\
\hline & 100 & 15.1 & 74.8 & 69.5 & 266.0 \\
\hline
\end{tabular}


$1 \mathrm{~kg}$ of this mixture therefore contains $0.15 \mathrm{~kg} \mathrm{DCP}, 0.75 \mathrm{~kg}$ TDN $0.70 \mathrm{~kg} \mathrm{SE}$ and $2.66 \mathrm{Mcal} \mathrm{ME}$.

Numerous concentrate mixtures can be worked out where the contents of DCP per $\mathrm{kg}$ may vary from 0.13 to $0.2 \mathrm{~kg}$, TDN from 0.55 to $0.75 \mathrm{~kg}$, SE from 0.6 to $0.7 \mathrm{~kg}$ and $\mathrm{ME}$ from 2.3 to $2.6 \mathrm{Mcal}$ The constituents of the above concentrate mixture can be altered according to the availability of feeds and their prices as below:

Table 23. Various suitable concentrate mixtures

Feed ingredient

\begin{tabular}{|c|c|c|c|c|c|c|c|c|c|}
\hline I & II & III & IV & V & VI & VII & VIII & IX $_{\%}$ & $X_{\%}$ \\
\hline 30 & - & - & 10 & 10 & 20 & 20 & 10 & 15 & - \\
\hline- & 30 & - & 10 & - & 10 & - & 20 & 15 & 15 \\
\hline- & - & 30 & 10 & 20 & - & 10 & - & - & 15 \\
\hline 10 & - & - & 10 & - & - & 10 & - & - & - \\
\hline- & 10 & - & 10 & 10 & 10 & - & 10 & 10 & 10 \\
\hline 30 & - & - & 20 & - & - & 10 & - & 15 & 10 \\
\hline- & 30 & - & - & 10 & 20 & 10 & 10 & - & - \\
\hline- & - & 30 & - & 20 & 20 & 10 & 20 & 15 & 20 \\
\hline 10 & - & 10 & 10 & - & 10 & 10 & - & 10 & - \\
\hline- & 10 & - & - & 10 & - & - & 10 & - & 10 \\
\hline 20 & 20 & 30 & 20 & 20 & 10 & 20 & 20 & 20 & 20 \\
\hline $12-15$ & $12-15$ & $12-15$ & $12-15$ & $12-15$ & $12-15$ & $12-15$ & $12-15$ & $12-15$ & $12-15$ \\
\hline $70-73$ & $70-73$ & $70-73$ & $70-73$ & $70-73$ & $70-73$ & $70-73$ & $70-73$ & $70-73$ & $70-73$ \\
\hline
\end{tabular}

One percent salt and two percent mineral mixture is added to the above concentrate mixtures.

The ration of an animal may be divided for convenience into two parts, one for maintenance and the other for production purposes. The maintenance ration is that portion of the diet that just enebles the animal at rest to carry on the essential processes of life, such as breathing and blood circulation 
without either gain or loss of weight. The maintenance ration depends on the animal's body weight and also on the level of production.

In computing a ration, the first consideretion should be the animal's appetite, which is measured by the total amount of dry matter in the ration that the animal can consume. Usually the dry matter consumption varies vith the live weight of the animal and also with the nature of production. Cattle generally eat about 2 to $2.5 \mathrm{~kg}$ dry matter per $100 \mathrm{~kg}$ of live weight. Nilk stock may eat a little more, while buffaloes are slightly better eaters than cows. The major portion, about two thirds or more, of the total dry matter to be consumed, should come from the roughage quota of the ration and the rest from concentrates. After the quantity of dry matter consumption is known, the next important information required is the quantity of digestible crude protein (DCP) and energy (TDN, SE or ME) which the ration must supply.

Sample calculation of rations for a cow weighing $400 \mathrm{~kg}$ and yielding $8 \mathrm{~kg}$ milk with $4.5 \%$ fat

The available feed stuffs are wheat straw, sorghum silage, barley, ground nut cake, wheat bran and gram husk.

The animal's capacity for total dry matter consumption will be between 8 and $10 \mathrm{~kg}$, which can be conveniently divided into two parts, one for maintenance and the other for milk production.

According to the table of feeding standards, maintenance is met by $0.245^{\mathrm{kg} D C P}, 3.1 \mathrm{~kg}$ TDN and $3.07 \mathrm{~kg} \mathrm{SE}$. The following maintenance quotas of rations can then be formulated:

\begin{tabular}{|l|c|c|c|c|c|}
\hline Feed & $(\mathrm{kg})$ & $\begin{array}{l}\mathrm{DM} \\
(\mathrm{kg})\end{array}$ & $\begin{array}{l}\mathrm{PCP} \\
(\mathrm{kg})\end{array}$ & $\begin{array}{l}\mathrm{TDN} \\
(\mathrm{kg})\end{array}$ & $\begin{array}{l}\mathrm{SE} \\
(\mathrm{kg})\end{array}$ \\
\hline $\begin{array}{l}\text { Wheat straw } \\
(\mathrm{DCP}=0 \%, \mathrm{TDN}=43 \%, \mathrm{SE}=22 \%)\end{array}$ & 3 & 2.7 & 0.00 & 1.20 & 0.66 \\
\hline $\begin{array}{l}\text { Sorghum } / \mathrm{Sil} \text { age } \\
(\mathrm{DCP}=0.7 \%, \mathrm{TDN}=15.3 \%, \mathrm{SE}=10 \%)\end{array}$ & 10 & 3.0 & 0.07 & 1.53 & 1.00 \\
\hline $\begin{array}{l}\text { Ground nut cake } \\
(\mathrm{DCP}=41.7 \%, \mathrm{TDN}=71 \%, \mathrm{SE}=67 \%)\end{array}$ & 0.5 & 0.45 & 0.21 & 0.36 & 0.34 \\
\hline Total & & 6.15 & 0.28 & 3.18 & 2.00 \\
\hline
\end{tabular}


The concentrate mixture for milk production may have the following composition.

\begin{tabular}{|l|c|c|c|c|}
\hline Feed & Parts & DCP & TDN & $S E$ \\
\hline Barley & 50 & 4.02 & 38.8 & 35.8 \\
\hline Ground nut cake & 10 & 4.17 & 7.1 & 6.7 \\
\hline Wheat bran & 20 & 2.12 & 13.5 & 12.4 \\
\hline Gram husk & 20 & 0.00 & 11.0 & 6.0 \\
\hline & 100 & 10.31 & 70.4 & 60.9 \\
\hline
\end{tabular}

That is, $1 \mathrm{~kg}$ of the above concentrate mixture has $0.10 \mathrm{DCF}, 0.70$ TDH, $0.61 \mathrm{SE}$ Since the feeding standards tables give as the requirement per $\mathrm{kg}$ of milk ( $4.5 \% \mathrm{fat}) 0.054 \mathrm{DCP}, 0.355 \mathrm{TDN}$ and $0.351 \mathrm{SE}, 1 \mathrm{~kg}$ of the above mixture is sufficient for the production of $2 \mathrm{~kg}$ of milk. In other words, to produce $8 \mathrm{~kg} \mathrm{milk}$, $4 \mathrm{~kg}$ of this concentrate mixture should be fed in addition to the maintenance ration.

The total nutrients provided for the required milk production will therefore be as follows ( $4 \mathrm{~kg}$ concentrate mixture yielding $3.6 \mathrm{~kg}$ concentrate dry matter):

\begin{tabular}{|c|c|c|c|c|}
\hline Purpose & $\begin{array}{c}\mathrm{DN} \\
(\mathrm{kg})\end{array}$ & $\begin{array}{l}\mathrm{DCP} \\
(\mathrm{kg})\end{array}$ & $\begin{array}{l}\mathrm{TDN} \\
(\mathrm{kg})\end{array}$ & $\begin{array}{l}\mathrm{SE} \\
(\mathrm{kg})\end{array}$ \\
\hline For maintenance & 6.15 & 0.28 & 3.18 & 2.00 \\
\hline For production of $8 \mathrm{~kg}$ milk & 3.60 & 0.40 & 2.80 & 2.44 \\
\hline Total & 9.75 & 0.68 & 5.98 & 4.44 \\
\hline
\end{tabular}

Sample calculation of the ration for a buffalo weighing $500 \mathrm{~kg}$ and yielding $10 \mathrm{~kg}$ milk with $\%$ fat content

The available feed stuffs are wheat straw, clover hay, crushed barley, cotton seed cake, wheat bran and gram husk. The animals capacity for dry matter consumption will be between 10 to $12.5 \mathrm{~kg}$, or slightly more.

The requirements for maintenance and milk production, taken from the feeding standards tables are as follows: 


\begin{tabular}{|c|c|c|c|}
\hline & $\begin{array}{l}\text { DM } \\
(\mathrm{kg})\end{array}$ & $\begin{array}{l}\text { DCP } \\
(\mathrm{kg})\end{array}$ & $\begin{array}{l}\text { TDN } \\
(\mathrm{kg})\end{array}$ \\
\hline For maintenance $500 \mathrm{~kg}$ body weight & 6.5 & 0.30 & 3.70 \\
\hline For $10 \mathrm{~kg}$ milk at $8 \%$ fat & & 0.69 & 5.10 \\
\hline Total & & 0.99 & 8.80 \\
\hline
\end{tabular}

The concentrate mixture for milk production may be computed as below:

\begin{tabular}{|l|c|c|c|c|}
\hline Feed & Parts & $\begin{array}{l}\text { DN } \\
(\mathrm{kg})\end{array}$ & $\begin{array}{l}\text { DCP } \\
(\mathrm{kg})\end{array}$ & $\begin{array}{l}\text { TDN } \\
(\mathrm{kg})\end{array}$ \\
\hline Barley(DCP 10\%, TDN 80\%) & 50 & 4.5 & 5.0 & 40.0 \\
\hline Cotton seed cake(DCP 28.0\%, TDN 70\%) & 20 & 18 & 5.6 & 15.6 \\
\hline Wheat bran(DCP 10\%, TDN 68\%) & 20 & 18 & 2.0 & 13.6 \\
\hline Gram husk(DCP 0.0\%, TDN 55\%) & 10 & 9 & 0.0 & 5.5 \\
\hline & 100 & 90 & 12.6 & 74.7 \\
\hline
\end{tabular}

$10 \mathrm{~kg}$ of the above concentrate mixture therefore contains $1.26 \mathrm{~kg}$ DCP and $7.47 \mathrm{~kg}$ TDN, which meets the protein requirement but falls short on TDN. The total ration given below will meet both $\mathrm{DCP}$ and TDN requirements.

\begin{tabular}{|c|c|c|c|c|}
\hline Wheat straw(DCP 0\%, TDN 43\%) & $\begin{array}{c}\text { Parts } \\
(\mathrm{kg})\end{array}$ & $\begin{array}{l}\text { DM } \\
(\mathrm{kg})\end{array}$ & $\begin{array}{l}\text { DCP } \\
(\mathrm{kg})\end{array}$ & $\begin{array}{l}\text { TDN } \\
(\mathrm{kg})\end{array}$ \\
\hline Clover hay(DCP 14\%, TDN 50\%) & 5 & 4.5 & 0.00 & 2.15 \\
\hline Concentrate(DCF 12.6\%, TDN 74.7\%) & 5 & 4.5 & 0.63 & 3.74 \\
Total & 5 & 4.5 & 0.70 & 2.50 \\
\hline
\end{tabular}

In addition to the above, $30 \mathrm{~g}$ salt and $60 \mathrm{~g}$ mineral mixture is also fed per day.

In actual practice, it is usual to make the animal eat all the scheduled concentrate and as much as possible of the greens or hay. The dry roughage is given in slight excess of what is prescribed, leaving the animal to adjust its appetite or its 
requirement of the total dry matter consumption.

4.2.4. Feeding Dry Cows and Buffaloes

At times some animals on a farm can run dry or are not pregnant due to one reason or another. These animals, although temporarily uneconomical, stil. need to be fed a maintenance ration. The maintenance requirements of a $500 \mathrm{~kg}$ cow or buffalo are $0.3 \mathrm{~kg}$ DCP, $3.7 \mathrm{~kg}$ TDN or $13.2 \mathrm{Mcal} \mathrm{Ng}, 20 \mathrm{~g}$ calcium and $15 \mathrm{~g}$ phosphorus, and can be met by feeding $30 \mathrm{~kg}$ of green maize or good quality sorghum containing 1 percent $\mathrm{DCP}, 14 \%$ TDN or $0.5 \mathrm{Mcal} \mathrm{ME}, 0.6$ gram calcium and $0.5 \mathrm{gram}$ per $\mathrm{kg}$ of green fodder. The dry animal is usually fed wheat or other straw along with a little concentrate mixture or oil cakes or hay whichever is available and cheaper. With wheat or rice straw as the basal roughage, about $7-8 \mathrm{~kg}$ straw and $750 \mathrm{gms}$ ground nut cake or $1 \mathrm{~kg}$ mustard, rape or cotton seed cake or $2-3 \mathrm{~kg}$ clover or other legurne hay are sufficient to maintain the animal.

\subsubsection{Feeding for Reproduction (Pregnancy)}

Ideally, a cow or buffalo should calve at 12-13 month intervals and should have a lactation length of about 300 days, but in practice calving intervals are aften longer and lactation periods shorter. Cows should have a dry period of 60 days and buffaloes 60-90 days, but in practice these may be. longer. During their dry periods cows and buffaloes should build up body reserves lost during their earlier lactation; they will also require additional nutrients to support the fast fetus growth which takes place in the last quarter of pregnancy.

Nutrients are also required for the regeneration of mammary tissues. During this period, called "steaming up" in practice, the dry aninals are offered extra quantities of concentrates increasing the amounts gradually during the last $6-8$ weeks of pregnancy. By calving time the amount of concentrates fed is 75 percent of what the animal is expected to need in early lactation. Steaming up increases milk production, in part by preparing the animal for the large rations of concentrates it may have to ingest in early lactation. During the last 60 days, pregnant animals undergo a $20-30 \mathrm{~kg}$ wei ght increase depending on breed, feeding and management. Protein requirements during pregnancy is more than for energy. Normally $50 \%$ DCP and $25 \%$ of the TDN of the maintenance diet are fed on top of the maintenance ration. These requirements are met by feeding an additional 1 to $1.5 \mathrm{~kg}$ concentrate nixture (DCP 15-20\%, TDN $60-70 \%$ ) over the maintenance ration. The basal roughage may be wheat or rice straw plus. leguminous fodder, either green or as hay. 


\subsubsection{Feeding Breeding Bulls}

The requirement for breeding bulls (cattle and buffalo) have been. given in tables of feeding standards. Mature breeding bulls should be fed just enough to maintain a positjve body weight. Over-feeding should be avoided to keep the bulls active and full of vigour. A cood cuality cereal focker like maize, sorghum or oats, when fed liberally with some straw, eliminates the need for concentrates. About 40-50 kg of cereal fodder and $2-3 \mathrm{~kg}$ wheat or rice straw will supply the nutrient requirement of a mature breeding bull weiging $600-700 \mathrm{~kg}$.

Table 24. Rations for a breeding bull weighing $600 \mathrm{~kg}$

\section{Ration $I$.}

\begin{tabular}{|c|c|c|c|c|c|}
\hline & $\begin{array}{l}\text { Quantity } \\
\mathrm{kE}\end{array}$ & $\begin{array}{l}\mathrm{DM} \\
\mathrm{kg}\end{array}$ & $\mathrm{PCP}$ & $\begin{array}{l}\text { TDNT } \\
\mathrm{kg}\end{array}$ & $\begin{array}{l}\mathrm{ME} \\
\mathrm{Mcal}\end{array}$ \\
\hline Reguirenent & & 9.6 & 0.390 & 6.1 & 22.1 \\
\hline $\begin{aligned} \text { Green oats }(\mathrm{DM} & =20 \%, \mathrm{DCP}=1 \%, \quad \mathrm{TDN}=12 \%, \\
\mathrm{ME} & =430 \mathrm{MCaI})\end{aligned}$ & 40 & 8.0 & 0.400 & 4.8 & $17 \cdot 4$ \\
\hline $\begin{array}{c}\text { Wheat straw }(\mathrm{DCP}=0 \%, \quad T \mathrm{DN}=4 \mathrm{O} \% \text {, } \\
\mathrm{ME}=14.4 \mathrm{MCZI})\end{array}$ & 3 & 2.7 & 0.000 & 1.2 & $4 \cdot 2$ \\
\hline Total & 43 & 10.7 & .400 & 6 & 21.6 \\
\hline
\end{tabular}

Ration II.

\section{Green grass \\ Concentrate Mixture \\ Wheat Straw}

Total

\begin{tabular}{|c|c|c|c|c|}
\hline 5 & 1.5 & 0.050 & 0.85 & 3.08 \\
\hline 2 & 1.8 & 0.320 & 1.40 & 5.00 \\
\hline 10 & 9.0 & 0.000 & 4.00 & 14.00 \\
\hline 17 & 12.3 & 0.370 & 6.25 & 22.08 \\
\hline
\end{tabular}

Ration III.

\begin{tabular}{|c|c|c|c|c|c|}
\hline $\begin{array}{c}\text { Green clover } \mathrm{DM}=15 \%, \mathrm{DCP}=1.5 \%, \\
\mathrm{TDN}=10 \%, \mathrm{ME}=360 \mathrm{Mcal}\end{array}$ & 25 & 3.75 & 0.375 & 2.5 & 9.00 \\
\hline Wheat straw & 9 & 8.10 & 0.000 & 3.6 & 12.6 \\
\hline Total & 34 & 11.85 & 0.375 & 6.1 & 21.6 \\
\hline
\end{tabular}




\subsubsection{Feeding Working Bullocks}

The nutrient recuirements of working bullocks and buffaloes are given in section 4.2.1. During the off season, when the animals are not workj.ng, they should be provided with maintenance rations only. However, for light or heavy work they must be fed additional energy supplements.

Table 25. Rations for working bullocks and buffaloes (weight about $500 \mathrm{~kg})$

Ration I

\begin{tabular}{|c|c|c|c|c|c|}
\hline & $\begin{array}{c}\text { Quantity } \\
\mathrm{kg}\end{array}$ & $\begin{array}{l}\mathrm{DM} \\
\mathrm{kg}\end{array}$ & $\mathrm{DCP}$ & $\begin{array}{l}\text { TDN } \\
\mathrm{kg}\end{array}$ & $\begin{array}{l}M E \\
M c a l\end{array}$ \\
\hline Requi rement & & 9.4 & 0.56 & 4.9 & 17.7 \\
\hline $\begin{array}{r}\text { Green cowpeas }(\mathrm{DM}=20 \%, \quad \mathrm{DCP}=2.5 \%, \\
\mathrm{TDN}=12 \%, \mathrm{ME}=43 \mathrm{ON} \text { cal })\end{array}$ & 22 & $4 \cdot 4$ & 0.55 & 2.64 & 9.5 \\
\hline $\begin{array}{l}\text { Paddy or Rice Straw }(\mathrm{DCP}=0 \%, \mathrm{TDN}=40 \% \text {, } \\
\qquad \mathrm{ME}=140 \mathrm{Mcal} \%)\end{array}$ & 6 & 5.4 & - & 2.40 & 8.4 \\
\hline Total & 28 & 2.8 & 0.55 & 5.04 & 19.9 \\
\hline
\end{tabular}

Ration II

\begin{tabular}{|c|c|c|c|c|c|}
\hline 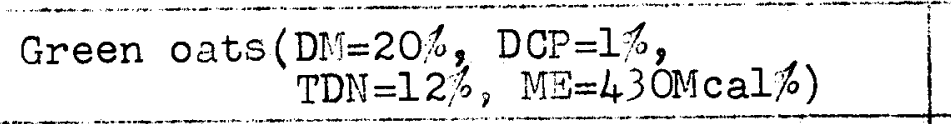 & 25 & 5.0 & 0.25 & 3.00 & 10.9 \\
\hline 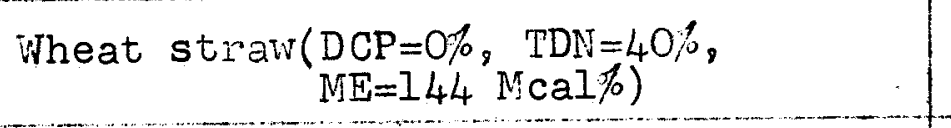 & 2 & 1.8 & 0.00 & $0.8 d$ & 2.8 \\
\hline 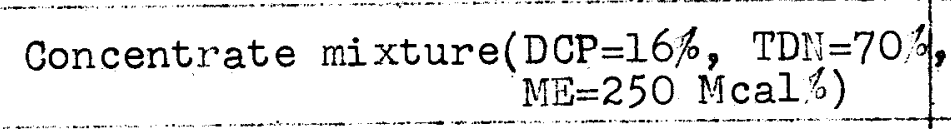 & 2 & 1.8 & 0.32 & 1.40 & 50 \\
\hline Total & 29 & 8.6 & 0.57 & 5.2 & 18.7 \\
\hline
\end{tabular}

Ration III

\begin{tabular}{|c|c|c|c|c|c|}
\hline 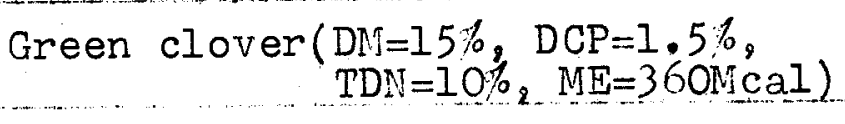 & 40 & 6.0 & 0.60 & 4.0 & 14.4 \\
\hline $\begin{array}{c}\text { Wheat straw }(\mathrm{DCP}=0 \%, T D N=40 \%, \\
M E=144 \mathrm{Mcal}\end{array}$ & 2 & 1.8 & 0.00 & 0.8 & 2.8 \\
\hline Total & 42 & 7.8 & 0.60 & 4.8 & 17.2 \\
\hline
\end{tabular}


The above rations meet the energy requirements for both light and heavy work. However, for heavy work, 8-1.0 kg extra cowpeas or Egyptian clover may be fed to take care of the extra protein requirement. Then wheat or rice straw forms the basal roughage, concentrate mixture(12\% DCP and $75 \%$ TDN) should be fed at the rate of $1.0,1.5,2.0$ and $2.5 \mathrm{~kg}$ to animals weighing 200,300 , 400 and $500 \mathrm{~kg}$ respectively, along with wheat/rice straw ad libitum, to satisfy light work requirements. For heavy work, $2,3,4$ and $5 \mathrm{~kg}$ of concentrate mixture should be fed along with straw. Two to five $\mathrm{kg}$ of green fodder maj be fed to satisfy vitamin A requirements.

\subsubsection{Feeding for Meat Production}

Steers were formerly reared on roughages-pastures in the summer and hay and other forages over winter. After making moderate and forced growth for 2 to 4 years, the animals were either turned into the feed lot or placed on more lush pastures for a reasonable amount of finishing. All this took 6-7 years for steers atiaining a body weight of $500^{\circ} \mathrm{kg}$. Today, top quality beef must be marketed at under 3 years old weighing upto $500 \mathrm{~kg}$, and be in prime condition-not too fat or lean. To achieve this target, the beast must gain an average of $0.45 \mathrm{~kg}$ live weight daily throughout its life. The faster the animal grows, the less feed it will consume, in total and therefore in terms of nutrients; the more rapidly the animal grows to market weight, the more econonical will be its production.

The approach to intensive beef production has been revolutionized during the past few years with the recognition that roughage is far less important in the diet of growing and fattening ruminants than had hitherto been generally accepted, and that it is, in fact, possible to rear animals for meat on a diet wholly composed of concentrate feeds.

In the temperate zones, the most radical change in rearing systems has been the introduction of barley becf, so called because a very high proportion of the fattening ration is composed of barley. The diet is effectively $90 \%$ concentrate feed from weaning, aiming at $390-410 \mathrm{~kg}$ live weight animals ready for slaughter in about 12 months. The rearing/fattening diet is fed ad lib from weaning onwards, consumption ranging from 2.5 to $7.0 \mathrm{~kg}$ of ration daily for each animal, depending on its weight. Live weight gains (IWG) should be 1 to $1.25 \mathrm{~kg}$ daily with a feed conversion effeciancy of $4.5-5.5 \mathrm{~kg}$ of feed for every $\mathrm{kg}$ LWG. When grains other than barley are used, $10 \%$ roughage in the ration is essential. This systen is, however, only possible in countries with adequate barley production. 
Intensive Finishing of Grass Reared Stock:

The high concentrate system is applicalble to the finishing of animals which have been grassreared and may have financial advantages over the total"barley beef "i systems or conventional finishing methods. A $14 \%$ protein or non-protein nitrogen ration is required along with $10 \%$ roughage the balance is grain. In Cuba, urea-molasses (UM) comprising $2.5 \%$ urea, $0.5 \%$ common salt, $1.5 \%$ added water and $95.5 \%$ molasses is fed ad lib. A very simple mineral mixture is also of fered ad lib, consisting of 50 parts of dicalcium phosphate (or sterilized powdered bone meal) and 50 parts common salt (and $0.1 \%$ cobalt sulphate where cobalt is deficient). Fish meal is fed at $0.5 \mathrm{~kg}$ per head daily. The roughage is $10 \mathrm{~kg}$ green maize or sorghum or Erazing. The animals being fed are zebu bulls starting at $200 \mathrm{~kg}$ and going to slaughter at $400 \mathrm{~kg}$. 
The feeding schedule for feed lot fattening of cattle on molasses based diets is as follows:

\begin{tabular}{|c|c|c|c|c|}
\hline Weeks of fattening & $\begin{array}{l}\text { Fresh forage } \\
\mathrm{kg}\end{array}$ & $\begin{array}{c}\text { Fish meal } \\
\mathrm{kg}\end{array}$ & $\begin{array}{l}\text { Urea- } \\
\text { molasses }\end{array}$ & Mineral mixture \\
\hline First & $\mathrm{ad}$ Iib & 0.5 & ad $l i b$ & $\mathrm{ad} I i b$ \\
\hline Second & 15 & 0.5 & ad Iib. & $a d i b$ \\
\hline Third & 10 & 0.5 & $a d$ lib. & $a d 1 i b$ \\
\hline Fourth & 10 & 0.5 & ad Iib. & ad $1 i b$ \\
\hline Fifth to Eight & 10 & 0.4 & ad lib. & $\mathrm{ad} 1 \mathrm{lb}$ \\
\hline Ninth onward & 10 & 0.3 & ad lib. & ad $1 i b$ \\
\hline
\end{tabular}

This system can be followed in countries where sugercane mol asses, urea and fish meal are available and at economic prices.

\section{Veal Froduction:}

Veal is calf meat from a highly finished carcass, pale-ileshed and weighing around $82 \mathrm{~kg}$, or $48 \mathrm{~kg}$ cold dressed weight. The degree of finish is nore important than the precise weight. The demand is, however, restricted as it is not economic.

Feeding of growing finishing steers and yearling buffalo calves for meat production:

Male calves normally available for meat production are between the ages 9 and 12 months and weighing 80-100 kg after they are weaned from their dams. The nutrient requirements for growing and finishing are given in section 4.2.1. The live weight gains given in the taules may be achieved when the calves are fed on good quality fodders and concentrate mixtures in the required proportions. Steers may consume between 2.5 and 3.0 percent dry matter on a good quality roughage during their growing period however during the finishing period, consumption may go down as low as 1.5 to 2 .0 percent. The use of additives and implants like melgesterol (MGA), synovex, ralgro, diethyl stilbesterol (DIS) and antibiotics may improve growth rates $8-12 \%$, and are being used in England and Anerica. For a growth of $0.7 \mathrm{~kg}$ per day in the case of steers, good quality leguminous roughages without the addition of concentrate mixture should be sufficient. For higher growth rates, concentrate feeding becomes essential. 
In the U.S.A finishing cattle are fed on very high levels of concentrates $(90 \%)$. This is of course not possible in all conuntries, where a 350 to $400 \mathrm{~kg}$ steer is considered adequate. A cow or buffalo steer of about 12 months of age, weighing $100 \mathrm{~kg}$ and expected to gain at the rate of $0.5 \mathrm{~kg}$ will require nutrients as detailed below:

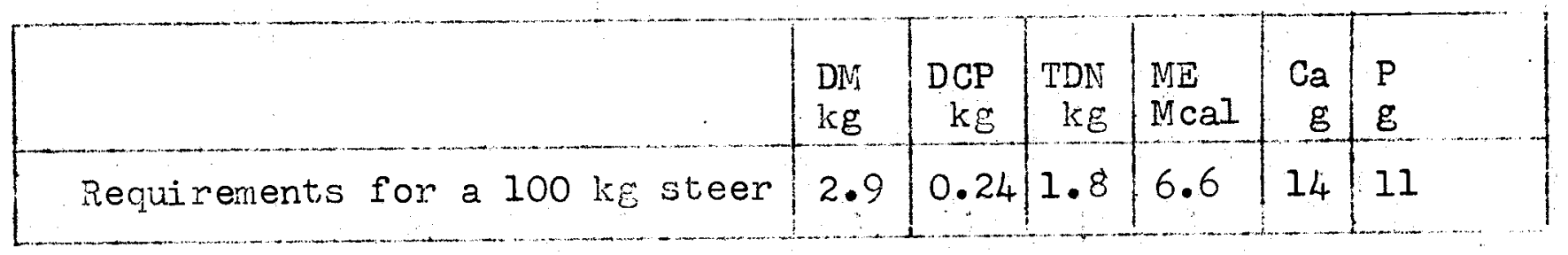

If clover/alfalfa/cow peas along with oats/maize are available in green or hay form, they can sustain a growth rate of $0.5 \mathrm{~kg}$ if $13 \mathrm{~kg}$ of greens are fed as per the calculations shown below:

\begin{tabular}{|c|c|c|c|c|c|c|c|}
\hline & $\begin{array}{c}\text { Quantity } \\
\mathrm{kg}\end{array}$ & $\begin{array}{l}\mathrm{DM} \\
\mathrm{kg}\end{array}$ & $\begin{array}{l}\mathrm{DCP} \\
\mathrm{kg}\end{array}$ & $\begin{array}{r}\text { TDN } \\
\mathrm{kg}\end{array}$ & $\begin{array}{l}\mathrm{NE} \\
\mathrm{Mical}\end{array}$ & $\begin{array}{r}C a \\
g\end{array}$ & $\begin{array}{l}\mathrm{P} \\
\mathrm{g}\end{array}$ \\
\hline $\begin{array}{l}\text { Green clover (DM } 20 \%, \mathrm{DCP} 3 \% \\
\text { TDN } 12 \%, \mathrm{ME} 45 \mathrm{Mcal} \%, \mathrm{Ca} 3.0 \\
\text { and } \mathrm{P} 0.7 \mathrm{gm} / \mathrm{kg} \text { ) }\end{array}$ & 8 & 1.6 & 0.24 & 0.96 & 3.6 & 24 & 5.6 \\
\hline $\begin{array}{l}\text { Green oats } / \text { mai ze (DM } 25 \%, \mathrm{DCP} 1 \% \\
\mathrm{TDN} 14 \%, \mathrm{ME} \text { (ON cal, } \mathrm{Ca} 0.6 \mathrm{gm} \\
\text { and } \mathrm{P} 0.5 \mathrm{gm} \text { per } \mathrm{kg})\end{array}$ & 5 & 1.2 & 0.05 & 0.70 & 2.5 & 4 & 2.5 \\
\hline Total & 13 & 2.8 & 0.29 & 1.66 & 6.1 & 28 & 8.1 \\
\hline
\end{tabular}

In the above ration, protein is a little liberal and TDN a little short but the ration is balanced with regard to an expected growth rate of $0.5 \mathrm{~kg}$ per day Similarly, a buffalo steer of $150 \mathrm{~kg}$ which is expected to gain $700 \mathrm{~g}$ per day will require the nutrients as follows:

\begin{tabular}{|c|c|c|c|c|c|c|}
\hline & $\begin{array}{l}\mathrm{DM} \\
\mathrm{kg}\end{array}$ & $\begin{array}{r}\mathrm{CP} \\
\mathrm{kg}\end{array}$ & $\begin{array}{r}\mathrm{TDN} \\
\mathrm{kg} \\
\end{array}$ & $\begin{array}{l}\mathrm{ME} \\
\mathrm{Mcal}\end{array}$ & \begin{tabular}{r|r}
$\mathrm{Ca}$ & $\mathrm{P}$ \\
$\mathrm{g}$ & $\mathrm{B}$ \\
\end{tabular} & $\begin{array}{c}\text { Vitamin } \\
1 . U\end{array}$ \\
\hline Requirements for $150 \mathrm{~kg}$ yearlings & 3.9 & 0.33 & 2.7 & 9.6 & $18: 14$ & 9000 \\
\hline
\end{tabular}

$1.2 \mathrm{~kg}$ of balanced concentrate mixture along with $15 \mathrm{~kg}$ of green maize\%ats will meet the $700 \mathrm{~g}$ growth rate requirement. The quantity of concentrate mixture can be replaced by $12 \mathrm{~kg}$ green Egyptian clover/alfalfa etc. 


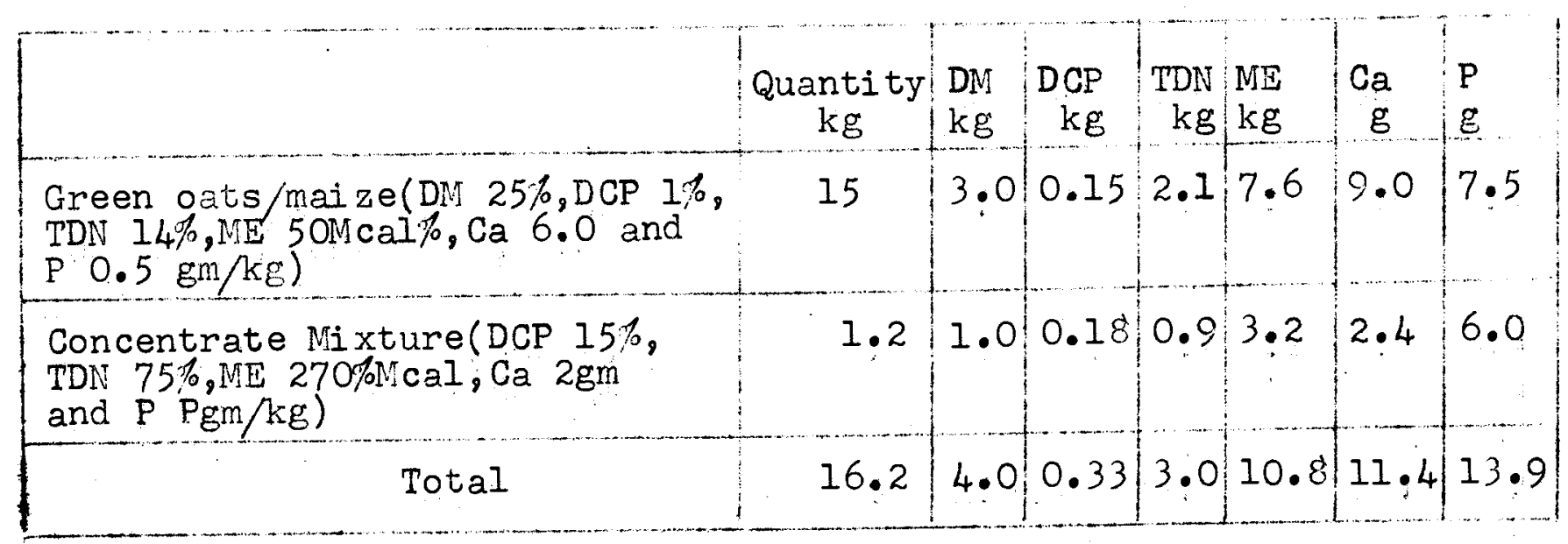

The concentrate mixture may contain $25 \%$ maize, $30 \%$ ground nut cake, $42 \%$ wheat bran, $2 \%$ mineral mixture and $1 \%$ common salt.

\section{Program of Practicals for the 5th Semester}

\section{Laboratory work}

1. Identification of common feeds and fodders of Afghanistan, their classification and chemical composition.

2. Acquaintance with various apparatus, equi pments and instruments used in the analysis of feeds and fodders.

3. Preparation of various standard solutions.

4. Quanti tiative analysis for 1) moisture (dry matter, 2) ash, 3) acid insoluble ash, 4) crude protein, 5) ammoni acal nitrogen, 6 urea nitrogen, 7) crude fat or ether extract, 8) crude fibre, 9) sodium chlorice, 10) calcium and 11) phosphorus.

5. Methods of estimating the nutritive value of feeds and fodders.

6. Demonstration of a metabolism/digestibility trial.

\section{Field observations}

1. Observation / demonstration of feeding of farm animals like cattle, buffaloes, sheep, goats, poultry, horses, camels, etc by visits to farms, pastures, ranges etc.

2. Observation / demonstration of silage and hay making practices. 


\subsection{Feeding Sheep}

Sheep, more than any other class of farin livestock, are dependent on natural pastures for maintenance and production. None of our other domesticated animals. surpass sheep in their need for and their ability to utilize pastures. Pasture and ranges are their natural habitat and they thrive on then under an extemely wide variety of climatic conditions utilizing the most adverse types of vegetation. Sheep are able to find the necessary nutrients from the grasses, legumes, weeds, herbs and shrubs that grow on both cultivated and uncultivated land. This makes them excellent weed destroyens, a class of livestock that can turn waste into profit and at the same time fertilize the land. Young, tender grass is, however, the preferred grazing.

The common leguminous green feeds, cowpeas, lobia (vigna cátjung, vigna species), berseem or Egyptian clover (Trifolium alexandrium), lucerne/alfalfa (medicago sativa), etc., are all relished by sheep. When fed in stalls, they can easily consume 2.5 to $3.0 \mathrm{~kg}$ of dry matter per head per day from good quality roughages. Some 15 percent more dry matter than this may be consumed on succulent pastures. Total dry matter intake may be considerably lower on inferior pasture, affecting the supply. of energy, as well as digestible crude protein. This situation. leads to anemia or even edema.

\subsubsection{The ivutritive Requirements of Sheep}

These may be conveniently examined under the headings energy, protein, minerals, vitamins and water.

Lack of energy results from inadequate feed consumption or from consumption of poor cuality feed, which is turn may be due to eating low quality forage, over grazing, snow covered fields, or low dry matter content of lush, washy feed.

The energy needs of sheep are generally met by the consumption and digestion of forages-pasture, hay and silace. Grains such as corn (maize), barley, milo (sorghum), wheat and oats are used to raise the energy level of the ration during periods when supplementation is necessary.

The following gactors increase the energy requirement of sheep: changes in the environment like temperature, humidity and wind outside the comfort zone; shearing in cold weather: stresses of any kind; gestation, lactation breeding lambs, finishing lambs, early vieaning of lambs.

The characteristic symptoms of energy deficiency are slowing and cessation of growth, loss of weight, reduced fertility or reproductive failure, lowered milk production and shortened lactation period, reduced quantity and quality of wool, lowered 
resistence to infection with internal parasites and increased mortality.

Protein. Sheep need protein for maintenance, growth, reproduction, finishing and for production of vool-a protein product. Wool is especially rich in the sulphur containing anino acids, cystine and methionine, whi ch are derived from rumen synthesis. Methionine is usually the most limiting amino acid for wool production.

Green pastures and legume hays (alfalfa, clover, soya beans, cowpeas, lobia etc) are excellent sources of protein for sheep in most areas. Where the ranges are bleached and dry for long periods or legume hays cannot be produced for winter feeding, it may be desirable to provide sheep with protein rich supplements like soyabean cake, cotton seed cake, linseed cake, or ground nut cake or a commercial protein supplement at the rate of about 100 to 150 srams per ere per day. The protein requirements of sheep are aftected by growth, pregnancy, lactation, mature size, weight for age, body condition, rate of gain and the protein/enorgy ratio.

The characteristic symptoms of protein deficiency are reduced appetite, lowered feed intake and poor feed effeciency. This deficiency causes poor growth, poor muscular development, loss of weight, reduced reproductive efficiency and reduced wool production.

There are about 40 mirerals that occur naturally in the tissues of plants and animals. Ot these, 7 major mineral constituents and nine trace elements have been ciemonstrated to be essential for sheep.

The major (or macro) minerals and the requirements for them as percentages of diet dry matier are: sodium and chlorine, i.e., common salt $(0.3$ to $0.4 \%)$; calcuim $(0.2$ to $0.5 \%)$, phosphorus ( 0.15 to $0.35 \%)$ magnesium $(0.04$ to $0.08 \%)$ potassium (0.45 to $0.50 \%)$, and sulphur $(0.13$ to $0.26 \%)$.

The trace (or mi cro) minerals and the requirements for them in parts per million (ppm) are: iron (40); manganese (30) cobalt ( 0.1 to 0.2 ) 3 copper ( 5 to 7$)$; molybdenum (1); fluorine ( 55 maximum): iodine $(0.5)$ selenium $(0.1)$; and zinc (17 to 32$)$. The deficiency of any of these minerals results in various symptoms.

Vitamins. Mature sheep reuire fat soluble vitamin $A, D$, $E$ and $K$, but they do not need added sources of $B$ vitamins since the latcer are synthesized in adequate amounts by rumen mi cro organisms.

Water. Sheep get water by drinking and from snow, dew and feed. The amount of water that sheep voluntarily consume is affected by temperature, rainfall, snow and dew covering, age, breed, stage of production, number of lambs carried, wool covering, respiratory rate, frequency of watering, 
kind and amount of feed and exercise. On an average, a mature sheep consumes about a gallon of water a day.

Additives. The folloving additives are fed to stimulate growth: -stilbesterol (diethyl stilbesterol), orally at the rate of $2 \mathrm{mg}$ per head per day.

-antibiotics, orally at the rate of 7-12 milligrams per pound of feed.

-stilbesterol + antibiotics

-stilbestrol (deithyl stilbestrol), implants at the rate $3 \mathrm{mg}$ per head.

-Ralgro, implant at the rate of $12 \mathrm{mg}$ per head.

The feeding standards or nutrient requirements for maintenance, growth and production are given in Table 26.

\subsubsection{Early weaning}

Early weaning refers to the practice of weaning lambs earlier than usual at five to ei ght weeks of age or even earlier. Early weaning is done because:

- of lambing out of season, multiple births, and more than one lamb crop per year.

- lactating ewes usually reach a peak in milk production 3 to 4 weeks after lambing, then decline thereafter. By 3 to 4 months after lambing, many ewes will be producing little milk.

- fewer parasite problens accompany an early weaning program.

- increased knowledge of nutrition now makes it possible for the scientist to inprove milk (except for colostrum), chiefly by reinforcing it with certain vitamins and minerals.

- young gains are cheap gains, due to a) the higher water and lower fat content of younger animals and $b$ ) the higher feed consumtion per unit of body maintenance of young animals.

- following weaning, ewes can be maintained on a limited feed allowance, thereby effecting cost savings.

To be succesful, superior nutrition and management are essential, especially during early wèning period. Early weaning of lambs is, to a considerable extent, a matter of preparation rather than the abrupt separation of lambs from their mothers. Lambs that are to be early weaned should be creep fed from the time they are old enough to eat. At weaning time, the separation should be made by removing the ewes from the lamb rather than the other way around to minimize the stress on the lambs. The creep ration for early weaned lambs should contain a minimum of 16 percent crude protein and be fortified with supplemental iron and equal amounts of calcium and 


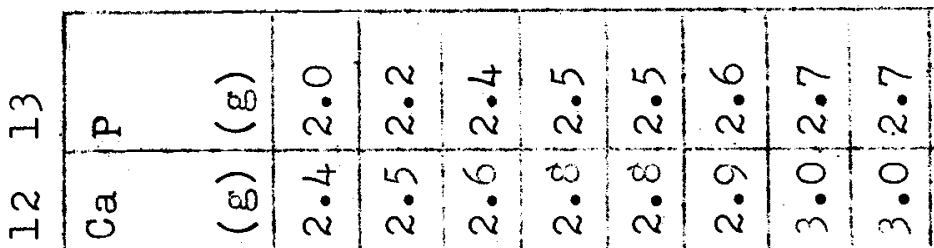

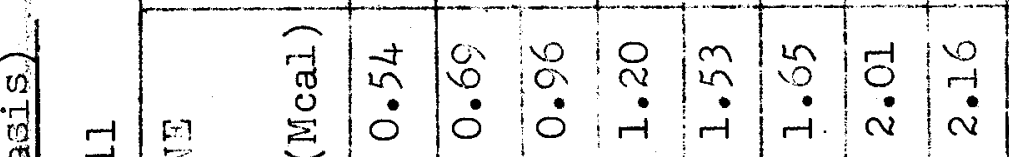

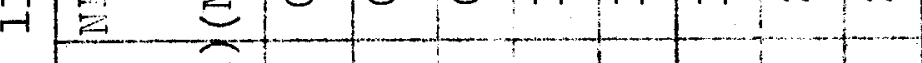

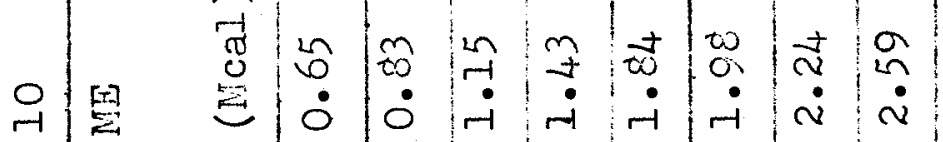
T-

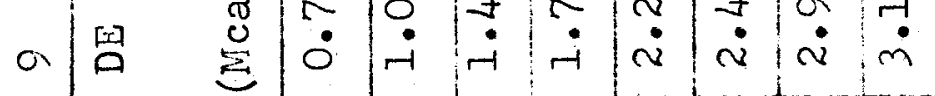
की め)田 ü

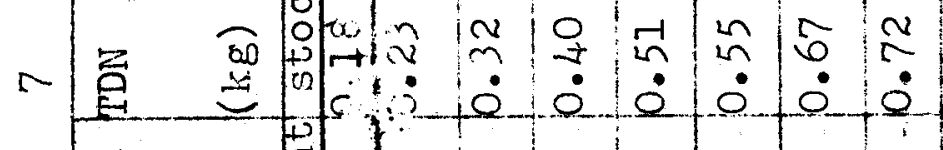
ڤ. : :

ㅇ.:

: :

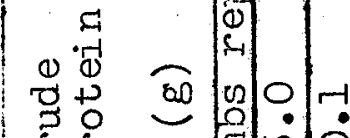

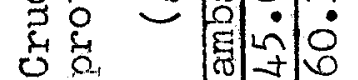

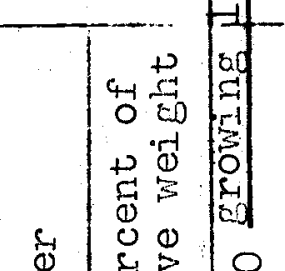

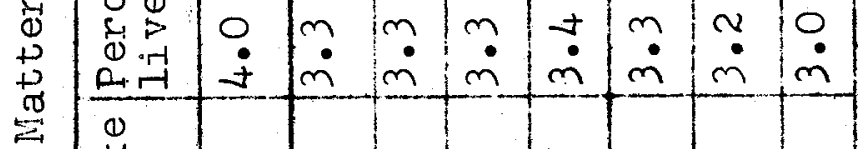

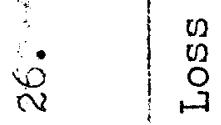

(

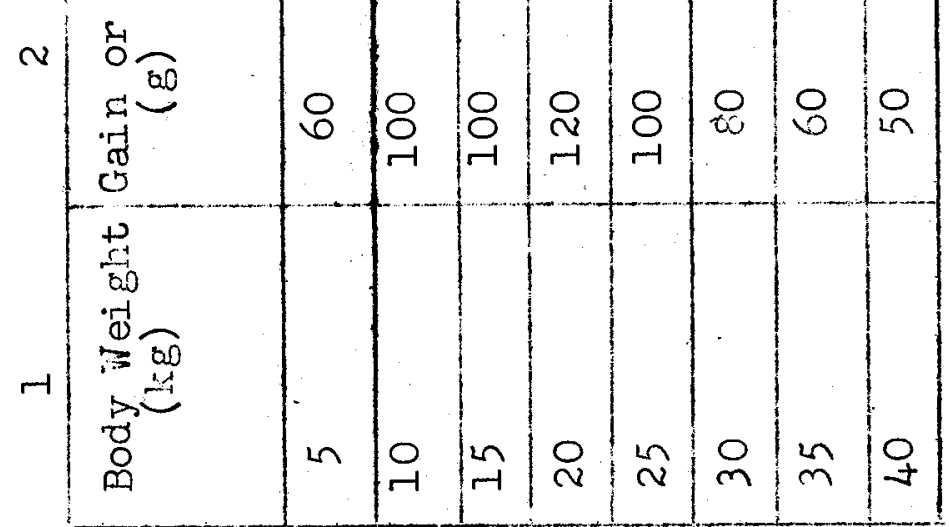

\begin{tabular}{|c|c|c|c|c|}
\hline$\stackrel{\sim}{\sim}$ & $\dot{\sim}$ & $\stackrel{+}{\dot{\sim}}$ & $\ddot{\sim}$ & $\begin{array}{l}0 \\
i\end{array}$ \\
\hline $\begin{array}{l}\infty \\
\dot{v}\end{array}$ & $\begin{array}{l}0 \\
\dot{v}\end{array}$ & $\begin{array}{l}\dot{0} \\
\dot{m}\end{array}$ & $\stackrel{v}{\dot{m}}$ & $\dot{m}$ \\
\hline $\begin{array}{l}\stackrel{8}{0} \\
\dot{0}\end{array}$ & $\stackrel{n}{m}$ & $\begin{array}{l}\infty \\
0 \\
\dot{-1}\end{array}$ & $\stackrel{n}{\sigma}$ & $\begin{array}{l}\tilde{w} \\
\stackrel{\sim}{v}\end{array}$ \\
\hline $\begin{array}{l}\infty \\
0 \\
\end{array}$ & $\begin{array}{l}\tilde{b} \\
\ddot{-}\end{array}$ & $\begin{array}{l}v \\
\dot{O} \\
\dot{v}\end{array}$ & $\vec{m}$ & $\stackrel{Q}{\stackrel{Q}{\sim}}$ \\
\hline$\stackrel{0}{?}$ & $\begin{array}{l}0 \\
\ddot{H} \\
\ddot{H}\end{array}$ & $\begin{array}{l}\ddagger \\
\dot{v}\end{array}$ & $\begin{array}{l}m \\
\dot{v}\end{array}$ & $\tilde{v}$ \\
\hline$\stackrel{c}{\stackrel{c}{*}}$ & $\frac{7}{ \pm}$ & $\stackrel{\text { Ln }}{\text { in }}$ & $\begin{array}{l}\overrightarrow{0} \\
0\end{array}$ & $\frac{7}{\tilde{0}}$ \\
\hline$\stackrel{\circ}{\dot{Q}}$ & $\stackrel{1}{ \pm}$ & $\stackrel{0}{\circ}$ & $\begin{array}{l}0 \\
0\end{array}$ & $\stackrel{2}{0}$ \\
\hline$\tilde{N}$ & $\stackrel{b}{m}$ & \begin{tabular}{l}
$\infty$ \\
$\dot{1}$ \\
\multirow{3}{*}{}
\end{tabular} & $\begin{array}{l}0 \\
\dot{N} \\
i n\end{array}$ & Oீ \\
\hline$\stackrel{\sim}{a}$ & \begin{tabular}{l}
5 \\
\multirow{2}{*}{}
\end{tabular} & $\begin{array}{l}\infty \\
-1 \\
+\infty\end{array}$ & $\begin{array}{l}a \\
\frac{1}{a}\end{array}$ & an \\
\hline$\dot{0}$ & $\begin{array}{l}0 \\
\dot{m}\end{array}$ & $\dot{v}$ & $\begin{array}{l}0 \\
\dot{v}\end{array}$ & $\ddot{\sim}$ \\
\hline 8 & 8 & $\begin{array}{l}0 \\
N \\
r-1\end{array}$ & O⿱丷口 & $\mid \begin{array}{l}0 \\
0 \\
\text { in } \\
r\end{array}$ \\
\hline$\stackrel{2 n}{\sim}$ & $\stackrel{\sim}{\sim}$ & $\stackrel{\sim}{\sim}$ & $\stackrel{\sim}{\sim}$ & $\stackrel{2 n}{2}$ \\
\hline$\stackrel{\odot}{\sim}$ & m & 10 & in & 10 \\
\hline
\end{tabular}




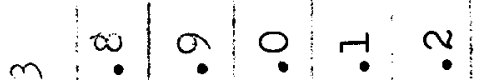
$\ddot{r} \dot{N} \dot{N} \dot{m} \dot{m}$

\begin{tabular}{l|l|l|l|l|l|}
$N$ & 0 & 0 & 0 & $v$ & $m$ \\
& $m$ & $m$ & $j$ & $-j$ & $i$
\end{tabular}

0 10 60 in in

w $N$ in $\infty$

\begin{tabular}{l|l|l|l|l|l|}
$H$ & $\dot{N}$ & $\dot{v}$ & $\dot{N}$ & $\dot{v}$
\end{tabular}

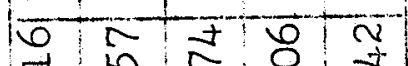

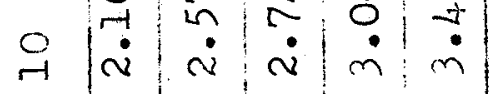

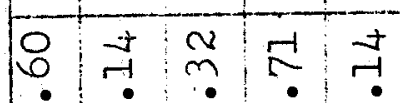

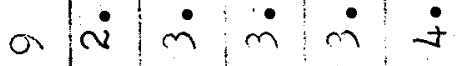

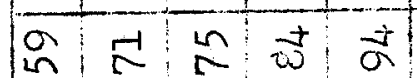

$\omega \mid \begin{array}{llllll}\dot{0} & \dot{0} & 0 & 0 & 0\end{array}$

\begin{tabular}{ll|l|l|l}
\hline & $\alpha$ & 0 & n & n
\end{tabular}

\begin{tabular}{lllllll}
\hline 0 & $\dot{0}$ & 0 & $\dot{0}$ & $\dot{0}$ \\
\hline
\end{tabular}

o n 0 is

\begin{tabular}{l|l|l|l|l}
\hline & $\infty$ & $\infty$ & + & 0 \\
\hline Ln & $\infty$ & 0 & 0 & $\infty$
\end{tabular}

밀

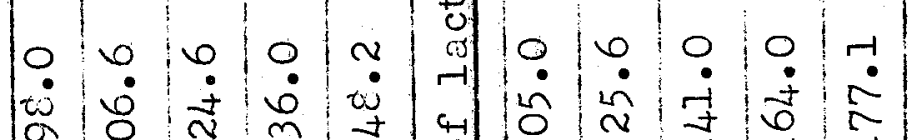

o. $\begin{array}{ccc:c}0 & v & m & \pm \\ & n & n & n\end{array}$

\begin{tabular}{ccccc} 
& & & \\
\hline & 0 & $r$ & \pm & 0 \\
\hline & $m$ & $m$ & $m$
\end{tabular}

递察:

$\sim$ 임일

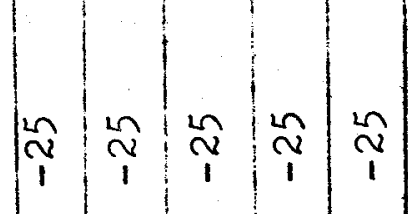

\begin{tabular}{ll|l|l|l}
0 & 0 & 0 & 0 & 0 \\
0 & 0 & 0
\end{tabular}

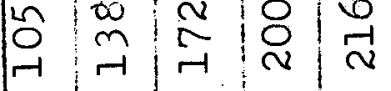

\begin{tabular}{l|l|l|l|l}
$\infty$ & 0 & $m$ & 0 & 0 \\
0 & 0 & 0 & -1 & -1
\end{tabular}

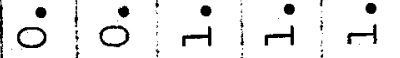

w $0: \pm 0$

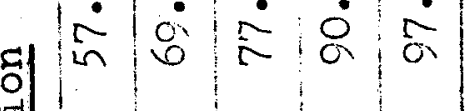
현

\begin{tabular}{ccc|c|c|}
0 & 0 & + & $n$ & $n$ \\
0 & 0 & 0 & 0 & $m$ \\
$n$ & 0 & 0 & 0 & $\infty$
\end{tabular}

6 \begin{tabular}{ll|l|l|l|}
0 & $\pi$ & 0 & $n$ & $n$ \\
0 & 0 & 0 & 0 & 0
\end{tabular}

\begin{tabular}{c:c|c|c|c}
0 & 0 & 0 & 0 & 0
\end{tabular}
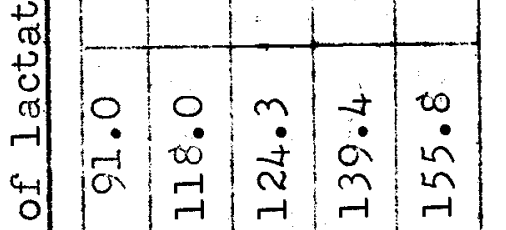

\begin{tabular}{c|c}
0 \\
0 \\
04 \\
01 \\
0 \\
3 \\
+1 \\
\hline 1
\end{tabular}

* 0 m 0

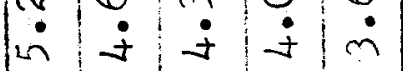
+1
0
0
$\rightarrow$

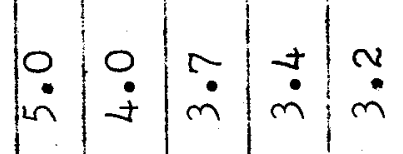

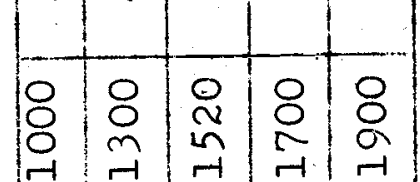
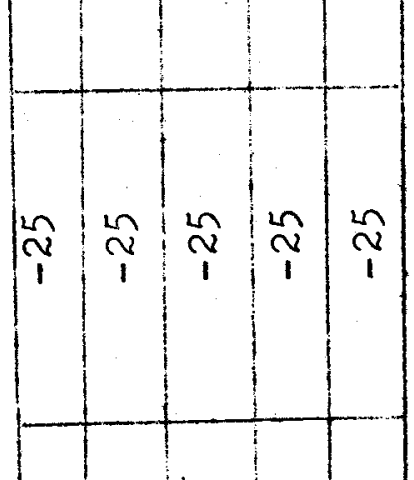

\begin{tabular}{c|c|c|c|c|c}
$n$ & 0 & 0 & 0 & 0 & 0 \\
& $v$ & $m$ & $g$ & $n$ & 0
\end{tabular}

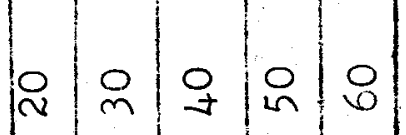

$\begin{array}{lllllll}n & n & n & n & n\end{array}$

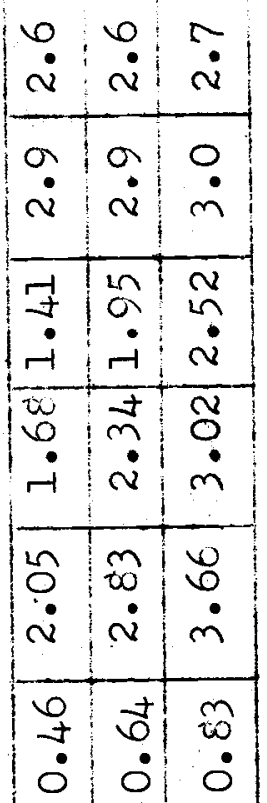

त n t

\begin{tabular}{c:c|c}
+ & 0 & $\infty$ \\
0 & 0 & 0
\end{tabular}

$\infty \quad 10$

i

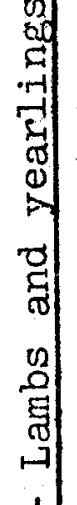

\begin{tabular}{l|l|l|l} 
& 0 & 0 & $n$ \\
क्ष & $m$ & $m$ & $m$
\end{tabular}

\begin{tabular}{|l|l|l|}
\hline 0 & 0 & 0 \\
\hline$N$ & 0 & 9 \\
\hline$N$ & $n$ & I-1 \\
\hline
\end{tabular}

$\mid$\begin{tabular}{c|c|c}
0 & 0 & 0 \\
0 & 0 & 0 \\
$n$ & &
\end{tabular}

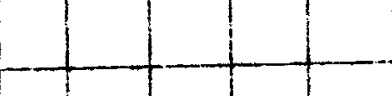

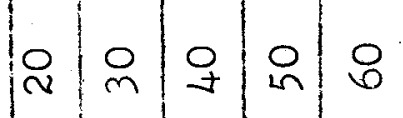

$\therefore: ㅇ$ 


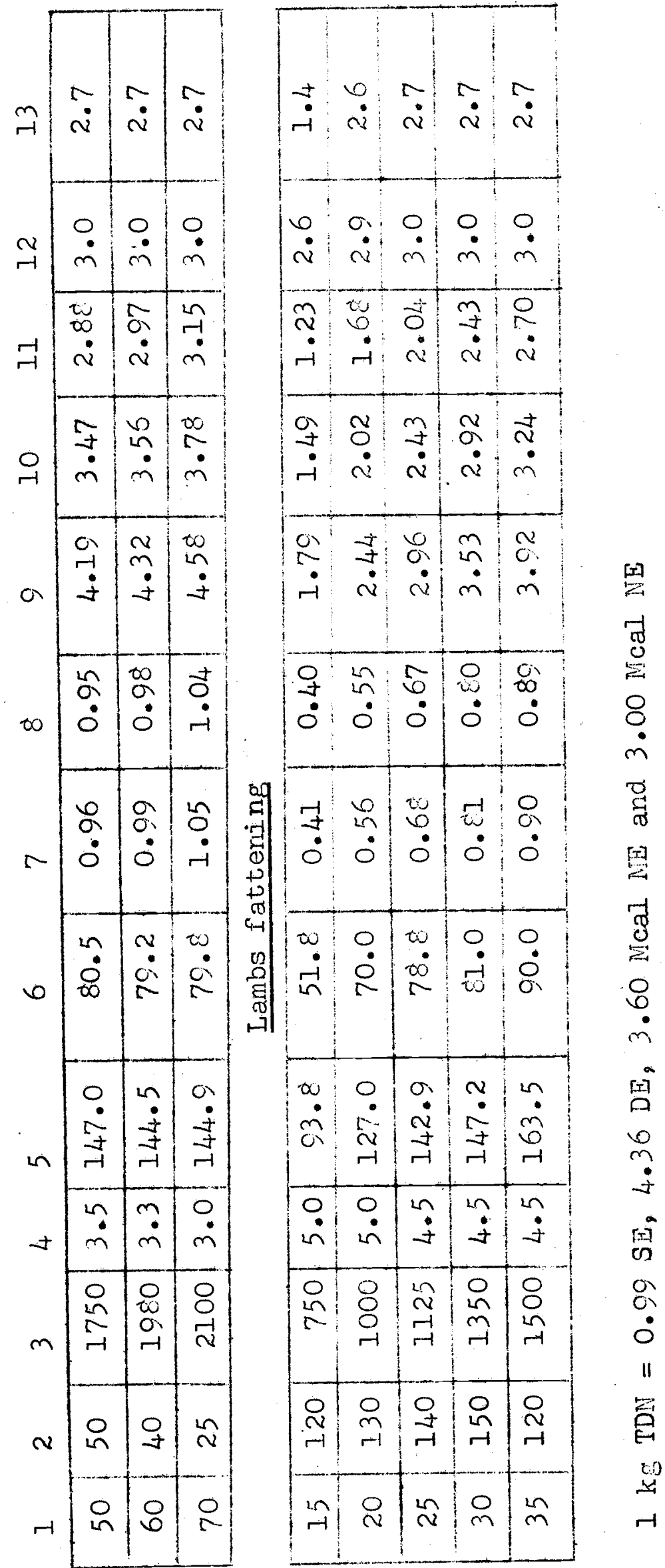


phosphorus. Milk replacers containing about $24 \%$ protein and $30 \%$ fat have been used successfully in feeding lambs receiving colostrum and weaned at one day of age. Replacers with reduced lactose content (from $27 \%$ to $42 \%$ on dry matter basis) give improved performance. The milk is fed cold at 20 to $4^{\circ} \mathrm{C}$, rather than warm, to reduce over eating and bacterial contamination, and free choice. From the begining, the lambs are offered a very palatable solid feed in addition to the milk. The milk replacer is discontinued when the lambs have begun eating sufficient quantitites of dry feed (about 250 grams per head daily), usually at 21 to 35 days old. The practice of supplemental feeding of nursing lambs in a separate enclosure away from their dams is known as creep feeding. Creep rations can be either hand fed or self fed. Eight creep mixtures are described in Table 27.

Feeding pre-weaned lambs from birth to 90 days:

Lambs upto 90 days of age suckling their dams should also be. given a creep mixture. They mornally start to consume some supplemental feed at about 15 days of age. The amounts of creep mixture eaten by them are inversely proportional to the ewes' milk production. However, after 40 to 50 days old, most Iambs will consume significant amounts of creep mixture in addition to the milk supplied by their dams unless they have access to high pasture.

The following creep mixtures have given good growth rates of more than 100 grans per head per day upto 90 days of age, and could be fed to lambs after 15 days of age in addition to milk. 
Table 27. Composition of creep mixtures for feeding lambs

\begin{tabular}{|c|c|c|c|c|c|c|c|c|}
\hline \multirow[t]{2}{*}{ Teed Ingredient } & \multicolumn{8}{|c|}{ Greep Mixtures (percent) } \\
\hline & $\mathrm{I}$ & II & III & IV & $\mathrm{V}$ & VI & VII & VIII \\
\hline Maize flour & 67 & 50 & 30 & 67 & 50 & 40 & 40 & 62 \\
\hline Barley flour & - & 17 & - & - & - & 27 & 15 & - \\
\hline Oat flour & - & - & 37 & - & 17 & - & 12 & - \\
\hline Grounnut cake & 10 & 10 & 10 & 10 & 10 & 10 & 10 & 10 \\
\hline Wheat bran & 10 & 10 & - & 10 & - & 10 & 5 & 10 \\
\hline Rice polish & - & - & 10 & - & 10 & - & 5 & - \\
\hline Fish meal & 10 & 10 & 10 & - & 10 & - & 5 & 10 \\
\hline Meat meal & - & - & - & 10 & - & 10 & 5 & - \\
\hline Molasses & - & - & - & - & - & - & - & 5 \\
\hline Common salt & 1 & 1 & 1 & 1 & 1 & 1 & 1 & 1 \\
\hline Mineral mixture & 2 & 2 & 2 & 2 & 2 & 2 & 2 & 2 \\
\hline Approximate DCP & $10-15$ & $\mid 10-15$ & $10-15$ & $10-15$ & $10-15$ & $10-15$ & $10-15$ & $10-15$ \\
\hline Approximate TDH & $75-80$ & $75-80$ & $75-80$ & $75-80$ & $75-80$ & $75-80$ & $75-80$ & $75-80$ \\
\hline
\end{tabular}

To $100 \mathrm{~kg}$ of the above mixtures 150 gram TM -5 and adequate amounts of vitamin. A should be added.

After the rumen is developed, good quality leguminous green fodder or hays (berseem, lucerne, cow peas, clover, etc.) should be made available to the lambs. The lambs should be allowed to suckle the dam twice daily and kept separately where creep mixture, roughage, mineral mixture and water are available free choice. 


\subsubsection{Feeding Growing and Finishing Lambs}

There is an increasing trend in farm flock lamb production to keep the lambs feeding on dry lots (i.e.in barns or open yards affording shelter) even though the ewes may be permitted to graze during the day. This is especially so when local sheep have been crossed with exotic germ plasm for mutton production. As these cross-breds are fast growing, they are unable to meet their nutritional requirements from grazing alone. Even if they were allowed to graze, the following quantities of concentrate mixture would be required to meet their nutritional requirements as specified in Table 26.

a) When good quality fodcers like green oats, maize, cow peas, doob, alfalfa and clover or their hays are available.

$\begin{array}{ccc}\begin{array}{c}\text { Body weight } \\ \mathrm{kg}\end{array} & \begin{array}{c}\text { Concentrate mixture } \\ \text { g/day }\end{array} & \begin{array}{c}\text { Roughage } \\ \text { g/day }\end{array} \\ 10-15 & 50 & 400 \\ 16-25 & 100 & 600 \\ 26-35 & 150 & 700\end{array}$

b) Then good quality fodders or their hays are not available and lambs are kept on mature grasses or stovers.

$\begin{array}{ccc}\begin{array}{c}\text { Body weight } \\ \mathrm{kg}\end{array} & \begin{array}{c}\text { Concentrate mixture* } \\ \text { g/day }\end{array} & \begin{array}{c}\text { Roughage } \\ \text { g/day }\end{array} \\ 10-15 & 300 & 400 \\ 16-25 & 400 & 600 \\ 26-35 & 600 & 700\end{array}$

* The following concentrate mixtures containing 12 to $18 \%$ DCP and about 70 to $75 \%$ TDN are recommended in feeder lamb/dry lot/finishing feeding. 
Table 28. Composition of concentrate mixtures for growing and finishing lambs from 15 to $35 \mathrm{~kg}$ body weight

\begin{tabular}{|c|c|c|c|c|c|c|c|c|c|c|c|c|}
\hline \multirow{2}{*}{$\begin{array}{l}\text { Feed } \\
\text { Ingredient }\end{array}$} & \multicolumn{12}{|c|}{ Concentrate mixtures (percent) } \\
\hline & I & II & III & IV & $\mathrm{V}$ & $\mathrm{VI}$ & VII & VIII & IX & $\mathrm{X}$ & XI & $X I I$ \\
\hline Maize & 25 & - & - & - & - & 25 & 25 & 25 & 25 & 25 & 25 & 10 \\
\hline Oats & - & 25 & - & - & - & - & - & - & - & - & - & 10 \\
\hline Barley & - & - & 25 & - & - & - & - & - & - & - & - & 5 \\
\hline Millet & - & - & - & 25 & - & - & - & - & - & $=$ & - & - \\
\hline Sorghum & - & - & - & - & 25 & - & - & - & - & $L$ & - & - \\
\hline $\begin{array}{l}\text { Groundnut } \\
\text { cake }\end{array}$ & 32 & 32 & 32 & 32 & 32 & - & - & - & - & 5 & 32 & 20 \\
\hline Sesamum cake & - & - & - & - & - & 35 & - & - & - & - & - & \\
\hline Linseed cake & - & - & - & - & - & - & 37 & - & - & - & - & 5 \\
\hline Mustard cake & - & - & - & - & - & - & - & 37 & - & - & - & - \\
\hline Soya bean cake & - & - & - & - & - & - & - & - & 37 & - & - & - \\
\hline \begin{tabular}{|c}
$\begin{array}{c}\text { Cotton seed } \\
\text { cake }\end{array}$ \\
\end{tabular} & - & - & - & - & - & - & - & - & - & 30 & - & - \\
\hline Wheat bran & 40 & 40 & 40 & 40 & 40 & 37 & 35 & 20 & 20 & 37 & $=$ & 20 \\
\hline Rice polish & - & - & - & - & - & - & - & 45 & 15 & - & 40 & 17. \\
\hline $\begin{array}{l}\text { Mineral } \\
\text { mixture }\end{array}$ & 2 & 2 & 2 & 2 & 21 & 2 & 2 & 2 & 2 & 2 & 2 & 2 \\
\hline Salt & 1 & 1 & 1 & 1. & 1 & 1 & 1 & 1 & 1 & 1 & 1 & 1 \\
\hline
\end{tabular}

$\mathrm{DCP}=15-20$ and $\mathrm{TDN}=70-75$ approximately, for all mixtures

To $100 \mathrm{~kg}$ of the above, 150 grams TM-5 and vitamin A supplement Vitablend may be added along with mineral mixture ad lib.

In the above concentrate mixtures, maize can be replaced fully or partially by oats, barley millet or sorghum; likewise, the groundnut cake by sesamum, linseed, mustard, soya bean or cotton seed cake, and wheat bran can be replaced by rice polish, 
without affecting DCP and TDN levels.

Feeding weaned lambs in stalls is also practised for intensive rearing of fat lambs; stalls are useful in rainy climates, as the animals do not relish wet grass. Lambs can also be reared in a semi-range condition where, in addition to 8 hours of grazing, they are fed $150-200 \mathrm{~g}$ of concentrates, harvested forages, crop residues, by-product feeds and a free choice of mineral mixture, common salt and adequate vitamin $A$.

The requirements of finishing rations ( $20-30 \mathrm{~kg}$ body weight) under intensive rearing conditions are DM $0.65-0.79 \mathrm{~kg}$, DCP 60-91 g, TDN $0.51-0.65 \mathrm{~kg}$ and $\mathrm{ME}$ (at $2.6 \mathrm{Mcal} / \mathrm{kg}$ ) 1.88-2.32 Mcal.

These requirements can be met by 700 to 900 grams of ration having $70 \%$ concentrate and $30 \%$ roughage, which will therefore supily DM $0.63-0.81 \mathrm{~kg}, \mathrm{DCP} 90 \mathrm{~g}$, TDN $0.5-0.6 \mathrm{~kg}$ and $\mathrm{ME}$ (at $2.6 \mathrm{Mcal} / \mathrm{kg}$ ) $1.73-2.22 \mathrm{Mcal}$.

Normal grazing will take care of the roughage part, while up to $150 \mathrm{~kg}$ concentrate per head per day may need to be fed during lean periods. A free choice of mineral mixture, common salt and vitamin $A$ supplement is also fed in addition.

\subsubsection{Feeding Breeding Ewes, Rams and Lactating Sheep}

Success in the sheep business is largely measured by the

percent of the lamb crop raised and the pounds of lamb marketed per ewe. The proper feeding of flushing ewes, pregnant ewes, ewes at lambing time and lactating ewes is critical. The special feeding of flushing eves should start 2 to 3 weeks prior to breeding time. They should be turned out to fresh luxuriant pasture, and if this is not available they should be fed 250 to 350 grams of grain mixture per head per day and a free choice of good quality hay. Pregnant ewes should be fed a suitable and well balanced ration, together with the necessary minerals and vitamins as required for maintenance, growth of the fleece and development of the fetus. Suitable shelter during inclement weather and plenty of exercise must be made available.

As lambing time approaches and immediately after lambing, each ewe should be placed in an individual holding or lambing pen. At this time the grain allowance should be materially reduced, but dry roughage may be fed free choice. A concentrate mixture of equal parts of maize or barley and wheat bran is excellent. Lactating ewes should be fed liberally with good concentrates and roughage.

During the last 6 weeks of gestation, a $50 \mathrm{~kg}$ animal requires $1.9 \mathrm{~kg} \mathrm{DM}, 0.08 \mathrm{~kg} \mathrm{DCP}$ and $0.69 \mathrm{~kg}$ TDN. A free choice of fodders like maize, cow peas, doob grass, alfalfa or chover, either green or as hay will meet these requirements without supplementing with concentrates. If, however, only inferior roughage is 
available the diet shown below is good.

$\begin{array}{ccll} & \begin{array}{c}\text { Dry matier } \\ \mathrm{kg}\end{array} & \begin{array}{l}\mathrm{DCP} \\ \mathrm{kg}\end{array} & \begin{array}{l}\mathrm{TDN} \\ \mathrm{kg}\end{array} \\ \begin{array}{c}\text { 400g concentrate mixture } \\ (\mathrm{DCP} 18 \%, \text { TDN 70\%) }\end{array} & 0.4 & 0.072 & 0.28 \\ 1.5 \mathrm{~kg} \text { straw or grass } & 1.5 & 0.045 & 0.60 \\ \begin{array}{c}\text { (DCP 3\%, TDN 40\%) } \\ \text { Total }\end{array} & 1.9 & 0.117 & 0.88\end{array}$

The feeding of rams should aim to keep them vigorous and active. They should in general be given the same kind of feed as ewes but in slightly larger quantities. Rams need a generous allowance of relatively high quality feed just before and during the breeding season, when pasture is not available.

Lactating sheep can be fed hay ad lib for the first 10 days and the feeding of concentrates may be curtailed. After the loth day, they may be fed $250 \mathrm{~g}$ of concentrate mixture (DCP 15-20\%, TDN $80 \%$ ) in addition to legume hay.

\subsubsection{Feeding Range Sheep}

Sheep are most commonly maintained on grazing areas with or without supplemental feeciing. Vegetation on the range consists of rather mature and bleached grasses or brush and browse. When the vegetation is sparse or covered by deep snow, supplemental feeds of hays, preferably alfalfa, clover or other availabie legumes, or concentrate mixtures must be provided. Three range supplements, ranging in protein content from high to low, are suggested in Table 29 below. 
Table 29. Formulas for Range Sheep Supplements

\begin{tabular}{|c|c|c|c|}
\hline \multirow{2}{*}{ Feed } & \multicolumn{3}{|c|}{$\begin{array}{c}\text { Recommended protein levels ( } \%) \\
\text { on an as such basis }\end{array}$} \\
\hline & High & Medium & Low \\
\hline $\begin{array}{c}\text { Cotton seed or mustard cake } \\
(\mathrm{CP} 41 \%)\end{array}$ & 62.5 & 32.5 & 0.0 \\
\hline $\begin{array}{l}\text { Groundnut, soya bean or linseed } \\
\text { cake }(\mathrm{CP} 41 \%)\end{array}$ & 10.0 & 10.0 & 0.0 \\
\hline Barley & 0.0 & 33.0 & 67.0 \\
\hline Maize & 5.0 & 10.0 & 15.0 \\
\hline $\begin{array}{c}\text { Alfalfa or clovermeal } \\
\text { (CP } 17 \% \text { ) }\end{array}$ & 12.5 & 6.0 & 5.0 \\
\hline Sugercane or Beet molasses & 5.0 & 5,0 & 10.0 \\
\hline Dicalcium phosphate & $4 \cdot 0$ & 3.0 & 2.0 \\
\hline Salt or trace mineralised salt & 1.0 & 1.0 & 1.0 \\
\hline DCP $\%$ & $26-27$ & $19-20$ & $8-9$ \\
\hline TDN $\%$ & & & \\
\hline Rate of feeding (grams/day) ${ }^{+}$ & $100-200$ & $100-200$ & $100-200$ \\
\hline
\end{tabular}

* The above feeds may be mixed and fed in meal form.

+ In an emergency the rate of feeding may be increased to 400-500g. 
How to Balance a Ration for Sheep

A balanced ration is one that provides the animal the proper proportions and amounts of all the required nutrients for a

A balanced ration can be computed by trial and error as outlined below.

The animal is a $50 \mathrm{~kg}$ ram. From the feeding standards tables the requirements are DM $1.75 \mathrm{~kg}$, DCP $80.5 \mathrm{~g}$ and TDN $0.96 \mathrm{~kg}$.

The feeds available are grass hay, corn, mustard cake and wheat bran with the following nutritive values, expressed as percentages on an as such basis:

$\begin{array}{lcc}\text { Feed } & \text { DCP } & \text { TDN } \\ \text { Maize } & 7 & 84 \\ \text { Mustard cake } & 28 & 74 \\ \text { Wheat bran } & 8 & 64 \\ \text { Grass hay } & 2 & 40\end{array}$

Compute a concentrate mixture on a protein and energy basis to provide about 15\% DCP and 70\% TDN as follows:

\begin{tabular}{lccccl} 
Feed Ingredients & Parts as such & & DM & DCP & TDN \\
\cline { 2 - 3 } Corn & 25 & 22.5 & 1.75 & 21.0 \\
Mustard cake & 35 & 31.5 & 9.80 & 25.9 \\
Wheat bran & 40 & 36.0 & 3.20 & 25.6 \\
& 100 & 90.0 & 14.75 & 72.5
\end{tabular}

The ration can be computed as follows on an arbitrary basis:

\begin{tabular}{lcccc} 
Feed & Weight as $\operatorname{such}(\mathrm{kg})$ & dry matter $(\mathrm{kg})$ & $\frac{\operatorname{DCP}(\mathrm{kg})}{\operatorname{TDN}(\mathrm{kg})}$ \\
\cline { 2 - 4 } & 1.5 & 1.35 & 30.0 & 0.600 \\
$\begin{array}{l}\text { Concentrate } \\
\text { Mixture }\end{array}$ & 0.2 & 0.18 & 29.5 & 0.145 \\
Total & 1.7 & 1.53 & 59.5 & 0.745
\end{tabular}


It will be seen that the DM, DCP and TDN in the above computed ration are lower than those prescribed by the feeding standards. Hence the quantity of hay is increased to $2 \mathrm{~kg}$ and that of concentrate mixture to $300 \mathrm{~g}$ and the dry matter, digestible protein and total digestible nutrients again worked out.

\begin{tabular}{lcccc} 
Feed & weight as $\operatorname{such}(\mathrm{kg})$ & $\frac{\mathrm{DM}(\mathrm{kg})}{\mathrm{DCP}(\mathrm{g})}$ & $\frac{\operatorname{TDN}(\mathrm{kg})}{\text { Hay }}$ \\
\cline { 2 - 4 } & 2.0 & 1.80 & 40.0 & 0.800 \\
$\begin{array}{l}\text { Concentrate } \\
\text { mixture }\end{array}$ & 0.3 & 0.27 & 44.2 & 0.218 \\
Total & 2.3 & 2.07 & 84.2 & 1.018
\end{tabular}

The above ration provides slightly higher values of DM,DCP and TDN. But it shoul be borne in mind that the fjgures given in the feeding standards tables are requirements and not allowances. considering all the factors affecting the nutritive needs of animals, it is always desirable to leave a margin of safety and provide 10 or 20 percent more than the requirements.

\subsubsection{Iffect of feeding on wool production}

Wool is a protein product and is especjally rich in sulphurcontaining amino acids like cystine, which is about 9 percent of the protein compared to $1.2 \%$ in the diet and $0.8 \%$ in muscle protein. This requirement is usually met by the cystine present in feeds or by the methionine distributed in natural sources. It is, therefore, obvious that the make-up of the amino acid pool available to the tissues in the circulating fluids will determine the quality and quantity of wool being produced in addition to genetic factors.

Fibre thickness and fibre length are markedly influenced by the level of protein in the diet. Recent studies have shown that increasing the protein intake from 7 to $13 \%$ of the ration increased fibre thickness significantly by about $8 \%$ (Cuthberston 10(9). Both fibre thj.ckness and length are reduced during periods of stress caused by changes in temperature, pregnancy and lactation. One other factor affecting wool growth is a low protein and low plane ration, on which a proportion of the fibres ceases to function, reducing wool prociuction. Minerals also play a very important role. Small quantities of selenium are essential in preventing white muscle disease, although large quantities are toxic. Similarly copper, cobalt, iodine and iron are all essential for good wool. 


\subsection{Cattle and Sheep feeding in the Scandinavian Feed Unit System}

The feeding standards tabulated in this section are based on the Scandinavian Feed Unit (SFU) to quantify enersy requirements. These standards have been established through a large number of scientific experinents, which have taken into account the species, category, kind and levels of production, ace, rate of Erowth, environmental concitions, physiological stages, etc. Such experiments are of course very expensive and require special equipment and facilities not readily available in many developing countries, where the practice is to adapt data published in the literature. The tables presented here have likewise been adapted to conditions in the liear East.

\subsubsection{Feeding Standards for Cattle}

\section{A. Dairy Cows}

The nutrient requirements for dairy covs depend on the live-weight (maintenance requirements) and on the daily milk production of the animals. The feeding standards for dairy cows of various body weights and levels of milk production are shown in Table 30 , and represent the total maintenance and production requirements. Where the daily milk production is higher than that indicated in the tables, approximately $50 \mathrm{~g}$ digestible protein and 0.43 to $0.46 \mathrm{SFU}$ must be given in addition per $\mathrm{kg}$ of milk produced over and above $25 \mathrm{~kg}$.

For young cows (first and second lactation), the amount of digestible protein should be increased in the ration by about 100 to $150 \mathrm{~g}$ and 0.85 to $1.25 \mathrm{SFU}$ per day per animal, in order to cover the growth requirements.

Special feeding practices are required for high-yielding cows during the last week before and the first week after calving. It is usually recommended to feed the cows for a few days before calving with rations providing only one half to one third of their normal nutrient requirements, particularly protein, in order to avoid swelling and inflammation of the udders. Consequently both roughages and concentrates fed to them should be reduced during tiis period. One or two days before and after calving, the cows should be given only $2-3 \mathrm{~kg}$ of hay of good quality and $1-2 \mathrm{~kg}$ of wheat bran (the latter can be mixed with water before being fed), which bas slightly laxative properties. Seven to ten deys after calving, the daily rations should be gradually increased to rormal so that the nutrient requirements for milk production are covered.

From the third to the eighth week after calving the cows should be given, in addition, approximately 100 to $150 \mathrm{~g}$ digestible protein and 0.8 to 1.2 SFU per day per animal over and above the other requirements in order to increase milk yield during this period. After that, when their milk production does not increase any 
further, the cows should be fed according to their actual milk yields.

Dry cows (6-8 weeks beiore calving) should be fed like those productrg 8-10 $\mathrm{kg}$ milk per day, in order to provide sufficient nuirients for their actively growing fetuses and to allow them to store some nutriento (protein, energy, minerals, etc.) in their orgarisms as the latter would be deficient, mainly during the first three months of their lactation especially for high-yield cows, even if their feeding standards were adequate for their actual milk production.

Table 30 Daily feeding standards for dainy cows Body weight $350-450 \mathrm{~kg}$

\begin{tabular}{lccccc}
\hline $\begin{array}{l}\text { MiJk } \\
\text { Production } \\
(\mathrm{kg} / \text { day })\end{array}$ & SFU & $\begin{array}{l}\text { Digestible } \\
\text { Protein } \\
\text { (g) }\end{array}$ & $\begin{array}{c}\text { Dry } \\
\text { Matter } \\
(\mathrm{kg})\end{array}$ & $\begin{array}{l}\mathrm{Ca} \\
(\mathrm{g})\end{array}$ & $\begin{array}{l}\mathrm{P} \\
(\mathrm{g})\end{array}$ \\
\hline $\begin{array}{l}\text { Up to } 4 \\
5-7\end{array}$ & 4.99 & 440 & $8-12$ & 23.8 & 16.8 \\
$8-10$ & 6.97 & 540 & $8-12$ & 28.2 & 20.2 \\
$11-13$ & 8.09 & 840 & $9-13$ & 34.8 & 25.3 \\
$14-16$ & 0.25 & 990 & $8-14$ & 41.4 & 30.4 \\
$17-19$ & 10.41 & 1140 & $10-14$ & 48.0 & 35.5 \\
$20-22$ & 11.67 & 1290 & $10-14$ & 54.6 & 40.6 \\
$23-25$ & 12.83 & 1440 & $11-15$ & 61.2 & 45.7 \\
\hline
\end{tabular}

Body weight $450-550 \mathrm{~kg}$

\begin{tabular}{rrrrrr}
\hline Up to 4 & 5.51 & 480 & $10-14$ & 26.8 & 18.8 \\
$5-7$ & 6.28 & 580 & $10-14$ & 31.0 & 22.2 \\
$8-10$ & 7.44 & 730 & $11-15$ & 37.6 & 27.3 \\
$11-13$ & 8.60 & 880 & $11-15$ & 44.2 & 32.4 \\
$14-16$ & 9.76 & 1030 & $12-16$ & 50.8 & 37.5 \\
$17-19$ & 10.92 & 1180 & $12-16$ & 57.4 & 42.6 \\
$20-22$ & 12.08 & 1330 & $13-17$ & 54.0 & 47.7 \\
$23-25$ & 13.24 & 1480 & $13-17$ & 70.6 & 52.8 \\
$26-28$ & 14.40 & 1630 & $14-18$ & 77.2 & 57.9 \\
\hline
\end{tabular}

Body weight $550-650 \mathrm{~kg}$

\begin{tabular}{rrrrrr}
\hline UP to 4 & 6.02 & 515 & $10-15$ & 39.8 & 20.8 \\
$5-7$ & 7.18 & 665 & $11-16$ & 46.4 & 25.9 \\
$8-10$ & 8.34 & 815 & $12-17$ & 53.0 & 31.0 \\
$11-13$ & 9.50 & 965 & $12-17$ & 59.6 & 36.1 \\
$14-16$ & 10.66 & 1115 & $12-18$ & 66.2 & 41.2 \\
$17-19$ & 11.82 & 1265 & $12-18$ & 72.8 & 46.3 \\
$20-22$ & 12.98 & 1415 & $13-19$ & 79.4 & 51.4 \\
$23-25$ & 14.14 & 155 & $13-19$ & 86.0 & 56.5 \\
$26-28$ & 15.30 & 1715 & $14-20$ & 92.6 & 61.6 \\
$29-31$ & 16.46 & 1865 & $14-20$ & 99.2 & 66.7 \\
\hline
\end{tabular}


B. Calves and Breeding Heifers

Young cattle (calves and breeding heifers and bulls) should be well fed so that they can take full advantage of their growth anci milk production potentialities. Tables 31 and 32 indicate the feeding standards recommended for rearing calves and raising heifers. Male calves, which usually grow faster than females, require 10 to 20 percent more digestible protein and SFU than those indicated in these tables which are actually for young females.

The rearing of calves requires very special care. Once the newborn calf has been cleaned from the delivery and dried up, it should be allowed to suck the colostrum, within an hour after birth. Colostrum is essential to the young animal as it contains conšiderable amounts of protein, minerals, vitamins and specific inmunizing antibodies which vili protect it against a number of major diseases, inclucing infections of the digestive tract.

When calves are separated from their mothers some 24 hours after their birth, it is easier to train them in bucket feeding with sitable amounts of wiole milk. The separation of calves from their mothers also allows significant savings of milk which would otherwise be suclred excesssively. Two to three week old calves hould have free access to concentrates and hay of good quality to get them used to feeding on solid.feeds as soon as possible. They will consume only small amounts of feed to begin with but this will nevertheless allow an early development of their rumen and create suitable fermentation conditions for roughages, leading to their efficient utilization in tie animal body. The rumen usually develops at the ace of 2-3 months. From that age onwards, the animals can therefore be fed with rations containing relatively large amounts of fresh green, ensiled or dried green fodder. of fresh green, ensiled or aried greifers are pregnant(about 1 -20 months old), feeding should gradually increase, particularly in the second half of the presnancy, during the last two months of which they should be fed like covs producing 10 to $12 \mathrm{~kg}$ of milk daily, so that they can be prepared for their lactation. If the pregnant heifers are too fat, the claily ration should contain approximately 1 to 2 STU less than indicated in Table 32 but the quantity of digestible protein should not be increased. 
201

Table 31. Daily feeding standards for rearing calves

\begin{tabular}{lcllllll}
\hline $\begin{array}{l}\text { Age } \\
\text { (days) }\end{array}$ & $\begin{array}{l}\text { Average } \\
\text { Body } \\
\text { Weight } \\
(\mathrm{kg})\end{array}$ & $\begin{array}{l}\text { Average } \\
\text { Daily } \\
\text { Gain } \\
(\mathrm{kg})\end{array}$ & 3Fu & $\begin{array}{l}\text { Digestible } \\
\text { Protein } \\
(\mathrm{g})\end{array}$ & $\begin{array}{l}\text { Dry } \\
\text { Matter } \\
(\mathrm{kg})\end{array}$ & $\mathrm{Ca}$ & $\mathrm{P}$ \\
\hline $\mathrm{g})$ & $(\mathrm{g})$ \\
\hline $1-10$ & 35 & 0.5 & 1.12 & 150 & 0.6 & 15 & 12 \\
$11-20$ & 39 & 0.4 & 1.12 & 180 & 0.7 & 15 & 12 \\
$21-30$ & 43 & 0.4 & 1.12 & 200 & 0.9 & 15 & 12 \\
$31-40$ & 47 & 0.4 & 1.16 & 205 & 1.1 & 15 & 13 \\
$41-50$ & 51 & 0.4 & 1.50 & 210 & 1.5 & 16 & 13 \\
$51-60$ & 55 & 0.5 & 1.98 & 240 & 1.6 & 16 & 14 \\
$61-70$ & 61 & 0.6 & 2.58 & 280 & 2.4 & 16 & 14 \\
$71-80$ & 67 & 0.6 & 2.68 & 330 & 2.7 & 16 & 14 \\
$81-90$ & 73 & 0.6 & 2.75 & 310 & 3.0 & 16 & 14 \\
\hline
\end{tabular}

Table 32. Daily feeding standards for raising young heifers

\begin{tabular}{|c|c|c|c|c|c|c|c|}
\hline $\begin{array}{l}\text { Age } \\
\text { (Months) }\end{array}$ & $\begin{array}{c}\text { Average } \\
\text { Bcdy } \\
\text { Weight } \\
(\mathrm{kg})\end{array}$ & $\begin{array}{l}\text { Average } \\
\text { Daily } \\
\text { Gain } \\
(\mathrm{kg})\end{array}$ & SFU & $\begin{array}{l}\text { Digestible } \\
\text { Protein } \\
\text { (g) }\end{array}$ & $\begin{array}{l}\text { Dry } \\
\text { Matter } \\
(\mathrm{kg})\end{array}$ & $\begin{array}{l}\mathrm{Ca} \\
(\mathrm{g}) \\
\end{array}$ & $\begin{array}{l}P \\
(g) \\
\end{array}$ \\
\hline $\begin{array}{r}3 \\
4 \\
5 \\
6 \\
7 \\
8 \\
9 \\
10 \\
11 \\
12\end{array}$ & $\begin{array}{r}80 \\
100 \\
120 \\
140 \\
165 \\
190 \\
215 \\
240 \\
265 \\
290\end{array}$ & $\begin{array}{l}0.6 \\
0.7 \\
0.7 \\
0.7 \\
0.8 \\
0.8 \\
0.8 \\
0.8 \\
0.8 \\
0.8\end{array}$ & $\begin{array}{l}2.6 \\
3.2 \\
3.4 \\
3.0 \\
4.2 \\
4.7 \\
5.0 \\
5.4 \\
5.6 \\
5.6\end{array}$ & $\begin{array}{l}315 \\
390 \\
420 \\
450 \\
520 \\
560 \\
580 \\
600 \\
620 \\
620\end{array}$ & $\begin{array}{l}2.8 \\
3.7 \\
4.1 \\
4.5 \\
5.3 \\
6.0 \\
6.4 \\
6.9 \\
7.4 \\
7.8\end{array}$ & $\begin{array}{l}15 \\
15 \\
15 \\
15 \\
15 \\
16 \\
16 \\
16 \\
16 \\
16\end{array}$ & $\begin{array}{l}12 \\
13 \\
14 \\
15 \\
15 \\
15 \\
15 \\
15 \\
16 \\
16\end{array}$ \\
\hline \multicolumn{2}{|c|}{$\begin{array}{l}\text { lst to } 7 \text { th } \\
\text { month of } \\
\text { pregnancy }\end{array}$} & - & 7.7 & 800 & 11.7 & 25 & 30 \\
\hline $\begin{array}{l}\text { 8th to } 9 \\
\text { month of } \\
\text { pregnanc }\end{array}$ & th - & - & $\varepsilon .6$ & 900 & $12 \cdot 5$ & 25 & 30 \\
\hline
\end{tabular}




\section{Fattening beef cattle}

Fattening young beef cattle require an increase of the retention rate of protein and fat in the fast-growing tissues of the body so that good quality carcasses may be obtained. Tables 33 and 34 show respectively two levels of feeding standards recommended for fattening beef cattle. The first (Table 33) illustrates a fattening method in two phases of which the second includes a more intensive feeding programme. During the first phase, which usually lasts until the age of 12 months, the animals are left on pasture or given green roughages and some concentrates. The resulting growth rate and daily gain are relatively low. During the second phase the daily gain per animal usually reaches 0.8 to $0.9 \mathrm{~kg}$ or even more. This period lasts 6 to 9 months. The percentage of concentrates in the rations during this period is considerably higher than during the initial one.

Table 33 Daily feeding standards for fattening beef cattle

in two consecutive phases

\begin{tabular}{|c|c|c|c|c|c|c|c|}
\hline $\begin{array}{l}\text { Age } \\
\text { (Months) }\end{array}$ & $\begin{array}{c}\text { Average } \\
\text { Body } \\
\text { Wei ght } \\
\text { (kg) } \\
\end{array}$ & $\begin{array}{l}\text { Average } \\
\text { Daily } \\
\text { Gain } \\
(\mathrm{kg}) \\
\end{array}$ & SFU & $\begin{array}{c}\text { Digestible } \\
\text { Protein } \\
(g) \\
\end{array}$ & $\begin{array}{l}\text { Dry } \\
\text { Matter } \\
(\mathrm{kg}) \\
\end{array}$ & $\begin{array}{l}\mathrm{Ca} \\
(\mathrm{g}) \\
\end{array}$ & $\begin{array}{l}P \\
(g)\end{array}$ \\
\hline \multicolumn{8}{|c|}{ Preliminary Period } \\
\hline $\begin{array}{r}4 \\
5 \\
6 \\
7 \\
8 \\
9 \\
10 \\
11 \\
12\end{array}$ & $\begin{array}{r}90 \\
110 \\
125 \\
145 \\
160 \\
180 \\
200 \\
215 \\
235\end{array}$ & $\begin{array}{l}0.6 \\
0.6 \\
0.6 \\
0.6 \\
0.6 \\
0.6 \\
0.6 \\
0.6 \\
0.6\end{array}$ & $\begin{array}{l}2.8 \\
2.9 \\
3.1 \\
3.3 \\
3.4 \\
3.6 \\
3.9 \\
4.1 \\
4.3\end{array}$ & $\begin{array}{l}350 \\
375 \\
380 \\
400 \\
400 \\
420 \\
450 \\
460 \\
475\end{array}$ & $\begin{array}{l}3.3 \\
3.5 \\
3.8 \\
4.2 \\
4.4 \\
4.6 \\
5.0 \\
5.0 \\
5.6\end{array}$ & $\begin{array}{l}24 \\
24 \\
24 \\
24 \\
24 \\
24 \\
24 \\
24 \\
24\end{array}$ & $\begin{array}{l}16 \\
16 \\
16 \\
16 \\
16 \\
16 \\
16 \\
16 \\
16\end{array}$ \\
\hline
\end{tabular}

Intensive fattening period

\begin{tabular}{llllllll}
13 & 260 & 0.8 & 5.2 & 570 & 6.7 & 24 & 16 \\
14 & 285 & 0.8 & 5.4 & 620 & 7.2 & 24 & 16 \\
15 & 305 & 0.8 & 6.0 & 630 & 7.8 & 24 & 16 \\
16 & 330 & 0.8 & 6.6 & 690 & 8.6 & 24 & 16 \\
$17-18$ & 320 & 0.8 & 6.9 & 720 & 8.9 & 24 & 16 \\
\hline
\end{tabular}


When the live weight of fattening cattle, especially heifers, reaches $400 \mathrm{~kg}$, the daily gain usually decreases. If so, it is more economical not to extend the fattening periods the animals are tien ready to be sold or slaughtered.

Table 34 shows. dajly feeding standards for the intensive fattening of beef catile. This usually starts at the age of 4 months and continues until the animals are 12 to 14 months old, depending upon their growth rate and average daily gain of live weight. The daily gain of young males is usually higher than that of young heifers kept under the sane feeding conditions. For this and other reasons, male and female animals should be fattened separately.

Table 34 Daily feeding standards for intensive fattening of

beef cattle

\begin{tabular}{cccccccc}
\hline Age & $\begin{array}{c}\text { Average } \\
\text { Live } \begin{array}{c}\text { Body } \\
\text { Weight } \\
(\mathrm{kg})\end{array}\end{array}$ & $\begin{array}{c}\text { Average } \\
\text { Daily } \\
\text { Gain } \\
(\mathrm{kg})\end{array}$ & $\begin{array}{c}\text { SFU } \\
\text { (Months) }\end{array}$ & $\begin{array}{c}\text { Digestible } \\
\text { Protein }\end{array}$ & $\begin{array}{c}\text { Dry } \\
\text { Matter }\end{array}$ & Ca & P \\
\hline 4 & 115 & 0.8 & 3.1 & 380 & 3.8 & 15 & 1.5 \\
5 & 140 & 0.8 & 3.4 & 420 & 4.0 & 15 & 15 \\
6 & 165 & 0.8 & 3.8 & 440 & 4.3 & 15 & 15 \\
7 & 185 & 0.8 & 4.1 & 480 & 4.6 & 1.5 & 15 \\
8 & 210 & 0.8 & 4.5 & 495 & 5.1 & 15 & 15 \\
9 & 235 & 0.8 & 4.7 & 520 & 5.5 & 16 & 15 \\
10 & 260 & 0.8 & 5.0 & 560 & 5.7 & 16 & 16 \\
11 & 285 & 0.8 & 5.2 & 580 & 6.0 & 16 & 16 \\
12 & 305 & 0.8 & 5.5 & 600 & 6.5 & 16 & 16 \\
$13-14$ & 355 & 0.8 & 5.7 & 600 & 7.0 & 16 & 16 \\
$15-16$ & 395 & 0.7 & 5.8 & 610 & 7.5 & 16 & 16 \\
$17-16$ & 435 & 0.6 & 5.0 & 630 & 8.5 & 16 & 16
\end{tabular}

Adult cattle (cows and bulls) of low productivity are very often culled and sold for slaughter. These animals, especially those in poor condition, produce a meat of very poor quality. In such a case, it is economical to fatten lean adult animals so that the resulting betcer quality beef carcassses get higher prices. Feeding standards for fattening adult cattle are given in Table 35 . The live body weights given in the table are those existing at the beginning of the fatiening period. The animals are usually fed the same rations for about 90 to 100 days. The average daily gain should be about $1 \mathrm{~kg}$ per aninal. If the daily gain of an animal, especially during the third month of fattening, decreases to become lower than $0.5 \mathrm{~kg}$, the animal should be solc or slaughtered. It should be pointed out that adult cattle may be fattened with silage and certain industrial by-products 
(e.g., sugar beet pulp, molasses, brewers' grains, etc.) as staple feeds along with relatively srill amounts of concentrates, whereas other feeds should be used for fattening young catile. The use of aero-industrial by-products in rations supplemented with urea as a protein substitute may considerably decrease feeding costs and increase, consequently, the profitability of fattening culled adult animals.

Table 35 Daily feecing standards for fattening adult cattle

\begin{tabular}{ccccccc}
$\begin{array}{c}\text { Body } \\
\text { Weight }\end{array}$ & $\begin{array}{c}\text { Average } \\
\text { Daily } \\
\text { Gain } \\
(\mathrm{kg})\end{array}$ & SFU & $\begin{array}{c}\text { Digestible } \\
\text { Frotein }\end{array}$ & $\begin{array}{c}\text { Dry } \\
\text { Matter }\end{array}$ & Ca & P \\
\hline $350-400$ & 1.0 & $7.5-8.3$ & $520-680$ & $11-13$ & 15 & 10 \\
$400-450$ & 1.0 & $7.7-8.6$ & $540-700$ & $11-13$ & 16 & 11 \\
$450-500$ & 1.0 & $7.9-8.8$ & $550-715$ & $12-14$ & 18 & 12 \\
$500-550$ & 1.0 & $8.2-9.0$ & $570-735$ & $12-14$ & 20 & 13 \\
$550-600$ & 1.0 & $8.5-9.3$ & $595-765$ & $12-14$ & 21 & 14 \\
\hline
\end{tabular}

\subsubsection{Feeding Standards for Sheep}

Methods for feeding sheep kept on the range in the Near East essentially depend on the nature of seasonal natural grasses and herbage available. Depending upon grazing facilities available, sheep productivity is fluctuating. In order to improve j.t on a yearly basis, suplementary feeding with roughages and concentrates should be provided, especially during drought periods witen malnutrition is observed and flock productivity rapidly decreases. In general, sheep requirements are fully covered if the animals are grazed on pasture or on the range, provided the latter contains green grass in sufficient amounts. However, milking and nursing ewes need additional feeding of concentrates.

\section{A. 车wes}

The energy and protein as well as mineral and vitamin requirements of eves depend on their physiological stage and body weight. Pregnant ewes require a gradually increasing suply of energy and protein for the development of their fetuses, keeping in mind that the most intensive growth of the fetus occurs during the last month of pregnancy. Young and growing pregnant ewes should be given additional energy and protein to support body weight increases during the pregnancy period. 
Table 36 Daily feeding standards for pregnant ewes

\begin{tabular}{|c|c|c|c|c|c|}
\hline $\begin{array}{l}\text { Live } \\
\text { Body } \\
\text { Weight } \\
(\mathrm{kg})\end{array}$ & $\mathrm{SFU}$ & $\begin{array}{c}\text { Digestible } \\
\text { Protein } \\
\text { (g) }\end{array}$ & $\begin{array}{c}\text { Dry } \\
\text { Matter } \\
(\mathrm{kg})\end{array}$ & $\begin{array}{l}\mathrm{Ca} \\
(\mathrm{g})\end{array}$ & $\begin{array}{l}P \\
(g)\end{array}$ \\
\hline \multicolumn{6}{|c|}{ pregnancy } \\
\hline \multicolumn{6}{|c|}{ Adult ewes } \\
\hline $\begin{array}{l}30 \\
40 \\
50 \\
60 \\
70 \\
80\end{array}$ & $\begin{array}{l}0.43 \\
0.57 \\
0.69 \\
0.82 \\
0.95 \\
1.02\end{array}$ & $\begin{array}{l}50 \\
60 \\
70 \\
80 \\
90 \\
95\end{array}$ & $\begin{array}{l}1.0 \\
1.3 \\
1.5 \\
1.8 \\
2.0 \\
2.2\end{array}$ & $\begin{array}{l}3.2 \\
3.3 \\
3.5 \\
3.8 \\
4.0 \\
4.2\end{array}$ & $\begin{array}{l}2.6 \\
2.7 \\
2.8 \\
3.1 \\
3.2 \\
3.4\end{array}$ \\
\hline \multicolumn{6}{|c|}{ Growing eves } \\
\hline $\begin{array}{l}30 \\
40 \\
50 \\
60 \\
70\end{array}$ & $\begin{array}{l}0.51 \\
0.65 \\
0.77 \\
0.95 \\
1.07\end{array}$ & $\begin{array}{r}65 \\
75 \\
85 \\
100 \\
110\end{array}$ & $\begin{array}{l}1.2 \\
1.4 \\
1.6 \\
1.9 \\
2.1\end{array}$ & $\begin{array}{l}3.5 \\
3.8 \\
4.0 \\
4.2 \\
4.4\end{array}$ & $\begin{array}{l}2.8 \\
3.1 \\
3.2 \\
3.4 \\
3.6\end{array}$ \\
\hline
\end{tabular}

(b) During the third and fourth months of pregnancy Adult ewes

$\begin{array}{rrrrrr}30 & 0.56 & 70 & 1.2 & 3.3 & 2.7 \\ 40 & 0.69 & 85 & 1.4 & 3.5 & 2.8 \\ 50 & 0.02 & 95 & 1.7 & 3.8 & 3.1 \\ 60 & 0.98 & 110 & 1.9 & 4.0 & 3.2 \\ 70 & 1.08 & 120 & 2.2 & 4.2 & 3.4 \\ 00 & 1.19 & 130 & 2.4 & 4.2 & 3.4\end{array}$

\section{Growing ewes}

$\begin{array}{rrrrrr}30 & 0.66 & 85 & 1.2 & 3.5 & 2.8 \\ 40 & 0.83 & 1.80 & 1.4 & 3.8 & 3.1 \\ 50 & 0.98 & 120 & 1.7 & 4.0 & 3.2 \\ 60 & 1.07 & 135 & 2.0 & 4.2 & 3.4 \\ 70 & 1.30 & 150 & 2.3 & 4.4 & 3.6\end{array}$




\begin{tabular}{|c|c|c|c|c|c|}
\hline $\begin{array}{r}\text { Live } \\
\text { Body } \\
\text { Weight } \\
(\mathrm{kg})\end{array}$ & SFU & $\begin{array}{c}\text { Digestible } \\
\text { Protein } \\
(\mathrm{g}) \\
\end{array}$ & $\begin{array}{c}\text { Dry } \\
\text { Natter } \\
(\mathrm{kg})\end{array}$ & $\begin{array}{l}\mathrm{Ca} \\
(\mathrm{g})\end{array}$ & $\begin{array}{l}P \\
(g)\end{array}$ \\
\hline (c) & \multicolumn{5}{|c|}{ During the last four to six weeks before lambing } \\
\hline \multicolumn{6}{|c|}{ Adult ewes } \\
\hline $\begin{array}{l}30 \\
40 \\
50 \\
60 \\
70 \\
80\end{array}$ & $\begin{array}{l}0.71 \\
0.85 \\
1.03 \\
1.17 \\
1.38 \\
1.54\end{array}$ & $\begin{array}{l}105 \\
130 \\
145 \\
160 \\
160 \\
200\end{array}$ & $\begin{array}{l}1.3 \\
1.5 \\
1.8 \\
2.0 \\
2.4 \\
2.6\end{array}$ & $\begin{array}{l}4.2 \\
4.3 \\
4.4 \\
4.5 \\
4.6 \\
4.8\end{array}$ & $\begin{array}{l}3.3 \\
3.5 \\
3.6 \\
3.7 \\
3.7 \\
3.8\end{array}$ \\
\hline & \multicolumn{5}{|c|}{ Growing ewes. } \\
\hline $\begin{array}{l}30 \\
40 \\
50 \\
60 \\
70\end{array}$ & $\begin{array}{l}0.83 \\
1.02 \\
1.24 \\
1.40 \\
1.65\end{array}$ & $\begin{array}{l}135 \\
160 \\
190 \\
205 \\
235\end{array}$ & $\begin{array}{l}1: 4 \\
1: 6 \\
1: 9 \\
2: 2 \\
2: 5\end{array}$ & $\begin{array}{l}4: 4 \\
4.5 \\
4: 6 \\
4.7 \\
4.9\end{array}$ & $\begin{array}{l}3.6 \\
3.7 \\
3.7 \\
3.8 \\
4.0\end{array}$ \\
\hline
\end{tabular}

Nursing or milking ewes require much more energy and protein than pregnant ewes, as the amount of nutrients (protein, sugar, fat, minerals, etc.) excreted daily in thejr milk after lambing exceeds the daily amount retained by the fetus before lambing. The daily nutrient requirements of milking and nursing ewes are given in Table 37. 


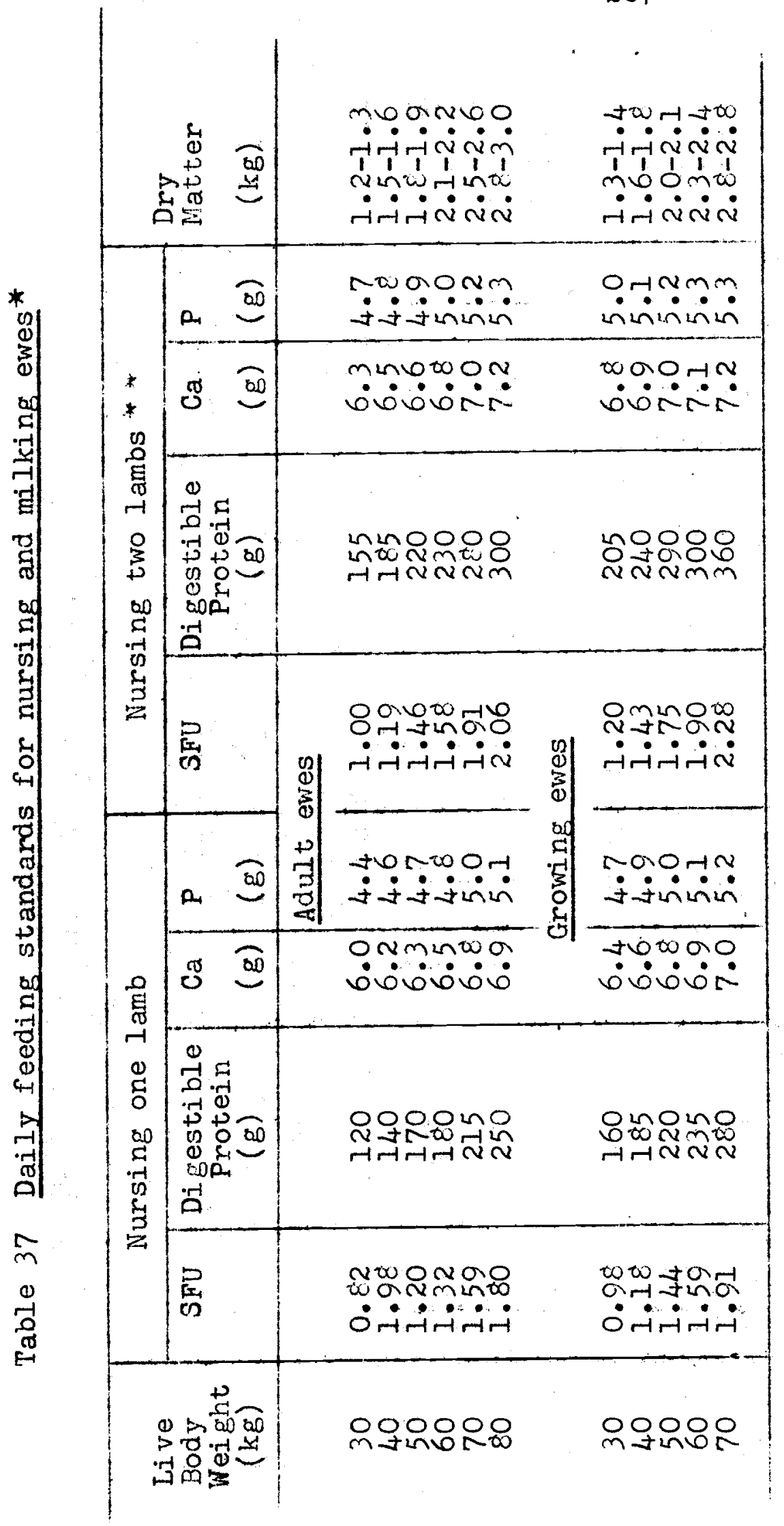

5

4

तु

30

\&

00

ه.

क. व

क्ष

() 0 क

대 है

\& 01

弯年

ond 0

प्र 8

- 0 तु

तथ 02

ㄴำ bी

- है त्र

00

लि口

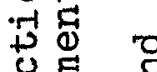

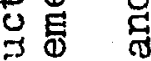

04

\&

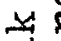

ज्ञम

माण

त्रण

ه

ond का का

or

\&ं न म

in 0

$\begin{array}{cc}0 & k 4 \\ -\pi & *\end{array}$ 
Growing ewes and those nursing two or more lambs require more energy and protein than adults or those nursing only one lamb (see footnotes to Table 37). Because of the relatively large differences existing between the nutrient requirements of ewes nursing respectively one or two lambs and those of growing ewes, all these animals should be kept separately in three groups as follows:

$$
\begin{aligned}
& \text { Group I -adult ewes nursing one lamb } \\
& \text { Group II -adult ewes nursing two lambs, and } \\
& \text { growing ewes nursing one lamb } \\
& \text { Group III-growing ewes nursing two lambs, and } \\
& \text { ewes nursing more than two lambs }
\end{aligned}
$$

Milking ewes, after weaning their lambs, should be fed according to their daily milk production (see footnotes of Table 37 ). The feeding standards for dry ewes after their lambs have been weaned are shown in Table 38 . When ewes are dry, their nutrient requirements are relatively low, but higher than those of ewes during the first two montins of their pregnancies. Dry ewes should be brought into good bodily condition (preparatory period) for the next normal estrus (heat) and for the ensuing pregnancy period.

Table 38 Daily feeding standards for ewes after weaning of lambs

\begin{tabular}{rccccc}
$\begin{array}{r}\text { Live } \\
\text { Body } \\
\text { Weight } \\
(\mathrm{kg})\end{array}$ & SFU & $\begin{array}{c}\text { Digestible } \\
\text { Protein } \\
(\mathrm{g})\end{array}$ & $\begin{array}{c}\text { Dry } \\
\text { Matter } \\
(\mathrm{kg})\end{array}$ & $\mathrm{Ca}$ & $\mathrm{P}$ \\
\hline 30 & 0.60 & $\mathrm{~g})$ & $(\mathrm{g})$ \\
\hline 40 & 0.75 & 75 & 1.2 & 3.5 & 2.8 \\
50 & 0.88 & 100 & 1.4 & 3.7 & 2.9 \\
60 & 1.03 & 110 & 1.7 & 3.8 & 3.1 \\
70 & 1.15 & 120 & 1.9 & 3.9 & 3.2 \\
90 & 1.25 & 125 & 2.2 & 4.0 & 3.3 \\
\hline
\end{tabular}




\section{B. Fattening sheep}

Lambs. To obtain the maximum growth potential of sheep, one should fatten lambs from 4 to 6 weeks of age, when they first start eating solid feeds (concentrates), in addition to milk suckled from their dams. There are two different fattening systems for lambs. The first, which is an intensive method, consists of feeding them ad libitum with concentrate mixtures containing 12 to 13 percent of digestible protein. The lambs remain permanently with their dams and have free access to suckling, the concentrate mixture is put at their disposal in a neighbouring pen. The fattening period usually lasts about 3 to 4 months until their live weight reaches around $35 \mathrm{~kg}$. The feeding standards $i$. e., the nutritive value of the concentrate mixture fed ad iibitum are indicated in Table 39. The second fattening method, which is less intensive, consists of feeding lambs with a smaller amount of concentrates and more roughages (good quality hay, silage and green fodder). The fattening period is longer, usually lasting until the lambs are 6 to 7 months old. They may stay with their dams or can be fed after early weaning with milk replacers, using a suckling accessory calleà a "lamber". Additional nutrient requirements besides suckled milk or milk replacers are recommended in Table 40 .

Table 39 Dailing feeding standards for fattening lambs up to $35 \mathrm{~kg}$ of live body weight, using ad libitum feeding*

$1 \mathrm{~kg}$ of feed mixture should contain:

\begin{tabular}{cccccc} 
Age in & SFU & $\begin{array}{c}\text { Digestible } \\
\text { Proeks } \\
\text { Wein }\end{array}$ & $\begin{array}{c}\text { Dry } \\
\text { Matter } \\
(\mathrm{g})\end{array}$ & $\begin{array}{c}\text { Ca } \\
(\mathrm{g})\end{array}$ & $\begin{array}{c}\mathrm{P} \\
(\mathrm{g})\end{array}$ \\
\hline $3-4$ & 0.81 & 120 & $0.85-0.90$ & 13.0 & 8.0 \\
$5-6$ & 0.79 & 120 & $0.85-0.90$ & 13.0 & 8.0 \\
$7-8$ & 0.77 & 120 & $0.85-0.90$ & 13.0 & 8.0 \\
$9-10$ & 0.75 & 125 & $0.85-0.90$ & 13.0 & 8.0 \\
$11-12$ & 0.75 & 125 & $0.85-0.90$ & 13.0 & 8.0 \\
$13-14$ & 0.74 & 130 & $0.85-0.90$ & 13.0 & 8.0 \\
$15-16$ & 0.72 & 130 & $0.85-0.90$ & 13.0 & 8.0 \\
\hline
\end{tabular}

Lambs are left with their dams throughout the fattening period. 
Table 40 Daily feeding standards for fattening lambs up to 6 months of age (Suckled milk not included)

\begin{tabular}{rccccc}
\hline $\begin{array}{c}\text { Age } \\
\text { in }\end{array}$ & SFU & $\begin{array}{c}\text { Digestible } \\
\text { Protein } \\
(\mathrm{g})\end{array}$ & $\begin{array}{c}\text { Dry } \\
\text { Matter } \\
(\mathrm{kg})\end{array}$ & $\begin{array}{c}\mathrm{Ca} \\
(\mathrm{g})\end{array}$ & $\begin{array}{l}\mathrm{P} \\
(\mathrm{g})\end{array}$ \\
\hline 3 & 0.09 & 10 & 0.10 & & \\
4 & 0.13 & 15 & 0.15 & & \\
5 & 0.17 & 20 & 0.20 & & \\
6 & 0.21 & 25 & 0.25 & & \\
7 & 0.26 & 40 & 0.35 & & \\
8 & 0.34 & 50 & 0.40 & 2.5 & 2.3 \\
9 & 0.39 & 55 & 0.45 & 2.7 & 2.4 \\
10 & 0.43 & 60 & 0.50 & 2.9 & 2.6 \\
11 & 0.47 & 70 & 0.60 & 2.9 & 2.6 \\
12 & 0.56 & 80 & 0.65 & 3.0 & 2.7 \\
13 & 0.60 & 90 & 0.70 & 3.0 & 2.7 \\
14 & 0.69 & 100 & 0.80 & 3.0 & 2.7 \\
$15-16$ & 0.82 & 120 & 0.95 & 3.0 & 2.7 \\
$17-18$ & 0.99 & 140 & 1.10 & 3.0 & 2.7 \\
$19-20$ & 1.07 & 155 & 1.35 & 3.1 & 2.7 \\
$21-22$ & 1.22 & 175 & 1.55 & 3.1 & 2.7 \\
$23-24$ & 1.42 & 200 & 1.70 & 3.1 & 2 \\
\hline
\end{tabular}

Adult sheep. Occasionally adult rams and ewes which are culled from a breeding flock may be fattened before slaughter, especially after periods when feeding conditions have been poor (shortage of green fodder in pasture, long dry season, etc.). From economical and meat quality points of view, it is advisable to fatten adult sheep (for example in large-scale feedlots) using various types of roughages ( by-products (bran, molasses with or without urea, fruit refuse, sugar beet pulp, etc.) as the main feedstuff.

The requirements of adult sheep for digestible protein are much lower than those of fattening lambs and breeding ewes and rains, but their energy needs are relatively high because of the high rate of fat retention in the body during the fattening period. The feeding standards for fattening adult sheep are indicated in Table 41. 
Table 41 Daily feeding standards for fattening adult sheep (Intensive fattening)

\begin{tabular}{cccccc}
$\begin{array}{c}\text { Live } \\
\text { Body } \\
\begin{array}{c}\text { Weight } \\
(\mathrm{kg})\end{array}\end{array}$ & SFU & $\begin{array}{c}\text { Digestible } \\
\text { Protein }\end{array}$ & $\begin{array}{c}\text { Dry } \\
\text { Matter }\end{array}$ & Ca & P \\
\hline 30 & 0.86 & $(\mathrm{~g})$ & $(\mathrm{kg})$ & $(\mathrm{g})$ & $(\mathrm{g})$ \\
\hline 40 & 1.12 & 100 & 1.3 & 2.2 & 1.8 \\
50 & 1.24 & 115 & 1.7 & 2.4 & 2.0 \\
60 & 1.50 & 140 & 1.8 & 2.8 & 2.3 \\
70 & 1.63 & 150 & 2.2 & 3.0 & 2.5 \\
80 & 1.76 & 160 & 2.4 & 3.0 & 2.5 \\
\hline
\end{tabular}

\subsubsection{Ration Formulation}

The formulation of suitable rations for productive animals requires an adequate knowledge of animal nutrition, feeding techniques and feed quality (palatability, influence of a particular feed on the quality of animal products, correct preparation of rations, etc.). Nutrient requirements and" the amount and nutritive value of the feedstuffs available on the farm are in practice the main data required for ration formulation, and Scandinavian Feed Units, digestible protein and the amounts of calcium and phosphorus required should be the main criteria. Sometimes the dry matter content in the rations, especially for high-yielding dairy cows, should be calculated and compared with the figures included in the feeding standards tables. Rations consisting of voluminous roughages (straw, poor quality hay and green fodder) usually have a low digestibility coefficient and a low concentration of digestible energy and protein per unit of dry matter. These factors limit the daily intake of digestible nutrients in feeds given ad libitum.

The use of the tables indicating feeding standards and feed nutritive ualues given before for the formulation of the rations is illustrated by two examples given in Table 42. Some examples of practical rations incorporating feedstuffs available in the Near East are given in Table 43 for dairy cows, in Table 44 for raising heifers, in Table 45 for fattening cattle and in Table 46 for fattening lambs.

Almost all rations fed to high-yielding animals require protein and/or energy supplementation through concentrate mixtures, either produced on a large scale in specialized 
plants or prepared on the farm. The proportion of each concentrate in the mixture depends upon its quality, protein content, price and principally the overall amount of protein required in the mixture which in turn depends on the nutritive value of the forages used in the rations. The price of concentrates and their availability on the market are essential factors which will determine their use in feed mixtures. The formulas used for concentrate mixtures given in Table 47 should include 15 to 20 percent of digestible protein per $\mathrm{kg}$. Some of the mixtures contain 2 or 3 percent of urea as a source of nitrogen to replace corresponding amounts of protein. Concentrate mixtures may be formulated according to the availability of components on the farm, if commercially produced mixtures are not used. If so, mineral components (salt and limestone or specific mineral premixes containing macro-and microelements) should be added so that the rations may cover all requirements.

Table 42 Simplified ration for milking cows of average:

Live body weight-about $500 \mathrm{~kg}$

Daily milk production $-20-22 \mathrm{~kg}$

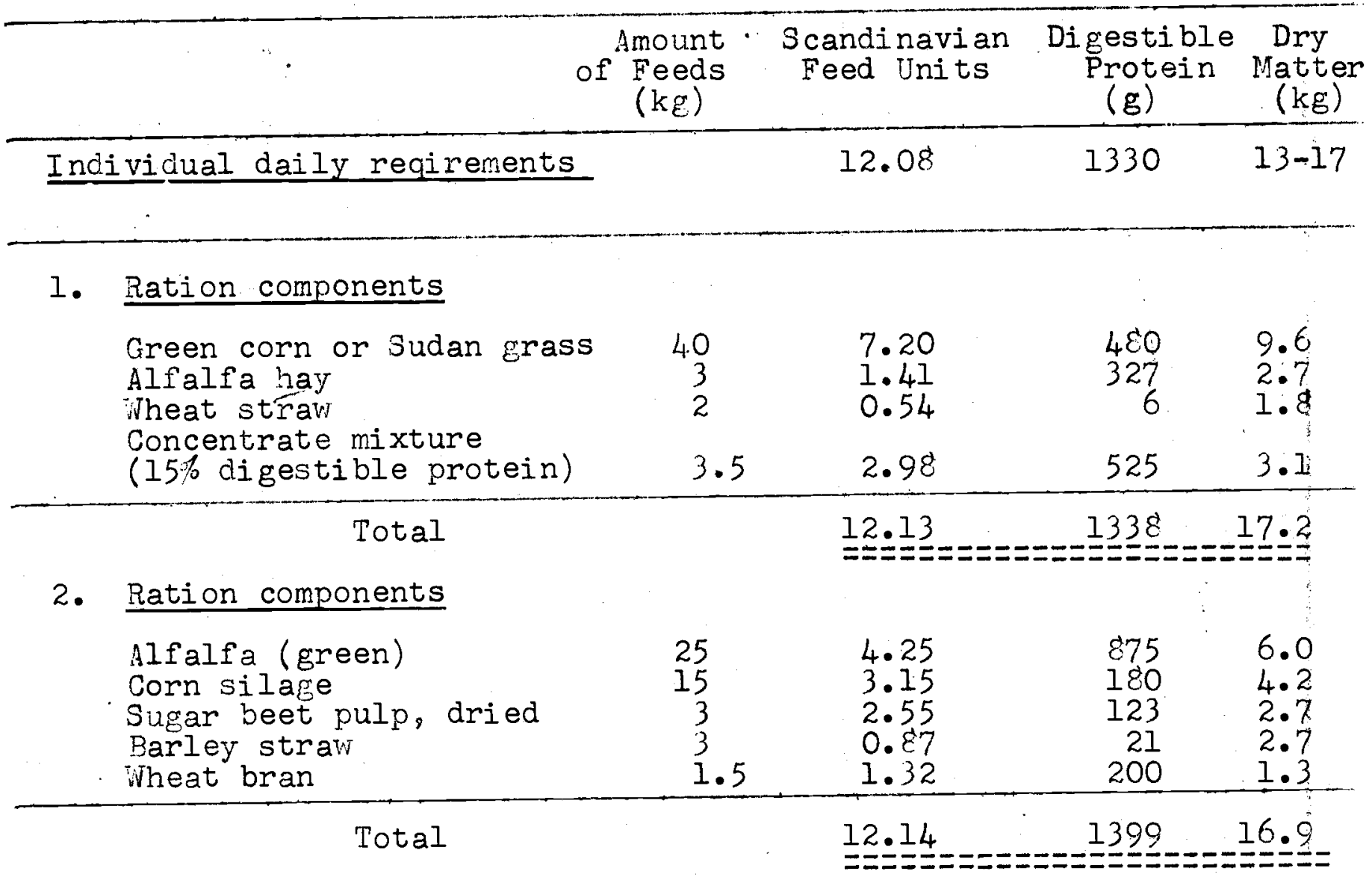


Table 43 Daily rations for dairy cows (average live body weight: $450-550 \mathrm{~kg})$

\begin{tabular}{|c|c|c|c|c|c|}
\hline \multirow{2}{*}{$\begin{array}{c}\text { Feedstuff } \\
\text { in } \mathrm{kg} \text { per day }\end{array}$} & \multicolumn{5}{|c|}{ Based on average daily milk production } \\
\hline & $\begin{array}{l}u_{p} \text { to } \\
10 \mathrm{~kg}\end{array}$ & $11-13 \mathrm{~kg}$ & $14-16 \mathrm{~kg}$ & $17-19 \mathrm{~kg}$ & $20-22 \mathrm{~kg}$ \\
\hline $\begin{array}{l}\text { Alfalfa, green } \\
\text { Corn silage } \\
\text { Barley straw } \\
\text { Wheat bran }\end{array}$ & $\begin{array}{r}15 \\
15 \\
5 \\
-\end{array}$ & $\begin{array}{r}20 \\
15 \\
5 \\
- \\
\end{array}$ & $\begin{array}{r}25 \\
20 \\
4 \\
1.0 \\
\end{array}$ & $\begin{array}{r}25 \\
20 \\
4 \\
1.5 \\
\end{array}$ & $\begin{array}{r}30 \\
25 \\
4 \\
2.0\end{array}$ \\
\hline $\begin{array}{l}\text { Sorghum, Suclan grass } \\
\text { or corn, green } \\
\text { Alfalfa hay } \\
\text { Sugar beet pulp, dried } \\
\text { Wheat straw } \\
\text { Concentrate mixture } \\
\text { (15 percent Dp)* }\end{array}$ & $\begin{array}{r}25 \\
2 \\
1 \\
2 \\
1\end{array}$ & $\begin{array}{r}30 \\
2 \\
1 \\
2 \\
1\end{array}$ & $\begin{array}{r}30 \\
3 \\
1 \\
2 \\
1.5\end{array}$ & $\begin{array}{l}35 \\
3 \\
1 \\
2 \\
2.5\end{array}$ & $\begin{array}{r}40 \\
3 \\
1 \\
2 \\
3.5\end{array}$ \\
\hline $\begin{array}{l}\text { Silage, Alfalfa: } \\
\text { Corn = I:I } \\
\text { Vetch and wheat, hay } \\
\text { Sugar beet, roots } \\
\text { Barley straw } \\
\text { Concentrate mixture } \\
\quad(15 \text { percent } D p)^{*}\end{array}$ & $\begin{array}{r}15 \\
2 \\
5 \\
3 \\
0.5\end{array}$ & $\begin{array}{r}20 \\
3 \\
5 \\
3 \\
0.5\end{array}$ & $\begin{array}{r}20 \\
3 \\
10 \\
3 \\
1.0\end{array}$ & $\begin{array}{r}25 \\
3 \\
10 \\
3 \\
1.0\end{array}$ & $\begin{array}{r}25 \\
3 \\
10 \\
3 \\
2.0\end{array}$ \\
\hline $\begin{array}{l}\text { Berseem, green } \\
\text { Corn stover, dried } \\
\text { Rice and wheat straw } \\
\text { Citrus pulp, dried } \\
\text { Molasses (beet or cane) } \\
\text { Concentrate mixture } \\
\quad(15 \text { percent Dp) }\end{array}$ & $\begin{array}{r}25 \\
2 \\
2 \\
1 \\
1 \\
0.5\end{array}$ & $\begin{array}{l}30 \\
2 \\
2 \\
1.5 \\
1 \\
1.0\end{array}$ & $\begin{array}{l}35 \\
2 \\
2 \\
1.5 \\
1 \\
1.0\end{array}$ & $\begin{array}{l}40 \\
2 \\
2 \\
2.0 \\
1 \\
1.5\end{array}$ & $\begin{array}{l}45 \\
2 \\
2 \\
2.0 \\
1 \\
2.0\end{array}$ \\
\hline
\end{tabular}

* Dp = Digestible protein 
Table 44 Daily rations for raising young heifers

\begin{tabular}{|c|c|c|c|c|c|}
\hline Average live body weight $(\mathrm{kg})$ & 100 & 150 & 200 & 250 & 300 \\
\hline Approximate age (in months) & $4-5$ & $6-7$ & $8-9$ & $10-11$ & $12-14$ \\
\hline Feedstuff & & in $\mathrm{kg} /$ & head/d & & \\
\hline $\begin{array}{l}\text { Alfalfa, green } \\
\text { Corn silage } \\
\text { Barley straw } \\
\text { Wheat bran }\end{array}$ & $\begin{array}{l}5 \\
5 \\
-1 \\
\end{array}$ & $\begin{array}{r}10 \\
5 \\
1 \\
1 \\
\end{array}$ & $\begin{array}{c}10 \\
10 \\
1 \\
0.5 \\
\end{array}$ & $\begin{array}{r}15 \\
10 \\
2 \\
- \\
\end{array}$ & $\begin{array}{r}15 \\
10 \\
2 \\
-\end{array}$ \\
\hline $\begin{array}{l}\text { Sorghum, Sudan grass or } \\
\text { corn, green } \\
\text { Alfalfa hay } \\
\text { Barley straw } \\
\text { Concentrate mixture } \\
\text { (15 percent Dp })^{*}\end{array}$ & $\begin{array}{c}10 \\
1 \\
0.5 \\
1.0\end{array}$ & $\begin{array}{c}14 \\
2 \\
1 \\
1.0\end{array}$ & $\begin{array}{l}15 \\
2 \\
1 \\
1.0\end{array}$ & $\begin{array}{l}20 \\
2 \\
2 \\
1.0\end{array}$ & $\begin{array}{l}25 \\
2 \\
2 \\
1.0\end{array}$ \\
\hline $\begin{array}{l}\text { Alfalfa, silage } \\
\text { Corn = } 1: 1 \\
\text { Vetch and wheat hay } \\
\text { Barley or wheat straw } \\
\text { Concentrate mixture } \\
\quad(15 \text { percent } D \text { p })^{*}\end{array}$ & $\begin{array}{r}10 \\
1 \\
- \\
1\end{array}$ & $\begin{array}{r}15 \\
1 \\
1 \\
1\end{array}$ & $\begin{array}{r}15 \\
2 \\
1.5 \\
0.8 \\
\end{array}$ & $\begin{array}{l}20 \\
2 \\
2 \\
0.5\end{array}$ & $\begin{array}{l}20 \\
3 \\
2 \\
0.5\end{array}$ \\
\hline $\begin{array}{l}\text { Berseem, vetch and wheat or } \\
\text { alfalfa, green } \\
\text { Wheat straw } \\
\text { Corn stover } \\
\text { Sugar beet pulp, dried } \\
\text { Concentrate mixture } \\
\quad \text { (15 percent Dp) }\end{array}$ & $\begin{array}{l}10 \\
1 \\
- \\
0.5 \\
1.0\end{array}$ & $\begin{array}{c}15 \\
2 \\
- \\
0.0 \\
0.5\end{array}$ & $\begin{array}{l}15 \\
2 \\
2 \\
1.0 \\
-\end{array}$ & $\begin{array}{l}15 \\
2 \\
3 \\
1.5 \\
-\end{array}$ & $\begin{array}{r}15 \\
2 \\
3 \\
2.0 \\
-\end{array}$ \\
\hline
\end{tabular}

* $D p=$ Digestible protein 
Table 45 Daily rations for intensive fattening of beef cattle

\begin{tabular}{|c|c|c|c|c|c|}
\hline Average live body weight ( $\mathrm{kg}$ ) & 100 & 150 & 200 & 300 & 400 \\
\hline Approximate age (in months) & 4 & $5-6$ & $7-8$ & $11-12$ & $15-16$ \\
\hline Feedstuff & & \multicolumn{4}{|c|}{ in $\mathrm{kg} / \mathrm{head} /$ day } \\
\hline \multirow{2}{*}{$\begin{array}{l}\text { Alfalfa, green } \\
\text { Vetch and wheat hay } \\
\text { Sugar beet pulp, dried } \\
\text { Wheat or rice straw } \\
\text { Concentrate mixture } \\
\quad(15 \text { percent Dp })^{*}\end{array}$} & $\begin{array}{l}5 \\
1 \\
0.5 \\
1\end{array}$ & $\begin{array}{r}10 \\
1 \\
1 \\
1\end{array}$ & $\begin{array}{r}10 \\
1 \\
2 \\
2\end{array}$ & $\begin{array}{r}15 \\
1 \\
2 \\
2\end{array}$ & $\begin{array}{l}15 \\
2 \cdot 5 \\
2\end{array}$ \\
\hline & 1 & 1 & 0.5 & 0.5 & 0.5 \\
\hline \multirow{2}{*}{$\begin{array}{l}\text { Corn silage } \\
\text { Alfalfa hay } \\
\text { Wheat straw } \\
\text { Concentrate mi xture } \\
\text { (15 percent } \mathrm{Dp})^{\star}\end{array}$} & $\begin{array}{l}5 \\
1 \\
1\end{array}$ & $\begin{array}{r}10 \\
2 \\
1\end{array}$ & $\begin{array}{r}15 \\
2 \\
1\end{array}$ & $\begin{array}{r}20 \\
2 \\
1\end{array}$ & $\begin{array}{r}25 \\
1 \\
1\end{array}$ \\
\hline & 1.5 & 1 & 1 & 1 & 1 \\
\hline \multirow{2}{*}{$\begin{array}{l}\text { Sugar beet tops silage } \\
\text { Barley or wheat straw } \\
\text { Citrus pulp, dried } \\
\text { Sugar beet pulp, dried } \\
\text { Concentrate mixture } \\
\quad(20 \text { percent Dp })^{*}\end{array}$} & $\begin{array}{l}5 \\
1 \\
0.5 \\
0.5\end{array}$ & $\begin{array}{l}10 \\
2 \\
1.0 \\
0.5\end{array}$ & $\begin{array}{l}10 \\
2 \\
1.5 \\
1.0\end{array}$ & $\begin{array}{l}1.5 \\
2 \\
1.5 \\
1.5\end{array}$ & $\begin{array}{l}15 \\
2 \\
1 \cdot 5 \\
2 \cdot 0\end{array}$ \\
\hline & 1 & 1 & 1 & 1 & 1 \\
\hline \multirow{3}{*}{$\begin{array}{l}\text { Chopped straw } \\
\text { Barley, ground } \\
\text { Molasses with } 5 \% \text { urea } \\
\text { Alfalfa, berseem or vetch } \\
\text { and wheat hay } \\
\text { Sugar beet pulp, dried } \\
\text { Concentrate mixture } \\
\quad(20 \text { percent Dp })^{*}\end{array}$} & $\begin{array}{l}1 \\
1 \\
0.5\end{array}$ & $\begin{array}{l}2 \\
1 \\
0.75\end{array}$ & $\begin{array}{l}3 \\
1 \\
1.0\end{array}$ & $\begin{array}{l}4 \\
0.5 \\
1.5\end{array}$ & $\begin{array}{l}4 \\
0.5 \\
2.0\end{array}$ \\
\hline & $\begin{array}{l}1 \\
0.5\end{array}$ & $\begin{array}{l}1 \\
1\end{array}$ & $\frac{1}{1}$ & $\frac{1}{2}$ & $\frac{1}{2}$ \\
\hline & 0.5 & 0.5 & 0.5 & 0.25 & 0.25 \\
\hline
\end{tabular}

* Dp = Digestible protein 
Table 46 Daily rations for fattening lambs up to 6 months of age

\begin{tabular}{|c|c|c|c|c|c|}
\hline Average age of lambs (months) & 2 & 3 & 4 & 5 & 6 \\
\hline Feedstuff & \multicolumn{5}{|c|}{ in $\mathrm{kg} / 101 \mathrm{ambs} / \mathrm{day}$} \\
\hline \multirow{2}{*}{$\begin{array}{l}\text { Alfalfa hay } \\
\text { Sugar beet pulp, dried } \\
\text { Barley straw } \\
\text { Concentrate mixture } \\
\quad(15 \text { percent Dp })^{*}\end{array}$} & $\begin{array}{c}1.0 \\
1.0 \\
-\end{array}$ & $\begin{array}{c}2.5 \\
2.0 \\
-\end{array}$ & $\begin{array}{l}4.5 \\
3.0 \\
1.0\end{array}$ & $\begin{array}{l}5.0 \\
3.5 \\
2.0\end{array}$ & $\begin{array}{l}6.0 \\
4.0 \\
4.0\end{array}$ \\
\hline & 2.0 & 3.0 & $4 \cdot 0$ & 5.0 & 6.0 \\
\hline \multirow{4}{*}{$\begin{array}{l}\text { Corn, sorghum or Sudan } \\
\text { grass silage } \\
\text { Chopped barley straw } \\
\text { Nolasses with } 2.5 \% \text { urea } \\
\text { Sugar beet pulp, dried or } \\
\text { rolled barley grain } \\
\text { Concentrate mixture }{ }^{*} \\
\quad(20 \text { percent Dp)* }\end{array}$} & & & & & \\
\hline & $\begin{array}{l}5 \\
1 \\
0.5\end{array}$ & $\begin{array}{l}8 \\
1 \\
1\end{array}$ & $\begin{array}{r}10 \\
3 \\
2\end{array}$ & $\begin{array}{r}15 \\
4 \\
3\end{array}$ & $\begin{array}{r}20 \\
4 \\
4\end{array}$ \\
\hline & 0.5 & 1 & 1 & 1 & 1 \\
\hline & 2 & 3 & 4 & 5 & 5 \\
\hline \multirow{2}{*}{$\begin{array}{l}\text { Green alfalfa, berssem or } \\
\text { vetch ard wheat } \\
\text { Chopped barley straw } \\
\text { Molass s } \\
\text { Concentrate mixture } \\
\quad(20 \text { percent } D p)^{*}\end{array}$} & $\begin{array}{l}10 \\
1 \\
0.5\end{array}$ & $\begin{array}{r}15 \\
1 \\
1\end{array}$ & $\begin{array}{r}25 \\
2 \\
1\end{array}$ & $\begin{array}{r}30 \\
3 \\
2\end{array}$ & $\begin{array}{r}35 \\
4 \\
3\end{array}$ \\
\hline & 1.5 & 2 & 2.5 & 3.0 & 4.0 \\
\hline \multirow{2}{*}{$\begin{array}{l}\text { Alfalfa or berseem hay } \\
\text { Sugar beet tops silage } \\
\text { Sugar beet roots } \\
\text { Concentrate mixture } \\
\text { (20 percent Dp })^{*}\end{array}$} & $\begin{array}{l}1 \\
5 \\
5\end{array}$ & $\begin{array}{r}2 \\
10 \\
5\end{array}$ & $\begin{array}{r}3 \\
15 \\
8\end{array}$ & $\begin{array}{r}4 \\
20 \\
10\end{array}$ & $\begin{array}{r}5 \\
20 \\
10\end{array}$ \\
\hline & 1.5 & 2.0 & 2.5 & 3.0 & 4.0 \\
\hline
\end{tabular}

* Dp = Digestible protein

* Concentrate mixture without urea supplement 
Table 47 Formulas for concentrate mixtures containing 15 and $20 \%$ digestible protein (DP) respectively

\begin{tabular}{|c|c|c|c|c|c|c|}
\hline \multirow{2}{*}{ Ingredients } & \multicolumn{3}{|c|}{ 15: Digestible Protein } & \multicolumn{3}{|c|}{$20 \%$ Digestible Protein } \\
\hline & $\%$ & $\%$ & $\%$ & $\not$ & $\%$ & $\%$ \\
\hline Barley, sorghum grain & 42 & 40 & 15 & 25 & 17 & 25 \\
\hline Corn grain & & & 15 & & & \\
\hline Wheat or rice bran & 38 & 15 & 17 & 32 & 20 & 40 \\
\hline Cottonseed meal or cake & 10 & 15 & 20 & 25 & 20 & 20 \\
\hline Soybean oil meal & 7 & & & 15 & & \\
\hline Sunflower oil meal & & & 10 & & 10 & \\
\hline Groundnut oil meal & & & & & & 5 \\
\hline Citrus pulp, dried & & 20 & 20 & & 20 & \\
\hline Molasses & & 5 & & & 7 & 5 \\
\hline Urea & & 2 & & & 3 & 2 \\
\hline Salt & 1 & 1 & 1 & 1 & 1 & 1 \\
\hline Limestone, ground & 2 & 2 & 2 & 2 & 2 & 2 \\
\hline
\end{tabular}


Goats are generally reared for meat and milk produotlon, although hairy breeds like Angora and Pashmina are bred for the hatr (Mohair) production. The nutrient requirement of thesetdfferent types of goats vary accordingly. Most goats are kept with the sheep in mixed flocks where the sheep graze the grass covert and the goats browse the shrubs. This is because they do
compete for the same feeds. Goats eat tree leaves, small compete for the same feeds. Goats eat tree leaves, small but they also eat cultivated fodders like Egyptian clover, alfalfa, cowpeas, oats, grasses, hays and silages under stall feeding conditions; they also normally consume fair amounts of grasses if they are grazed in paddocks under controlled conditions. Milk production is of primary importance in the milch breeds of goats. The average milk yield of nondescript does is 60 li.tres, Barbari does 100 litres and Jamunapari does 250 litres in a lactation period of 120 days.

Goats can easily utilize coarse, fibrous feeds but for efficient production the energy loses in heat production and digestion processes have to be minimised to get a maximum returr in the form of edible products (meat and milk). On the basj.s of several feeding trials, it has been observed that the dry matter intake of goats is quite high relative to the larger farm animals, varying from $3-4 \%$ to $7-11 \%$ live weight, depending on the size of the goat. Due to their smali stomach capacity, the daily feed allowance may be offered 3 to 4 times a day goats are known for their round-the-clock eating habits. A little higher level of protein seems to be beneficial for goat feeding, although the use of oil cakes as source of protein should be avoided. Grain alone forms one of the best feeds. With a higher proportion of cereal grains in the concentrate mixture, urea can be used as source of dietary nitrogen to the extent of 30 to 40 percent of total protein requirements.

Nutrient requirements for maintenance. On the basis of work done in India, the crude protein and digestible crude protein requirements have been found to be $260 \mathrm{~g}$ and $112 \mathrm{~g}$ respectively per $100 \mathrm{~kg}$ body weight. The protein requirements of Barbari and Jamunapari goats was found to be $126 \mathrm{~g} \mathrm{DCP}$ per $100 \mathrm{~kg}$ body weight: The dry matter consumption by Jamunapari goats was 2.42 to $3.58 \mathrm{~kg}$ per $100 \mathrm{~kg}$ body weight, while that by other breeds was 1.47 to $2.65 \mathrm{~kg}$ per $100 \mathrm{~kg}$ body weight. Angora goats in America can consume from 6.5 to 11 percent of their body weight.

Nutrient requirement for growth: Work done in India on Jamunapari goats showed that the growth rate was about $90 \mathrm{~g}$ 
per day and that kids fed in stalls upto 15 weeks old attained body weights of around $12.5 \mathrm{~kg}$ (females). The kinds in the browsing group under identical conditions recorded a $64 \%$ higher rate of growth than the stall-fed group.

Nutrient requirement for milk production. No systemmatic work has been done on the nutrient requirements of lactating goats. On the basis of the work done in India and other countries, tentative requirements are given in Table 4 . 






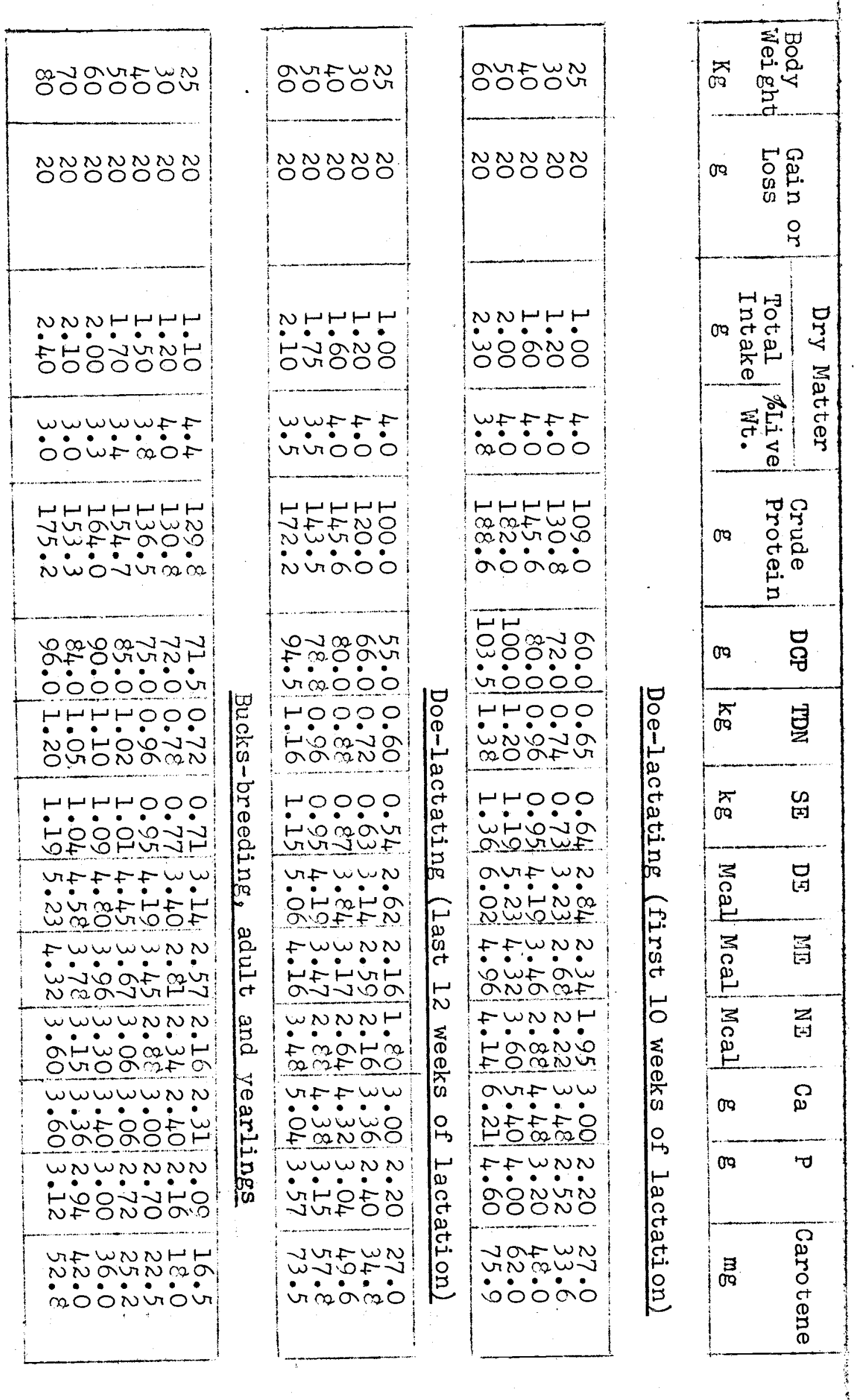


\section{Feeds for goats}

Goats are natural browsers. They are continually travelling in search of food and can effectively utilize feeds that are normally refused by other livestock; care should be taken, though, to keep them away from poisonous plants. Goats are the best animals for the utilization of unimproved pasture. Mohair and meat type goats are used extensively to graze unimproved pasture and range areas where vegetation is generally of low quality. Since goats are good browsers, they can be used effectively to control brushes and undergrowth. Forages and good pasture can provide the vast bulk of the nutrients required for maintenance, pasture can replace one half the concentrates in the ration of lactating does. Range forages are generally very low in phosphorus and salt and often marginal in levels of vitamin $A$, calcium and trace minerals; these must therefore be supplemented. It should be noted that as forages mature, their nutritive value and digestibility decline. Improved pasture is a necessity for does and yearlings: in order to prevent over-grazing the grass should be allowed to get 3 to 4 inches high before the animals are allowed on to it. Some of the grasses and legumes that can be effectively used in pasture management for goats are alfalfa, clover, timothy, blue grass, Sudan grass and the millet grasses. Temporary pastures can provide excelient forage. Rye, wheat and barley are very good for early spring or late fall grazing. Rape, or a mixture of rape and oats are also good.

If pasture and range feeds are rot available, hay and dry roughages make the next most economical feeds for goats. A good quality legume hay or a mixed legume (50\%) and grass ( $50 \%)$ hay provide an excellent source of highly digestible nutrients. Grass hays require supplementation with concentrates. Some of the other hays commonly fed to goats are alfalfa, alsike clover, red clover, ladine clover, soya bean hay and vetch hay. Silages and haylages are never used extensively as feed for goats. If fed the amount is normally 0.5 to $1 \mathrm{~kg}$ per head per day. Goats are fond of root crops and garden products like carrots, beets, turnips and cabbage, of which not more then half to one $\mathrm{kg}$ per head per day should be fed. Cereal grains like corr, oats, barley and wheat are excellent sources of energy as concentrates. The amount of cereals in the ration should be determined by production demands. Molasses is also a good source of energy and can constitute 5-10\% of the mixture. Cottonseed meal, soya bean meal, coconut meal, peanut meal, sunflower meal, safflower meal and brewers grain are good sources of protein. Urea or non protein nitrogen (NPN) can be used upto 1 percent by weight of the total concentrate mixture. Rations containing NPN should be introduced gradually in the feeding schedule.

Some breeds of goat are kept in stalls and not allowed to graze, especially in and around cities. This is particularly true of the hybrids resulting from various cross breeding programs; the higher production potential of the animals means that they will be unable to meet their nutritional requirements by browsing poor types of vergetation. 
Table 49. Feeding goat kids upto 3 months old

\begin{tabular}{|c|c|c|c|c|c|}
\hline $\begin{array}{c}\text { Age } \\
(\text { days })\end{array}$ & $\begin{array}{c}\text { Body wt. } \\
(\mathrm{kg})\end{array}$ & $\begin{array}{l}\text { No. of } \\
\text { Feedings }\end{array}$ & $\begin{array}{c}\text { Dams milk } \\
\text { or } \\
\text { cow's milk }\end{array}$ & Green feed & $\begin{array}{l}\text { Creep } \\
\text { mixture } \\
(\mathrm{g})\end{array}$ \\
\hline $1-7$ & $1-3$ & with dam & 300 & - & - \\
\hline $8-30$ & $3-6$ & 3 & 350 & free choice & free choice \\
\hline $31-60$ & $6-9$ & 2 & 400 & $*$ & $100-150$ \\
\hline $60-90$ & $9-12$ & 2 & 200 & & $200-250$ \\
\hline
\end{tabular}

If the milk is bottle-fed, then it should be at the body temperature of the kids.

The size of adult goats is so variable, ranging from 25 to $75 \mathrm{~kg}$ according to the breed, that there is a wide variation in the birth weight of kids, which range from 1 to $5 \mathrm{~kg}$. To spare. the goat milk for human consumption and to get a faster growth it is necessary to provide them a balanced starter feed called a creep ration until the kids are 10 weeks old. They should be kept on these rations after separation from their dams after the first 4 to 7 days during which they received colostrum and milk. They are allowed restricted suckling 2 to 3 times a day or may be bottle-fed a definite milk allowance. Free choice legume hay, minerals and drinking water should be made available along with the starter ration. A few examples of preweaning rations calculated to supply about 12 to 18 percent DCP and 2.5 to $2.9 \mathrm{Mcal}$ per $\mathrm{kg}$ of feed have been given in Table 50 .

Table 50. Starter/Creep Feeds for Goats

\begin{tabular}{|l|c|c|c|c|c|c|c|}
\hline Feeds (\%) & \multicolumn{7}{|c|}{ Ration } \\
\cline { 2 - 7 } & I & II & III & IV & V & VI & VII \\
\hline Maize & 60 & 40 & 20 & 15 & - & 25 & 30 \\
Barley/oats & - & 23 & 45 & 40 & 40 & 40 & 30 \\
Groundnut cake & 20 & 20 & 20 & 20 & 22 & 10 & 10 \\
Fish meal & 10 & 10 & 10 & 10 & 10 & 10 & 10 \\
Molasses & - & - & - & 10 & 20 & -1 & 10 \\
Wheat bran & 7 & 7 & 2 & 3 & 5 & 12 & 7 \\
Mineral mixture & 2 & 2 & 2 & 2 & 2 & 2 & 2 \\
Salt & 1 & 1 & 1 & 1 & 1 & 1 & 1 \\
DCP & 18 & 17 & 17 & 17 & 17 & 12 & 12 \\
TDN & 78 & 77 & 75 & 71 & 70 & 72 & 70 \\
ME(Mcal/kg) & 2.9 & 2.9 & 2.9 & 2.6 & 2.5 & 2.7 & 2.7 \\
\hline
\end{tabular}


To each $100 \mathrm{~kg}$ of these creep mixtures add $150 \mathrm{~g} \mathrm{TM}-5$ or Aurofacs $25 \mathrm{~g}$ vitablend rovimix or 1 teaspoon of shark liver oil per kid per day.

Linseed cake, mustard cake or rape cake may be used to replace groundnut cake on equinitrogen basis. Millet or sorghum may be used to substitute $1 / 3$ rd of the maize, barley or oats.

Rice polish may be used to replace wheat bran on a weight to weight basis.

Under the above feeding regime, the kids may be expected to attain 3 to 4 times their birth weight, gaining at the rate of 60-80 $\mathrm{g}$ in small breeds and 100-120 $\mathrm{g}$ per day in the large breeds. At 60 days, when they are weaned they will weigh $6-12 \mathrm{~kg}$, depending on breed. The creep feeding will have sav $ə d$ about 0.5 liter (small goats) and 1 to 1.5 liter (large does) of the dam's milk per day for human consumption. After the 60th day, all milk produced is available for humans; in a 1 lactation period of 120 days, some 60 to $200 \mathrm{~kg}$ of milk can thus be saved.

The requirements of DCP and TDN for growing kids after weaning have been given elsewhere. A complete ration providing about $10 \%$ DCP and 62 to $65 \%$ TDN with 20 to $25 \%$ dry matter from good quality roughage will meet the requirements. Fodders containing less protein and energy are to be balanced with concentrate mixtures as shown in Table 51.

Table 51. Growers Concentrate Mixtures for Goats

\begin{tabular}{|c|c|c|c|c|c|c|c|c|c|c|c|}
\hline \multirow[t]{2}{*}{ Feeds $(\%)$} & \multicolumn{11}{|c|}{ Ration } \\
\hline & $I$ & II & III & IV & $\mathrm{V}$ & VI & VII & VIII & IX & $X$ & $X I$ \\
\hline maize & 50 & 30 & - & 30 & 12 & - & 20 & 15 & 201 & h 5 & 15 \\
\hline oats/barley & - & - & 50 & - & 15 & 20 & - & 10 & 20 & 15 & 15 \\
\hline gran & $\therefore$ & - & - & 30 & 25 & - & - & - & - & - & 10 \\
\hline cowpeas/lobia & - & - & - & - & - & - & - & 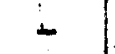 & 30 & 10 & - \\
\hline gingelly/sesame cake & $\cdots$ & $\therefore$ & - & - & - & 25 & $=$ & - & 10 & - & 10 \\
\hline linseed cake & & - & - & - & - & 15 & 15 & 10 & - & 10 & 10 \\
\hline mustard cake & - & - & - & - & - & - & 15 & 10 & - & 10 & - \\
\hline groundnut cake & 10 & 25 & 20 & - & 10 & - & - & 10 & 10 & 10 & 10 \\
\hline wheat bran & 30 & 42 & 20 & 30 & 25 & 27 & 25 & 15 & 7 & 10 & 20 \\
\hline rice polish & - & - & - & - & - & - & - & 15 & - & 10 & 5 \\
\hline gram husk & - & - & - & - & 5 & 7 & - & - & - & - & 2 \\
\hline common vetch & - & - & - & - & - & - & 10 & $10: 1$ & - & 5 & -1 \\
\hline molasses & 7 & - & 7 & 7 & 5 & 3 & 3 & 3 & - & 2 & -1 \\
\hline mineral mixture & 2 & 2 & 2 & 2 & 2 & 2 & 2 & 2 & 2 & 2 & 2 \\
\hline salt & 1 & 1 & $\perp$ & 1 & 1 & 1 & 1 & 1 & 1 & $1:$ & 7 \\
\hline
\end{tabular}


The normal expectation during the finishing period of goat breeding is for a one-third gain in body weight. Feeding during this period must be regularized according to market demands. Cereal-based energy rich feeds will be needed for fatty carcasses, while the roughage content should be about $20-25 \%$ of the dry matter for a fatty finish and 30-40\% for lean carcass production. A complete ration providing 5 to $6 \% \mathrm{DCF}$ and 60 to $65 \% \mathrm{TDN}$ is quite satisfactory. When the pasture and browse are poor and hay is being fed, the concentrates in the ration should be increased to about 600 grams. If kids are being marketed at weaning ( 4 to 5 months old), it is unnecessary to castrate them; if they are to be held over until yearlings, they can remain uncastrated until they are about 9 to 10 months old.

Most female kids and a few males are reared for breeding purposes. For them feeding is so adiusted that sexual maturity and body size are achieved at about one year of age and at 15 to $20 \mathrm{~kg}$ live weight in small breeds and 20 to $25 \mathrm{~kg}$ in large breeds. After weaning at $\&$ to $10 \mathrm{~kg}$ body weight, no supplementary feeding of concentrate is required on good pasture and browsing conditions. However, in lean periods, 250 to 500 grams of concentrate mixture providing 10 to $12 \% \mathrm{DCP}$ and 62 to $70 \%$ TDN may be required. This replacement stock should be kept growing and should be given adequate protein, minerals and vitanin $A$ in addition to good quality forage.

Breeding bucks should be fed at the rate of 3 to $3.5 \%$ of the live weight. Rations providing 4 to $6 \%$ DCP and 50 to $60 \%$ TDN, with sufficient minerals and vitamins will maintain normal health and fertility. Growing bucks may be given about 200 to 250 grams grains or concentrate mixture per head daily. A week or so before turning them out with the does, and throughout the breeding season, concentrate supplementation should be maintained at 150 to 250 grams per head daily.

On good ranges in spring, mature dry goats will consume enough feed to satisfy all their nutrient demands and no supplemental feeding is required, except minerals, especially salt and phosphorus. If the pasture and browsing is poor, about 100 grams concentrate mixture per head daily may be fed.

The last one third of the gestation period is an active time for the fetus ard about 70 to $80 \%$ gain in fetal mass is achieved. Under an inadequate feeding regine, the dam's body reserves will be depleted and structural components also mobilized to meet the increasing demands of the fast growing fetus. As a result, several. deficiency diseases of pregnancy become apparent, causing considerable monetary loss to the owner. Protein, calcium and phosphorus intake must therefore be increased during this period. A balanced ration containing 5 to $6 \%$ DCP and 55 to $60 \%$ TDN will be quite satisfactory; a free choice lick of mineral mixture will take care of the calcium and phosphorus supply. On good pasture/browsing, about 200 grams concentrate mixture per head daily may be fed. In milch breed rations a higher level of concentrate mixture, about 30 percent of the dry matter requirement, will sustain better milk

production. 
A good dairy doe will give on average $2.5 \mathrm{~kg}$ milk or more per day over a lactation period of 10 months. Superior breeds like. Angora and Spanish goats may give 4 to $5 \mathrm{~kg}$ or more. The following diets are recommended for high milk yields.

Table 52. Dairy Goat Feeding Guide

\begin{tabular}{|c|c|c|}
\hline $\begin{array}{l}\text { Age and stage } \\
\text { of production }\end{array}$ & Feed ingredients & Daily amount to be fed \\
\hline Birth to 3 days & Colostrum & Ad lib \\
\hline 3 days to 3 weeks & $\begin{array}{l}\text { Whole milk or replacer } \\
\text { Water and salt }\end{array}$ & $\begin{array}{l}1 \text { to } 2 \text { litres } \\
\text { Ad lib }\end{array}$ \\
\hline $\begin{array}{l}3 \text { weeks to } 4 \\
\text { months }\end{array}$ & $\begin{array}{l}\text { Whole milk or replacer } \\
\text { Creep feed } \\
\text { Alfalfa hay, water and salt }\end{array}$ & $\begin{array}{l}1 \text { to } 9 \text { litres upto } 8 \mathrm{w} \text {. } \\
\text { upto } 0.5 \mathrm{~kg} \text { per day } \\
\text { Ad lib }\end{array}$ \\
\hline $\begin{array}{l}4 \text { months } \\
\text { to } \\
\text { freshning }\end{array}$ & $\begin{array}{l}\text { High protein grain mixture } \\
\text { Alfalfa hay or pasture } \\
\text { Water and salt }\end{array}$ & $\begin{array}{l}\text { upto } 0.5 \mathrm{~kg} \text { per day } \\
\text { Ad lib } \\
\text { Ad lib }\end{array}$ \\
\hline Dry pregnant & $\begin{array}{l}\text { Grain mixture } \\
\text { Alfalfa hay or pasture }\end{array}$ & $\begin{array}{l}\text { upto } 0.5 \mathrm{~kg} \text { per day } \\
\text { Ad } \mathrm{lib}\end{array}$ \\
\hline Milking doe & $\begin{array}{l}\text { Grain mixture } \\
\text { Alfalfa hay } \\
\text { Water and salt }\end{array}$ & $\begin{array}{l}1 \mathrm{~kg} \text { for every } 2 \mathrm{~kg} \text { milk } \\
\text { Ad lib } \\
\text { Ad lib }\end{array}$ \\
\hline
\end{tabular}

In most cases, it is good practice to dry off dairy goats about six weeks prior to kidding. This gives the doe a brief rest from the heavy demands of lactation, enables her to meet the nutrient needs of the rapidly growing fetus and allows her to build the body reserves with which to meet the rigourous requirements of the lactation to follow. In the last six weeks of gestation, good pasture or good hay will maintain the pregnent doe. If the doe is thin, her ration can be supplemented with 200 to 600 grams of concentrate mixture, and minerals and vitamin $A$. Four to five days before kidding the grain allowance should reduced to half. Wheat bran can be substituted in order to. clear out the digestive tract to facilitate kidding.

When the doe is producing milk the following feeding schedules may be used as a guide.

$$
\text { 1. Clover or alfalfa hay }=1 \mathrm{~kg} \text { per day }
$$


Corn silage

Grain mixture

OR

2. Clover or alfalfa hay

Grain mixture
$=0.5$ to $1.0 \mathrm{~kg}$ per day

$=0 . t$ to $1 . \mathrm{p} \mathrm{kg}$ per day

$=$ about $1.5 \mathrm{~kg}$ per day

$=0.5$ to $1.0 \mathrm{~kg}$ per day

The grain mixture should be fed at the rate of $1 \mathrm{~kg}$ for every $2 \mathrm{~kg}$ milk produced.

Table 53. Rations for Lactating Dairy Goats

\begin{tabular}{|l|l|l|l|l|l|}
\hline Feeds (\%) & I & II & III & IV & V \\
\hline corn meal/mai ze meal & 40 & 30 & 20 & 10 & 30 \\
\hline ground oats & 20 & 20 & 30 & 10 & 20 \\
\hline linseed meal/cake & 10 & 10 & 10 & 15 & 10 \\
\hline cotton seed meal/cake & 5 & 10 & 10 & 15 & 10 \\
\hline wheat bran & 25 & 30 & 30 & 30 & 30 \\
\hline corn and cob meal & - & - & - & 20 & - \\
\hline fodder-free choice & alfalfa & alfalfa & $\begin{array}{l}\text { mixed } \\
\text { legume and } \\
\text { grass }\end{array}$ & $\begin{array}{l}\text { Iegume } \\
\text { and } \\
\text { grass }\end{array}$ & clover \\
\hline
\end{tabular}

Feeding the dairy kid. For the first 3 to 4 days, the new born kid should be fed colostrum from its mother. If the kid is to be raised without its mothers milk, it should be allowed to nurse for 3 or 4 days only or not at all. Generally the nipple bottle is preferred to pan feeding as it tends to be more natural, resulting in less injested air, After the kid is removed from colostrum feeding, it can be fed milk replacer along with a calf starter. The following points are pertinent to feeding.

-Cleanliness. The feeding utensils should be washed and sanitized

-Proper preparation of milk and milk replacers. The milk or milk replacers should be heated to about $39 \mathrm{C}^{\circ}$. A young kid will consume about half to one liter of milk 3 to 5 times daily. 
-Economics. If cow's milk is cheaper than goat's milk, it should be used. A suitable kid starter can be prepared by mixing 30 parts corn meal, 30 parts gound oats, 30 parts wheat bran and 10 parts of an oil cake/meal.

-Milk feeding. Milk feeding may be discontinued as soon as possible. The kid starter may be fed after 3 weeks of age. Fine quality hay may also be offered. The milk may be discontinued by the age of 3 to 4 months.

- Over feeding or under feeding. Feeding too much or too little should be avoided.

Feeding the dairy buck. The buck being larger than the doe will need more forage. Bucks should, in addition, receive half to one $\mathrm{kg}$ grains/grain mixture daily. Overweight bucks make ineffecient breeders, so it is important to have the buck in good physical condition. As the breeding season approaches, the amount of grain should be increased to help the buck prepare for this heavy production period. Exercise is a necessity to keep the herd buck healthy and sexually active. A $1: 1$ mixture of salt and dicalcium phosphate should be available free choice, as well as an abundent supply of water.

\subsection{Feeding poultry}

Eggs and poultry meat are important as protective foods in human nutrition. Eggs are an excellent source of protein, minerals and vitamins. They form an ideal di et because of their low sugar content, the high biological value of their proteins and the availability of iron for the formation of hemoglobin. Foultry meat is one of the most palatable and easily digestible of all meats.

Recent advances in poultry nutrition have brought about revolutionary changes in the poultry industry of many. countries, providing a means of livelihood to an increasing number of people. Nutrition is by far the most important single factor in the mocern poultry industry, as it accounts for 60-70\% of the cost of rearing. The feeding of poultry is complicated since, unlike ruminants, they require all the essential animo acids and vitamins of the $B$ complex group besides other organic and inorganic nutrients such as carbohydrates, lipids, proteins and minerals.

The nutrient requirement for growth, egg and broiler production, according to American and Indian standards, are given in Tables 54 through 56. 
Table 54. Energy, protein and amino acid requirements of chickens

\begin{tabular}{|c|c|c|c|c|c|c|}
\hline & Broiler & $\begin{array}{l}\text { Repl } \\
\text { egg }\end{array}$ & $\begin{array}{l}\text { lacement } \\
\text { or meat }\end{array}$ & $\begin{array}{l}t \text { pullet } \\
t \text { type }\end{array}$ & & $\begin{array}{l}\text { Laying } \\
\text { or Bree } \\
\text { ding He } \\
\text { ns } \text { 'egg } \\
\text { or meat }\end{array}$ \\
\hline & $\begin{array}{l}0-6 \\
\text { weeks }\end{array}$ & $\begin{array}{l}6-9 \\
\text { weeks }\end{array}$ & $\begin{array}{l}0-6 \\
\text { weeks }\end{array}$ & $\begin{array}{l}6-14 \\
\text { weeks }\end{array}$ & $\begin{array}{l}14-20 \\
\text { weeks }\end{array}$ & type \\
\hline $\begin{array}{l}\text { Metabolisable } \\
\text { Energy (Kcal/kg) }\end{array}$ & 3,200 & 3,200 & 2,900 & 2,900 & 2,900 & 2,850 \\
\hline Total protein $(\%)$ & 23 & 20 & 20 & 16 & 12 & 15 \\
\hline Calories/Protein Ratio & $139: 1$ & $160: 1$ & $137: 1$ & $158: 1$ & $190: 1$ & $190: 1$ \\
\hline Crude Fibre $\%$ & 4 & 4 & 5 & 8 & 10 & 10 \\
\hline$\frac{\text { Amino acids } \%}{\text { Arginine }}$ & 1.4 & 1.2 & 1.2 & 0.95 & 0.72 & 0.8 \\
\hline Glycine & 1.15 & 1.0 & 1.0 & 0.80 & $0.6 d$ & $?$ \\
\hline Histidine & $c .46$ & 0.4 & 0.4 & 0.32 & 0.24 & $?$ \\
\hline Isoleucine & 0.8 & 0.75 & 0.75 & 0.6 & 0.45 & 0.5 \\
\hline Leucine & 1.6 & 1.4 & 1.4 & 1.1 & 0.84 & 1.2 \\
\hline Lysine & 1.25 & 1.1 & 1.1 & 0.9 & 0.66 & 0.5 \\
\hline Methionine & 0.86 & 0.75 & 0.75 & 0.6 & 0.45 & 0.53 \\
\hline $\begin{array}{c}\text { or } \\
\text { Methionine }\end{array}$ & 0.46 & 0.40 & 0.40 & 0.32 & 0.24 & 0.28 \\
\hline $\begin{array}{l}\text { Plus } \\
\text { Cystine }\end{array}$ & 0.40 & 0.35 & 0.35 & 0.28 & 0.21 & 0.25 \\
\hline $\begin{array}{c}\text { Phenyl alanine } \\
\text { or }\end{array}$ & 1.50 & 1.3 & 1.3 & 1.05 & 0.78 & $?$ \\
\hline $\begin{array}{c}\text { Phenyl alanine } \\
\text { plus }\end{array}$ & 0.8 & 0.7 & 0.7 & 0.55 & 0.42 & $?$ \\
\hline Tyrosine & 0.7 & 0.6 & 0.6 & 0.50 & 0.36 & $?$ \\
\hline Threonine & 0.8 & 0.7 & 0.7 & 0.55 & 0.42 & 0.4 \\
\hline Tryptophan & 0.23 & 0.2 & 0.2 & 0.16 & 0.12 & 20.11 \\
\hline Valine & 1.00 & 0.85 & 0.85 & 0.70 & 0.50 & $?$ \\
\hline
\end{tabular}


Table 55. Vitamins, minerals, and linoleic acid requirements of chickens (In percent or amount per $\mathrm{kg}$ feed)

\begin{tabular}{|c|c|c|c|c|}
\hline Nutrients & $\begin{array}{l}\text { Starting } \\
\text { Chi ckens } \\
\text { (0-8 weeks) } \\
\end{array}$ & $\begin{array}{l}\text { Growing } \\
\text { Chickens } \\
\text { ('0-18 weeks) }\end{array}$ & $\begin{array}{l}\text { Laying } \\
\text { hens }\end{array}$ & $\begin{array}{c}\text { Breeding } \\
\text { hens }\end{array}$ \\
\hline $\begin{array}{l}\quad \text { Vitamins } \\
\text { Vitamin A or Provitamin A } \\
\text { activity (IU) }\end{array}$ & 1500 & 1500 & 4000 & 4000 \\
\hline Vitamin D (IDU) & 200 & 200 & 500 & 500 \\
\hline Vitamin $E(I U)$ & 10 & 5 & 5 & 10 \\
\hline Vitamin $\mathrm{K}(\mathrm{mg} / \mathrm{kg})$ & 0.53 & 0.5 & 0.5 & 0.5 \\
\hline Thiamine $(\mathrm{mg} / \mathrm{kg})$ & 1.8 & 1.3 & 0.8 & 0.8 \\
\hline Riboflavin $(\mathrm{mg} / \mathrm{kg})$ & 3.6 & 0.8 & 2.2 & 3.8 \\
\hline Pantothenic acid( $\mathrm{mg} / \mathrm{kg}$ ) & 10 & 10 & 2.2 & 10 \\
\hline $\mathrm{Ni} \operatorname{acin}(\mathrm{mg} / \mathrm{kg})$ & 27 & 11 & 10 & 10 \\
\hline Pyridoxine (mg/kg) & 3 & 3 & 3 & 4.5 \\
\hline Biotin $(\mathrm{mg} / \mathrm{kg})$ & 0.15 & 0.10 & 0.10 & 1.15 \\
\hline Choline (mg/kg) & 1300 & 500 & $500^{\circ}$ & 500 \\
\hline Folacin (starch diet) $(\mathrm{mg} / \mathrm{kg})$ & 1.2 & 0.25 & 0.25 & 0.35 \\
\hline Vitamin $\mathrm{B}_{12}(\mathrm{mg} / \mathrm{kg})$ & 0.009 & 0.003 & 0.00 & 0.003 \\
\hline Linoleic acid $\%$ & 1.0 & 0.8 & 1.0 & 1.0 \\
\hline Calci $\frac{\text { Minerals }}{u m}$ & 1.0 & 0.8 & 2.75 & 2.75 \\
\hline Phosphorus $\%$ & 0.7 & 0.4 & 0.6 & 0.6 \\
\hline Sodium $\%$ & 0.15 & 0.15 & 0.15 & 0.15 \\
\hline Potassium $\%$ & 0.2 & 0.16 & 0.1 & 0.1 \\
\hline Manganese $(\mathrm{mg} / \mathrm{kg})$ & 55 & 25 & 25 & 33 \\
\hline Iodine $(\mathrm{mg} / \mathrm{kg})$ & 0.35 & 0.35 & 0.30 & 0.30 \\
\hline Nagnesium (mg/kg) & 600 & 400 & 500 & 500 \\
\hline $\operatorname{Iron}(\mathrm{mg} / \mathrm{kg})$ & 80 & 40 & 50 & 80 \\
\hline Copper $(\mathrm{mg} / \mathrm{kg})$ & 4 & 3 & 3 & 4 \\
\hline Zinc $(\mathrm{mg} / \mathrm{kg})$ & 50 & 35 & 50 & 65 \\
\hline Selenium $(\mathrm{mg} / \mathrm{kg})$ & 0.1 & 0.1 & 0.1 & 0.1 \\
\hline
\end{tabular}


Table 56. Nutrient requirements for poultry (Indian Standards Institution)

\begin{tabular}{|c|c|c|c|c|c|}
\hline \multirow[b]{2}{*}{ Characteristics } & \multicolumn{5}{|c|}{ Requi rements for } \\
\hline & $\begin{array}{l}\text { Starter } \\
0-8 \\
\text { weeks }\end{array}$ & $\begin{array}{l}\text { Grower } \\
8-20 \\
\text { week }\end{array}$ & 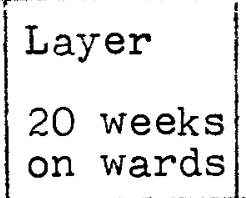 & $\begin{array}{l}\text { Broiler } \\
\text { starter } \\
0-6 \\
\text { weeks }\end{array}$ & $\begin{array}{l}\text { Broiler } \\
\text { Finisher } \\
6 \text { weeks to } \\
\text { market age }\end{array}$ \\
\hline Moisture $\%$ maximum & 10 & 10 & 10 & 10 & 10 \\
\hline Crude protein $\%$ minimum & 20 & 16 & 15 & 22 & 19 \\
\hline Crude fibre $\%$ maximum & 7 & 8 & 10 & 6 & 6 \\
\hline Crude fat $\sharp$ minimum & 3 & 3 & 3 & - & - \\
\hline Acid insoluble ash $\not$ maximum & 4 & 4 & 4 & 3.5 & 3.5 \\
\hline Calcium 7 minimum & $i$ & 1 & 2 & $1.0-1.2$ & $0.8-1: 0$ \\
\hline Available phosphorus $\not \circ$ minimum & 0.5 & 0.5 & 0.5 & 0.4 & 0.4 \\
\hline Lysine $\%$ minimum & 0.9 & 0.7 & 0.5 & - & - \\
\hline Methionine $\%$ minimum & 0.4 & 0.35 & 0.30 & - & - \\
\hline $\begin{array}{l}\text { Metabolisable energy } \mathrm{Kcal} / \mathrm{kg} \\
\text { minimum }\end{array}$ & 2640 & 2530 & 2740 & - & - \\
\hline Caloric/protein ratio & $134: 1$ & $158: 1$ & $182: 1$ & $135: 1$ & $165: 1$ \\
\hline Manganese $\mathrm{mg} / \mathrm{kg}$ & 55 & 55 & 55 & 60 & 60 \\
\hline Iodine $\mathrm{mg} / \mathrm{kg}$ & 1 & 1 & 1 & 1 & 1 \\
\hline Iron $\mathrm{mg} / \mathrm{kg}$ & 20 & 20 & 20 & 40 & 40 \\
\hline Copper $\mathrm{mg} / \mathrm{kg}$ & 2 & 2 & 2 & 4 & 4 \\
\hline Zinc $\mathrm{mg} / \mathrm{kg}$ & - & - & - & 50 & 50 \\
\hline Vitamin $\mathrm{A}(\mathrm{IU} / \mathrm{kg})$ & 4000 & 4000 & 8000 & 6000 & 6000 \\
\hline Vitamin $\mathrm{D}(\mathrm{ICU} / \mathrm{kg})$ & 600 & 600 & 1200 & 600 & 600 \\
\hline Thi amine $\mathrm{mg} / \mathrm{kg}$ & 6 & 6 & 6 & 2 & 2 \\
\hline Ribofavin $\mathrm{mg} / \mathrm{kg}$ & 5 & 5 & 5 & 5 & 5 \\
\hline Pantothenic acid $\mathrm{mg} / \mathrm{kg}$ & 10 & 10 & 15 & 12 & 12 \\
\hline Nicotinic acid $\mathrm{mg} / \mathrm{kg}$ & 20 & 20 & 20 & 40 & 40 \\
\hline Biotin $\mathrm{mg} / \mathrm{kg}$ & 0.1 & 0.1 & 0.15 & 0.1 & 0.1 \\
\hline Vitamin $\mathrm{B}_{12} \mathrm{mg} / \mathrm{kg}$ & 15 & 15 & 15 & 8 & 8 \\
\hline Alpha tocepherol $\mathrm{mg} / \mathrm{kg}$ & 10 & 10 & 10 & 20 & 20 \\
\hline Choline chloride $\mathrm{g} / \mathrm{kg}$ & - & - & - & 1.4 & 1.4 \\
\hline
\end{tabular}


The digestive system of the fowl is relatively much simpler and the process of digestion faster than in mammals. They swallow their food more or less whole, with the undigested residues being excreted in as little as 2 hours after the food leaves the crop. The entire intestine is emptied within 18 hours after a full meal, while the crop is emptied in 6-12 hours. of the species of poultry, namely the chicken, duck, goose and turkey, ducks appear to digest their food slightly better than chickens and turkey, whose digestibilities do not differ significantly. For example, ducks can digest fish scales which are not so well digested by chickens. Geese have a more efficient digestive system and the amylase activity is much greater than in any other species of poultry.

Maize, barley and wheat are good sources of energy for poultry. Yellow maize is preferred as it contains cryptoxanthine, a precursor of vitamin $A$, and xanthophyll a pigment which imparts a rich yellow colour to egg yolks. White maize. is usually not fed. Barley has a slightly higher fibre content and is less palatable than maize. Wheat is a good source of energy. Oat is not fed to poultry as it contains high amounts of fibre. Wheat and rice brans are palatable and good sources of iron, manganese and vitamin $B$ complex. Rice polishings is a very good source of energy and vitamins. Molasses is a good source of energy but its inclusion in poultry mashes has to be restricted to certain levels. Groundnut, cotton seed, sunflower, coconut and sesame cake are vegetable protein sources used in poultry mashes. When using cotton seed cake, care should be taken that it is free from gossypol, as levels above 0.04 percent of this substance in laying birds cause discclouration of egg yolk. Sesame cake is a good source of protein and is rich in arginine, methionine and tryptophan but low in lysine, cystine and glycine, while groundnut cake is the richest source of protein. Mustard cake can supply only part of the protein requirements, higher levels may be detrimental due to the presence of goitrogens, although $20 \%$ mistard cake can be used without any depressing effect on growth. Fish meal, meat meal and blood meal are the animal protein sources most used in poultry rations to make up the deficiencies of essential amino acids in vegetable proteins.

Compounded mineral mixtures and synthetic vitamin products like brewer's yeast and fish oils are used to supplement poultry diets. Antibiotic feed supplements (2-10 ppm) are capable of stimulating growth in young chicks.

The composition of mashes for starters, growers, layers and broilers are given in Tables 57 through 60. The composition of these mashes can be changed as per the availability of the the feed ingredient. While substituting any feed ingredient for the one given in the tables, the nutritive values should be more or less equal. 
Table 57. Chick Starter diets (0-8 weeks)

\begin{tabular}{|c|c|c|c|c|c|c|c|c|}
\hline \multirow[b]{2}{*}{ Ingredients } & \multicolumn{8}{|c|}{ Amounts in $\%$ by weight } \\
\hline & $I$ & II & III & IV & $\mathrm{V}$ & VI & VII & VIII \\
\hline Yellow maize & 42 & 10 & 20 & - & - & 25 & 25 & 10 \\
\hline Sorghum & - & 32 & 20 & 30 & 10 & - & - & - \\
\hline Barley & 10 & - & - & 10 & 42 & - & - & - \\
\hline Millet & - & 10 & - & 5 & - & - & - & 10 \\
\hline Wheat bran & 10 & 10 & 10 & 20 & - & 10 & 16 & 15 \\
\hline Rice polishings & - & 10 & 10 & - & - & 25 & 20 & 10 \\
\hline Groundnut cake(decorticated) & 25 & 20 & 25 & - & 30 & 20 & 20 & 15 \\
\hline Sesame cake & - & - & - & 20 & - & 10 & - & 10 \\
\hline Fish meal & 8 & 6 & 8 & - & - & - & - & 5 \\
\hline Meat meal & - & - & - & $\varepsilon$ & 6 & 5 & 5 & 5 \\
\hline Clover/Alfalfa meal & 3 & $=$ & - & - & 10 & 3 & 5 & 3 \\
\hline Brewers yeast & - & - & - & - & - & - & 2 & - \\
\hline Maize gluten meal & - & - & - & - & - & - & - & 10 \\
\hline Molasses & - & - & 5 & 5 & - & - & 5 & 5 \\
\hline Mineral mixture & 1.5 & 1.5 & 1.5 & 1.5 & 1.5 & 1.5 & 1.5 & 1.5 \\
\hline Salt & 0.5 & 0.5 & 0.5 & 0.5 & 0.5 & 0.5 & 0.5 & 0.5 \\
\hline Vitamin premix ${ }^{*}$ & - & - & - & - & - & - & - & - \\
\hline Antibiotics ${ }^{*}$ & - & - & - & - & - & - & - & - \\
\hline
\end{tabular}

* The mineral mixture consists of common salt (30), limestone $(40)$, steamed bone meal (28), manganese oxide ( 0.45$)$, ferrous carbonate $(0.45)$, potassium iodide $(0.02)$, starch $(0.10$, Sodium carbonate $(0.10)$, sodium thiosulphate $(0.10)$, zinc carbonate $(0.65)$ and copper hydroxide $(0.16)$ parts.

* The vitamin premix contains $0.1 \mathrm{~g}$ of vitamin $A$ acetate or $0.2 \mathrm{~g}$ vitamin $A$ palmitate ( $300,000 \mathrm{IU}), 0.1 \mathrm{~g}$ of vitamin $\mathrm{D}_{3}$
$(30,000 \mathrm{ICU})$ and $0.36 \mathrm{~g}$ of Riboflavin, mixed with starch to make up $100 \mathrm{~g}$. The premix may also include $50 \mathrm{~g}$ of either aureomycin or terramycin. 
Table 58. Pullet developer diets ( $8-10$ weeks)

\begin{tabular}{|l|c|c|c|c|c|c|c|c|}
\hline & \multicolumn{7}{|c|}{ Amounts in $\%$ by weight } \\
\cline { 2 - 7 } & I & II & III & IV & V & VI & VII & VII \\
\hline Yellow maize & 35 & IO & - & - & - & 20 & 30 & 30 \\
\hline Sorghum & - & 25 & 25 & - & - & 15 & 10 & - \\
\hline Barley & 15 & - & 18 & 25 & - & 15 & 10 & - \\
\hline Wheat bran & 10 & 15 & - & - & - & 10 & 5 & - \\
\hline Rice bran & - & - & 20 & - & - & - & 5 & 10 \\
\hline Rice Polishings & - & 20 & - & 20 & 40 & - & 5 & - \\
\hline Groundnut cake & 20 & 18 & - & 25 & 14 & 20 & 10 & 10 \\
\hline Sesame cake & - & - & 20 & 7 & - & - & 10 & 20 \\
\hline Fish meal & 6 & 5 & 10 & 6 & 8 & 4 & - & 5 \\
\hline Meat meal & 7 & - & - & - & - & 4 & 8 & 5 \\
\hline Broken gram & - & - & - & 10 & - & 5 & - & 10 \\
\hline Molasses & 5 & 5 & 5 & 5 & 8 & 5 & 5 & 8 \\
\hline Maize gluten & - & - & - & - & 25 & - & - & - \\
\hline Mineral mixture & 1.5 & 1.5 & 1.5 & 1.5 & 1.5 & 1.5 & 1.5 & 1.5 \\
\hline Salt & 0.5 & 0.5 & 0.5 & 0.5 & 0.5 & 0.5 & 0.5 & 0.5 \\
\hline Vitamin Premix & - & - & - & - & - & - & - & - \\
\hline Antibiotics & - & - & - & - & - & - & - & - \\
\hline
\end{tabular}


Table 59. Diets for layers and breeders

\begin{tabular}{|l|c|c|c|c|c|c|c|c|}
\hline & \multicolumn{7}{|c|}{ Amounts in \% by weight } \\
\hline Ingredients & I & II & III & IV & V & VI & VII & VIII \\
\hline Yellow maize & 35 & - & - & 10 & 45 & 25 & 20 & - \\
\hline Barley & 15 & - & - & - & - & 10 & - & 10 \\
\hline Sorghum & - & 30 & - & 15 & - & 10 & 10 & 10 \\
\hline Millet & - & - & 10 & 15 & - & - & 15 & 10 \\
\hline Ground nut cake & 20 & 20 & 15 & 15 & 15 & 10 & 10 & 15 \\
\hline Sesame cake & - & - & 10 & - & - & 5 & 5 & 5 \\
\hline Broken gram & - & - & 20 & - & - & 10 & 10 & - \\
\hline Wheat bran & 15 & - & - & 5 & - & 10 & - & 20 \\
\hline Rice Polishings & - & 30 & 25 & 20 & 20 & 10 & 10 & 10 \\
\hline Fish meal & 5 & - & 5 & 5 & 10 & - & 5 & 5 \\
\hline Meat Meat & - & 7 & - & 5 & - & 5 & 5 & 5 \\
\hline Lard & - & - & - & - & 2 & - & - & - \\
\hline Clover/Alfalfa meal & - & - & 2 & - & - & - & 2 & 2 \\
\hline Molasses & 3 & 5 & 5 & 2 & - & 2 & - & - \\
\hline Limestone (ground) & 5 & 5 & 5 & 5 & 5 & 5 & 5 & 5 \\
\hline Mineral Mixture & 2.4 & 2.4 & 2.4 & 2.4 & 2.4 & 2.4 & 2.4 & 2.4 \\
\hline Salt & 0.5 & 0.5 & 0.5 & 0.5 & 0.5 & 0.5 & 0.5 & 0.5 \\
\hline Vitamins and & 0.1 & 0.1 & 0.1 & 0.1 & 0.1 & 0.1 & 0.1 & 0.1 \\
antibiotics & & & & & & & 5 \\
\hline
\end{tabular}


Table 60. Diets for broilers (amounts in $\%$ by weight)

\begin{tabular}{|l|c|c|c|c|c|c|c|c|}
\hline & \multicolumn{2}{|c|}{ Starter 0-6 weeks } & \multicolumn{2}{|c|}{ Fini sher 6-9 weeks } \\
\cline { 2 - 8 } Ingredients & I & II & III & IV & I & II & III & IV \\
\hline Yellow maize & 60 & 20 & 10 & - & 64 & 20 & 10 & - \\
\hline Ground oats & - & - & 25 & - & - & - & 10 & 10 \\
\hline Ground barley & - & - & - & 20 & - & - & 10 & 12 \\
\hline Sorghum & - & 36 & 15 & 30 & - & 40 & 24 & 30 \\
\hline Groundnut cake & 10 & 20 & 27 & 15 & 7 & 15 & 15 & 15 \\
\hline Sesame cake & 10 & - & - & 5 & 7 & - & 5 & 5 \\
\hline Wheat bran & 6 & - & 6 & - & 10 & - & 10 & - \\
\hline Rice polishings & - & 10 & - & 6 & - & 15 & - & 10 \\
\hline Fish meal & 4 & 11 & 10 & 8 & 4 & 7 & 8 & 10 \\
\hline Meat meal & 7 & - & - & 4 & 5 & - & - & - \\
\hline Clover/Alfalfa & - & - & - & 4 & - & - & - & 5 \\
\hline Molasses & - & - & 4 & 5 & - & - & 5 & - \\
\hline Mineral mixture & 2.4 & 2.4 & 2.4 & 2.4 & 2.4 & 2.4 & 2.4 & 2.4 \\
\hline Salt & 0.5 & 0.5 & 0.5 & 0.5 & 0.5 & 0.5 & 0.5 & 0.5 \\
\hline Vitamin premix & 0.1 & 0.1 & 0.1 & 0.1 & 0.1 & 0.1 & 0.1 & 0.1 \\
and Antibiotics & & & & & & & & \\
\hline
\end{tabular}

The mineral mixture, vitamin premix and antibiotic supplement in Tables 58, 59 and 60 are as specified for the chick starters (Table 57): 
Table 61. Feed Required by Chickens of Different Live Weights for Maintenance and for Production per Year

\begin{tabular}{|l|c|c|c|c|}
\hline $\begin{array}{l}\text { Average live } \\
\text { weight (kg) }\end{array}$ & \multicolumn{4}{|c|}{$\begin{array}{c}\text { Average total feed (kg) required per bird per } \\
\text { year } \\
\text { for maint enance and production of } \\
\text { indicated numbers of eggs }\end{array}$} \\
\cline { 2 - 5 } & 0 Eggs & 100 Eggs & 200 Eggs & 300 Eggs \\
\hline 1.36 & 21.5 & 28.0 & 34.0 & 40.5 \\
1.59 & 23.5 & 30.5 & 36.5 & 43.0 \\
1.81 & 25.5 & 32.5 & 38.5 & 45.0 \\
2.04 & 27.5 & 34.0 & 40.5 & 47.0 \\
2.27 & 29.5 & 36.0 & 42.5 & 49.0 \\
2.50 & 31.5 & 38.0 & 44.5 & 51.0 \\
2.73 & 33.5 & 40.0 & 46.5 & 52.5 \\
2.95 & 35.5 & 42.0 & 48.0 & 54.5 \\
3.91 & 37.0 & 43.5 & 50.0 & 56.5 \\
\hline
\end{tabular}

Table 62. Feed required and time required to obtain certain average live weights with common breeds of chickens

\begin{tabular}{|c|c|c|c|c|c|c|c|c|}
\hline \multirow{3}{*}{$\begin{array}{c}\text { Av live } \\
\text { weight } \\
\mathrm{kg}\end{array}$} & \multicolumn{8}{|c|}{$\begin{array}{c}\text { Kind of chickens and quantity of Kind of chickens and age at } \\
\text { feed required } \\
\text { whi ch certain live weights } \\
\text { are reached }\end{array}$} \\
\hline & \multicolumn{2}{|c|}{ White leghorns } & \multicolumn{2}{|c|}{ Broiler Strains } & \multicolumn{2}{|c|}{ White I eghorns } & \multicolumn{2}{|c|}{ Broiler Strains } \\
\hline & $\begin{array}{c}\begin{array}{c}\text { Females } \\
\mathrm{kg}\end{array} \\
\end{array}$ & $\begin{array}{c}\text { Males } \\
\mathrm{kg} \\
\end{array}$ & $\begin{array}{c}\begin{array}{c}\text { Females } \\
\mathrm{kg}\end{array} \\
\end{array}$ & $\mathrm{kg}$ & es & & $\begin{array}{c}\text { Females } \\
\text { wk }\end{array}$ & $\begin{array}{l}\text { Males } \\
\text { wk }\end{array}$ \\
\hline $\begin{array}{l}0.25 \\
0.5 \\
0.75 \\
1.0 \\
1.25 \\
1.5 \\
1.75 \\
2.0\end{array}$ & $\begin{array}{l}0.5 \\
1.15 \\
1.85 \\
2.65 \\
3.8 \\
5.3 \\
8.2 \\
- \\
\end{array}$ & $\begin{array}{l}0.45 \\
1.0 \\
1.6 \\
2.35 \\
3.15 \\
4.1 \\
5.3\end{array}$ & $\begin{array}{l}0.85 \\
1.35 \\
2.0 \\
2.7 \\
3.5 \\
4.4 \\
5.4 \\
\end{array}$ & $\mid \begin{array}{l}0 \\
1 \\
1 \\
2 \\
3 \\
3 \\
4\end{array}$ & $\begin{array}{r}3.2 \\
5.8 \\
8.2 \\
10.6 \\
13.3 \\
16.4 \\
19.8\end{array}$ & $\begin{array}{r}2.9 \\
5.0 \\
6.8 \\
8.3 \\
9.7 \\
11.3 \\
13.0\end{array}$ & $\begin{array}{r}2.4 \\
3.8 \\
5.0 \\
6.0 \\
7.0 \\
8.0 \\
9.0 \\
10.4\end{array}$ & $\begin{array}{l}2.0 \\
3.6 \\
4.4 \\
5.3 \\
6.0 \\
6.9 \\
7.9 \\
8.5 \\
\end{array}$ \\
\hline
\end{tabular}

Source: NRC, 1971. 
Table 64. Mineral, vitamin and linoleic acid requirements of Turkey rations' (in $\%$ age or amount per kilogram of ration)

\begin{tabular}{|c|c|c|c|c|}
\hline Nutrient & $\begin{array}{l}\text { Moisture Basis } \\
\text { (As-fed=est. } \\
\text { dd\% dry } \\
\text { matter.M-F=. } \\
\text { moisture- } \\
\text { free) }\end{array}$ & $\mid \begin{array}{l}\text { Starting } \\
\text { Poults } \\
(0-8 \\
\text { weeks })\end{array}$ & $\begin{array}{l}\text { Growing } \\
\text { Turkeys } \\
\text { ( } 8 \text { weeks } \\
\text { to market } \\
\text { or prebre- } \\
\text { eding) } \\
\end{array}$ & $\begin{array}{l}\text { Breeding } \\
\text { Turkeys }\end{array}$ \\
\hline $\begin{array}{l}\text { MINERALS } \\
\text { Macro mi }\end{array}$ & , & $(\mathrm{kg})$ & $(\mathrm{kg})$ & $(\mathrm{kg})$ \\
\hline 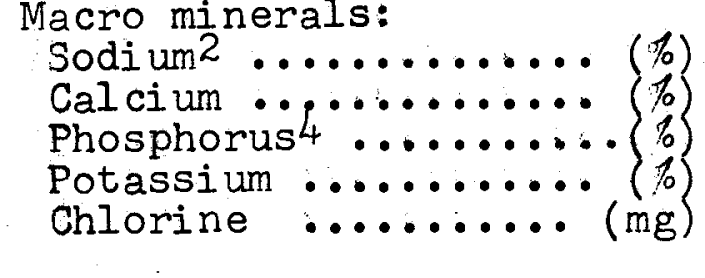 & $\begin{array}{l}\text { As-fed } \\
M-F\end{array}$ & $\begin{array}{l}0.15 \\
1.2 \\
0.8 \\
0.4 \\
\frac{800}{911}\end{array}$ & $\begin{array}{r}0.15 \\
0.8 \\
0.7 \\
0.4 \\
\frac{800}{911}\end{array}$ & $\begin{array}{l}0 . \\
\frac{0.0}{200} \\
211\end{array}$ \\
\hline $\begin{array}{l}\text { Magnesi um } \ldots \ldots \ldots \ldots(m g) \\
\text { Micro minerais: }\end{array}$ & As-fed & 500 & $\frac{500}{568}$ & $\begin{array}{ll}211 \\
500 \\
560\end{array}$ \\
\hline $\begin{array}{l}\text { Mi cro minerals: } \\
\text { Copper } \ldots \ldots \ldots \ldots \ldots(\mathrm{mg})\end{array}$ & $\begin{array}{c}M-F \\
A s-f e d \\
M-F\end{array}$ & $\begin{array}{l}568 \\
6 \\
6.8\end{array}$ & $\frac{568}{4}$ & 6 \\
\hline Iodine $\ldots . . . . . . . .$. (mg) & $\begin{array}{l}A s-f e d \\
M-F\end{array}$ & $\frac{0.4}{0.44}$ & & \\
\hline Iron $\ldots \ldots \ldots \ldots \ldots(\mathrm{mg})$ & $\begin{array}{l}A s-f \text { ed } \\
M-F\end{array}$ & $\begin{array}{l}60 \\
67\end{array}$ & 40 & \\
\hline Manganese ...........(mg) & $\begin{array}{l}\text { As }-f e d \\
M-F\end{array}$ & $\begin{array}{l}55 \\
62\end{array}$ & $\frac{24}{25}$ & \\
\hline Seleni um .......... (mg) & $\begin{array}{l}A s-f e d \\
M-F\end{array}$ & $\begin{array}{l}0.2 \\
0.22\end{array}$ & & \\
\hline $\operatorname{Zinc} \ldots \ldots \ldots \ldots \ldots(\mathrm{mg})$ & $\begin{array}{l}A s-f e d \\
M-F\end{array}$ & $\begin{array}{l}75 \\
86\end{array}$ & $\frac{40}{45}$ & \\
\hline $\begin{array}{l}\text { VI TAMINS } \\
\text { Fat-soluble: } \\
\text { Vitamin A activity } 5 \ldots \text { (IU) }\end{array}$ & & 4,000 & & \\
\hline Vitamin $D^{6} \ldots \ldots \ldots \ldots$ (ICU) & $\begin{array}{l}\mathrm{M}-\mathrm{-} \\
\mathrm{As}-\end{array}$ & $\begin{array}{r}4,545 \\
900\end{array}$ & & \\
\hline Vitamin $E \ldots \ldots \ldots \ldots$ (IU) & As & $\begin{array}{l}023 \\
12 \\
11\end{array}$ & $\frac{10}{15}$ & 25 \\
\hline $\begin{array}{l}\text { Vitamin } K_{1} \ldots \ldots \ldots(m g) \\
\text { Water-soluble: } \\
\text { Vitamin } B_{12} \ldots \ldots \ldots(m)\end{array}$ & $\begin{array}{l}A s-f \text { ed } \\
M-F \\
A s-f \text { ed } \\
M-F\end{array}$ & $\begin{array}{l}\frac{14}{1} .12 \\
0.003 \\
0.003\end{array}$ & 63 & $\frac{1}{7}$ \\
\hline Biotin ..............(mg) & $\begin{array}{l}\text { As-fed } \\
M-F\end{array}$ & $\begin{array}{l}0.2 \\
0.22\end{array}$ & & \\
\hline Choline .............. (mg) & $\begin{array}{l}A s-f \text { ed } \\
M-F\end{array}$ & 00 & & $\frac{00}{35}$ \\
\hline Folacin(folic acid)...(mg) & $A s-f$ ed & 1 & $\mathrm{O}_{2}$ & \\
\hline Niacin(ni cotini $c$ acid). $(m g)$ & As-fed & $\begin{array}{l}70 \\
79\end{array}$ & $\frac{50}{57}$ & \\
\hline Pantothenic acid $\ldots$. (mg) & $\begin{array}{l}A s-f e d \\
M-F\end{array}$ & i1 12.5 & 10. & 18 \\
\hline Pyridoxine $\left(B_{6}\right) \quad \ldots \ldots$ (mg) & $\begin{array}{l}A s-f \text { ed } \\
M-F\end{array}$ & 4.5 & & \\
\hline Ri boflavin( $\left.B_{2}\right) \ldots \ldots(m g)$ & $\begin{array}{l}A s-f e d \\
M-F\end{array}$ & 3.6 & & \\
\hline $\begin{array}{r}\text { Thiamin }\left(B_{1}\right) \ldots \ldots \ldots \ldots(m g) \\
\text { Essential fatty acid: } \\
\text { Linoleic acid } \ldots \ldots \ldots(\%)\end{array}$ & $\begin{array}{l}A s-f \text { ed } \\
M-F\end{array}$ & $\begin{array}{l}2 \\
2 \cdot 2 \\
1\end{array}$ & 1 & \\
\hline
\end{tabular}


$1_{\text {Adapted from Nutrient Requirements of Poultry, No, } 1.7 \text { th }}$ rev.ed., NRC National Academy of Sciences, 1977,p. 31. Table 5. These figures are estimates of requirements and include no margins of safety. Values underlined are estimates.

2 Equivalent to $0.37 \%$ of sodium chloride.

3 This amount of calcium need not be incorporated in the mixed feed because calcium supplements fed free-choice are considered part of the ration.

4 At least $0.5 \%$ of the total feed of starting poults should be inorganic phosphorus. All the phosphorus of nonplant feed ingredients is considered to be inorgainc. Approximately $30 \%$ of the phosphorus of plant products is nonphytin phosphorus and may be considered part of the inorganic phosphorus required. Fresumably, a portion of the requirement of growing and breeding turkeys must also be furnished norganic form.

5 May be vitamin A or provitamin A.

6 These levels of vitamin $D$ are satisfactory when levels of calcium and readily available phosphorus conform to this table.

The feed requirements and the time required to obtain certain average live weights of larg-type turkeys, including sex differences is given in Table 65.

Table 65. Growth rate and feed consumption of large-type turkeys ${ }^{*}$ $(m=$ male, $f=$ femal $)$

\begin{tabular}{|c|c|c|c|c|c|c|}
\hline \multirow{2}{*}{$\begin{array}{l}\text { Age } \\
\text { (weeks) }\end{array}$} & \multicolumn{2}{|c|}{ Body weight } & \multicolumn{2}{|c|}{$\begin{array}{l}\text { Feed Consumption } \\
\text { by } 2 \text {-Week Periods }\end{array}$} & \multicolumn{2}{|c|}{$\begin{array}{l}\text { Cumulative } \\
\text { Feed Consumption }\end{array}$} \\
\hline & $\mathrm{m}$ & $f$ & $\mathrm{~m}$ & $f$ & $\mathrm{~m}$ & $f$ \\
\hline & $(\mathrm{kg})$ & $(\mathrm{kg})$ & $(\mathrm{kg})$ & $(\mathrm{kg})$ & $(\mathrm{kg})$ & $(\mathrm{kg})$ \\
\hline $\begin{array}{r}2 \\
4 \\
6 \\
8 \\
10 \\
12 \\
14 \\
16 \\
18 \\
20 \\
22 \\
24 \\
26 \\
28\end{array}$ & $\begin{array}{r}0.3 \\
0.8 \\
1.7 \\
2.9 \\
4.3 \\
5.7 \\
7.0 \\
8.3 \\
9.7 \\
11.0 \\
12.3 \\
13.7 \\
14.9 \\
16.0\end{array}$ & $\begin{array}{c}0.2 \\
0.6 \\
1.5 \\
2.5 \\
3.4 \\
4.4 \\
5.3 \\
5.9 \\
6.6 \\
7.2 \\
7.6 \\
8.0 \\
- \\
-\end{array}$ & $\begin{array}{r}0.3 \\
0.8 \\
1.7 \\
2.1 \\
2.9 \\
1.6 \\
4.7 \\
4.6 \\
6.4 \\
6.0 \\
5.2 \\
6.8 \\
8.5 \\
10.5\end{array}$ & $\begin{array}{c}0.2 \\
0.7 \\
1.6 \\
1.9 \\
2: 8 \\
2.5 \\
3.1 \\
3.3 \\
3.6 \\
3: 3 \\
3.7 \\
3: 0 \\
- \\
-\end{array}$ & $\begin{array}{r}0.3 \\
1.1 \\
2.8 \\
4.9 \\
7.8 \\
11.4 \\
16.1 \\
20.7 \\
27.1 \\
33.1 \\
38.3 \\
45.1 \\
53.6 \\
64.1\end{array}$ & $\begin{array}{c}0.2 \\
0.9 \\
2.5 \\
4.4 \\
7.2 \\
9.7 \\
12.8 \\
16.1 \\
19.7 \\
23.0 \\
26.7 \\
29.7 \\
- \\
-\end{array}$ \\
\hline
\end{tabular}

* From "Nutrient Requirements of Poultry," No: 1,7th rev.ed., N National Academy of Sciences 1977 , p.41, Table 16. 
Turkeys grow faster than chickens and consequently have relatively higher feed and protein requirements, Young turkeys use feed efficiently. They require about 3 to $4 \mathrm{~kg}$ feed to produce $1 \mathrm{~kg}$
live weight when grown to their market weight of about 13 to $14 \mathrm{~kg}$ at 24 weeks of age. Good ranges provide green feed and reduce costs. The University of Minnesota has suggested several turkey rations, given below in Tables 66, 67 and 68 .

Table 66. Flexible formula starter and grower turkey rations ${ }^{1}$

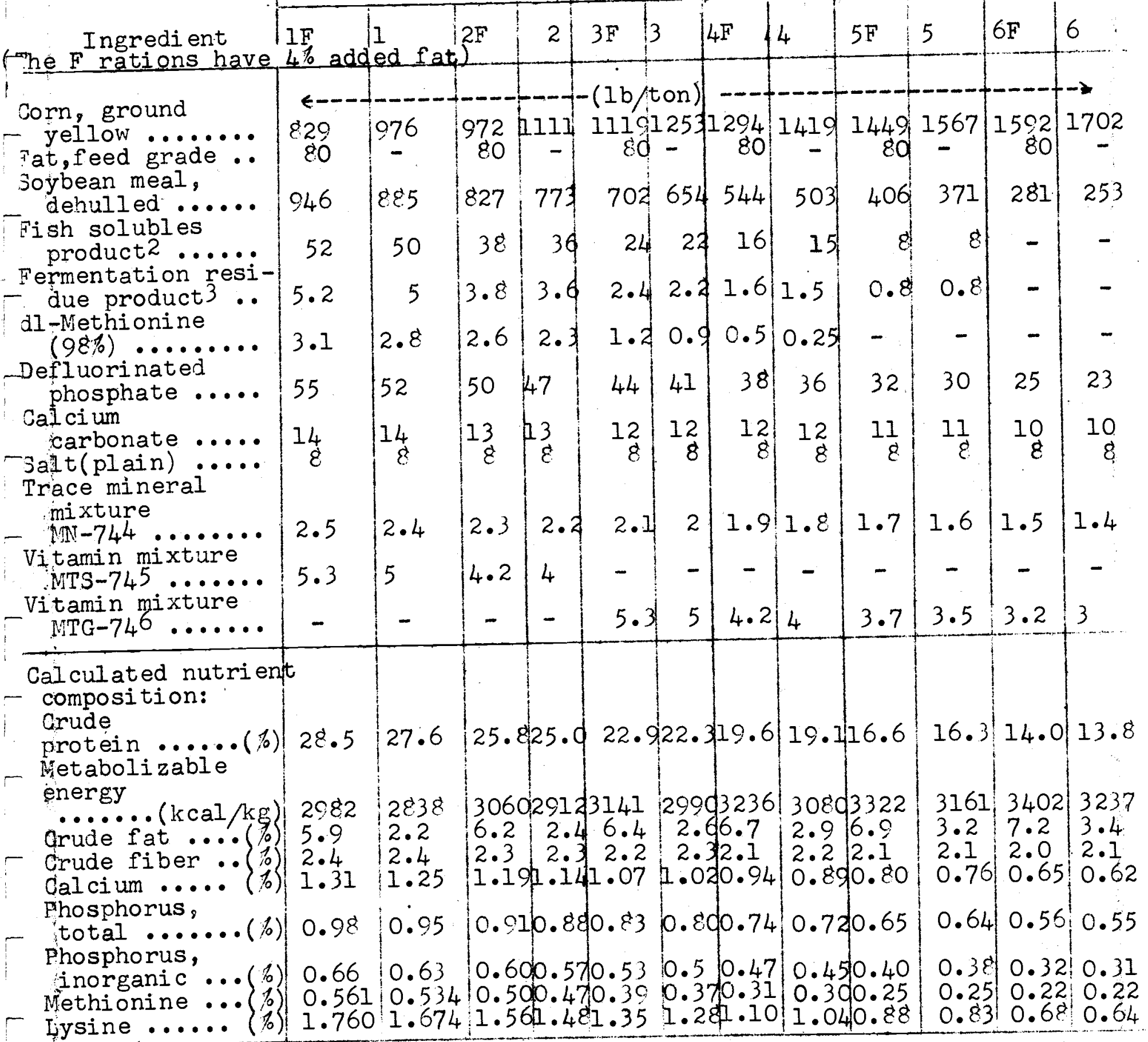


$1_{\text {Suggested rations courtesy of the University of Minnesota. }}$ Does not include antibiotics, medicinal drugs, or optional selenium supplementation.

2 Fish solubles product is fish solubles dried on soybean meal at $100 \%$ equivalence( $52 \%$ protein).

3 Fermentation residue products e.g. Fermacto-500(Bordon). Biofac (Thompson-Hayward).

4Mineral mix. iron, $2.0 \%$ manganese, $6.0 \%$, zinc, $6.0 \%$ iodine, $0.12 \%$.

5MTS-74: vitamin A acetate, 2,000,000 IU/1b, vitamin $D_{3}$,

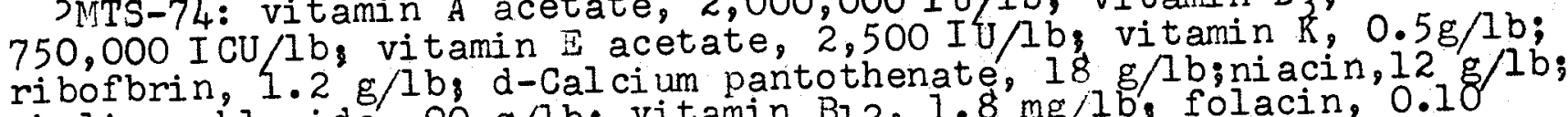
choline chloride, $90 \mathrm{~g} / 1 \mathrm{~b}$, vitamin $\mathrm{B} 12,1.8 \mathrm{mg} / 1 \mathrm{~b}$, folacin, 0.10 $\mathrm{g} / \mathrm{lb}$; pyridoxine, $0.25 \mathrm{~g} / \mathrm{lb}$; biotin, $10 \mathrm{mg} / \mathrm{lb}$.

6 MTG-74: vitamin A acetate, $1,500,0001 U / 1$ b; vitamin $D_{3}$,

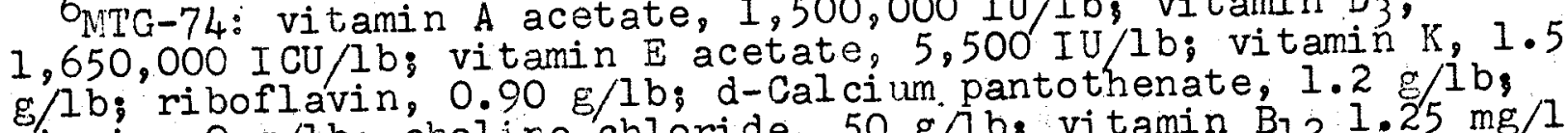
niacin, $9 \mathrm{~g} / \mathrm{lb}$; choline chloride, $50 \mathrm{~g} / \mathrm{lb}$, vitamin $B_{12} 1.25 \mathrm{mg} / \mathrm{lb}$.

Table 67. Ration Guide for feeding large and medium turkeys ${ }^{1}$

\begin{tabular}{|c|c|c|c|c|c|}
\hline \multirow{2}{*}{\multicolumn{2}{|c|}{$\begin{aligned} \text { Ration Identification Number } & \text { (in Table 66) }\end{aligned}$}} & \multicolumn{2}{|c|}{ Large } & \multicolumn{2}{|c|}{ Medium } \\
\hline & & Males & Females & Males & Females \\
\hline $\begin{array}{l}1 F \\
2 F \\
3 F \\
4 F \\
5 F \\
6 F\end{array}$ & 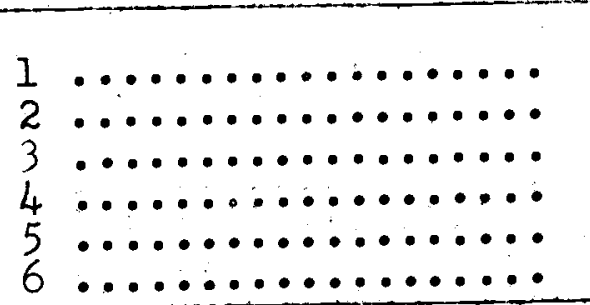 & $\begin{array}{l}4--- \\
0-4 \\
5-8 \\
9-12 \\
13-16 \\
17-20 \\
21-\end{array}$ & $\begin{array}{c}-- \text { - age } \\
0-4 \\
5-8 \\
9-11 \\
12-14 \\
15-17 \\
18-\end{array}$ & $\begin{array}{l}\text { in week } \\
0-4 \\
5-8 \\
0-12 \\
13-15 \\
16-17 \\
18-\end{array}$ & \begin{tabular}{|l}
$0-4$ \\
$0-4$ \\
$5-8$ \\
$9-11$ \\
$12-14$ \\
$15-16$ \\
$17-$
\end{tabular} \\
\hline
\end{tabular}

$l_{\text {Current recommendations of the University of Minnesota. }}$ 
Table 68. Complete turkey holding and breeding diets ${ }^{1}$

\section{Ingredi ant}

Corn, ground vellow.

Oats, ground Wheat standard middi ings .............. Soybean meal, solvent $(44,0) \ldots \ldots \ldots \ldots$. Fish solubles, carrier dried $2 \ldots \ldots \ldots \ldots$ Whey, dried whole or partially delactosed Alfalfa meal ( $17 \%$ dehy) . $\ldots j \mathrm{j} j \ldots \ldots \ldots$ Dicalci um phosphate, (min.i \&\%p) $\ldots \ldots \ldots$ Cal ci um carbonate, $(\min .38 \% \mathrm{Ca}) \quad \ldots \ldots \ldots$ Salt, iodized $\ldots \ldots \ldots \ldots \ldots \ldots \ldots$ Manganese sulfate $(27 \% \mathrm{Mn}) \quad \ldots \ldots \ldots \ldots \ldots$ Zinc oxide $(72 \% \mathrm{Zn}) \ldots \ldots \ldots \ldots \ldots \ldots \ldots$

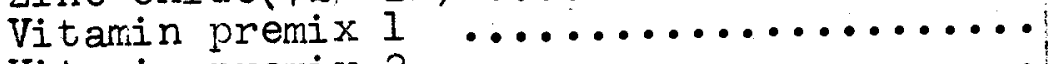
Vitamin premix $2 \quad \ldots \ldots \ldots \ldots \ldots \ldots \ldots \ldots$ Total

\section{Calculated nutrient composition:}

Crude protein $\ldots \ldots \ldots \ldots \ldots \ldots \ldots \ldots \ldots$ (kcal $/ \%)$
Metabolizable energy $\ldots \ldots \ldots \ldots$ (kal

Calorie-protein ratio

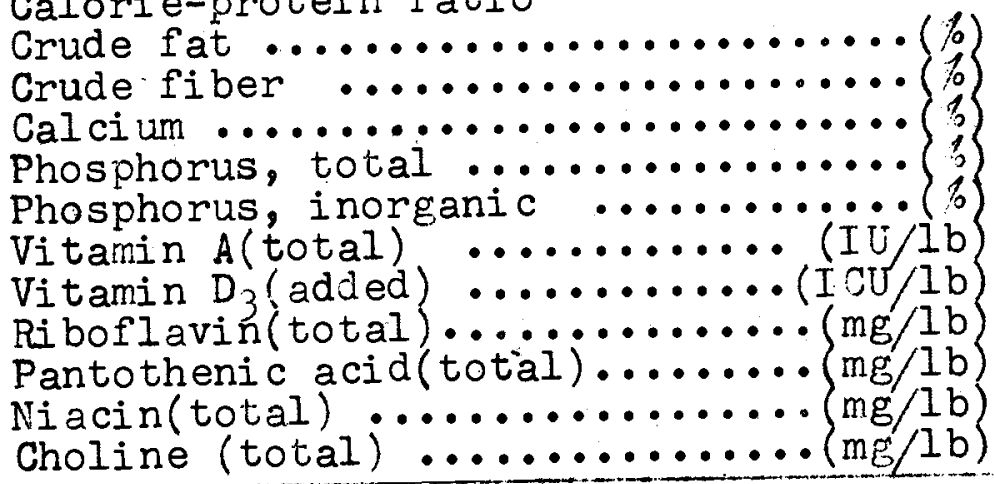

Composition of Premixes

Vitamin $\mathrm{A}(30,000 \mathrm{IU} / \mathrm{g})$

Vitamin D $\{15,000 I \mathrm{CU} / \mathrm{g}\}$

Vitamin $\mathrm{K}(16 \mathrm{~g} / \mathrm{lb})$

Riboflavin ( $16 \mathrm{~g} / 1 \mathrm{~b}) \ldots \ldots \ldots \ldots \ldots \ldots$ d-Calcium pantothenate $(32 \mathrm{~g} / \mathrm{lb}) . . . \ldots \ldots$

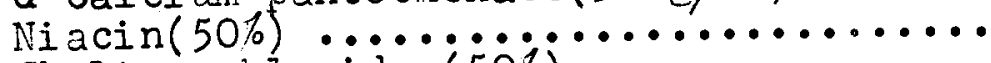

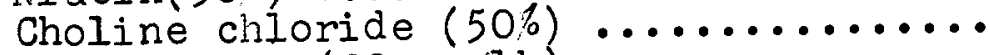
Vitamin $B_{12}(20 \mathrm{mg} / \mathrm{lb})$ Folic acid $(3 \%)$ Ethoxyquin Carrier

Total

\begin{tabular}{|c|c|c|}
\hline \multicolumn{3}{|c|}{ Holding } \\
\hline Ration 1 & Ration 2 & Breeding \\
\hline $\begin{array}{c}-1,535 \\
- \\
- \\
310 \\
20 \\
20 \\
60 \\
25 \\
20 \\
8 \\
0.40 \\
0.15 \\
4.0 \\
- \\
2,002.6\end{array}$ & $\begin{array}{c}\text { per ton)- } \\
1,200 \\
200 \\
100 \\
220 \\
20 \\
20 \\
100 \\
25 \\
15 \\
8 \\
0.40 \\
0.15 \\
4.0 \\
- \\
2,002.6\end{array}$ & $\begin{array}{c}1,322 \\
- \\
380 \\
50 \\
50 \\
60 \\
35 \\
90 \\
8 \\
0.60 \\
0.20 \\
\overline{5.0} \\
2,002.8\end{array}$ \\
\hline $\begin{array}{c}14.7 \\
1,346 \\
91.6 \\
3.25 \\
3.22 \\
0.81 \\
0.59 \\
0.35 \\
4,566 \\
640 \\
2.61 \\
5.50 \\
25.3 \\
458\end{array}$ & $\begin{array}{c}14.0 \\
1,288 \\
91.7 \\
3.51 \\
4.63 \\
0.82 \\
0.60 \\
0.35 \\
5,640 \\
640 \\
2.71 \\
6.52 \\
26.5 \\
453\end{array}$ & $\begin{array}{c}16.3 \\
1,252 \\
76.6 \\
2.92 \\
3.26 \\
2.27 \\
0.62 \\
0.44 \\
6,460 \\
1,000 \\
4.32 \\
10.33 \\
24.7 \\
516\end{array}$ \\
\hline
\end{tabular}

Identification

Vitamin Premix I Vitamin Premix2 $\rightarrow-(\mathrm{g}$ per $1 \mathrm{~b})-\cdots$

\begin{tabular}{r|r}
33.3 & 53.3 \\
21.3 & 26.7 \\
18.2 & 90.8 \\
8.5 & 11.4 \\
22.7 & 34.0 \\
14.2 & 34.0 \\
14.0 & 10.0 \\
60.0 & 40.0 \\
27.2 & 54.5 \\
0.0 & 6.7 \\
2.0 & 4.0 \\
232.6 & 88.6 \\
\hline 454.0 & 454.0
\end{tabular}

ISuggested rations courtesy of the University of Minnesota.

2 Fish solubles product is condensed and dried on soybean meal ( $54 \%$ protein). Other products may be used, providing the fish solubles equivalence is maintained. 


\section{Ducks and Geese}

The nutritive requirements of ducks and geese are given in table 69. Table 69. Nutrient requirments of duck and geese rations ${ }^{1}$ (In\% age or amount per $\mathrm{kg}$ of ration)

Nutrient

Netabolizable

energy

Protein

AMINO ACIDS

Lysine $\ldots \ldots \ldots \ldots(\%)$

MINERALS

Macro minerals:

Sodi um

Calcium ...................

Phosphorus ......... (1)

Magnesium

$\cdots$

Mi cro mineral:

Manganese

\section{- VITAMINS}

Fat-soluble:

Vitamin A(carotene) (IU)

Vitamin D

( I GU)

Water-soluble:

Niacin(nicotinic

$$
\text { acid) .....(mg) }
$$

Pantothenic acid ...(mg)

Pyridoxine $\left(\mathrm{B}_{6}\right) \ldots . .(\mathrm{mg})$

Riboflavin $\left(B_{2}\right) \ldots(m g)$

Moisture
Basis( As-
ed=est.
ed dry dry
matter.
M-F=mois-
ture-free)

As-fed

$\mathrm{M}-\mathrm{F}$

As-fed

$M-F$

As-fed

$\mathrm{M}-\mathrm{F}$

As-fed

$M-F$

As-fed

$M-F$

As-fed

$M-F$

As-fed

$M-F$

As-fed

$\mathrm{M}-\mathrm{F}$

As-fed $M-F$

\begin{tabular}{|c|c|}
\hline \multicolumn{2}{|c|}{ Ducks } \\
\hline 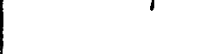 & \\
\hline $\begin{array}{l}\text { 3tarting } \\
\text { and } \\
\text { Growing }\end{array}$ & Breeding \\
\hline
\end{tabular}

Geese

(kg)

(kg)

2,900

3,293

$\frac{0.9}{\frac{8}{9}}$

2,900

3,293

$\frac{0.75}{5.5}$

$\frac{5.5}{6.0}$

0.15

0.6

0.6

500

$\underline{565}$

40

45

$\frac{11.4}{12.9} \frac{25}{28}$

$\frac{0.15}{\frac{2.75}{0.6}}$

500

$\underline{565}$

$\frac{\frac{4,000}{4,544}}{500}$

$\frac{\frac{4,000}{4,544}}{\frac{500}{565}}$

$\underline{0.8}$

$\underline{0.6}$

$\frac{2.25}{0.6}$

Bree-

ding

\begin{tabular}{l|c}
$0-6$ & Growing \\
weeks) & after \\
weeks)
\end{tabular}

(kg)

(kg)

(kg)

2,900

3,293

2,900

, 293

0.9

$\underline{0 . \frac{15}{6}}$

$0 . \frac{15}{0}$

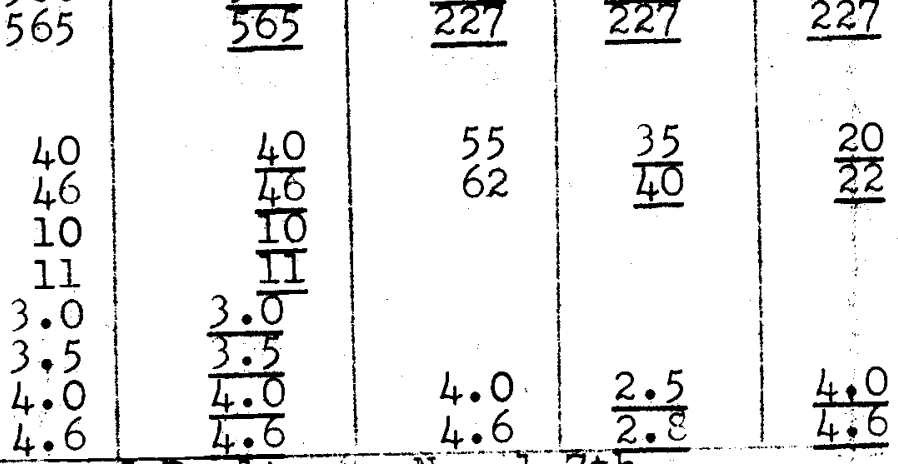

No. $1,7 \mathrm{th}$

\begin{tabular}{c|c|c}
$\frac{1,500}{1,705}$ & $\frac{1,500}{1,705}$ & $\frac{4,000}{4,544}$ \\
\hline$\frac{200}{227}$ & $\frac{\frac{200}{227}}{20}$ & $\frac{\frac{200}{227}}{2}$ \\
55 & $\frac{35}{40}$ & $\frac{20}{22}$ \\
62 & $\frac{20}{}$ & \\
4.0 & $\frac{2.5}{2.8}$ & $\frac{4.0}{4.6}$ \\
4.6 & &
\end{tabular}

Adapted from "Nutrien Academy of Sciences, 1977,p.33, Tables 7 and

8. These figures are requirements and do not include any margins of safety. Values underlined are estimates. For nutrients not listed, see requirments for chickens as a guide. 2 Increasing protein level to $22 \%$ for the first 2 weeks will increase early growth. 
Ducks are raised for their egg and meat; they may also be kept for ornamental purposes in parks, sanctuaries, etc. Ducklings can be bred in rearing sheds after hatching for upto 4 weeks. During this time, their ration should contain adequate protein and energy (minimum of $2,500 \mathrm{kcal} / \mathrm{kg}$ ) for rapid growth. For table purposes, ducks should be fed pelleted feeds containing 17\% protein for upto 4 weeks and $15 \%$ protein upto marketing weight. They can be raised on dry or wet mashes. It is better to feed green feeds which are chaffed and are of good quality, like clover and alfalfa.

The feeding schedule for ducks followed in Canada and India are given in the tables below.

TABLE 70 DUCK FEED FORMULAS ${ }^{1}$

\section{Ingredi ent:}

Ground yellow corn ........1,000

Wheat shorts ........................... 100

Market Ducks

All-Mash Formulas

Holding and

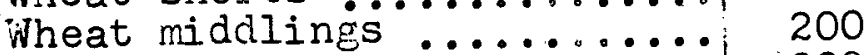

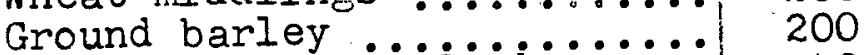

Dehydrated green feed.

Meat meal ( $50 \%$ protein) $\ldots . .$.

Fish meal (60\% protein) $\ldots$...

Dried whey

Soybean meai (50\% protein)

Ground limestone $\dot{0}$

Dicalcium phosphate ............

Salt (iodized)

Trace mineral premix

Vitamin premix

Total

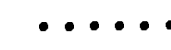

(iib) $\frac{10}{2,000}$

No. 2

Age in wekks

Breeding Formulas

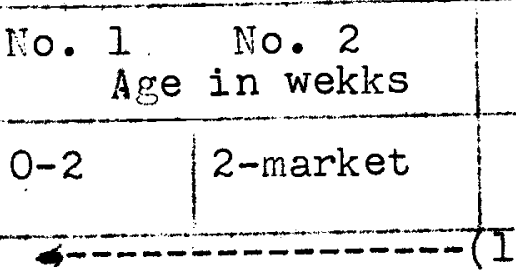

No. 3 No. 4 No. 5 No.6 Holding Breeding

A11 Mash Al1 Mash

Mash Grain Mash Grain

Trace mineral premix:

Manganous oxide $(56 \% \mathrm{Mn}) \quad \ldots$

Zinc oxicie $(80 \% \mathrm{Zn}) \ldots . . . .22 .0$

Groun limestone

Total

\section{Vitamin premix:}

Vitamin A..(millions of USPU)

Vitamin $\mathrm{D}_{3}$..)(millions of I CU

Riboflavin .............. (g)

d-Calcium pantothenate ... (g)

Vitamin $B_{12} \ldots \ldots . . . .$. (mg)

Niacin ...............

Menadione sodium bisulfite $(\mathrm{g})$

Ground yellow corn to $101 \mathrm{~b}$.. Total

Ib/ton)

\begin{tabular}{|c|c|}
4.0 & 3.0 \\
2.0 & 2.0 \\
2.0 & 1 \\
.75 .0 & 75.0 \\
\hline
\end{tabular}

2,000

\begin{tabular}{r|r|r|r}
760 & 700 & 735 & 600 \\
200 & 200 & 200 & 100 \\
400 & 200 & 200 & 200 \\
400 & 285 & 400 & 200 \\
80 & 160 & 90 & 180 \\
- & - & 40 & 40 \\
- & - & 40 & 80 \\
- & - & 30 & 50 \\
100 & 360 & 130 & 345 \\
20 & 40 & 100 & 150 \\
20 & 30 & 15 & 30 \\
5 & 10 & 5 & 10 \\
5 & 5 & 5 & 5 \\
10 & 10 & 10 & 10 \\
\hline 000 & 2,000 & 2,000 & 2,000 \\
\hline
\end{tabular}

1,040

200

150

200

40

40

40

285

20

20

5

10
40

$-$

270

20

10

2,000

)

$-$

$-1$

Mash aratn

$3.0+6.0+3.0+6.0$

$2.0 \quad 4.0 \quad 2.0 \div 4.0$ $7 \frac{7.0}{5.0}+\frac{70.0}{5.0}+\frac{75.0}{5.0}+\frac{70.0}{5}$

\begin{tabular}{l|l|l|l|l}
5.0 & 5.0 & 5.0 & 5.0 & 5.0
\end{tabular}

\begin{tabular}{|c|c|c|c|c|c} 
& & & & \\
4.0 & 4.0 & 2.0 & 4.0 & 3.0 & 6.0 \\
0.0 & 0.5 & 0.5 & 1.0 & 1.0 & 2.0 \\
4.0 & 3.0 & 3.0 & 6.0 & 3.0 & 8.0 \\
5.0 & 4.5 & 3.0 & 6.0 & 5.0 & 10.0 \\
6.0 & 6.0 & 4.0 & 8.0 & 4.0 & 8.0 \\
30.0 & 25.0 & 20.0 & 40.0 & 10.0 & 20.0 \\
1.0 & 1.0 & 1.0 & 2.0 & 1.0 & 2.0 \\
- & - & - & - & - & - \\
\hline 10.0 & 10.0 & 10.0 & 10.0 & 10.0 & 10.0 \\
\hline 10 & & &
\end{tabular}

IFrom Duck and Goose Raising, Ontario(Canada)Departement of Agriculture Pub.532,p.73. Practical formulas of this type can be adapted to any area by judicious feed substitutions based on available feeds and prices. 
Table 71. Compostion of Rations (percent)

\begin{tabular}{lccc}
\hline Ingredients & Starter & Growers & Layers \\
\hline Yellow maize & 35 & 30 & 30 \\
\hline Rice polish & 20 & 25 & 25 \\
\hline Ground nut cake & 25 & 25 & 22 \\
\hline Fish meal & 7 & 5 & 5 \\
\hline Wheat bran & 10 & 12 & 15 \\
\hline Mineral mixture & 2.5 & 2.5 & 2.5 \\
\hline Vitamin mixture & 0.5 & 0.5 & 0.5 \\
\hline & 100 & 100 & 100 \\
\hline
\end{tabular}

The same mineral mixture and vitamin mixture recommended for poultry may be fed for ducks also.

\section{Feeding geese}

Geese are very hardy, and are the closest grazers known, and can Geese are very hardy, and good pasture. The geese eat grass and young
live almost entirely on geds as quickly as they appear, but they do not touch certain cultivated plants. The feed formulations followed in Canada is given below: 
TABLE 72. GOOSE FEED FORNULAS ${ }^{1}$

\section{Ingredient:}

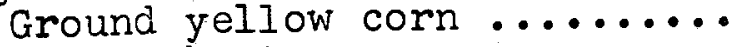

Theat shorts .............

Wheat middlings

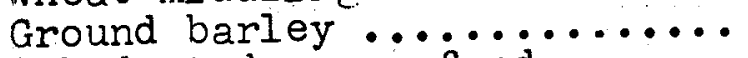

Dehydrated green feed

Meat meal (50\%protein) ........

Fish meal (60\% protein) .....

Dried whey $\dot{\text { Soybean meal }(50 \% \text { protein }) . . .}$

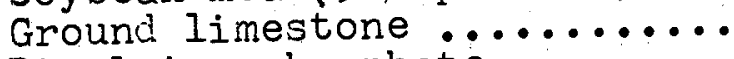

Dicalci um phosphate .......

Salt (iodized) .............

Trace mineral premix .......

Vitamin premix

$n$ premix
Total $\ldots \ldots \ldots \ldots \ldots$ (ib)

Trace mineral premix:

Manganous oxide $(56 \% \mathrm{Mn}) \ldots \ldots$

Zinc oxide $(80 \% \mathrm{zn}) \ldots \ldots \ldots \ldots$

Ground limestone

Total

Vitamin premix:

Vitamin A...(millions of USPU)

Vitamin $D_{3} \ldots$ (millions of ICU

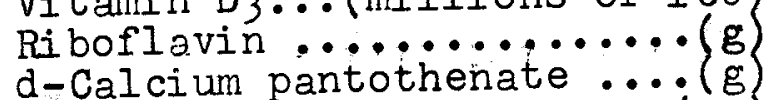

d-Calcium pantothenate .................

Niacin 12

Menadione sodium bisulfite.

Vitamin $\mathrm{E}$... (thousands of IJ)

Ethoxyquin ............. (oz)

Ground yellow corn to $101 \mathrm{~b}$.. Total ............... (1b)

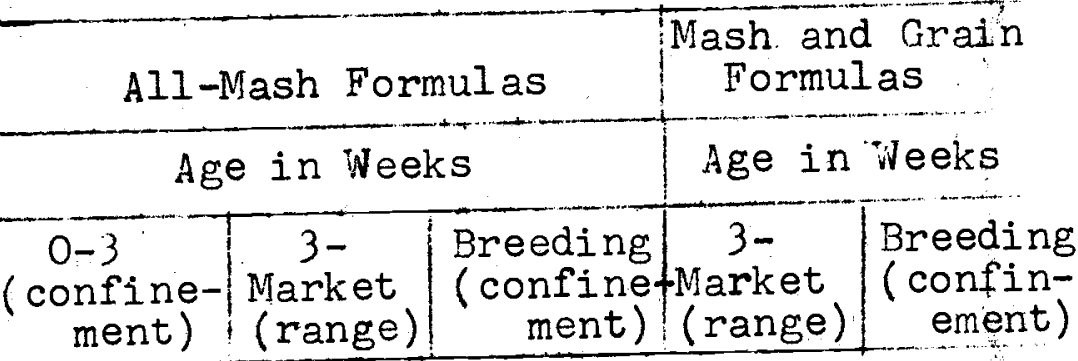




\section{Pheasants and Quails}

The nutrient requirements and rations for pheasants and quails is given in tables below.

Table 73. Nutrient Requirements of Pheasant and Quail Rations (in percentage or amount per $\mathrm{kg}$ of ration)

\section{- Nutrient \\ Metabolizable \\ energy}

Frotein

AMINO ACIDS

Lysine

Methionine+cystine

Glycine+serine

IINERALS

Macro minerals:

Sodium

Chlorine

Calci um

Phosphorus

Magnesium

Micro minerals:

Iodine

Manganese

Zinc

VI TAMINS

Fat-soluble

Vitamin A activity 4

Vitamin D

Water-soluble:

Choline

Niacin(nicotinic acid)

Pantothenic acid

Riboflavin ( $\left.B_{2}\right)$

Essential fatty acid:

Linoleic acid

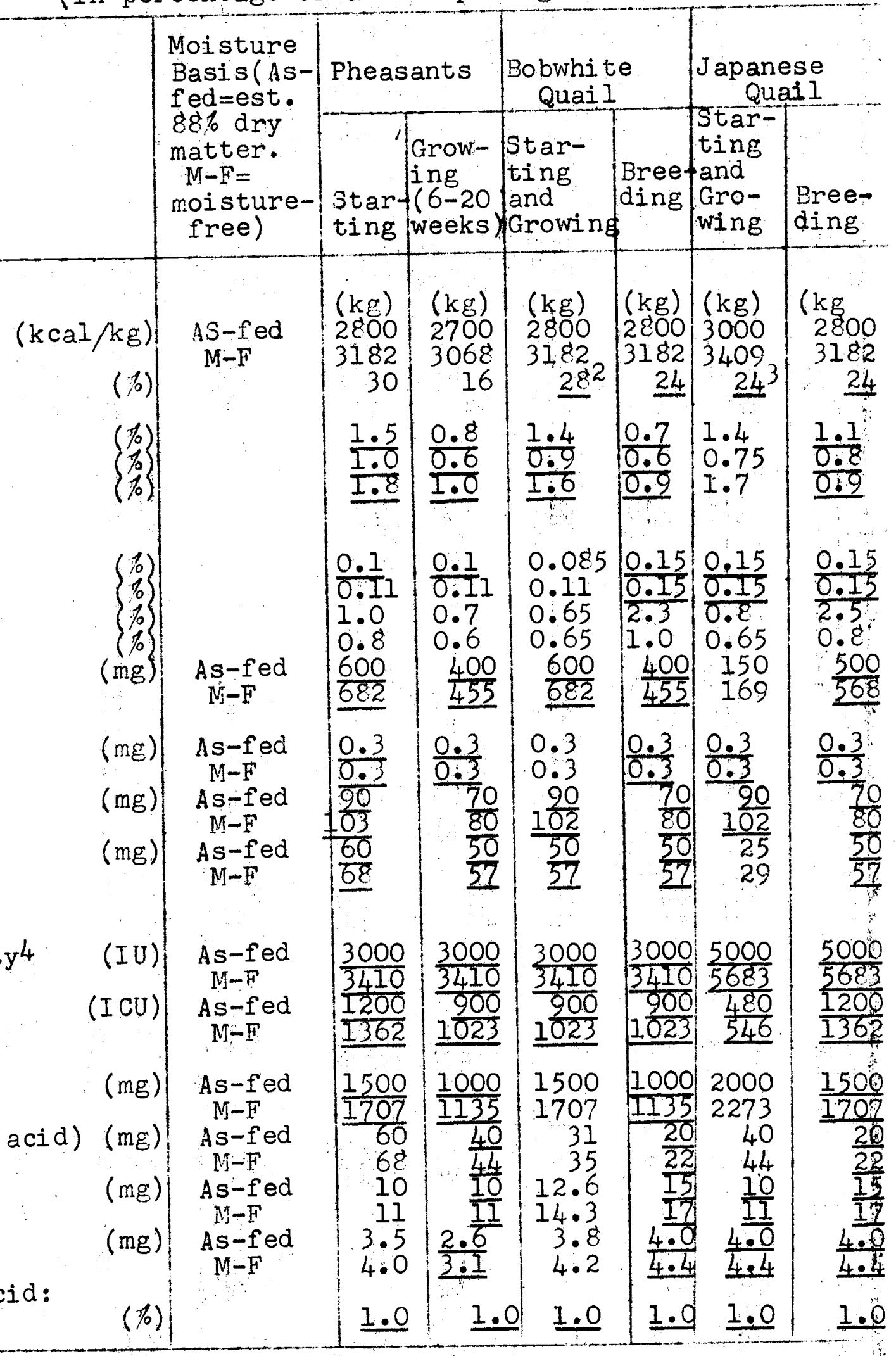


IAdapted from"Nutrient Requirements of Poultry", No.1,7th rev.ed., NRC-National Academy of Sciences, 1977,p.32, Table6. These figures are requirements and include no margins of safety. For nutrients not. listed, see requirements for chickens as a guide. Values underlined are estimates.

${ }_{3}$ May be reduced to $20 \%$ at 6 weeks of age.

${ }_{3}$ May be reduced to $20 \%$ at 3 weeks of age.

$4 \mathrm{May}$ be vitamin $\mathrm{A}$ or provitamin A.

Table 74. Rations for Quail and Pheasants 1

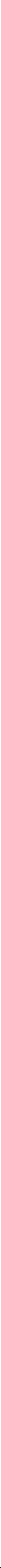
total of $\ldots \ldots \ldots(1 b)(10) \quad(10) \quad(10)$ I Scott, M.I.,"The Nutrition of Pheasants and Quail, "Distiller Feed Research Council Conference, 1966, pp.30-35.

$21 / 16$ pellets+grain ad lib.9-18 weeks: 
The protein requirements of quails are fairly high. Their performance is better when their diets contain above $2,300 \mathrm{kcal}$ of $M E$ per $\mathrm{kg}$ of feed, although very high energy diets containing oils may cause heavy mortality.

The following feeding schedule may be used for starters, growers, breeders and layers.

Table 75. Composition of rations (percent) for Quails

\begin{tabular}{l|c|c|c|c} 
& \multicolumn{2}{|c|}{ Starter/Grower ration } & Breeder/Layer ration \\
\cline { 2 - 4 } Ingredients & I & II & I & II \\
\hline Maize & 34 & 38 & 30 & 40 \\
\hline Rice bran & 10 & 8 & 20 & 12 \\
\hline Ground meat cake & 42 & 40 & 36 & 32 \\
\hline Fish meal & 13 & 12 & 7 & 8 \\
\hline Limestone & - & - & 6 & 6 \\
\hline Minerals and vitamins & 1 & 1 & 1 & 2 \\
\hline
\end{tabular}

* Contains(gram/100g): common salt, 400; ferrous sulphate, 25; manganese sulphate, 30; zinc sulphate, 30; copper sulphate, 1.5; potassium iodide, 0.1 ; bone meal, 1300; vitamin $\mathrm{A}_{2} \mathrm{~B}_{2}, \mathrm{D}_{3}$ (rovimix), 25; biotin, 0.2 , pantothenic acid, 4, vitamin E, 4 pyridoxine hydrochloride, 0.5; folic acid, 0.1 ; choline chloride, 100 in starter/grower and 50 in breeder/layer rations. The above mashes may be fed dry or wet. The birds may grow between 40 and $50 \mathrm{~g}$ from 0 to 8 weeks and produce 60 to 70 percent eggs with a feed efficiency of $4.5 \mathrm{~kg}$ feed per $\mathrm{kg}$ of egg production.

\subsection{Feeding Horses, Ponies, Mules and Donkeys}

The nutritive needs of horses is a major factor in determining their effeciency and years of service. As with other animals horses need nutrients for maintenance, growth, fattening, reproduction and production. With horses, the production need is mostly for recreation, cartage, sport and as cow ponies. Unlike most animals, however, the work is usually irregular and often very strenuous-characteristics which create a particular stress on the animal and makes the job of feeding difficult. 
In India, horses are mostly used for pulling carts while donkeys are used for carrying loads. The army uses horses for general purposes as well as for mountain artillery; it also produces and uses mules by cross breeding horses and donkeys. Horses are also bred for the -races. Good horses have a mature weight of $400 \mathrm{~kg}$ mountain horses may attain $500 \mathrm{~kg}$ - Cart ponies weigh about $300 \mathrm{~kg}$, while donkeys weigh around $200 \mathrm{~kg}$. The digestiye tracts of horses, ponies and donkeys differs anatomically and physiologically from those of the cow(ruminant), but both species thrive on the same feedstuffs namely forages and concentrates. The stomach of the horse is designed for almost constant intake of small quantities of feeds rather than large amounts at one time. The stomach of a horse will empty completely in $24 \mathrm{hrs}$, whereas it takes $72 \mathrm{hrs}$ in the cow, because the horse stomach has only a single compartment while that of the cow has four. There is much microbial action in the rumen of the cow and very little in the horse. Horses, in fact, do not possess rumens, but their cecum is well developed. The limited protein synthesis in the horse(compared to ruminants) and the lack of efficiency of absorption due to the cecum being on the lower end of the gut(thereby not giving the small intestine a chance at the ingesta after it leaves the cecum), clearly indicates that horse rations should contain high quality protein, adequate in amino acids. Compared to a cow, therefore, a horse should be fed less roughage, more high quality protein(no urea) and perhaps added B vitamins. The nutrient requirements of horses are given below in Tables 76 through 79 .

Requirements and allowances should be distinguished in ration formulation, since the former do not provide for margins of safety. Feeds for horses include:

-Forages, which include hay, pasture, and silage. Generally timothy, alfalfa, oat and grass hay, either individually or in rotation or mixed, are fed. Horses are also allowed on pasture if available. Silage is never fed more than 1/3 of the roughage allowance or $5 \mathrm{~kg}$ per head per day. Horses, mules and donkeys prefer doob(cynodon dactylon) grass or its hay.

-Concentrates. Oats, maize, barley, sorghum, wheat, gram, wheat bran, jaggery or molasses.

-Protein supplements. Groundnut cake, linseed cake, cotton seed cake, fish meal or meat meal.

-Special feeds like corn oil at the rate of 4 tablespoonfuls per horse per day, and soaked whole flex seed(a handful per horse per day) are sometimes fed to horses to import bloom or gloss to their hair.

-Treats. Roots, carrots, fruits, pumpkins or squashes are fed to horses as special treats.

Wheat bran or linseed meal/cake are included in the concentrates for bowel regulation. The amount of concentrates in the diet must be increased relative to the roughage content in proportion 
Table 76. Daily nutrient requirements of mature horses, pregnant mares, and lactating mares ${ }^{1}$ (per animal)

\begin{tabular}{|c|c|c|c|c|c|c|c|}
\hline Body Weight & Daily Feed & $\begin{array}{c}\text { Digestible } \\
\text { Energy }\end{array}$ & Protein & $\begin{array}{r}\text { Digestible } \\
\text { Protein }\end{array}$ & $\mathrm{Ca}$ & $\mathbf{P}$ & Vitamin $A^{3}$ \\
\hline$(\mathrm{kg})$ & $(\mathrm{kg})$ & $(\operatorname{Mcal})$ & $(g)$ & $(g)$ & $(g)$ & $(g)$ & $(1,000 I U)$ \\
\hline $\begin{array}{c}\text { Mature hors } \\
200 \\
400 \\
500 \\
600\end{array}$ & $\begin{array}{l}\text { es at rest (maj } \\
3.00 \\
5.04 \\
5.96 \\
6.83\end{array}$ & $\begin{array}{c}\text { intenance): } \\
8.24 \\
13.86 \\
16.39 \\
18.79\end{array}$ & $\begin{array}{l}300 \\
505 \\
507 \\
684\end{array}$ & $\begin{array}{l}160 \\
268 \\
317 \\
364\end{array}$ & $\begin{array}{l}8.0 \\
16.0 \\
20.0 \\
24.0\end{array}$ & $\begin{array}{r}6.0 \\
12.0 \\
15.0 \\
18.0\end{array}$ & $\begin{array}{r}5.0 \\
10.0 \\
12.5 \\
15.0\end{array}$ \\
\hline \multicolumn{8}{|c|}{ Mature horses at light work( $2 \mathrm{hr} / \mathrm{day}$ ): } \\
\hline $\begin{array}{l}200 \\
400 \\
500 \\
600\end{array}$ & $\begin{array}{l}3.80 \\
6.68 \\
7.96 \\
9.23\end{array}$ & $\begin{array}{l}10.44 \\
18.36 \\
21.89 \\
25.39\end{array}$ & $\begin{array}{l}383 \\
672 \\
803 \\
930\end{array}$ & $\begin{array}{l}202 \\
355 \\
424 \\
491\end{array}$ & $\begin{array}{l}8.0 \\
16.0 \\
20.0 \\
24.0\end{array}$ & $\begin{array}{r}6.0 \\
12.0 \\
15.0 \\
18.0\end{array}$ & $\begin{array}{l}5.0 \\
10.0 \\
12.5 \\
15.0\end{array}$ \\
\hline \multicolumn{8}{|c|}{ Mature horses at medium work( $4 \mathrm{hr} / \mathrm{day})$ : } \\
\hline $\begin{array}{l}200 \\
400 \\
500 \\
600\end{array}$ & $\begin{array}{r}4.79 \\
8.65 \\
10.43 \\
12.22\end{array}$ & $\begin{array}{l}15.16 \\
23.80 \\
28.69 \\
33.55\end{array}$ & $\begin{array}{r}483 \\
871 \\
1,047 \\
1,229\end{array}$ & $\begin{array}{l}255 \\
460 \\
553 \\
649\end{array}$ & $\begin{array}{r}9.0 \\
17.2 \\
21.2 \\
25.2\end{array}$ & $\begin{array}{l}7.0 \\
13.0 \\
16.0 \\
19.0\end{array}$ & $\begin{array}{l}5.0 \\
10.0 \\
12.5 \\
15.0\end{array}$ \\
\hline \multicolumn{8}{|c|}{ Mares, last 90 days of pregnancy: } \\
\hline $\begin{array}{l}200 \\
400 \\
500 \\
600\end{array}$ & $\begin{array}{l}3 \cdot 16 \\
5 \cdot 41 \\
6 \cdot 31 \\
7 \cdot 25\end{array}$ & $\begin{array}{r}8.70 \\
14.88 \\
17.35 \\
19.95\end{array}$ & $\begin{array}{l}364 \\
613 \\
725 \\
837\end{array}$ & $\begin{array}{l}216 \\
375 \\
434 \\
507\end{array}$ & $\mid \begin{array}{l}10.4 \\
10.5 \\
24.0 \\
28.0\end{array}$ & $\begin{array}{r}8.0 \\
15.0 \\
18.0 \\
21.0\end{array}$ & $\begin{array}{l}10.0 \\
20: 0 \\
25.0 \\
30.0\end{array}$ \\
\hline \multicolumn{8}{|c|}{ Mares,peak of lactation: } \\
\hline $\begin{array}{l}200 \\
400 \\
500 \\
600\end{array}$ & $\begin{array}{r}5.54 \\
8.91 \\
10.04 \\
10.92\end{array}$ & $\begin{array}{l}15.21 \\
24.39 \\
27.62 \\
30.02\end{array}$ & $\begin{array}{r}750 \\
1,181 \\
1,317 \\
1,404\end{array}$ & $\begin{array}{l}480 \\
748 \\
829 \\
876\end{array}$ & $\begin{array}{l}34.0 \\
42.0 \\
47.0 \\
51.0\end{array}$ & $\begin{array}{l}23.4 \\
35.6 \\
38.6 \\
39.0 \\
\end{array}$ & $\begin{array}{l}10.0 \\
20.0 \\
25.0 \\
30.0\end{array}$ \\
\hline
\end{tabular}

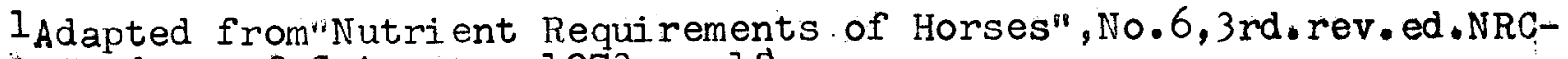
National Academy of Sciences, 1973, p. 18. dry feed.

2 Assume $2.75 \mathrm{Mcal}$ of digestible energy per kilogram of $100 \%$

3 One mg of beta-carotene equals 400 IU of vitamin A. 
Table 77. Daily nutrient requirements of growing horses(per animal) ${ }^{1}$

\begin{tabular}{|c|c|c|c|c|c|c|c|c|c|c|}
\hline Age & $\begin{array}{l}\text { Body } \\
\text { Weight }\end{array}$ & $\begin{array}{l}\text { Per- } \\
\text { centage } \\
\text { of } \\
\text { Mature } \\
\text { Weight }\end{array}$ & $\begin{array}{l}\text { Daily } \\
\text { Gain }\end{array}$ & $\begin{array}{l}\text { Daily } \\
\text { Feed } 2\end{array}$ & $\begin{array}{c}\text { Digest- } \\
\text { ible } \\
\text { Energy }\end{array}$ & $\begin{array}{ll} & D \\
\text { Pro- } & t \\
\text { tein } & F\end{array}$ & $\begin{array}{l}\text { Diges- } \\
\text { tible } \\
\text { Protein }\end{array}$ & $\mathrm{Ca}$ & $P$ & $\begin{array}{l}\text { Vit- } \\
\mathrm{amin}^{3}\end{array}$ \\
\hline (mo) & $(\mathrm{kg})$ & $(\%)$ & $(\mathrm{kg})$ & $(\mathrm{kg})$ & (Mcal) & $(g)$ & (g) & $(g)$ & $(\mathrm{g})$ & \\
\hline \multicolumn{11}{|c|}{ mature weight $(200 \mathrm{~kg})$ : } \\
\hline $\begin{array}{r}3 \\
6 \\
12 \\
18 \\
42\end{array}$ & $\begin{array}{r}50 \\
90 \\
135 \\
165 \\
200\end{array}$ & $\begin{array}{r}25.0 \\
45.0 \\
67.5 \\
82.5 \\
100.0\end{array}$ & $\begin{array}{l}0.70 \\
0.50 \\
0.20 \\
0.10 \\
0\end{array}$ & $\begin{array}{l}2.94 \\
3.10 \\
2.89 \\
2.94 \\
3.00\end{array}$ & $\begin{array}{l}7.43 \\
8.53 \\
7.95 \\
8.08 \\
8.24\end{array}$ & $\begin{array}{l}526 \\
462 \\
330 \\
314 \\
300\end{array}$ & $\begin{array}{l}383 \\
315 \\
206 \\
181 \\
160\end{array}$ & $\begin{array}{r}17.4 \\
16.6 \\
12.0 \\
10.4 \\
8.0\end{array}$ & $\begin{array}{r}10.9 \\
10.4 \\
7.5 \\
6.9 \\
6.9\end{array}$ & $\begin{array}{l}2.0 \\
3.6 \\
5.4 \\
6.6 \\
5.0\end{array}$ \\
\hline \multicolumn{11}{|c|}{ mature weight $(400 \mathrm{~kg})$ : } \\
\hline $\begin{array}{r}3 \\
6 \\
12 \\
18 \\
42\end{array}$ & $\begin{array}{r}85 \\
170 \\
260 \\
330 \\
400\end{array}$ & $\begin{array}{r}21.3 \\
42.5 \\
65.0 \\
82.5 \\
100.0\end{array}$ & $\begin{array}{l}1.00 \\
0.65 \\
0.40 \\
0.25 \\
0\end{array}$ & $\begin{array}{l}3.80 \\
4.51 \\
4.96 \\
5.13 \\
5.04\end{array}$ & $\begin{array}{l}10.44 \\
12.41 \\
13.63 \\
14.10 \\
13.86\end{array}$ & $\begin{array}{l}747 \\
640 \\
600 \\
575 \\
505\end{array}$ & $\begin{array}{l}553 \\
430 \\
370 \\
5 \\
539 \\
268\end{array}$ & $\mid \begin{array}{l}26.1 \\
35.0 \\
22.0 \\
19.0 \\
16.0\end{array}$ & $\begin{array}{l}16.4 \\
21.9 \\
14.9 \\
13.9 \\
12.0\end{array}$ & $\begin{array}{r}3.4 \\
96.8 \\
910.4 \\
914.2 \\
910.0\end{array}$ \\
\hline \multicolumn{11}{|c|}{ mature weight $(500 \mathrm{~kg})$ : } \\
\hline $\begin{array}{r}3 \\
6 \\
12 \\
18 \\
42\end{array}$ & $\begin{array}{l}110 \\
225 \\
325 \\
400 \\
500\end{array}$ & $\begin{array}{r}22.0 \\
45.0 \\
65.0 \\
80: 0 \\
100.0\end{array}$ & $\begin{array}{l}1.10 \\
0.80 \\
0.55 \\
0.35 \\
0\end{array}$ & $\begin{array}{l}4.39 \\
5.60 \\
6.11 \\
6.24 \\
5.96\end{array}$ & $\begin{array}{l}12.07 \\
15.40 \\
16.81 \\
17.16 \\
16.39\end{array}$ & $\begin{array}{l}834 \\
800 \\
750 \\
700 \\
597\end{array}$ & $\begin{array}{l}618 \\
536 \\
0 \\
0472 \\
418 \\
717\end{array}$ & $\begin{array}{l}30.5 \\
46.0 \\
26.0 \\
23.0 \\
20.0\end{array}$ & $\begin{array}{l}19.1 \\
28.7 \\
17.4 \\
16.1 \\
15.0\end{array}$ & $\begin{array}{r}4.4 \\
9.0 \\
417.0 \\
116.0 \\
\text { d1 } 2.5\end{array}$ \\
\hline \multicolumn{11}{|c|}{ mature weight $(600 \mathrm{~kg})$ : } \\
\hline $\begin{array}{r}3 \\
6 \\
12 \\
18 \\
42\end{array}$ & $\begin{array}{l}140 \\
265 \\
385 \\
480 \\
600\end{array}$ & $\begin{array}{r}23.3 \\
44.2 \\
64.1 \\
80.0 \\
100.0\end{array}$ & $\begin{array}{l}1.25 \\
0.85 \\
0.60 \\
0.35 \\
0\end{array}$ & $\begin{array}{l}5.15 \\
6.26 \\
6.86 \\
6.98 \\
6.83\end{array}$ & $\begin{array}{l}14.15 \\
17.21 \\
18.86 \\
19.20 \\
18.79\end{array}$ & $\begin{array}{l}958 \\
870 \\
837 \\
775 \\
684\end{array}$ & $\begin{array}{ll}8 & 705 \\
0 & 582 \\
7 & 524 \\
5 & 458 \\
4 & 364\end{array}$ & $\begin{array}{l}52.0 \\
51.2 \\
32.9 \\
31.3 \\
24.0\end{array}$ & $\begin{array}{l}32.2 \\
32.0 \\
20.6 \\
19.6 \\
18.0\end{array}$ & $\begin{array}{l}25.6 \\
010.6 \\
615.4 \\
619.2 \\
015.0\end{array}$ \\
\hline
\end{tabular}

${ }^{1}$ Adapted by the authors from "Nutrient Requirements of Horses," No. 6,3rd rev.ed. NRC-National Academy of Sciences, 1973, $\mathrm{p}$. 19. 2 Assume $2.75 \mathrm{Mcal}$ of digestible energy per kilogram of $100 \%$ $\mathrm{dry}_{3}$ feed. $\mathrm{mg}$ of beta-carotene equals $400 \mathrm{IU}$ of vitamin $\Lambda$. 
Table 78. Nutrient requirements of rations for mature horses,

pregnant mares, and lactating $\operatorname{mares}^{1}$ (in $\%$ or amount

per $\mathrm{kg}$ of ration)

Body Weight

(kg)

Mature horses at rest(maintenance) 200

400

500

600 As-fed

$\mathrm{M}-\mathrm{F}$

As-fed

$M-F$

As-fed

$\mathrm{M}-\mathrm{F}$

As-fed

$\mathrm{M}-\mathrm{F}$

3.33

3.00

5.60

5.04

5.96

7.59

6.83

Nature horses at light work(2hr/day):

200

400

500

600

As-fed

$M-F$

As-fed

$\mathrm{N}-\mathrm{F}$

As-fed

$\mathrm{M}-\mathrm{F}$

As - fed

$\mathrm{M}-\mathrm{F}$

Mature horses at medium work ( $4 \mathrm{hr} / \mathrm{day})$ :

200

400

500

600

As-fed

$\mathrm{M}-\mathrm{F}$

As-fed

$\mathrm{M}-\mathrm{F}$

As-fed

$M-F$

As-fed

$\mathrm{M}-\mathrm{F}$

4.22

3.80

7.42

6.68

7.96

10.24

5.32

4.79

9.61
8.65

11.59

10.43

13.58

12.22

of pregnancy:

Mares, last 90 days of pr
200
$\mathrm{As}-\mathrm{fed}$

400

$M-F$

As-fed

$M-F$

As-fed

$\mathrm{M}-\mathrm{F}$

As-fed

$\mathrm{M}-\mathrm{F}$

600

ation:

As-fed

$\mathrm{M}-\mathrm{F}$

As-fed

$M-F$

As-fed

$\mathrm{Ni}-\mathrm{F}$

As-fed

$\mathrm{M}-\mathrm{F}$
3.51

3.16

6.01

5.41

5.90

5.31

7.25

$6.16 \div 12.2$

5.54

9.90

8.91

11.16

10.04

12.13

10.92

11.5

10.4

11.5

10.4

11.5

10.4

11.5

\section{5}

12.0

13.3

11.8

13.1

11.6

12.9
(\%)

9

10

10

10

9

10

9

9

10

10

9

.

9
10
9
10
9
10
9
10

10.4

600
Digestible Protein

(\%)

4.8

5.3

4.8

5.3

4.8

5.3

4.8

5.3

4.8

5.3

4.8

5.3

4.8

5.3

4.8

5.3

4.8

5.3

4.8

5.3

4.8

5.3

4.8

5.3

6.2

6.9

6.2

6.9

6.2

6.9

6.2

6.9

7.8

8.7

7.6

8.4

7.5

8.3

7.2

8.0 \begin{tabular}{c|c|c} 
Di gestible & $\mathrm{Ca}$ & $\mathrm{P}$ \\
Energy & & \\
\hline (Mcal per & $(\%)$ & $(\%)$
\end{tabular}

2.48

2.75

2.48

2.75

2.48

2.75

2.4 ह

2.75

2.48

2.75

2.48

2.75

2.48

2.75

2.48

2.75

2.48

2.75

2.48

2.75

2.48

2.75

2.48

2.75

2.48

2.75

2.48

2.75

2.48

2.75

2.48

2.75

0.230 .18

0.260 .20

0.280 .22

0.340 .24

0.300 .23

0.33 0.25

0.320 .23

0.350 .26

0.190 .14

0.270 .15

0.220 .16

0.240 .18

0.230 .16

0.250 .18

$0.23 \quad 0.17$

0.25019

0.170 .13

0.190 .14

0.180 .14

$0.20 \quad 0.15$

$0.180,14$

0.2010 .15

0.1 \& 0.14

0.200 .15

$0.30 \quad 0.23$

0.3310 .25

0.320 .25

$0.36,0.22$

0.340 .26

0.380 .29

0.350 .26

0.390 .29

2.48

2.75

2.48

2.75

2.48

2.75

2.48

2.75
0.550 .37

0.610 .41

0.420 .36

0.470 .40

0.4210 .33

$10.47 \quad 0.37$

$0.420,32$ $0.470: 36$

Idapted from "Nutrient Requirements of Horses, No.6,3rd.rev.ed., NRC-National Academy of Sciences, 1973,p.20. 
Table 79. Nutrient requirements of rations for growing horses ${ }^{1}$

(in percentage or amount per $\mathrm{kg}$ of ration)

\section{Age Body \\ Weight \\ (mo) \\ $(\mathrm{kg})$ \\ $(\mathrm{kg})$ \\ Gain}

$\mathrm{M}-\mathrm{F}=$

(200 kg) mature wei ght:

Moisture

Basis ( $\Lambda$ s-

fed $=$

$90 \%$ dry

matter.

free)

1

6

90

12

18

90

0.70 is $=$ fed

Ms $=f e d$
$M=f e d$

$0.50 \quad \begin{array}{ll}A s-f \text { fed } \\ M-F \\ 0.20\end{array}$

135

165

$0.10 \mathrm{M}$ Ms

200

$0 \quad \hat{s}-f$ ed

$M-F$

$(400 \mathrm{~kg})$ mature weight:

\begin{tabular}{|c|c|c|c|}
\hline 3 & 85 & .00 & is-fed \\
\hline 6 & 170 & 0.65 & As-fed \\
\hline 12 & 260 & 0.40 & $\begin{array}{l}A s-f e d \\
M-F\end{array}$ \\
\hline 18 & 330 & 0.25 & As-fed \\
\hline 42 & 400 & 0 & $\begin{array}{c}A s-f e d \\
M-F\end{array}$ \\
\hline
\end{tabular}

(500kg) mature wei ght:

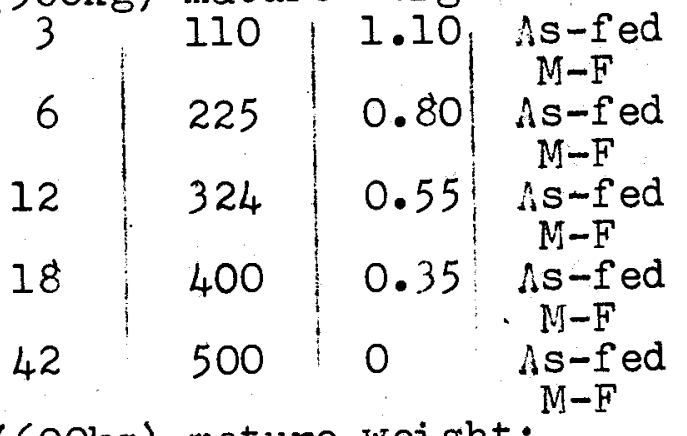

$(600 \mathrm{~kg})$ mature weight:

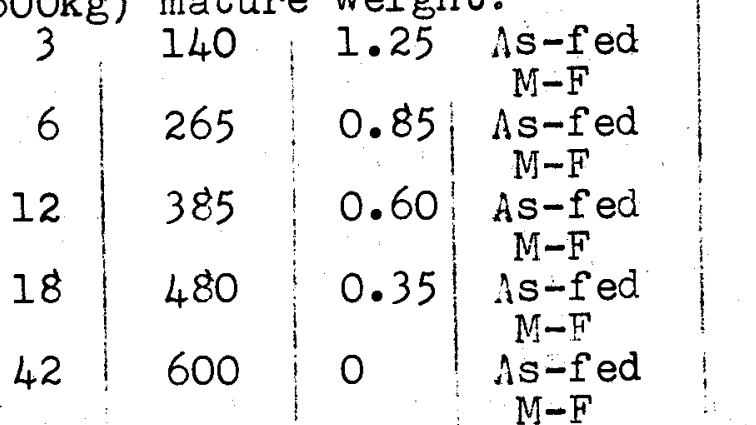

\section{Daily}

Feed

Consumption ${ }^{2}$

(kg)

3.27

2.94

3.44

$3: 10$

3.21

2.89

3.27

2.94

3.33

3.00

4.22

3.80

5.01

4.51

5.51

4.96

5.70

5.13

5.60

5.04

4.88

4.39

6.22

5.60

6.79

6.11

6.93

6.24

6.62

5.96

5.72

5.15

6.96

6.26

7.62

6.86

7.76

6.98

7.59

6.83

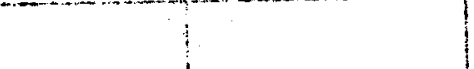

Diges-
tible

Protein Protein Energy

(\%)

6.1

7.9

3.4

4.9

1.7

9.6

0.7

9.0

0.0

17.6

19.5

12.8

14.2

10.9

12.1

10.1

11.2

9.0

10.0

17.1

19.0

12.1

13.4

11.1

12.3

10.2

11.3

9.0
10.0

10.0

16.7
13.6
12.5
13.9
11.0
12.2
10.0
11.1
0.0

(\%)

11.7
13.0
9.2
10.2
6.4
7.1
5.6
6.2
4.8
5.3

13.1

14.6

8.6

6.8

7.5

5.9

6.6

4.8

5.3

12.7

14.1

8.6

9.6

6.9

7.7

6.0

6.7

4.8

5.3

12.3

13.7

8.3

9.2

6.8

7.6

5.9

6.6

4.8

5.3
Mcal per (\%) (\%)

( $\mathrm{kg})$

2.48

0.530 .33

\begin{tabular}{l|ll}
2.75 & 0.59 & 0.37
\end{tabular}

$2.48 \quad 0.480 .31$

\begin{tabular}{l|ll}
2.75 & 0.53 & 0.34
\end{tabular}

\begin{tabular}{l|lll}
2.48 & 0.37 & 0.23
\end{tabular}

$\begin{array}{llll}2.75 & 0.47 & 0.25\end{array}$

$2.48 \quad 0.320 .20$

\begin{tabular}{l|ll}
2.75 & 0.35 & 0.22
\end{tabular}

$2.48 \quad 0.260 .18$

$2.75 \quad 0.290 .20$

\begin{tabular}{l|l|l}
2.48 & 0.61 & 0.39
\end{tabular}

$2.75 \quad 0.68 \quad 0.43$

$2.48 \quad 0.70 \quad 0.43$

$\begin{array}{llll}2.75 & 0.78 & 0.48\end{array}$

$2.48 \quad 0.41 \quad 0.27$

$\begin{array}{llll}2.75 & 0.45 & 0.30\end{array}$

$2.48 \quad 0.33 \quad 0.24$

\begin{tabular}{l|l|l}
2.75 & 0.37 & 0.27
\end{tabular}

$\begin{array}{llll}2.48 & 0.29 & 0.22\end{array}$

2.75. 0.320 .24

$\begin{array}{llll}2.48 & 0.62 & 0.40\end{array}$

$\begin{array}{llll}2.75 & 0.69 & 0.44\end{array}$

$2.48 \quad 0.74 \quad 0.46$

$\begin{array}{lllll}2.75 & 0.82 & 0.51\end{array}$

$\begin{array}{llll}2.48 & 0.39 & 0.25\end{array}$

$\begin{array}{llll}2.75 & 0.43 & 0.22\end{array}$

$2.48 \quad 0.330 .23$

\begin{tabular}{l|lll}
2.75 & 0.37 & 0.26
\end{tabular}

$2.48 \quad 0.31 \quad 0.23$

$\begin{array}{llll}2.75 & 0.34 & 0.25\end{array}$

2.48

2.75

2.48

2.75

2.48

2.75

2.48

2.75

2.48

$0 . 9 1 \longdiv { 0 . 5 7 }$

$1.01,0.63$

0.730 .46

0.810 .51

0.430 .27

0.4810 .30

0.4010 .25

$0.45,0.28$

2.75
0.32
0.35 0.23

IAdapted from"Nutrient Requirements of Horses", No.6,3rd.vev.ed., NRCNational icademy of Sciences.1973,p.31.

$2 \Lambda$ ssume $2.75 \mathrm{Mcal}$ of digestible energy per kilogram of $100 \%$ dry feed. 
as the energy need rises with a greater amount, severity or speed of work thus race horses receive a minimum of roughage. Horses consume dry matter at the rate of $1.2 \%$ of the body weight when they are at rest. The dry matter intake increases to $2 \%$ of body weight during medium work and lactation it may reach $3 \%$ body weight during the early growth period (up to $100 \mathrm{~kg}$ ). Roughages are fed at the rate of 1 percent of the body weight.

Calculation of rations for a 9 months old colt weighing $225 \mathrm{~kg}$ (mature weight $500 \mathrm{~kg}$ ):

The feeding standards tables give. the nutrient requirements as $5.6 \mathrm{~kg} \mathrm{DM} ; 800 \mathrm{~g}$ total protein; $536 \mathrm{~g} \mathrm{DCP} ; 15.4$ MCal DE; $46 \mathrm{~g}$ $\mathrm{Ca} ; 28.7 \mathrm{~g} \mathrm{P}$, and $9000 \mathrm{IU}$ vitamin $\Lambda$.

Oat hay is a suitable roughage, containing about $4 \%$ digestible protein and $2 \mathrm{Mcal} \mathrm{DE}$ per kilogram. The colt may be fed this at the rate of $1 \%$ of body weight, $i . e ., 2.25 \mathrm{~kg}$ per day. Assuming $75 \%$ dry matter, this will be met by $3 \mathrm{~kg}$ of hay per day ( $(75 / 100 \times 3=2.25 \mathrm{~kg})$.

The concentrate mixture may contain 12 to $13 \% \mathrm{DCP}$ and 3 to 3.2 $\mathrm{Mcal} \mathrm{DE}$, and may be computed as below:

\begin{tabular}{|c|c|c|c|}
\hline Ingredients & $\%$ in mixture & $\mathrm{DCP}(\mathrm{kg})$ & $\mathrm{ME}$ (Mcal) \\
\hline Barley (DCP $6.6 \%$ DE $3.4 \mathrm{Mcal} / \mathrm{kg}$ ) & 25 & 1.7 & 85. \\
\hline Grain(DCP 13\%; DE $3.3 \mathrm{Mcal} / \mathrm{kg}$ ) & 20 & 2.6 & 66 \\
\hline Wheat $\operatorname{bran}(\mathrm{DCP} 10 \% \mathrm{DE} 2.9 \mathrm{Mcal} / \mathrm{kg}$ ) & 43 & $4 \cdot 3$ & 124 \\
\hline Groundnut cake(DCP $40 \%, \mathrm{DE} 3.3 \mathrm{Mcal} / \mathrm{kg}$ ) & 10 & 4.0 & 13 \\
\hline Mineral mixture & 1 & - & - \\
\hline Salt & 1 & - & - \\
\hline & 100 & 12.6 & 288 \\
\hline
\end{tabular}

In the above concentrate mixture barley and grain have been included as sources of energy, groundnut cake as a protein source and wheat bran as an economical source of nutrients and as a laxative. The mineral mixture and salt have been added to balance the concentrate mixture and as a mineral source. 
The following could then be a complete balanced diet:

\begin{tabular}{|l|c|c|c|c|c|}
\hline Ingredients & $\begin{array}{c}\text { Quantity } \\
(\mathrm{kg})\end{array}$ & $\begin{array}{c}\text { Dry matter } \\
(\mathrm{kg})\end{array}$ & $\begin{array}{c}\text { Total protein } \\
(\mathrm{g})\end{array}$ & $\begin{array}{l}\text { DCP } \\
(\mathrm{g})\end{array}$ & $\begin{array}{l}\text { DE } \\
\text { Mcal })\end{array}$ \\
\hline Oat hay & 3.5 & 2.63 & 280 & 140 & 7.00 \\
\hline Concentrate mixture & 3.2 & 2.90 & 500 & 403 & 9.22 \\
\hline & 6.7 & 5.53 & 780 & 543 & 16.22 \\
\hline
\end{tabular}

Listed below are some alternative ingredients for the concentrate mixture.

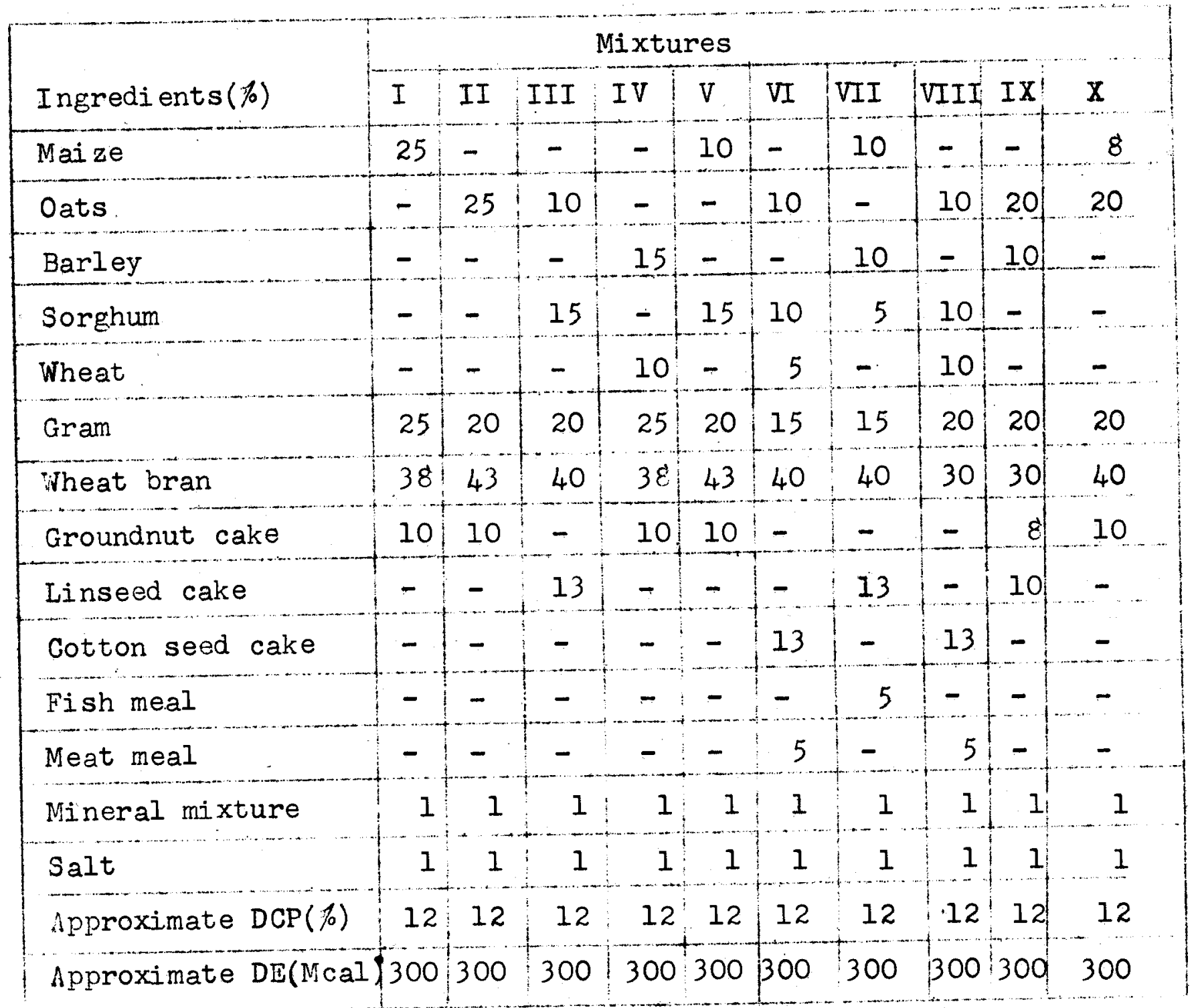


Table 80. Recommended feeding schedule for horses on stud farms (per animal per day)

\begin{tabular}{|c|c|c|c|c|c|c|}
\hline & $\begin{array}{c}\text { Grain } \\
\mathrm{kg}\end{array}$ & $\begin{array}{c}\text { Barley } \\
\mathrm{kg}\end{array}$ & $\begin{array}{l}\text { Wheat bran } \\
\mathrm{kg}\end{array}$ & Mineral mixture & $\begin{array}{c}\text { Salt } \\
g\end{array}$ & $\begin{array}{l}\text { Fodder } \\
\text { hay kg }\end{array}$ \\
\hline Brood mares & 0.91 & 1.36 & 0.91 & 30 & 30 & $5-8$ \\
\hline Lactating mares & 1.36 & 1.81 & 0.91 & 30 & 30 & $6-10$ \\
\hline Dry mares & 0.50 & 0.50 & 0.50 & 30 & 30 & $4-5$ \\
\hline
\end{tabular}

Ponies are fed in the same way as horses, but the requirements are less. A pony can be maintained on doob grass hay instead of the leguminous hay required for a horse. When the pony is doing the leguminous hay required for a horse.
hard work, for example pulling carts for 8 to 10 hours, 2 to $2.5 \mathrm{~kg}$
of mixture consisting of oats, gram, and wheat bran in equal parts along with salt is fed in addition to 5 to $6 \mathrm{~kg}$ of grass hay.

Mules. Since the anatomy and physiology of the digestive system are like those of horses, the feeding practice follows a similar pattern. For a working mule a ration that provides coarse fodder at the rate of 1 to 1.6 percent of the body weight is a good average diet. Thus a mule on medium work may receive a daily ration, according to its weight of 2.7 to $5 \mathrm{~kg}$ grain and 4.5 to 7 $\mathrm{kg}$ hay. This should be divided into two or three feeds. An average daily ration might consist of $3.5 \mathrm{~kg}$ of oats or barley, $0.9 \mathrm{~kg}$ of wheat bran and $6.5 \mathrm{~kg}$ of hay. Crushed barley, crushed maize, millet or beans may be substituted either wholly or partially in the concentrate ration (DCP $12 \%$, ME $300 \mathrm{Mcal} / 100 \mathrm{~kg}$ ) . $A$ commercial salt lick or rock salt at a level of $14 \mathrm{~g}$ per mule per day should also be made available. When good grazing is available, the concentrate ration of a working mule may be reduced by a half. Mules doing only light or no work can be sustained on grazing alone. Mules should be watered 3 times a days they require between 25 and 75 liters of water daily.

Donkeys can be maintained on dry food both in winter and summer. They prefer meadow hay containing various weeds and herbs; unlike horses they do not'like or need rich clover or other leguminous hays. Donkeys can also be fed straws but such a diet will need to be supplemented with hay or concentrates. The daily requirement for meadon hay is between 4.5 and $5.5 \mathrm{~kg}$. It is not essential to give any feed other than meadow hay or doob grass hay of good 
quality to mares not foaling and to geldings, Extra food is needed for growing younf animals, foaling mares and working animals. $A$ concentrate mixture for donkeys consists of 25 parts rolled oats, 25 parts flaked maize and 50 parts wheat bran. Any of the supplements suggested for horses is suitable for donkeys the quantity needed is about half that for ponies.

Camels are found in Asia (specially in India, Pakistan, Afghanistan and Iran), Africa, Australia, California and the USSR. The single humped species (camelus dromedarius) is most common in Afghanistan but there are also some of the tow humped variety (camelus tractarianus linn). Camels can subsist on a varied type of vegetation, trees, shrubs, etc., not suitable for other herbivores. They are mostly kept for draught (transport) and milk; their milk is like cow's milk and is used for human consumption. When used for this purpose by pastoralis and nomadic people camels frequently have to suffer periods without food, partiaclarly during the summer. They are seldom fed adequate supplementary rations, while the calves are allowed only a limited supply of milk during the early stages of growth, and never the full amount of colostrum.

Camel cow calves normally give milk continuously every second year. Camels start breeding at the age of three years when they are of about $300 \mathrm{~kg}$ body weight. Bulls are used for breeding from 6-7 years of age. The camel cow yields between 8 and 10 liters of milk, most of which is consumed by humans. Camel milk is rich in protein $(3.7 \%)$ and can sustain the foal for growth. Camels are fully grown at about 5 years old $(500-700 \mathrm{~kg})$. They are very good.draught animals in arid and semi-arid regions, performing all agricultural operations including transport. Camel meat is good food and Camel leather is used for shoes and many other things, includinghuge water bags for the bulk transport of water. Brushes, ropes and blankets are made from camel hair.

Feeding habits very from area to area. Camels normally subsist on browsing and grazing. They can be stall fed when grazing in not available. In Arabia, the plants generally grazed are Alhazi maurorum, salavadoras, capparis, acacias and tamarisk. In India, camels eat acacia leaves, khejri (prosopis) salvadoras, etc., the brushes grazed are zi zyphus, wild olive, bekariya(Indigofera), salt bush etc, ; they also eat the green doob grass and meadow grass available in the monsoon season. A list of the plants/shrubs/tree leaves browsed by Indian camels is given below. 
Local name Botanied name

Anjeer

Ficus indica

Ficus relegiosa

Babul

Guar

-

Sorghum

Khejri

Moth

Pala

Beri

Seni

Mung
Acacia arabica

Cyampsis psoralioides

Salvadera in dica

Sorghum bulgare

Prosopis spicigeral

Phaseolus Aconitifolius

Zi zyphus nummalaria

Zizyphus jujuba

Mellilotus parviflora

Phaseolus mungo

\section{Characteristics}

Leaves relished by camels, sheep, goats and cattle.

Leguminous fodder grown for camels

The hay is fed to camels

The tree leaves are lopped for camels and sheep.

Legume; both grain and straw are fed to camels

Common shrub in arid and semiarid areas

Good protein content

Leguminous weed and excellent fodder for camel

Grains consumed by humans and the straw fed to camels

The camel in India is by and large a browsing animal and rarely grazes except on tall, young, succulent grass. It requires 2.5 to $3.0 \mathrm{~kg}$ of dry matter per $100 \mathrm{~kg}$ body weight. Larger camels require 28 to $3 z \mathrm{~kg}$ per day of good quality fodder, taking about six to nine hours to obtain this from browsing. In most countries where the camel is expected to work, additional feed is given. In Egypt berseem/clover (trifolium alexandria) is an important the absence of adequate grazing or browsing, stall feeding of camels should be supplemented. The rations may be green or dry fodders (preferably chopped), with or without supplementation of grains. Green fodders are normally preferred over the dry fodders since feeding the former oboiates the need for grains. The common green fodders fed in camel raising areas are moth (phaseolus aconitifolius), mung (phaseolus mungo), guar (cyamopsis paoralioides) and senji (melilotus parviflora). Green gram, maize and sorghum fodders are also fed. The dry fodders are sundried leaves of trees, bushes and hay. The commonly used dry leaves of jharberi (ziziphus nummularia) are a good protein supplement. Crop residues like straws from cereals like wheat, and leguminous crops like moth, mung, and guar are also used as dry fodders. No systemmatic work has been reported on the nutrient requirements 
of camels for growth, maintenance, work, milk production etc. Systemmatic studies are now being conducted at the Animal Nutrition Department of Rajasthan Agricultural University, Bikaner, India. The following are theoretical energy requirements:

$$
\begin{aligned}
& \text { Resting camel }-21 \text { to } 22 \mathrm{Mcal} / \mathrm{day} \\
& \text { Working camel }-30 \text { to } 46 \mathrm{Mcal} / \mathrm{day}
\end{aligned}
$$

On an average, an adult resting camel consumes about $2 \mathrm{~kg}$; growing, working and lactating animals from 2.5 to $3.0 \mathrm{~kg}$ of dry matter per dáy per $100 \mathrm{~kg}$ body weight. The animals are mostly allowed to graze/browse with little supplementation of chaffed straw of leguminous crops and gram geains; about $8-10 \mathrm{~kg}$ chaffed straw of leguminous crops along with 1 to $1.5 \mathrm{~kg}$ of barley/gram $/ \mathrm{moth}$ are fed as a supplemental feed to resting animals, when the grazing is poor or not available. Green fodders like guar also fed during the months of September-October.

In concentrates sesame cake and wheat bran are mixed in equal proportions and fortified with salt, and fed along with sorghum fodder. Sarson/rape (brassia compestris) cake is also fed when available. Half a kilogram of jaggary is also fed to working animals. Camels require abot 100 grams of salt per animal daily.

\section{Program of Practicals for the 6th Semester}

\section{Laboratory work}

1. Methods of estimating the nutritive value of feeds and fodders not covered in 5 th semester.

2. Demonstration/conducting of a metabolism/digestibility trial.

3. Further quantitative analysis of nutrients.

4. Computation of rations with due attention to the economi as for various kind of farm animals: cattle, buffaloes, sheep, goats, poultry, horses and camels and economics of feeding.

5. Preparation of calf starters.

\section{Field observation}

1. Further observation/demonstration of feeding farm animals by visits to farms, pastures and ranges.

2. Further observation/demonstration of silage and hay making practices.

3. Feeding calves. Field trips to observe the cultivation of fodders, pastures, range forests, etc. 


\section{BI BLI OGZAPHY}

\section{Textbooks}

- Maynard, L.A. and Loosli, J.K., 1969, Animal Nutrition, McGraw Hill Book Co., New York, NY.

- McDonald, P., Edwards, R.A, and Green, J.F.D., 1977 , Animal Nutrition, 2nd edition, Longman Inc., New York, NY.

- Morrison, F.B., 1967, Feeds and Feeding, 23rd edition, Morrison Publishing Co., Clinton, Iowa.

- Ranjhan, S.K., 1976, Animal Nutrition and Feeding Practices in India, Vikas Publishing House, 5 Ansari Rood, New Delhi:

- Ranjhan, S:K., 1980, Animal Nutrition in Tropics, Vikas Publishing House, 5 Ansari Road, New Delhi.

\section{References}

- Barrett, M.A. and Larkin, P.J., 1974, Milk and Beef Production in the Tropics, Oxford University Press, London.

- Cassard, D.W. and Juergenson, E.M., Approved Practices in Feeds and Feeding, The Interstate Printers and Publishers Inc., Danville, Illinois

- Cullison, A., 1975, Feeds and Feeding, Reston Publishing Co.Inc., Reston, Virginia.

- Ensminger, M:E:, 1977, Animal Science, The Interstate Printers and Publishers Inc., Danville, Illinois.

- Ensminger, M.E:, 1971, Poultry Science, The Interstate Printers and Publishers Inc., Danville, Illinois. 
- Ensminger, M. E., 1970, Sheep and Wool Science, 4th edition, The Interstate Printers and Publishers, Danville, Illinois.

- Ensminger, M.E., 1972, Breeding and Raising Horses, Agricultural Research Service, USDA, Washington, D.C.

- Heath, M.E., Metcalfe, D.S. and Barnes, R.F., 1973, Forages, The Science of Grassland Agriculture, 3rd edition, The Iowa State University Press, Ames, Iowa.

- Henry, W.A., 1898, Feeds and Feeding, M.J. Cantwell Printers, Madison, Wisconsin.

- Henser, G.F., 1955, Feeding Poultry, John Wiley and Sons Inc., New York, NY.

- Nackenzie, David, 1970, Goat Husbandry, rev.edition, Fabev and Faber, London.

- Perry, T.i., 1975, Feed Formulations, The Interstate Printers and Publishers Inc., Danville, IIlinois.

- Reaves, P.M. and Henderson, H.O., Dairy Cattle Feeding
and Management, John Wiley and Sons Inc., New York, NY.

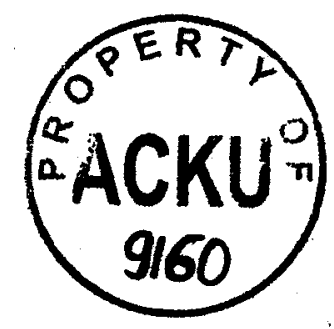

